\title{
II. Bestände und Umstände
}

Um im Ganzen übersehen zu können, welche Informationen das archivalische Material tatsächlich bietet, wird dieses in einem ersten Schritt in Form einer Bestandsaufnahme aufbereitet. "Bestände « heißt in diesem Sinn die zunächst quantifizierende und analytische Erfassung der oben auf der theoretischen Ebene benannten Strukturelemente, dies auch in deren Beziehungen zueinander. "Umstände « in den Blick zu nehmen bedeutet, auf Richtungen, Bindungen und Gewichtungen zu achten, so daß die jeweilige Identität der einzelnen Beziehungen bestimmt werden kann, wie diese durch die je spezifischen Geschenke vermittelt wurden. Den Abschluß bildet eine deskriptiv-statistische Darstellung des Gesamtzusammenhangs. Mit Blick auf einige Bestimmungsfaktoren der von Wolfgang Reinhard ${ }^{1}$ für die geschichtswissenschaftliche Nutzung aufbereiteten Netzwerkanalyse wie Nähe und Distanz, Beziehungsherkunft, Sektorenbildung oder Multiplexität soll des weiteren versucht werden, Antworten darauf zu finden, ob Freigebigkeit als einseitiger sozialer Zwang richtungsweisend gewesen war, ob symmetrische oder asymmetrische Beziehungen überwogen, ob der Geschenkaustausch als Hierarchienbildung oder -abbildung zu bewerten ist oder ob es Kontinuitäten und Brüche neben den bereits oben festgestellten ${ }^{2}$ gab. Ein letzter Schritt soll sich schließlich den Schenkbeziehungen ausgewählter Schenker in vergleichbaren Jahren und den Wesensmerkmalen des Schenkverhaltens zuwenden.

\section{Geschenke}

a) Sortiert und gewertet

Die der Orientierung dienende Tabelle 3 zeigt zunächst eine jahrweise Beobachtung der verschenkten Gegenstände des Gesamtzeitraumes ${ }^{3}$. Ein Geschenk

1 Hierzu unten S. $210 \mathrm{ff}$.

2 Siehe die Übersicht im vorliegenden Kap. Abschn. I.

3 Unter 》Gegenständen « werden hier auch die Neujahrsgedichte verstanden. - Zur einschlägigen spätmittelalterlichen Terminologie mit Erläuterungen und zahlreichen Quellenbelegen siehe Léon-Emmanuel-Simon-Joseph de LABORDEs »Glossaire français du moyen âge, à l'usage de l'archéologue et de l'amateur des arts« nach dem Schatzinventar Herzog Ludwigs von Anjou von 1390: LABORDE, Glossaire, 1872. Das »Glossaire archéologique du moyen âge et de la renaissance«, Bd. lff., Paris $1887 \mathrm{ff}$. von Victor GAY war leider nicht zur Gänze zugänglich. Ein weiteres Hilfsmittel gibt die Bibl. von Carla LORD zu dem Bereich der »Royal French Patronage of Art in the Fourteenth Century«: LORD 1985. - 2 pieces de velueau (Anhang - Katalog/Jahreslisten, Nr. 110), 4 pieces de draps (Anhang - Katalog/ 
ist in diesem Abschnitt dann als Geschenk definiert, wenn es sich einer namentlich oder nicht namentlich bekannten Person zuordnen läßt, egal, ob es sich um einen oder mehrere Gegenstände handelt, zumal diese häufig auch in einer Buchung zusammengefaßt erscheinen. Sonst wurden Geschenke an eine Person, die nach ihrer Art von großer Unterschiedlichkeit waren (wie beispielsweise Pferde und Perlen), gerade auch dann, wenn die Buchungsorte auch hinsichtlich der Datierung - sehr stark divergierten, als Einzelgeschenke angesehen. Verschenkte Gegenstände, die auch über den Kreis der Beschenkten keine eindeutige quantitative Bestimmung zuließen, fanden keinen Eingang in die Tabelle, hingegen aber auch solche, deren Wert nicht überliefert ist ${ }^{4}$. Bei insgesamt 6.403 notierten Geschenken (nicht identisch mit Schenkvorgängen, weil mehrere Geschenke auch in einem Schenkvorgang zusammengefaßt erscheinen können, und nicht identisch mit den Nummern des Katalogs im Anhang, weil einzelne Schenkvorgänge dort teilweise aufgelöst wurden) ist von 182 Posten nicht bekannt, was es war, das verschenkt worden ist. Das entspricht einem relativ geringen Anteil von weniger als $3 \%$. Hinzuzufügen sind 19 nicht datierbare Gegenstände, von denen aber alle bekannt sind (der Prozentsatz unbekannt gebliebener Gaben mindert sich dadurch unwesentlich um etwa $0,008 \%$ ). Das Gesamtbild wird also durch die Vernachlässigung archivalisch nicht faßbarer Gegenstände nicht wesentlich beeinträchtigt. In wenigen Fällen sind die unbekannt gebliebenen Geschenke überliefert, weil beispielsweise in den Rechnungen Botenentlohnungen notiert sind, die darüber informieren, daß ein Geschenk eintraf, und dann meistens auch, von wem es stammte, aber bei 19 Botengängen nicht, um was es sich gehandelt hat. Wichtig sind diese unbekannt gebliebenen Gaben, weil sie weiteren Aufschluß geben über die unten zu betrachtenden Beziehungen, was auch für die Geschenke gilt, von denen keine Wertzuweisungen notiert sind. Die Gesamtzahl dieser Geschenke liegt allerdings bei 2080, was einem Anteil von etwa 32\% an allen Geschenken der Tabelle 3 entspricht. Dies ist ein relativ hoher Prozentsatz, kann aber nicht bedeuten, den Faktor »Wert« nun gänzlich unberücksichtigt zu lassen, zumal die Streuung der wertmäßig nicht faßbaren Geschenke über die Jahre einigermaßen gleichmäßig ist.

Jahreslisten, Nr. 213), un gobellet et une aiguiere (Anhang - Katalog/Jahreslisten, Nr. 222) etc. sind demgemäß als jeweils ein Geschenk gezählt worden. Entspr. weitere Hinweise in den Erläuterungen zu Tab. 3.

4 Die Werte sind im folgenden unkorrekt, aber der Einfachheit halber in der Regel in livre angegeben. 


\begin{tabular}{|c|c|c|c|}
\hline Jahr & insgesamt & $\begin{array}{c}\text { nicht } \\
\text { bekannte } \\
\text { Objekte }\end{array}$ & $\begin{array}{c}\text { ohne } \\
\text { Wert- } \\
\text { angabe }\end{array}$ \\
\hline 1381 & 16 & 1 & 1 \\
1382 & 71 & - & - \\
1383 & 51 & - & 6 \\
1384 & 28 & 7 & 7 \\
1385 & 139 & - & - \\
1386 & 178 & 3 & 3 \\
1387 & 41 & - & 1 \\
1388 & 81 & 4 & 6 \\
1389 & 36 & 7 & 10 \\
1390 & 126 & 6 & 13 \\
1391 & 156 & 1 & 21 \\
1392 & 79 & 2 & 6 \\
1393 & 59 & 3 & 6 \\
1394 & 98 & 13 & 22 \\
1395 & 115 & - & 16 \\
1396 & 132 & 22 & 23 \\
1397 & 104 & 2 & 8 \\
1398 & 163 & 27 & 32 \\
1399 & 13 & 5 & 7 \\
1400 & 144 & 3 & 122 \\
1401 & 255 & 5 & 179 \\
\hline
\end{tabular}

\begin{tabular}{|c|c|c|c|}
\hline Jahr & insgesamt & $\begin{array}{c}\text { nicht } \\
\text { bekannte } \\
\text { Objekte }\end{array}$ & $\begin{array}{c}\text { ohne } \\
\text { Wert- } \\
\text { angabe }\end{array}$ \\
\hline 1402 & 410 & 24 & 365 \\
1403 & 269 & 7 & 236 \\
1404 & 300 & 1 & 276 \\
1405 & 18 & - & 8 \\
1406 & 345 & - & 4 \\
1407 & 37 & 2 & 2 \\
1408 & 27 & 6 & 6 \\
1409 & 13 & 1 & 8 \\
1410 & 32 & 9 & 17 \\
1411 & 1763 & 2 & 565 \\
1412 & 61 & 3 & 8 \\
1413 & 45 & 4 & 39 \\
1414 & 53 & 4 & 14 \\
1415 & 34 & - & 23 \\
1416 & 10 & - & 7 \\
1417 & 25 & - & 3 \\
1418 & 45 & - & - \\
1419 & 667 & 7 & 4 \\
1420 & 57 & 1 & 3 \\
1421 & 6 & - & 3 \\
1422 & 101 & - & - \\
\hline
\end{tabular}

Tab. 3: Bekannte und unbekannte Geschenke und Geschenkwerte 1381-14225

Erläuterungen zu Tabelle 3 unter Bezug auf die in Anhang - Katalog/Jahreslisten notierten Nummern

1382: Ausgeschlossen wurde Nr. 18 (der Falke im "Songe de Charles VI«, den Ludwig von Male Karl VI. 1382 nach Jean Froissart schenkte).

1384: Nr. 103 blieb wegen der unbestimmbaren Geschenke an die Pagen Karls VI. durch Philipp den Kühnen unberücksichtigt.

1385: 91 perles, siehe Nr. 132, wurden als jeweils ein Geschenk gezählt, obwohl es sich möglicherweise um eine ähnliche Gabe wie diejenige an Margarete von Bayern 1388 handelte: 60 grosses perles [...] pour les mettre en son chapeau d'or, siehe Nr. 275.

1388: Ausgeschlossen wurden die weder zuzuordnenden noch quantitativ zu bestimmenden draps et veluyaux, die Philipp der Kühne verschenkt hatte, siehe Nr. 283, sowie die Seidentücher Ludwigs von Orléans und Valentinas Visconti, siehe Nr. 246 und 288.

1390: Das Geschenk Karls VI. an Jacqueline Quipie, I patenostre et I reliquaire d'or, siehe Nr. 350, wurde als Einheit betrachtet. - Die divers joyaux Philipps des Kühnen an plusieurs autres seigneurs de sa Cour blieben als nicht quantifizierbare Größe unberücksichtigt, siehe $\mathrm{Nr} .391$.

1391: Plusieurs gobelets et ayguieres dorez hachiez et pointonnez, siehe Nr. 402, wurden entsprechend der Anzahl der Empfängerinnen, Hofdamen und Hoffräulein Isabeaus de Bavière, als acht Einzelgeschenke betrachtet. -24 boutons d'or a faire 
signez a patenostrez, siehe Nr. 424, wurden nicht einbezogen, ebenso nicht die nicht quantifizierbaren Geschenke, die Isabeau de Bavière von autres seigneurs erhalten hatte, siehe Nr. 445, und die anneaux, die Valentina Visconti verschenkt hatte, siehe Nr. 476. - Nr. 472 wurde als ein Geschenk bewertet.

1392: 6 hanaps d'argent, die Karl VI. Charles Poupart geschenkt hatte, sind als Einzelgeschenk gezählt worden. - Nr. 509 bezieht sich auf unbestimmte Personen, die Valentina Visconti beschenkt hatten und blieb entsprechend unberücksichtigt.

1393: Die in Nr. 582 notierten anneaux d'or blieben als nicht quantifizierbar unberücksichtigt. Unberücksichtigt blieben ebenso die deux ménages ducal et comtal de quatre coupes de marbre blanc, die Philipp der Kühne sich offenbar selbst geschenkt hatte, siehe Nr. 596. - Valentina Viscontis Geschenk des Burgunderherzogs, tasses, flacons et bassins, wurde als Einheit angesehen, siehe Nr. 602.

1394: Unberücksichtigt blieb der unbestimmte Geschenkverkehr zwischen »N.N.« und Philipp dem Kühnen, siehe Nr. 617.

1395: Bei den in Anhang - Katalog/Jahreslisten notierten Nr. 664 und 665 handelt es sich um Gegenstände, die diesmal von Karl VI. zwar zum Zweck des Verschenkens am Neujahrstag gekauft worden waren, die aber dann trotzdem im Schatz verblieben und deshalb in die Auswertung nicht einbezogen worden sind.

1396: Obwohl es zwei Pferde waren, die Heinrich III. von Spanien Philipp dem Kühnen sandte, ist Nr. 700 (wie auch Nr. 877, siehe unten zum Jahr 1398, wie auch Nr. 1175, siehe unten zum Jahr 1402) als singulärer Vorgang nur als Einzelgeschenk berücksichtigt worden.

1397: Der Vorgang Philipp der Kühne: une livrée de robe de drap cramoisi an Philipp den Kühnen, siehe Nr. 856, wurde nicht aufgenommen.

1398: Eingeschlossen ist die Ludwig von Orléans von Eustache Deschamps gewidmete Ballade, siehe Nr. 867. - Auch hier das Geschenk zweier Pferde, diesmal durch Karl III. von Navarra an Ludwig von Orléans, die zusammen als Einzelgeschenk bewertet wurden, siehe Nr. 877 (siehe auch Nr. 700, siehe oben zum Jahr 1396, siehe auch Nr. 1175, siehe unten zum Jahr 1402). - Als nicht quantifizierbare Größen blieben unberücksichtigt Nr. 904 (anneaux et verges d'or an nicht identifizierbare Empfänger) und 906 (unbestimmte joyaux d'or et draps de soie). - Bei Nr. 984 handelt es sich wiederum um Gegenstände, die Philipp der Kühne für sich selbst vorgesehen hatte, weshalb sie in die obige Tabelle keinen Eingang fanden.

1399: Nr. 1017 konnte als nicht quantifizierbare Größe nicht gewertet werden.

1400: Unberücksichtigt blieben 50 queues de vin de Beaune, die Philipp der Kühne verteilen ließ, siehe Nr. 1048, und anneaux, die Valentina Visconti an ihre Kammerzofen verschenkt hatte, siehe Nr. 1057.

1401: Nr. 1086 bezeichnet den Kauf einer grande espée im Wert von $2.250 \mathrm{fr}$, den Ludwig von Orléans sich selbst vorbehalten hatte, weshalb es in die tabellarische Auflistung keinen Eingang gefunden hat. - 14 écus, die die Pagen Ludwigs von Orléans von ihrem Herrn erhielten, blieben unberücksichtigt, weil nicht zu ermitteln war, um wieviel Pagen es sich gehandelt hat, siehe Nr. 1091. Dieselbe Begründung liegt vor für Nr. 1128 und $1133-1135$.

1402: Als in ihrer Zuordnung nicht quantifizierbare Geschenke wurden ausgeschlossen Nr. 1157 (Zuwendung Karls VI. an Philipp den Kühnen in Höhe von $10.000 \mathrm{fr}$., siehe unten S. 299, Anm. 10), 1212 (une somme d'argent Valentinas Visconti an verschiedene officiers und serviteurs) und 1168 (deux cent quarante fromages de Brie, die Ludwig von Orléans verteilte ${ }^{6}$ ). - Nr. 1175 ( $I V$ mules, $I V$ coursiers, IV singes, II sarrazins moriens, Geschenke Martins von Aragon an Philipp den Kühnen; siehe

6 Nach DeLiSLE, Les Collections de Bastard d'Estang à la Bibliothèque Nationale, 1886, S. XVI). 
auch Nr. 700 und 877, siehe oben zu den Jahren 1396 und 1398) wurde als Einheit gezählt.

1403: Wegen fehlender Quantifizierbarkeit wurden Nr. 1268 (colliers et fermanx de l'ordre de monseigneur, die Philipp der Kühne verteilt hatte) und 1279 (une somme $d$ 'argent Valentinas Visconti an verschiedene officiers und serviteurs) ausgeschlossen. 1404: Ausgeschlossen wurde Nr. 1331 (wiederum une somme d'argent der Valentina Visconti an verschiedene officiers und serviteurs).

1405: Nicht aufgenommen wurden Nr. 1346 und 1350 wegen mangelnder Quantifizierbarkeit und Zuordnungsfähigkeit ebenso wie $\mathrm{Nr}$. 1354 (erneut une somme $d$ 'argent der Valentina Visconti an verschiedene officiers und serviteurs).

1406: Nr. 1362 wurde nicht in die Auswertung einbezogen, weil der von Johann von Berry gekaufte Ring zwar zum Zweck des Verschenkens zum neuen Jahr erworben worden war, aber dann doch im Schatz verblieb. Nr. 1376 (une somme d'argent der Valentina Visconti an verschiedene officiers und serviteurs) wurde wiederum wegen mangelnder Quantifizierbarkeit und Zuordnungsfähigkeit ausgeschlossen.

1407: Bei den Nr. 1380-1382 genannten Gegenständen handelt es sich wiederum um Geschenke, die zum neuen Jahr erworben worden waren, aber dann doch im Schatz des Herzogs von Berry verblieben und deshalb nicht in die Auswertung eingegangen sind. - Nr. 1383 nennt "musikalische Unterhaltung« als Neujahrsgeschenk und blieb deshalb unberücksichtigt, entsprechend die Nr. 1384 notierte Belohnung für die Musiker. - Als nicht quantifizierbare und nicht zuordnungsfähige Geschenke blieben Nr. 1401, 1402 und 1423 ebenfalls unberücksichtigt.

1408: Wegen nicht möglicher Quantifizierbarkeit wurde Nr. 1452 von der Zählung ausgenommen.

1409: Bei Nr. 1457 und 1458 handelt es erneut um Geschenke, die zum neuen Jahr erworben worden waren, aber dann doch im Schatz des Herzogs von Berry verblieben und deshalb nicht in die Auswertung eingehen konnten.

1410: Nicht Eingang in die Auswertung fanden einige der niveaux de maçon Johanns Ohnefurcht, notiert in Nr. 1484 (an tous ses chevaliers et les nobles de son hostel) und 1487 (an plusieurs autres seigneurs).

1411: Die hohen Angaben dieses Jahres sind Folge der von Johann Ohnefurcht in großer Zahl verschenkten goldenen und silbernen Hobel und silbernen Bienenkörbe. Nr. 1506 ist auch hier ein von Johann von Berry gekauftes Geschenk, das aber dann doch in seinem Schatz verblieb. - Nr. 1510 (L feulles pour mettre sur un décopure d'un chaperon) wurde als ein Geschenk gewertet.

1412: Nr. 1551 (nicht bekannte Geschenke Karls von Orléans an die serviteurs König Karls VI.) mußte als nicht quantifizierbar vernachlässigt werden.

1413: Bei den Nr. 1568-1570 handelt es sich wiederum um von Johann von Berry zum Zweck des Verschenkens zum neuen Jahr erworbene Gegenstände, die dann aber doch in seinem Schatz verblieben. - Nr. 1589 und 1591 konnten als nicht quantifizierbare Größen nicht gewertet werden.

1414: Nr. 1650 nennt nur unbestimmte Personenkreise ohne konkrete Gegenstände und blieb deshalb unberücksichtigt.

1415: Nr. 1668 ist erneut ein von Johann von Berry zum Zweck des Verschenkens zum neuen Jahr erworbener Gegenstand, der dann aber doch im Schatz verblieb.

1416: Nr. 1696 blieb als nicht quantifizierbarer Vorgang unberuicksichtigt.

1419: Die hohen Angaben kamen durch die Neujahrsgeschenke Karls VI. zustande, die dieser an plusieurs chevaliers, écuyers, dames, damoiselles et plusieurs de ses officiers, serviteurs et autres in Form kleiner blau emaillierter Windhunde vergeben hatte. - Als nicht quantifizierbar blieben unberücksichtigt Nr. 1754 und Nr. 1756.

1420: Nicht Eingang in die Auswertung fanden die ebenso nicht quantifizierbaren Posten von Nr. 1759, 1760 und 1810. 
Nachdem somit eine weiterführende Übersicht gegeben ist, soll nun dargestellt werden, welchen zahlen- und wertmäßigen Stellenwert die einzelnen Geschenkarten einnahmen.

Tafelgeschirr 7 , meist aus Gold und Silber in unterschiedlicher Ausstattung, als da sind prachtvolle Tafelschiffe ${ }^{8}$, reich verzierte, aber auch einfach gestaltete Pokale ${ }^{9}$, Humpen ${ }^{10}$ und Kelche ${ }^{11}$, Aquamanilen und Krüge ${ }^{12}$, Salzbehälter ${ }^{13}$, Schüsseln ${ }^{14}$, Näpfe und Schalen ${ }^{15}$, einfache Platten ${ }^{16}$, Tranchierplatten ${ }^{17}$ und Konfektschalen ${ }^{18}$, aber auch (Vorlege-)Besteckteile wie eine einzelne Gabel ${ }^{19}$ und einige Löffel ${ }^{20}$, aber keine Messer, entspricht zahlenmäßig einem Anteil von etwa $5 \%$ an allen Schenkakten mit nicht ganz 84.0001 . bei etwa $16 \%$ vom Gesamtvolumen (bei einem Drittel der Gaben dieser Zugehörigkeit sind allerdings die Kosten nicht bekannt).

Den wertvollsten Gegenstand schenkte Philipp der Kühne sich 1403 selbst: une nef d'or constellée de pierres précieuses et de perles ${ }^{21} \mathrm{im}$ Wert von 12.000 écus. Ein Tafelschiff erhielt 1397 auch Isabeau de Bavière von Ludwig von Orléans: une nef d'or garnie d'emaux en facon d'emaux de [glittre] et

7 Siehe LABORDE, Glossaire, 1872: Stw. "vaisselle«, S. 531f., Stw. »vaisselle usuelle«, S. 532. Arbeiten über das Tafelgeschirr v.a. von ROBIN 1975 (über den Tafelluxus der Prinzenhöfe 1360-1480) und ROBIN 1983 (bezogen auf Anjou).

8 Siehe LABORDE, Glossaire, 1872: Stw. »navette«, S. 403, Stw. »nef«, S. 403-405. Zahlreiche Abb. bei OMAN 1963.

9 Siehe LABORDE, Glossaire, 1872: Stw. »coupe«, S. 230. Einen Prunkpokal zeigt bspw. die Abb. Nr. 213, in: Les fastes du Gothique (Ausstellungskatalog), 1981.

10 Siehe LABORDE, Glossaire, 1872: Stw. »hanap«, S. 337-339. Vgl. die Abb. Nr. 206-C, in: Les fastes du Gothique (Ausstellungskatalog), 1981, schönere Stücke bspw. Nr. 206-L, M, -N. Siehe, die Übergänge sind fließend, LABORDE, Glossaire, 1872: Stw. "gobelet«, S. 331. Eine einfache Form aus dem 14. Jh. ist abgebildet in: Les fastes du Gothique (Ausstellungskatalog), 1981, Nr. 176, ebenso die Nr. 206-I und 207-A.

11 Siehe LABORDE, Glossaire, 1872: Stw. »calice«, S. $183 \mathrm{f}$.

12 Siehe ebd.: Stw. »aiguière«, S. 124f., Stw. »pot«, S. 457f. Einige schöne Abb. in: Les fastes du Gothique (Ausstellungskatalog), 1981, Nr. 172, 173, 174, 180 und 183.

13 Siehe LABORDE, Glossaire, 1872: Stw. »salière«, S. 489-491.

14 Siehe ebd.: Stw. "plats«, S. 453. Eine Abb. in: Les fastes du Gothique (Ausstellungskatalog), 1981, Nr. 177.

15 Auch in Entsprechung unserer Teller, siehe LABORDE, Glossaire, 1872: Stw. mescuelle«, S. 272.

16 Siehe ebd.: Stw. "plats«, S. 453.

17 Siehe ebd.: Stw. »tranchoir«, S. 520-523.

18 Siehe ebd.: Stw. »drageoir«, S. $255 \mathrm{f}$.

19 Siehe ebd.: Stw. »fourchette«, S. 321-324.

20 Siehe ebd.: Stw. "cuiller«, S. 238, v.a. aber ebenfalls unter dem Stw. "fourchette«, S. 321-324, behandelt. Vgl. die Abb. in Les fastes du Gothique (Ausstellungskatalog), 1981, Nr. 206-E und -F.

21 Anhang - Katalog/Jahreslisten, Nr. 1275. 
deux tigres sur les deux bouts 22 . Es hatte $1.489 \mathrm{fr} .13 \mathrm{~s} .8 \mathrm{~d}$. gekostet. Insgesamt wurden neun Tafelschiffe verschenkt ${ }^{23}$, darunter auch ein galiot de cristal $^{24}$, den Johann von Berry von Ludwig II. von Anjou 1407 bekam ${ }^{25}$. Es handelt sich hier also um ein Geschenk, das offensichtlich nur auf der höchsten gesellschaftlichen Ebene zirkulierte. Ludwig von Orléans erscheint als Schenker innerhalb der Gruppe derer, die die wertmäßig faßbaren zehn teuersten Gegenstände 26 aus diesem Bereich verschenkten, nur noch einmal. Ebenfalls 1397 erhielt Karl VI. von ihm un grand hanap d'or a pié et a couvercle esmaillé par dehors a pampes de rozes vertes et blanches par manieres d'esmaux de [...] et le fretelet par maniere d'une couronne d'empereur garnie audessus d'un gros balay et de quatre perles de compte et autour de la couronne quatre perles, deux balais et deux saphirs et un petit balay enclavé dedans la couronne et au colet dudit couvercle trois gros balaiz et neuf perles et autour dudit couvercle sont onze balaiz et vingt deux perles, et sur ledit couvercle six grosses perles pendans, et autour du hanap a six treffles chascun de trois perles pendans, et autour de pié sont cinq saphirs et dix perles couvert d'emaux en facon de [...] de roses, garni de 28 balais, 7 saphirs et 73 grosses perles en fretelet ${ }^{27}$, der $2.250 \mathrm{fr}$. gekostet hat und dessen Beschreibung einen exemplarischen Eindruck der Gestaltungskraft der Goldschmiede auch bei verhältnismäßig einfachen Gegenständen vermittelt. Alle anderen wertvollen Gaben hat Philipp der Kühne verschenkt. Seiner Frau Margarete von Flandern überreichte er 1397 XII tasses et un couvercle d'or ${ }^{28}$ (1.995 1.), 1400 un service de bouche: aiguière et gobelet d'or 29 (3.038 1.), 1403 XII tasses en façon de hanaps d'or ${ }^{30}(2.2001$ 1.) und 1404 un hanap d'or à couvercle avec images d'apôtres en relief ${ }^{31}(2.000$ l.), dem König 1399 un hanap et une aiguière d'or

22 Anhang - Katalog/Jahreslisten, Nr. 789.

231398 Karl III. von Navarra von Ludwig von Orléans, ebd., Nr.898; 1395 Philipp der Kühne an seinen Kanzler, ebd., Nr. 679; 1406 Johann von Berry von Beraud III d'Auvergne une petite salliere d'or et de grenat, en façon d'une nef garnie aux deva bouz chascun d'un balay, et le fretelet d'une perle, seant sur deux bestes estranges, ebd., Nr. 1357; 1391 Margarete von Flandern von ihrem Mann, ebd., Nr. 444; 1395 und 1405 Karl VI. von Johann von Berry, ebd., Nr. 662, 1345.

24 Siehe LABORDE, Glossaire, 1872: Stw. "galiot«, S. 326, das aber nur auf das Stw. »nef» verweist, siehe oben S. 149, Anm. 8.

25 Anhang - Katalog/Jahreslisten, Nr. 1407. Eine salière Berrys hatte ebenfalls die Form einer galiot: une salliere d'argent doré, faicte en maniere d'un petit galiot, ou milieu duquel a un mast d'argent doré, garni entour de VI langues de serpent, et dessus un grant serpent volant et deux petis; et à chascun bout dudit galiot a un autre serpent volant, siehe ebd., Nr. 1280.

26 Siehe zu den insgesamt faßbaren teuersten Geschenken unten S. 207-207 mit Tab. 7.

27 Anhang - Katalog/Jahreslisten, Nr. 793.

28 Ebd., Nr. 835.

29 Ebd., Nr. 1046.

30 Ebd., Nr. 1265.

31 Ebd., Nr. 1319. 
à façon de genestes 32 (2.700 1.), 1400 un hanap d'or esmaillié aux XII apostres et autres ymaiges sur un pié garni de plusseurs balays, saphirs et perles ${ }^{33}$ (2.250 1.) und 1401 un hanap et une aiguière d'argent doré $e^{34}$ (3.000 1.).

Humpen, Kelche usw. ${ }^{35}$ waren auch gem gewählte Präsente, die, dann weniger wertvoll, an Hofdamen und Hoffräulein ${ }^{36}$ oder Diener und Zofen ${ }^{37}$ vergeben wurden. Aus anderen Zusammenhängen bekannt, im gegebenen Zusammenhang aber nicht belegbar, ist die Bedeutung von Trinkgeschirr als Gabe im Rahmen der Gastfreundschaft: Der Gast durfte nicht nur seinen Becher austrinken, sondern konnte auch den Pokal, in dem sich der Wein befunden hatte, behalten ${ }^{38}$. Daß Philipp der Kühne seinen burgundischen Wein als Neujahrsgeschenk verwendete, ist hingegen überliefert ${ }^{39}$.

Eine zahlenmäßige Aufschlüsselung des verschenkten Tafelzubehörs zeigt, $\mathrm{da} ß$ - jeweils mindestens und abgesehen von den oben erwähnten Tafelschiffen - 123 Humpen ${ }^{40}, 56$ flache Schüsseln und Platten (teilweise auch aus

\section{Anhang - Katalog/Jahreslisten, Nr. 1011. \\ 33 Ebd., Nr. 1038. \\ 34 Ebd., Nr. 1104.}

35 Siehe zur "Sonderstellung der Emailgefäße« hinsichtlich ihrer Gebrauchsfunktion im Unterschied zu Reliquiaren etc. EIKELMANN 1984, S. 494ff.

36 Vgl. etwa die plusieurs gobelets at ayguieres dorez hachiez et pointonnez, die Isabeau de Bavière an ihre Hofdamen Alips de Beauchamp, Catherine de Fastavarin, Catherine de Villiers, Isabelle La Bouteillière, Jeanne de Montueil, Jeanne de La Tour, Marguerite de Germonville und Marie de Duisy 1391 verschenkt hat, siehe Anhang - Katalog/Jahreslisten, Nr. 402.

37 Z.B. Anhang - Katalog/Jahreslisten, Nr. 484, 487 oder 488.

38 Siehe u.a. GRIMM 1865, S. 179ff., v.a. S. 181 f., auch VoGT 1997, S. 32ff. Vgl. auch die einleitenden Ausführenden zur Begriffsbestimmung von »schenken«, oben S. 14-15 mit Anm. 25f. - Trinkgefäß, Wein und Ehre bildeten eine besondere Einheit, die sich auch in dem Begriff des »Ehrenweins« wiederfindet (und dann auch als "pots-de-vin«, Literatur siehe oben S. 12, Anm. 17). Darauf, daß auch dies ein Thema ist, das der weiteren Erforschung bedarf, hat zuletzt Holger Kruse hingewiesen: KruSE 1996, S. 33 mit Anm. 111. GROEBNER 1993, S. 168 mit Anm. 40f. berichtet am Beispiel Nürnbergs von diesem Brauch und daß die Stadt den einziehenden Kaisern Friedrich III. und Maximilian I. Geldgeschenke in kostbaren Trinkgefäßen überreichte.

39 Siehe Anhang - Katalog/Jahreslisten, Nr. 1048 die Verteilung von 50 queues de vin de Beaune zum Neujahrstag 1400 durch Philipp den Kühnen nach ACO B 1519, fol. 252 mit der vielsagenden Interpretation Henri Davids: „Mais le duc ne se contente pas de distribuer des hanaps: il les remplit. [...] C'est, à l'échelle de la cour de Bourgogne, cette politique du pot de vin [de la queue de vin, devrait-on dire] qu'inaugure le père et que le fils doit bientôt, non seulement pratiquer, mais étendre sans mesure. Les ducs ont trouvé là un de leurs plus persuasifs et perpétuel ambassadeur«, DAVID 1947, S. 64; vgl. VAUGHAN 1962, S. 12. Zum "commerce des vins de Beaune au moyen âge« siehe DION 1955, hier v.a. S. $216 \mathrm{ff}$., vgl. NIEUWENHUYSEN 1984, S. 391 f., S. 392 mit Anm. 42.

40 Humpen, Pokale etc. häufig mit Deckeln, couverts, die mit Knäufen in Fruchtform, frutellez, frételés (siehe LABORDE, Glossaire, 1872: Stw. »fretel«, S. 325), verziert waren und auch als Einzelgeschenk Verwendung fanden. 
Holz), 122 Tassen ${ }^{41}$ und 53 Pokale, 48 Krüge und einige kleinere Krüglein ${ }^{42}$, 24 Salzbehälter - die bis auf eine Ausnahme alle der Herzog von Berry erhielt ${ }^{43}$-, $15 »$ Töpfe ${ }^{44}$, einige bouteilles und flacons ${ }^{45}$, zwei justes und einige quartes $^{46}$, vier coupes ${ }^{47}$, vier Konfektschalen, drei Näpfe, zwei Kelche, ein Service und vaisselle im Wert von $5.153 \mathrm{l}$., des weiteren sechs Tranchier-

41 In nicht immer eindeutiger Unterscheidung von den Humpen, vgl. XII tasses en façon de hanaps d'or, die Margarete von Flandern von Philipp dem Kühnen 1403 erhielt, siehe Anhang - Katalog/Jahreslisten, Nr. 1319. Vgl. LABORDE, Glossaire, 1872: Stw. »tasse«, S. 514.

42 Wie z.B. die beiden kleinen buretes de matiste, garnies d'argent doré, esmaillees sur les piez et couvercles en maniere d'une garenne; en chascune une ance esmaillee $\grave{a}$ fueillages et un biberon engoulé d'une teste de lion; et sur le couvercle de chascune a une pierre en maniere de saphir, die der Herzog von Berry von einem Unbekannten 1403 geschenkt bekam, siehe Anhang - Katalog/Jahreslisten, Nr. 1240.

43 Die Ausnahme war ein Geschenk Valentinas Visconti 1396 an Ludwig von Orléans: une saliere d'or d'un porc epy a un fretelet garni de six perles et un balay, siehe ebd., Nr. 768 (zu dieser Bilddevise des Herzogs von Orléans vgl. PRIETzEl 1999, S. 130). Johann von Berry erhielt salières, gefertigt aus dem häufig weißen cassidoinne-Chalzedon oder aus meist grünem Jaspis, dem oxydierten Chalzedon, und die nur dann, wenn sie kleiner waren, aus Kristall oder Granatstein (i.e.S. der rote Pyrop) bestanden, 1403 von Bonne de Berry, siehe ebd., Nr. 1216; 1404 von Martin Gouge und Anna von Bourbon, siehe ebd., Nr. 1295 und 1280; 1405 von Jean IV d'Armagnac und Charles d'Albret, siehe ebd., Nr. 1344 und 1333; 1406 von Bonne de Berry, Beraud III d'Auvergne und Pierre de Savoisy, siehe ebd., Nr. 1358, 1357 und 1375; 1407 von Simon de Cramaud, Bernhard VII. von Armagnac und Guillaume de Lodes, siehe ebd., Nr. 1421, 1377 und 1379; 1408 von Béatrix de Navarre, Beraud III d'Auvergne, Guillaume de Ruilly und Ascelin Royne, siehe ebd., Nr. 1426, 1427, 1429 und 142; 1410 von Ludwig II. von Anjou und Ludwig II. von Bourbon, siehe ebd., Nr. 1490 und 149; 1412 von Charles d'Artois, siehe ebd., Nr. 1543; 1413 von Guillaume de Montrevel, Jeanne de Boulogne und Macé Heron, siehe ebd., Nr. 1564, 1567 (als Geste gegenüber dem Hundesammler en façon d'un petit chiennet) und 1601; 1415 von Guillaume de Lodes und Adhémar Aleman, siehe ebd., Nr. 1663 und 1655; 1416 von Marie de Berry, siehe ebd., Nr. 1695.

44 Als pot dem Sinn nach ein (Wasser-)Krug und damit synonym für eine einfachere aiguière, vgl. LABORDE, Glossaire, 1872: Stw. "pot«, S. 457f.

45 Ebd.: Stw. »bouteille«, S. 171, weist darauf hin, daß die bouteilles nur ausnahmsweise aus Glas gewesen seien, sondern hauptsächlich aus Leder gefertigt waren und ein typisches Reiseutensil gewesen sind, kein Tafelzubehör. Diese Flüssigkeitsbehälter unterschieden sich damit zunächst dem Material nach von den flacons, dann aber auch dem Verschluß nach, der bei den flacons ebenfalls meist aus Glas war, bei den bouteilles jedoch nur ein einfacher Stöpsel, vgl. ebd.: Stw. "flacon«, S. 317f. Siehe zu den Flakons Anhang - Kata$\log /$ Jahreslisten, Nr. 357, 602, 1600 und 1628.

46 Siehe LABORDE, Glossaire, 1872: Stw. "juste«, S. 352, Stw. »quarte«, S. 475. Justes sind nur einmal als Geschenk an den König 1395 belegt: deux grans justes touttes plaines sur le couvercle un oiseau environné de costes de genestes et dedans un esmail de france a un tygre qui se mire en une fontaine, siehe Anhang - Katalog/Jahreslisten, Nr. 674. Quartes sind überliefert 1398 (Philipp der Kühne an Marie de Blaringhehem, siehe ebd., Nr. 944), 1401 (Ludwig von Orléans an Ludwig II. von Bourbon, siehe ebd., Nr. 1085), 1404 (Philipp der Kühne an Jean Canard, siehe ebd., Nr. 1303) und 1407 (Johann Ohnefurcht an Jean de Montagu, siehe ebd., Nr. 1390, und derselbe an seine Frau, siehe ebd., Nr. 1399).

47 Siehe oben S. 149, Anm. 9. 
platten armoyé des armes de France ${ }^{48}$, sechs Löffel ${ }^{49}$ und eine Gabel d'or et de cristal $^{50}$ verschenkt wurden. Eine gewisse Besonderheit, weil einzig, bilden die beiden gardemengiers ${ }^{51}$, die Ludwig von Orléans 1395 von Ludwig II. von Bourbon erhalten hatte 52 . Schließlich gehörten zu den Tischutensilien auch die bacins à laver ${ }^{53}$ zum Zweck des Reinigens von Geschirr und Händen, deswegen häufig gemeinsam mit den aiguières verschenkt, und fioles, deren Rosenwasserfüllung ebenfalls der Handreinigung nach dem Mahl diente 54 .

Schmuck ${ }^{55}$ - hauptsächlich Spangen, Ringe, Ketten und Kolliers - und Edelsteine $^{56}$ - Diamanten, Rubine und Balasrubine, vereinzelte Saphire und

48 Ein Geschenk der beiden receveurs des aides von Paris Michel du Sablon und Roger Lemere an den König 1395, siehe Anhang - Katalog/Jahreslisten, Nr. 675.

49 Geschenke der Königin an ihre Hofdamen 1391, siehe ebd., Nr. 400.

50 Une petite forchete, die Berry 1405 von seinem Enkel Charles d'Artois erhielt, siehe Anhang - Katalog/Jahreslisten, Nr. 1334.

51 Es handelt sich hier um Glocken zum Warmhalten von Speisen, siehe LABORDE, Glossaire, 1872: Stw. »Garde mengier«, S. 307.

52 Anhang - Katalog/Jahreslisten, Nr. 699.

53 Siehe LABORDE, Glossaire, 1872: Stw. »bacins à laver«, S. 151-153, und insbes. bacins à laver sur table, siehe Anhang - Katalog/Jahreslisten, Nr. 704 (1396: Ludwig von Orléans an Isabeau de Bavière deux bassins d'or à laver, à chascune un émail au fond d'un tigre, siehe oben das Geschenk seiner Frau aus demselben Jahr an die Königin), 893 (1398: wiederum Ludwig von Orléans an die Königin deux bassins d'or), 994 (1398 Valentina Visconti an Enguerrand de Coucy deux bassins d'argent doré), 995 (ebenfalls 1398 Valentina Visconti an Isabeau de Bavière deux bassins d'or a laver a chascun un email au fond d'un tigre, siehe oben das Geschenk ihres Mannes Herzog Ludwigs aus demselben Jahr an die Königin), 1097 (1401: Ludwig von Orléans an Pierre de Navarre deux bacins d'argent dorés esmaillés ou fons), 1158 (Ludwig II. von Bourbon an Johann von Berry un paire de bassins d'argent, dorez, au font desquelx a une rose esmaillee aux armes de monseigneur, et ou milieu de ladicte rose a un ours esmaillé de noir, et sur les bours desdiz bassins a fleurs de lis et ours enlevez), 1189 (1402: Philipp der Kühne an Karl VI. deux bassins d'argent doré façonnés à godrons et dont la bordure s'orne alternativement de rubis et de perles), zu unterscheiden von den liturgischen Zwecken dienenden bacins, siehe ebd., Nr. 1368 (Johann Ohnefurcht an Margarete (II.) von Burgund dewx bacins pour chappelle, un bateur pour ladicte maniere, une aiguiere et un benoistier).

54 Vgl. une fyole d'argent dorée à mettre eaue rose, à une fleur de lis ou frételet, die Ludwig von Orléans 1403 von Jean de Brisay erhalten hatte, siehe ebd., Nr. 1229. Siehe LABORDE, Glossaire, 1872: Stw. »fiole«, S. 317.

55 Mittelalterlichen Schmuck behandelt Ronald W. LiGHTBOWNs "Mediaeval European Jewellery«: LiGHTBOWN 1992, hier S. 66-78 »Jewellery for men and women, gifts and religious offerings«, zu einem Großteil gestützt auf die schriftl. Überlieferung von Neujahrsgeschenken. Zu den einzelnen Schmuckarten: fermails, S. 160-170; enseignes, S. 188-201; pendentifs, S. 202-230; chaînes und colliers, S. 235-292 (colliers à l'ordre, S. 251-264); bracelets, boucles d'oreille, jarretières und agrafes, S. 293-305; ceintures, S. 306-341; chapelets, S. 342-354; pommeaux, mirroirs etc., S. 354-358; costume etc., S. 359-374. Zu Schmuck mit sakraler Thematik siehe EICKELMANN 1984, S. 358ff.

56 Einen kontextbezogenen Überblick gibt EVANS 1970, S. 53-70. Die hauptsächlich verwendeten und bekannten Edelsteine waren Rubine (Balasrubine, Spinellrubine, siehe 
Smaragde, dazu zu zählen aber auch Perlen -, fast unabhängig vom jeweiligen Geschlecht getragen, benutzt, bekommen und verschenkt ${ }^{57}$, sind mit ca. $23,5 \%$ an den Gesamtaufwendungen bei einem zahlenmäßigen Anteil von gut $43 \%$ vertreten.

Edelsteine, vor allem Diamanten ${ }^{58}$, deren Bearbeitungsmöglichkeiten sich durch Schleifen und Schneiden erst in den Jahren vor 1400 entwickelt hatten und um 1350 noch nicht bekannt waren ${ }^{59}$, und einfacher Schmuck, schienen den fürstlichen Schenkern besonders geeignet als »Allzweck «-Geschenke für größere und hierarchisch nicht unbedingt homogene Personengruppen wie den

LABORDE, Glossaire, 1872: Stw. »Balay«, S. 156, ebd.: Stw. "Ballesseau«, S. 157 und ebd: Stw. "Rubis«, S. 487f. - anzumerken ist, daß der Spinell ein zwar wenig bekannter, aber eigener Edelstein ist, der wegen seiner roten Färbung den Rubinen zugeordnet wurde, wohl auch, weil Rubine, Saphire und Spinelle in denselben Lagerstätten vorkommen), Saphire (siehe ebd.: Stw. "Saphir«, S. 492), Diamanten. und Smaragde (siehe ebd.: Stw. »Esmeraudes«, S. 299). Zu den Edelsteinen im Mittelalter hinsichtlich ihrer Bedeutung in Aberglauben, Medizin und Theologie auf der Grundlage mittelalterlicher Lapidarien (hierzu JÜTTNER, Guido: Art. "Lapidarien«, in: LexMA, Bd. S, 1991, Sp. 1714-1715. Wichtige mittelalterliche Steinbücher waren aufbauend auf antiken Vorbildern der "Liber de lapidibus seu de gemmis" des Marbod von Rennes, Albertus Magnus' "De mineralibus" und Hildegard von Bingens »Physica»): FRIESS 1980 (ergänzend MEIER 1977, die den wichtigen Komplex der Edelsteinallegorese behandelt). Wichtig weiterhin die folgenden Art.: HAHN, Karin: Art. „Edelsteine. I. Definition und Bestimmungsskriterien«, in: LexMA, Bd. 3, 1986, Sp. 1560, HAHN, Karin: Art. »Edelsteine. III. Spätantike und Mittelalter. Einteilung der Edelsteine; Gelehrte Tradition; Gebrauch und Symbolik: [2] Beispiele für Verwendung als Amulett und zu magisch-volksmed. Zwecken «, in: ebd., Bd. 3, 1986, Sp. 1563f., ELBERN, Victor H.: Art. "Edelsteine. IV. Edelsteine in der ma. Zierkunst: [2] Verwendung«, in: ebd., Bd. 3, 1986, Sp. 1564-1565, HAHN, Karin, ElBERN, Victor H.: Art. »Edelsteine. IV. Edelsteine in der ma. Zierkunst: [1] Schliff und Schnitt», in: ebd., Bd. 3, 1986, Sp. 1564, und JÜTTNER, Guido: Art. »Edelsteine. III. Spätantike und Mittelalter. Einteilung der Edelsteine; Gelehrte Tradition; Gebrauch und Symbolik: [1] Allgemein«, in: ebd., Bd. 3, 1986, Sp. 1561-1563 . Hierher gehören auch Perlen, siehe ElBERN, Victor H.: Art. »Perle«, in: ebd., Bd. 6, 1993, Sp. 1891f., und LABORDE, Glossaire, 1872: Stw. »Perle«, S. 437.

57 Einzige Ausnahme waren die 2 jaretières - „Strumpfbänder«, die Marie de Sully 1397 Margarete von Flandern schickte, siehe Anhang - Katalog/Jahreslisten, Nr. 805. Siehe LABORDE, Glossaire, 1872: Stw. »jaretière«, S. 348.

58 Siehe LABORDE, Glossaire, 1872 : Stw. "Diamant«, S. 247-253, und JÜTTNER, Guido: Art. "Diamant«, in: LexMA, Bd. 3, 1986, Sp. 967. Vgl. LENZEN 1966 zur "Produktions- und Handelsgeschichte des Diamanten.« Populärwissenschaftlich, aber m.E. gut geeignet für einen ersten technischen und kulturhistorischen Gesamtüberblick ist: Der Diamant, hg. von JETTER, 1981. Aus einem Abschn. einer Arbeit über Wesen und Wert von Edelsteinen bei den Kulturvölkern von Philipp Schmidt: SCHMIDT 1948, S. 68-107 zur »Bewertung der Edelsteine im Mittelalter«, hier S. 104f., geht hervor, daß der Diamant im Mittelalter weder zu den sog. "Apostelsteinen« gehörte noch den ihm später zuerkannten Wert hatte, wie er etwa ab der Zeit Karls des Kühnen bestand (von besonderem Wert dann dessen Diamant »Le Sancy «, hierzu auch BAPST 1889, 186ff.), seine helle Färbung aber als Symbol für Charakterstärke galt. Grundlegend die Arbeit FALK 1975 über »Edelsteinschliff und Fassungsformen «, hier zu den Anfängen der Diamantenbearbeitung in Frankreich S. 11-36.

59 Vgl. FALK 1975, S. 12-15. 
eigenen Hofhalt (ohne daß dieser in den Rechnungen namentlichen Niederschlag gefunden hätte), in etwas besserer Qualität dann auch für die eigene Familie, ohne daß je besonderer Wert auf eine individuelle Ausgestaltung gelegt worden wäre 60 . Die Informationen, die sich daraus destillieren lassen, geben aber auch Anhaltspunkte für die Größe der einzelnen Hofhaltungen und Beziehungsnetze. Wenn Karl von Orléans 1411 neben einer Reihe von Personen, deren Namen notiert sind - von Bonne d'Armagnac, seiner Frau, über seine beiden Brüder bis hin zu seinem Kanzler Jean Davy und dessen Frau (und dabei auch seinen Verbündeten Johann I. von Bourbon nicht übersieht) -, noch six dyamens pointus 61 und vint ung dyamens ${ }^{62}$ an die gentilshommes, écuyers, chambellans de l'hôtel, neben six boursètes de fil d'argent blanc ${ }^{63}$ auch douze verges d'or ${ }^{64}$ an seine serviteurs verteilte, dann kann in etwa die Größe seines Hofhalts und der am Neujahrstag zusätzlich Anwesenden abgeschätzt werden. Diese Bedeutung ließe sich auch den 230 Diamanten unterstellen, die Philipp der Kühne 1404 verteilte65. 1403 waren es 19366 (da war der Herzog auf dem Rückweg aus der Bretagne und feierte den Neujahrstag in Corbeil67), 1402 aber gar 320 dieser Steine ${ }^{68}$ und im Verein mit den für dieses Jahr in den burgundischen Rechnungen mit ihren Namen geführten Empfängern wäre dies nach Dom Plancher die Gesamtheit der »seigneurs de la Cour de France, Bretagne, Bourgogne, Flandres, Brabant, Artois. "69 Der von dem Burgunderherzog auf diesem Weg beschenkte Kreis hat augenscheinlich eine relativ sprunghafte Weiterung erfahren, denn 1401 waren es nur $108^{70}, 1400$ nur 74 Diamanten, die Philipp verschenkt hatte ${ }^{71} .1398$ mögen es hingegen auf Vorrat gekaufte Schmuckstücke, in erster Linie Spangen, gewesen sein, die Philipp erworben hatte in Erwartung derer, die ihm zum neuen Jahr ihre Aufwartung machen würden. Es sind 37 fermaux, fermillets, colliers und anels und diaments in seinen Rechnungen verzeichnet, mit denen er sich bei den ihn

Z.B. die Kolliers, die Philipp der Kühne 1398 an Maria (I.) und (II.) Margarete (II.) von Burgund verschenkt hat, immerhin jeweils im Wert von 1.000 1., siehe Anhang - Kata$\log / \mathrm{J}$ ahreslisten, Nr. 938, 942 und 943.

61 Ebd., Nr. 1532.

62 Ebd., Nr. 1535.

63 Ebd., Nr. 1533.

64 Ebd., Nr. 1534.

65 Ebd., Nr. 1323.

66 Ebd., Nr. 1273.

67 Siehe Anhang - Neujahrstage und Aufenthaltsorte 1381-1422 zum 1. Januar 1403.

68 Anhang - Katalog/Jahreslisten, Nr. 1202.

69 Plancher, MERLE, Histoire générale et particulière de Bourgogne, Bd. 3, 1748, S. $188 \mathrm{f}$.

70 Hier allerdings mit der nicht ganz zutreffenden Interpretation nach DAVID 1945, S. 27: "Aux personnes qui viennent le complimenter«, siehe Anhang - Katalog/Jahreslisten, Nr. 1109.

71 Anhang - Katalog/Jahreslisten, Nr. 1047. 
Beschenkenden wohl habe erkenntlich zeigen wollen ${ }^{72}$. Diese Reihe läßt sich weiter zurückverfolgen ${ }^{73}$, erreichte aber nie den Umfang der Jahre nach 1400. Es wäre sicher keine Fehlinterpretation, die im Lauf der Zeit bis zu Philipps Tod 1404 nach Wert und Zahl angewachsenen Geschenke nicht nur dieser Art in Beziehung zur gestiegenen Bedeutung Burgunds zu setzen. Philipp der Kühne war aber nicht der einzige, der diese Form des Geschenkverkehrs betrieb, mit der er auch erst 1396 begonnen hatte ${ }^{74} .1412$ verteilte beispielsweise Ludwig von Guyenne 46 Diamanten an plusieurs des dames de compagnie de sa mère ${ }^{75}$. Seine Mutter, die Königin, bedachte 1414 den wahrscheinlich identischen Kreis mit ebenfalls 46 Diamanten unterschiedlichster Werte. Dieser Vorgang könnte zum einen darauf hinweisen, daß die Zahl der königlichen Hofdamen trotz der Wirren des Jahres 1413 zumindest dem Umfang nach konstant geblieben ist ${ }^{76}$, zum anderen offenbaren, daß es eine konkret bestimmbare Rangordnung mit acht Stufen gab. Vier Gruppen zu je fünf Personen erhielten Diamanten zu 200 1., 80 1., 70 l. und 60 1.77. Ein sechs Personen umfassender mittlerer Rang bekam Steine zu je etwa 41 1., gefolgt von zwei Personen, die sich mit jeweils etwa 331 . zufrieden geben mußten. Sechs Personen erhielten nur Diamanten zu etwa 201 ., und 12 nur noch kleine Steine à $101 .{ }^{78}$. Zusätzlich verschenkte Isabeau aber auch 12 Dutzend nicht näher bestimmbarer Gegenstände (wahrscheinlich verges), so daß diese Zahl noch zu ihrem Hofhalt addiert werden müßte und sich der Personenbestand damit auf 58 erhöhte ${ }^{79}$. Isabeaus Sohn, der künftige König Karl VII., immerhin bereits 11 Jahre alt, aber zu diesem Zeitpunkt noch nicht Dauphin, bekam 1414

72 Anhang - Katalog/Jahreslisten, Nr. 945-981, darunter auch ein hanap und eine der beliebten Kombinationen von Krug und Humpen.

73 Vgl. für 1382 ebd., Nr. 31 (50 verges d'or) und pass., für 1383 ebd., Nr. 45 (une douzaine de verges d'or), 46-77 (verschiedene fermaux), für 1385 ebd., Nr. 119-131 (wiederum verschiedene Spangen), v.a. aber 133 (91 perles) oder für 1393 ebd., Nr. 582591, für 1394 Anhang - Katalog/Jahreslisten, Nr. 638f. (25 petiz fermaillets en façon de gibecières an die bons officiers, siehe DAVID 1947, S. 59, und ebenso viele agrafes diamantées an die haute clientèle, siehe ebd., S. 59).

74 Siehe Anhang - Katalog/Jahreslisten, Nr. 689 ( $L X$ petites verges d'or). Vgl. dann für 1397 ebd., Nr. 839-853 mit Anm. 967.

75 Siehe ebd., Nr. 1556 mit den entspr. Anm. zur Auflösung des Personenkreises.

76 GRANDEAU 1975 , S. 168 nennt für 1414 als namentlich nachweisbar nur die Hofdame Jeanne de Brimiers (AN KK 48, fol. 121v).

77 Zum Vergleich eine Reihung von Diamanten, die der König 1390 an die Hofdamen der Königin verschenkte, die namentlich aufgefüht sind. Catherine de Fastavarin, die im selben Jahr von des Königs Bruder Ludwig einen Saphir zu 12 1. bekam, siehe Anhang - Kata$\log /$ Jahreslisten, Nr. 358, Isabelle La Bouteillière, Marie de Duisy und Marie de Quiemieu erhielten jeweils einen Stein im Wert von 25 1., Catherine de Villiers, Jeanne de Montueil, Jeanne de La Tour, Mabillette und Marguerite de Germonville einen zu je 21 1., siehe ebd., Nr. 332, 333, 335, 340, 341, 345, 346, 348 und 349.

78 Siehe ebd., Nr. 1618-1625.

79 Siehe ebd., Nr. 1617. 
ebenfalls Diamanten, deren Gesamtwert mit 1121.10 s.t. bemerkenswerterweise weit unter dem Wert derer lag, den die Hofdamen erhielten, die die obersten fünf Ränge bekleidet hatten. Diesen Beispielen ließen sich weitere hinzufügen, doch kein Schenkvorgang erreichte nach Wert und Umfang burgundische Größe ${ }^{80}$. Es bleibt die Frage, ob bei diesen teilweise doch recht umfänglichen Stückzahlen die Schenker tatsächlich »verteilten« oder doch eher »verteilen ließen«, zum Beispiel - siehe oben - durch einen chambellan, wie er möglicherweise auf dem Januarblatt der »Très Riches Heures《 zu sehen ist, der dann wohl auch die Geschenke in Empfang nahm, so daß sich der Fürst auf die ihm Ebenbürtigen konzentrieren konnte. Dafür, daß étrennes persönlich zur Verteilung kamen, könnte aber der Kauf einer gibessiere de velours azur zu dezx francs 5 solz tournois durch Ludwig von Orléans 1398 sprechen, die bestimmt war pour mettre les anneaulx et verges d'or qu'il distribue le jour des etrennes 81 .

Edelsteine sind nicht nur verwendet worden, um größere Personengruppen möglichst lückenlos zu beschenken. Sie dienten auch als Einzelstücke der Bekräftigung individueller Beziehungen und sind dann in den Rechnungen mit den Namen der Empfänger versehen. Meist waren es wiederum Diamanten, die in den Geschenkverkehr Eingang fanden. Die wertvollsten dieser Steine erhielten 1387 Ludwig, noch Herzog der Touraine, von Margarete von Flandern $^{82}$, 1392 der König von seiner Schwägerin Valentina ${ }^{83}$ und 1407 der Herzog von Berry von Johann Ohnefurcht ${ }^{84}$. Der teuerste aller Edelsteine war aber un bel et gros balay longuet im Wert von 18.000 écus. Das Geschenk Karls VI. für seinen Onkel Johann von Berry bestand darin, daß er sich am Erwerb dieses Steins mit 14.000 écus beteiligte, verteilt auf die drei Neujahrs-

So bekamen 138826 nicht näher bestimmbare Personen von dem König fermeilles et cosses de genestes d'argent dor. et esmaill. zu 13 l. 6 s.t., siehe Anhang - Katalog/Jahreslisten, Nr. 245, 139056 Personen 7 aneaulx a perles, 3 patenostres d'or, 6 balaiz en 6 aneaulx, 40 petiz dyamens zu 203 fr., siehe ebd., Nr. 355. Die Königin verteilte 139138 anneaulx d'or tant a perles et a rubis d'Alixandre zu $208 \mathrm{fr}$. an plusieurs dames et damoiselles [...] de son hostel und an plusieurs dames et damoiselles de lostel de nostre dicte sueur de touraine, also an die eigenen Hofdamen und an diejenigen Valentinas Visconti, siehe ebd., Nr. 412f. Valentina verschenkte 140125 fermeillets d'or, garnis de perles und 13 fremailles d'or garnis de perles an ihre Dienerschaft und plusieur personnes, siehe ebd., Nr. 1129 und 1132. 1418 bedachte Margarete von Bayern, die Gattin Johanns Ohnefurcht, 45 seigneurs, dames et demoiselles de son hostel mit sept gros dyamans de plusieurs moisons de neuf, neuf molinez d'or à grosses perles, quatorze verges d'or esmailliés, trois haneaulx, chascun à trois parles, trois aneaulx d'or esmailliez en façon de singes, six verges d'or maciffes und quatre verges d'or, siehe ebd., Nr. 1715.

81 Siehe BNF ms.fr. 10431, S. 403f., Nr. 2299, siehe Anhang - Katalog/Jahreslisten, Nr. 904.

82 Anhang - Katalog/Jahreslisten, Nr. 203.

83 Ebd., Nr. 537.

84 Ebd., Nr. 1395. 
tage der Jahre 1402 bis $1404^{85}$. Berry hatte diesen Balasrubin später in ein Kreuz setzen lassen, das er dem König kurz vor seinem Tod 1416 geschenkt hat ${ }^{86}$. Der Rubin appellé le ruby de l'oreille, den der Herzog 1410 von seiner Frau Jeanne de Boulogne erhalten hatte, war von sicher nicht geringerem Wert ${ }^{87}$. Ein schönes Stück schien auch der gros balay cabochon, appellé le balay de la chasteigne, assis en une branche d'orengier gewesen zu sein, den Berry 1415 von Ludwig von Guyenne bekommen hatte ${ }^{88}$. Der Balasrubin, den Philipp der Kühne 1404 dem König verehrt hatte ${ }^{89}$, und der zu den teuersten Einzelsteinen gehört, die zum neuen Jahr geschenkt worden sind, hatte dazu den relativ geringen Wert von nur 1.2001 . Saphire wurden nur sehr selten als Einzelstücke präsentiert ${ }^{90}$.

Perlen ${ }^{91}$ dienten in aller Regel nicht als Einzelgeschenk, sondern der Verzierung von Gegenständen und als Accessoire wie die 60 grosses perles für Margarete von Bayern pour les mettre en son chapeau d'or, immerhin zu $4801 .^{92}$, die diese 1388 von ihrem Schwiegervater erhalten hatte ${ }^{93}$.

Sehr beliebte Neujahrsgeschenke waren Spangen, Fibeln oder Agraffen als Mantelschließen ${ }^{94}$ oder Schmuckspangen ${ }^{95}$, zumindest bis 1404 , denn ab diesem Jahr bis 1422 sind nur noch sechs Spangen verschenkt worden. Die Archivalien nennen über 500 Exemplare, das sind mehr als $8 \%$ aller Geschenke. Diese Spangen hatten zwar als Mantelschließen auch die Funktion eines notwendigen Utensils, gerieten wohl auch deshalb gleich serienweise in den Gabentausch, waren aber als für alle stets sichtbares Attribut mit der Person des jeweiligen Trägers direkt verbunden auch Objekt für individuelle Gestal-

85 Anhang - Katalog/Jahreslisten, Nr. 1156, 1233 und 1292. Vgl. AUTRAND, Le Jour de l'An, 1999, S. 3.

86 Oder schenken wollte? Vgl. MEISs, French Painting in the Time of Jean de Berry: The Late Forteenth Century, Bd. 2, 1967, S. 48. Siehe auch oben S. 62, Anm. 132.

87 Anhang - Katalog/Jahreslisten, Nr. 1474. Der Rubin, den Johann Ohnefurcht dem Herzog von Berry 1413 überreicht hat, hatte einen Wert von nur 100 l., siehe ebd., Nr. 1581.

88 Ebd., Nr. 1676.

89 Ebd., Nr. 1311.

90 Vgl. etwa ebd., Nr. 76 den allerdings 200 1. teuren Saphir einem unbekannten Empfänger im Jahr 1383 zukommen ließ.

91 Siehe LABORDE, Glossaire, 1872: Stw. "perle«, S. 436f. Zur allegorischen und symbolischen Bedeutung der Perle MCCulloch 1960: Stw. "pearl«, S. 155f.

92 Anhang - Katalog/Jahreslisten, Nr. 275. Demselben Zweck galten möglicherweise 1396 die Perlen von Ludwig von Orléans für Marie la Mayence und eine weitere unbekannte Person, siehe ebd., Nr. 709 und 710.

93 Vgl. etwa die als Neujahrsgeschenk deklarierten $L$ feulles pour mettre sur un décopure d'un chaperon, fait de brodeure, die Johann Ohnefurcht 1411 - nicht an eine Gruppe, sondern an einen unbekannten Empfänger - verschenkte, siehe ebd., Nr. 1510.

94 Auch als ataiche de mantel bezeichnet, siehe ebd., Nr. 632.

95 Vgl. LABORDE, Glossaire, 1872: Stw. »fermail«, S. $312 \mathrm{f}$. Der Begriff »Brosche« stammt aus dem 19. Jh. und ein solcher Gegenstand ist immer mit einer Nadel zur Befestigung versehen, wohingegen die fermaux auch fest mit einem Kleidungsstück verbunden sein konnten. 
tungen ${ }^{96}$, als »Gesellschaftsabzeichen« Mittel zur Demonstration von Gruppenzugehörigkeiten ${ }^{97}$.

Verwendung fanden zahlreiche Motive, hauptsächlich aus dem (auch fabelhaften) Bereich der Tier- und Pflanzenwelt, wie (Frankreichs) Lilien ${ }^{98}$, Rosen 99 , (Margarete von Flanderns) Margeriten ${ }^{100}$ und Veilchen ${ }^{101}$ oder (burgundischer) Weißdorn ${ }^{102}$, Brombeere ${ }^{103}$ und (königliche) Ginsterzweige ${ }^{104}$ (aber nicht der Hopfen Johanns Ohnefurcht), Hunde im allgemeinen ${ }^{105}$ und Windhunde im besonderen ${ }^{106}$, Rentiere ${ }^{107}$, Hirsche ${ }^{108}$, natürlich auch der geflügelte weiße Hirsch des Königs ${ }^{109}$, und Hirschkühe ${ }^{110}$, Eichhörnchen 111 , Falken ${ }^{112}$, Greifen 113 und Adler ${ }^{114}$, Panther ${ }^{115}$ und Löwen ${ }^{116}$, auch (königliche) Tiger(hunde) ${ }^{117}$, zahlreiche Vögel ${ }^{118}$, aber kein

96 Vgl. etwa den farbig bebilderten Art. von Renate Eikelmann über die "Sechzehn Agraffen « zur Kat.-Nr. 17, in: Das Goldene Rössl. Ein Meisterwerk der Pariser Hofkunst um 1400 (Ausstellungskatalog), 1995, S. 248-255, v.a. aber EIKELMANN 1984, S. 405 ff.

97 Vgl. ebd., S. 405. Beispiele hierzu unten S. 191-195.

98 Anhang - Katalog/Jahreslisten, bspw. Nr. 26.

99 Ebd., bspw. Nr. 66 oder 98.

100 Ebd., bspw. Nr. 513.

101 Ebd., bspw. Nr. 517.

102 Ebd., bspw. Nr. 564.

103 Ebd., bspw. Nr. 60.

104 Ebd., bspw. Nr. 245.

105 Ebd., bspw. Nr. 25. Zu den allegorischen und symbolischen Bedeutungsgehalten von Hunden MCCULLOCH 1960: Stw. »dog«, S. $110 \mathrm{f}$.

106 Anhang - Katalog/Jahreslisten, bspw. Nr. 53.

107 Ebd., bspw. Nr. 130.

108 Ebd., bspw. Nr. 65. Zur allegorischen und symbolischen Bedeutung des Hirsches MCCULLOCH 1960: Stw. »stag«, S. 172-174, als Element der christlichen Bildersprache SCHMIDT 1981, S. 67-70.

109 Anhang - Katalog/Jahreslisten, Nr. 442.

110 Ebd., bspw. Nr. 52.

111 Ebd., bspw. Nr. 137.

112 Ebd., bspw. Nr. 62.

113 Ebd., bspw. Nr. 7, siehe auch LABORDE, Glossaire, 1872: Stw. "griffon«, S. 335f. Zur allegorischen und symbolischen Bedeutung des Greifen MCCuLLOCH 1960: Stw. "griffin", S. 122f., als Element der christlichen Bildersprache SCHMIDT 1981, S. 63-66.

114 Anhang - Katalog/Jahreslisten, bspw. Nr. 73. Zur allegorischen und symbolischen Bedeutung des Adlers nach mittelalterlichen Bestiarien siehe MCCULLOCH 1960: Stw. "eagle«, S. 113-115, als Element der christlichen Bildersprache SCHMIDT 1981, S. 34-40.

115 Anhang - Katalog/Jahreslisten, bspw. Nr. 70. Zur allegorischen und symbolischen Bedeutung des Panthers MCCULLOCH 1960: Stw. "panther«, S. 148-150.

116 Anhang - Katalog/Jahreslisten, bspw. Nr. 196. Zur allegorischen und symbolischen Bedeutung des Löwen MCCULLOCH 1960: Stw. »lion«, S. 137-140, als Element der christlichen Bildersprache SCHMIDT 1981, S. 78-86.

117 Anhang - Katalog/Jahreslisten, bspw. Nr. 682. Zur allegorischen und symbolischen Bedeutung des Tigers MCCULLOCH 1960: Stw. »tiger«, S. $176 f$.

118 Anhang - Katalog/Jahreslisten, bspw. Nr. 192. 
Schwan, dafür Tauben ${ }^{119}$, Rebhühner ${ }^{120}$ und Lerchen ${ }^{121}$ sowie Papageien ${ }^{122}$ und Strauße ${ }^{123}$, des weiteren Bären ${ }^{124}$, aber auch Einhorne ${ }^{125}$ usw. Teilweise sind auf den Spangen Szenen dargestellt wie un enfant nud qui chevauche une panthère, et au dessus un angelot ${ }^{126}$, un aigle d'or qui tient entre ses pieds un cougnin ${ }^{127}$, une dame de rouge cler, assise sur une biche ${ }^{128}$, un cerf noiiant en l'eaue et 2 levriers ${ }^{129}$ oder une dame assise sur une licorne ${ }^{130}$. Nur selten fanden hier religiöse Motive wie un saint Michel 131 Verwendung.

Spangen nahmen am Gesamtwertvolumen des höfischen Geschenkverkehrs von 1381 bis 1422 den nicht unbeträchtlichen Satz von nicht ganz 12,5\% ein. Aus diesem Bereich stammt auch eines der wertvollsten Geschenke überhaupt, eine Spange, die Philipp der Kühne dem Herzog von Berry 1388 überreicht hat: un fermail ront a ung gros balay quarré, environne de 6 grosses perles 132 . Eine offensichtlich äußerst einfach gestaltete Arbeit, deren hoher Wert von 5.500 1. wohl auf den Balasrubin zurückzuführen ist. Andere wertvolle Spangen, deren Wert jeweils über 1.0001 . betrug, waren ein schlichter, aber 1.8001 . teurer fermail Antons von Burgund an seinen Vater $1404^{133}$, ein colier d'or a un fermail pendant garni de 3 balays a bon chouces et de 3 grosses perles Philipps des Kühnen an den König $1396^{134}$ und an denselben 1395 ein fermail d'or à une beste appelée tigre ${ }^{135} \mathrm{zu}$ Preisen von $1.700 \mathrm{l}$. und $1.600 \mathrm{l}$., ein petit fermail d'or a un cerf voulant garni de trois grois dyamans, un roby, et trois grosses perles zu 1.534 l., den Isabeau dem König 1390 schenkte136,

119 Anhang - Katalog/Jahreslisten, bspw. Nr. 131. Zur Taube als Element der christlichen Bildersprache SCHMIDT 1981, S. 110-119.

120 Bspw. Anhang - Katalog/Jahreslisten, Nr. 469.

121 Ebd., bspw. Nr. 449.

122 Anhang - Katalog/Jahreslisten, bspw. Nr. 80. Zur allegorischen und symbolischen Bedeutung des Papageis MCCULLOCH 1960: Stw. "parrot«, S. 151.

123 Anhang - Katalog/Jahreslisten, bspw. Nr. 139. Zur allegorischen und symbolischen Bedeutung des Strauß' MCCUlLOCH 1960: Stw. »ostrich«, S. 146f.

124 Anhang - Katalog/Jahreslisten, bspw. Nr. 531. Zur allegorischen und symbolischen Bedeutung des Bären, einem der Zeichen des Herzogs von Berry, MCCULlOCH 1960: Stw. »bear«, S. $94 \mathrm{f}$.

125 Anhang - Katalog/Jahreslisten, bspw. Nr. 79. Zur allegorischen und symbolischen Bedeutung des Einhorns MCCULLOCH 1960: Stw. "unicorn«, S. 179-183, als Element der christlichen Bildersprache SCHMIDT 1981, S. 46-54.

126 Anhang - Katalog/Jahreslisten, Nr. 13.

127 Ebd., Nr. 123.

128 Ebd., Nr. 138.

129 Ebd., Nr. 276.

130 Ebd., Nr. 398.

131 Ebd., Nr. 193.

132 Ebd., Nr. 268.

133 Ebd., Nr. 1281.

134 Ebd., Nr. 733.

135 Ebd., Nr. 682.

136 Ebd., Nr. 330. 
die von Philipp dem Kühnen 1393 an einen unbekannten Empfänger gerichtete Spange à un gros balay quarré et quatre grosses perles ${ }^{137}$, die 1.500 l. gekostet hat, und 1394 schließlich wiederum ein Geschenk des Burgunderherzogs, diesmal an seinen Neffen, den Herzog von Orléans, das gemeinsam mit einem großen Diamanten einen Wert von 1.040 1. darstellte138.

Den Blick am Beispiel der Spangen einmal von den wertvollen Geschenken weg auf die »billigeren« Gaben gerichtet, von denen Preis und Empfänger bekannt ist, gerät eine ganz andere Gruppe von Beschenkten in den Blick. 1386 erhielten Estienne, ein Sticker ${ }^{139}$, Jehanncon, ein Kammerdiener, und Jean Nau, ein Geflügelwart, von ihrem Herrn, dem Herzog Johann von Berry, Spangen a facon d'oreilles, a un chiennet und a un petit chiennet ${ }^{140} \mathrm{zu} 6 \mathrm{l}$. und 81 . Philipp der Kühne schenkte Blanche, einer Kammerzofe der Marie de Sully, 1389 un petit fremaillet d'or à I safir et 6 perles, der 151 . gekostet hatte ${ }^{141}$, und Berthelot Helyot, einem seiner Kammerdiener, 1398 eine einfache Spange zu 201.142 .

Noch häufiger als Spangen 143 wurden Ringe - anneaux ${ }^{144}$, verges ${ }^{145}$, bagues $^{146}$ - als Neujahrsgeschenke verwendet ${ }^{147}$, in der Mehrzahl der Fälle in Verbindung mit einem Edelstein, meistens mit einem Diamanten in den gängigen Formen 148 . Über 800 Ringe sind in den Rechnungen verzeichnet, verteilt über fast alle Jahre, wobei der Anteil am Gesamtwert aller Geschenke aber nicht einmal 3\% beträgt. Ringe scheinen wie die Diamanten ein typisches Massengeschenk gewesen zu sein, teilweise gleich dutzendfach verschenkt, was vielleicht - ganz banal - auch mit ihrer verhältnismäßig einfachen Handhabung zusammenhing: klein, leicht und problemlos auch in größeren Mengen

137 Anhang - Katalog/Jahreslisten, Nr. 594.

138 Ebd. Nr. 631.

139 Die Arbeit Staniland, Kay: Les brodeurs, Paris 1992, war bis Abschluß der vorliegenden Arbeit leider nicht zugänglich.

140 Anhang - Katalog/Jahreslisten, Nr. 150-152.

141 Ebd., Nr. 303.

142 Ebd., Nr. 921.

143 Oben nicht aufgeführt sind die beiden goldenen bracelets, jeweils verziert mit une chaenette et d'une verge d'or, Armreifen (siehe LABORDE, Glossaire, 1872: Stw. »bracelet«, S. 472f. und Stw. "armille«, S. 137), die Philipp der Gute 1421 Agnes und Anna von Burgund geschenkt hat, siehe Anhang - Katalog/Jahreslisten, Nr. 1812f.

144 LABORDE, Glossaire, 1872: Stw. »annel«, S. 131.

145 Ebd.: Stw. »verge«, S. 536. Gemeint sind hier wohl keine Ruten, Gerten oder Zweige, sondern einfache Ringe, so daß dieser Begriff seine Bedeutung der biegsamen Eigenschaft kleiner Gerten oder Zweige verdankt.

146 Ebd.: Stw. »bague«, S. 155.

147 Schöne Beispiele in: Les fastes du Gothique (Ausstellungskatalog), 1981, Nr. 197-D, $-E,-F$, und $-G$ sowie Nr. 200 und 201.

148 Über die Formgebung Aufschluß gibt FALK 1975, pass., siehe v.a. das Schaubild S. 16. 
zu transportieren ${ }^{149}$. Nicht alle Ringe sind jedoch als »Billigware« anzusehen, denn immerhin 50 dieser Schmuckstücke erreichen Werte von über 100 1. Die beiden wertvollsten wurden 1393 von Philipp dem Kühnen an unbekannte Empfänger verschenkt und kosteten $650 \mathrm{l}$. beziehungsweise 400 1. 150 . Isabeau de Bavière, sein Kammerherr Guy de La Trémoille und seine Frau Margarete von Flandern konnten 1388 und 1389 von ihm Ringe in Empfang nehmen, die ebenfalls hohe Werte von einmal 3251 . und zweimal 3001 . erreichten 151 . Auch waren nicht alle dieser Ringe phantasieloser Fingerschmuck, der nur als Träger teurer Edelsteine von Bedeutung war. 1411 schenkte beispielsweise Karl von Orléans seinem Bruder Jean d'Angoulême ung annel d'une esméraude en maniere d'une bouteille, enmis de deux dyamans ${ }^{152}$, Johann von Berry bekam 1408 von Johann I. von Bourbon un annel d'or, ouquel a un heaume et rescu de mesmes, fait d'un saphir, aux armes de monseigneur, un ours d'esmeraude et un cigne de cassidoine blanc soustenant ledit heaume ${ }^{153}$ und von Charles d'Artois un annel d'or ou il a deux testes d'ours, l'une d'un balay et l'autre de cassidoine blanc, un cuer de saphir à l'un des costez, et à l'autre costé une esmeraude roonde ${ }^{154}, 1410$ von Guichard Dauphin un annel d'or ou il a un escu d'un saphir à III fleurs de lis d'or, endenté de menuz balaisseaulx aux armes de monseigneur 155,1413 wiederum von Charles d'Artois un annel d'or ouquel est le visaige de monseigneur le Duc contrefait

149 Siehe Anhang - Katalog/Jahreslisten die an ungenannte Empfänger verschenkten Ringe von Philipp dem Kühnen: Nr. 31, 1382: 50 verges d'or, Nr. 45, 1383: une douzaine de verges $d$ 'or, plainnes, esmaillees de blanc, $\mathrm{Nr}$. 689, 1395: LX petites verges $d$ 'or und $\mathrm{Nr} .846$, 1397: XII petits anneaux à diaments, diejenigen Johanns von Berry: Nr. 154 a touz St chappellains et autres officiers de son hostel, BNF ms.fr. 10369, fol. 55r, 1386: $1112^{\text {eme }}$ de verges d'or, diejenigen Isabeaus de Bavière: Nr. 412 und 413, 1391: jeweils 19 anneaulx d'or tant a perles et a rubis d'Alixandre und Nr. 496, 1392: dix sept anneaulx d'or, diejenigen Valentinas Visconti: Nr. 479 und 482, 1391: III anneaux und XII verges d'or, Nr. 538, 1392: III anneaulx, Nr. 770, 773 und 776, 1396: douze verge d'or plates, quatre anneaux d'or emaillés en chascun une grosse perle ronde und deux diaments en deux anneaux, $\mathrm{Nr}$. 1056, 1400: deux douzaines et demie de verges d'or und Nr. 1119, 1401: 12 verges d'or, diejenigen Ludwigs von Orléans: Nr. 711, 1396: cinq diaments en anneaux und Nr. 1094, 1401: XIX dyamens en anneaulx, diejenigen Johanns Ohnefurcht: Nr. 1710, 1417: 6 anneaux c'est assavoir deux à chascun 2 dyamens et une esmeraude, l'autre un ruby et un dyament, l'autre à une vermeille et un dyament et les deux autres à chascun 1 dyament und schließlich diejenigen Karls VI.: Nr. 1748, 1419: quatre petits ronds rubis mis chascun en un anneau d'or et 24 diamants carrés, dont 12 plats et 12 à pointe, mis chascun en un anneau d'or.

150 Siehe Anhang - Katalog/Jahreslisten, Nr. 593 und 589.

151 Siehe ebd., Nr. 259, 254 und 320.

152 Siehe ebd., Nr. 1521.

153 Siehe ebd., Nr. 1433. Zur allegorischen und symbolischen Bedeutung des Bären MCCULlOCH 1960: Stw. »bear«, S. 94f., des Schwanes MCCULLOCH: Stw. »swan«, S. 176.

154 Siehe Anhang - Katalog/Jahreslisten, Nr. 1428.

155 Siehe ebd., Nr. 1470. 
d'une pierre de camahieu ${ }^{156}$ usw. Der Aufbewahrung von Ringen dienten nachgemachte Finger, meist aus Holz. Auch einen solchen doigtier verzeichnen die Rechnungen als Neujahrsgeschenk, die Königin erhielt ihn 1400 von Philipp dem Kühnen, geschmückt mit fünf Diamanten 157 .

Ketten 158 und Kolliers 159 machten nur einen sehr kleinen Teil der verschenkten Gegenstände zum neuen Jahr aus. Es waren nur 159 l., die für neun Ketten in den Jahren 1382, 1390, 1395 und 1397 ausgegeben wurden, und nur 40 Kolliers, diese aber zu einem Gesamtwert von 21.4451 . 1 s. 3 d. entsprechend etwa $4 \%$ am Gesamtvolumen, die vergeben wurden. Kolliers waren meistens als Kollanen mit den jeweils spezifischen Abzeichen Ausweis für bestimmte Gruppenzugehörigkeiten, Ketten wurden als Schmuck ohne weitere Funktion um den Hals oder um die Hüfte getragen. Un collier d'or fait en guise de chaîne et à sa devise hatte der König 1394 von dem Burgunderherzog bekommen ${ }^{160}$.

Abgesehen von den an dieser Stelle ausgeklammerten Ordenskollanen ${ }^{161}$ wiesen nur sechs Kolliers symbolische Anspielungen auf. So überreichte Philipp der Kühne seinem Parteigänger Waleran von Luxemburg im Jahr 1400 un gros collier d'or ouvré à marguerites et, dedens chaque fleur, à perles $\mathrm{zu}$ dem nicht unbeträchtlichen Wert von $5301 .{ }^{162}$ und 1397 hatten die Kinder Frankreichs Johann, Karl, Maria und Michelle von ihrem Onkel, dem Herzog von Orléans, jeweils ein Kollier d'or ronds faits de fil d'or sans pierreries, ausquels est attachée une cosse d'or de geneste, garnie de deux grosses et d'un gros diament erhalten ${ }^{163}$. Ansaldo Spinola, ein Genueser, der sich in den Verhandlungen um das Lösegeld für Johann Ohnefurcht nach der verlorenen Schlacht von Nikopolis Verdienste erworben hatte, bekam 1401 von dem Burgunder un collier d'argent à sa devise zu einem leider unbekannten Preis 164 . 1411 schließlich war es Johann von Berry, dessen Inventar eine detaillierte

156 Siehe Anhang - Katalog/Jahreslisten, Nr. 1560. Vgl. den annel d'or, ou il a une teste d'un More fait de cassidoine, den Ludwig der Bärtige 1415 Johann von Berry geschenkt hat, siehe ebd., Nr. 1675 und den annel d'or ou il a une teste d'un viez homme à grans cheveux et barbe, faicte de camahieu, den Berry 1408 von einem Unbekannten erhielt, siehe ebd., Nr. 1447.

157 Siehe Anhang - Katalog/Jahreslisten, Nr. 1028, vgl. FALK 1975, S. 12, Anm. 7, siehe LABORDE, Glossaire, 1872: Stw. »doittier«, S. 253f.

158 Siehe LABORDE, Glossaire, 1872: Stw. »chaene«, S. 198f. Vgl. die Abb. S. 267 der Kette der Michelle de France zum Art. von Annette SCHOMMERS, in: Das Goldene Rössl. Ein Meisterwerk der Pariser Hofkunst um 1400 (Ausstellungskatalog), 1995, S. 265-268.

159 Siehe LABORDE, Glossaire, 1872: Stw. " collier«, S. 220.

160 Anhang - Katalog/Jahreslisten, Nr. 627.

161 Siehe unten S. 191.

162 Anhang - Katalog/Jahreslisten, Nr. 1050.

163 Ebd., Nr. 792, 794, 796 und .797.

164 Ebd., Nr. 1070. 
Beschreibung zu verdanken ist, dem von seinem trésorier Macé Heron un collier de fil d'or trait plat, garni par les bours de boutons d'or roons, et semé de petis ours esmaillez de blanc, de petites rosetes, et en chascune rosete a un petit dyament plat, et de plusieurs petis clos en façon de lozanges geschenkt wurde ${ }^{165}$.

Karl von Frankreich, der 1392 geborene Dauphin, dem sein Bruder Ludwig von Guyenne erst nach seinem Tod 1401 nachfolgte, erhielt 1397 von Philipp dem Kühnen une chayne d'or de coste et de fleurs de genestes à plusieurs sonettes pendants et à ycelle pendant un fermail d'un tigre, garni de III perles et d'un ruby zu einem Wert von 501.166 Der cornet d'or pendant a une chaine d'or, led. cornet garni de trois balais, un saphir et neuf perles, der Karl im selben Jahr von Valentina Visconti geschenkt wurde, war wohl eher als Spielzeug gedacht ${ }^{167}$. Jean Martel, ein Knappe der Königin, und Raoul Cassinel, ein Neffe des den Marmousets zuzurechnenden Ferri Cassinel, bekamen von ihrer Herrin 1395 jeweils eine mit zahlreichen Schellen versehene silberne Kette zu je $291.10 \mathrm{~s} .168$ Die an den Ketten häufig angebrachten Anhänger machten nicht selten die Kette zur Nebensache und diese Geschenke wurden dann als un pendentif avec une chaîne bezeichnet ${ }^{169}$.

Die wertvollsten Kolliers hatte bis auf den 1.0941 . teuren colier d'or garny de XVIII rubiz XVIII dyamans et XI perles, das der König von der Königin 1392 bekam ${ }^{170}$, wiederum Philipp der Kühne verschenkt. Allein drei erhielt seine Gattin in den Jahren 1396, 1398 und 1402 zu Preisen von 2.500 1.171, 2.600 1.172 und 2.300 1.173 Der König bekam 1396 und 1404 jeweils ein Kollier zu 1.7001 .174 und 2.5001 .175 Für den collier d'or rond a petites cosses emailles de blanc et de rouge clair, a un fermelet d'or pendant pendant aud. collier,

165 Anhang - Katalog/Jahreslisten, Nr. 1538.

166 Ebd., Nr. 825. Die ebd. unter der Nr. 787 nach einer anderen Quelle notierte chesne d'or toute plainne de sonnettes [...] un tigre pendu ou milieu de la dicte chesne, die Karl im selben Jahr an eine unbekannte Person vergeben hat (oder in Anbetracht seines Alters veranlaßt wurde, zu vergeben), ist möglicherweise identisch mit der Kette, die er von dem Burgunder bekam.

167 Ebd., Nr. 863. Siehe auch unten S. 179 mit Anm. 309.

168 Ebd., Nr. 658 und 660.

169 Z.B. ebd., Nr. 375 und 379. Vgl. auch die fleur de lis d'or pour mectre oisellez de Chipre à parfumer, pendant à une petite chaiennete d'or, et au bout un crochet, die Anna von Bourbon Johann von Berry 1406 schenkte, siehe ebd., Nr. 1355.

170 Ebd., Nr. 490.

171 Ebd., Nr. 744.

172 Ebd., Nr. 941.

173 Ebd., Nr. 1200.

174 Ebd., Nr. 733.

175 Ebd., Nr. 1312. 
garni de trois grosses perles, trois gros diaments et un fin rubi au milieu, den Valentina Visconti 1396 bekam, mußte ihr Mann immerhin noch 9001. aufwenden ${ }^{176}$.

Heiligenbildnisse als Tafelbilder ${ }^{177}$ oder Goldschmiedearbeiten und -plastiken ${ }^{178}$ mit religiösen Motiven nach Art des »Goldenen Rößls« nahmen im Rahmen des höfischen Geschenkverkehrs eine Sonderstellung hinsichtlich ihrer teilweise äußerst aufwendigen Gestaltung, ihrer meist hohen Werte und ihrer fast ausschließlichen Verwendung innerhalb des Hochadels ein - abge-

176 Anhang - Katalog/Jahreslisten, Nr. 714.

177 Vgl. etwa das Geschenk der Charlotte de Bourbon 1410 an den Herzog von Berry: uns anciens tableaux de bois à pignon, faiz de paincture, de la Passion Nostre Seigneur, en IIII pieces fermans à couplez; et y a plusieurs fillolles de cuivre doré, siehe ebd., Nr. 1466. Freie Tafelbilder in diesem Sinn sind Bilder mit Darstellungen meist religiösen Inhalts, hierzu LABORDE, Glossaire, 1872: Stw. »Tableau«, S. 508f. Bei den sog. images handelt es sich um Goldschmiedearbeiten, siehe ebd.: Stw. "Images d'or et d'argent«, S. 343f. Siehe auch BELTING 1990, 470-474.

178 Heranzuziehen sind zunächst für den allg. Überblick NIEHOFF, Franz: Art. »Goldschmiedekunst. I. Westen (Frühmittelalter bis 1500)«, hier v.a.: »[3] 1200-1500«, in: LexMA, Bd. 4, 1989, Sp. 1548-1551, zum Beruf des Goldschmieds BAUM, Hans-Peter: Art. "Goldschmied«, in: ebd., Bd. 4, 1989, Sp. 1547f. mit weiteren Nachweisen) und FRITZ 1982 (allerdings beschränkt auf Mitteleuropa, hier zu den Goldschmieden S. 37ff.), zu Email LABARTE 1856, STEINGRÄBER, Erich: Art. "Email«, in: Reallexikon zur deutschen Kunstgeschichte, hg. von ScHMIDT, Bd. 5, 1960, Sp. 1ff., ELBERN, Victor H.: Art. »Email. I. Allgemein«, in: LexMA, Bd. 3, 1986, Sp. 1868f. und ElBERN, Victor H.: Art. "Email. III. Abendland«, in: ebd., Bd. 3, 1986, Sp. 1871-1873. Die unterschiedlichen v.a. technischen Ausdrücke finden sich bei LABORDE, Glossaire, 1872: S. 273-299 unter den Stw. „Esmail« bis "Esmailleure«. In allg. Hinsicht für den diachronischen Vergleich Marie-Madeleine GAUTHIERs umfangreiche Arbeit zu den "Emaux du moyen âge occidental«: GAUTHIER 1972, hier v.a. S. 279-310 (siehe S. 281ff. „Les princes amateurs: France, Anjou, Berry, Bourgogne, Bohème et Angleterre«, 297ff. "Les étrennes ducales et cardinalices «). Grundlegende Ausführungen bei VASSELOT, Jean-Joseph Marquet de: L'orfèvrerie et l'émaillerie aux XIII et XIV ${ }^{e}$ siècles, in: MICHEL, Histoire de l'Art, Bd. 2,2, 1906, S. $917-$ 989, hier S. 939-953 über Email, S. 953-973 über Goldschmiedearbeiten, S. 973-988 über Email des 14. Jh.s, v.a. S. 982-986 explizit zur französischen Emailkunst, bibl. Nachweise siehe S. 988f. Ergänzend zu benutzen STEINGRÄBER 1962 und STEINGRÄBER 1969. Zur allg. Geschichte der französischen Goldschmiedekunst HAVARD 1896. Ein ebenso veralteter allg. Überblick über »Abendländische Schmelzarbeiten« stammt von BURGER 1930, hier S. 146172. Über die für die Zeit charakteristischen Goldemailarbeiten informieren grundlegend mit konkretem Bezug MÜlLER, STEINGRÄBER 1954 (französische Goldemailplastik um 1400), KovaCs 1975, sowie insbes. EIKELMANN 1984 (zum Forschungsstand EIKELMANN 1992 über »Emailkunst an den französischen Fürstenhöfen im Spätmittelalter« und insbes. EIKELMANN, Goldemail um 1400, 1995), hier S. 18-121 zur Technik des »émail en ronde bosse«. Ergänzend heranzuziehen: Silber und Gold. Augsburger Goldschmiedekunst für die Höfe Europas (Ausstellungskatalog), 1994, allerdings wird hier erst die Zeit ab dem 17. Jh. behandelt, siehe aber insbes. auch hier die Bedeutung der Goldschmiedekunst für die Neujahrsgeschenke S. 34 mit S. 51, Anm. 79. 
sehen von Martin Gouge 179 , Jean de Montagu180, der Gruppe der Sekretäre des Herzogs von Berry 181 und dem Genueser Händler Janus de Grimault (Grimaldi) ${ }^{182}$, die jeweils einmal als Schenkende auftraten, und unter Vernachlässigung von Marie de Duisy 183 und Nicole d'Estrée ${ }^{184}$ als Empfänger. Insgesamt wurden 92 tableaux d'or, ymages d'or, statuettes oder joyau d'or 185 - davon allein 61 in den zehn Jahren von 1395 bis 1404 - mit einem Gesamtwert bei nur 68 notierten Preisen von knapp 74.000 l., entsprechend etwa 14\% des Gesamtvolumens.

6.000 1. hat Philipp den Kühnen das grant tableau de la Trinité, garny de plusieurs gros balais, gros saphirs et plusieurs grosses perles gekostet, das er 1389 seinem Bruder Berry überreichte ${ }^{186}$. Bezahlt habe der Herzog aber erst 1398187. Auch die Finanzierung der 3.600 1. der Annonciation de Nostre Dame d'or esmailliee, garnie de pierreries, assize en un tabernacle d'argent, die der König dem Burgunderherzog 1397 geschenkt hatte, schien Probleme bereitet zu haben, denn $1.600 \mathrm{l}$. mußte Philipp selbst aufbringen ${ }^{188}$. Un tableau d'or à la Vierge à l'enfant s'y opposant à la Crucifixion, comme dans un dyptique, das Margarete von Flandern von ihrem Gatten 1399 bekam, war das drittwertvollste Geschenk dieser Art, hatte aber nur einen Wert von 2.700 1. ${ }^{189}$.

179 Er verschenkte 1415 an den Herzog ein petis tableaux d'or, ou il a plusieurs histoires de la Vie et Passion Nostre Seigneur et Nostre Dame, esmaillez par dedans et dehors, ployans à troys couplez, c'est assavoir: deux aux coustés et ung dessus unbestimmbaren Wertes, siehe Anhang - Katalog/Jahreslisten, Nr. 1680.

180 Von ihm bekam Johann von Berry 1410 ein Tafelbild: uns grans tableau de bois tous neuf, de la longueur d'un autier ou environ, bien ouvrez de menuz ymaiges de paincture, de la Vie et Passion Nostre Seigneur et de plusieurs sains et sainctes; et sont en VI pieces fermans à couplez d'argent doré zu 1871 . 10 s., siehe ebd., Nr. 1473.

181 Erard Moriset, Jean de Cande, Michel le Beuf und Pierre de Gynes gaben ihrem Herrn 1405 un joyau d'argent doré en maniere d'une table, ou est Dieu et les XII appostres; et sur ladicte table a escript devant chascum appostre son nom; et tiennen en leurs mains chascun en petit reliquiere, siehe ebd., $\mathrm{Nr} .1337$.

182 Hier war es un petit tableau d'or quarré, en deux pieces, ou il a, par dedans, deux ymaiges faiz de camahieu, et, par dehors, d'un des costez a un crucifix, et de l'autre Nostre Dame tenant son enffant, garni de menue pierrerie de petite valeur $\mathrm{zu} 80 \mathrm{I}$,, das der Herzog von Berry 1408 erhielt, siehe ebd., Nr. 1431.

183 Die Hofdame der Königin erhielt von Valentina Visconti 1395 derx tableawx d'or à émauxx, représentant l'Annonciation, siehe ebd., Nr. 696.

184 Der burgundische Gefolgsmann bekam von Johann Ohnefurcht 1417 un tableau d'or à une Nostre Dame esmaillee de blanc et 3 crochez de perles, un saphirs et un balay, siehe Anhang - Katalog/Jahreslisten, Nr. 1708.

185 EVANS 1970, S. 55 macht darauf aufmerksam, daß der Begriff joyau erst um 1390 die uns heute geläufige Bedeutung annahm und davor für das Tafelgeschirr benutzt wurde.

186 Anhang - Katalog/Jahreslisten, Nr. 311.

187 Siehe Inventaires mobiliers, hg. von PROST, PROST, Bd. 2, 1908-1913, S. 472, Anm. 2 nach ACO B 1514, fol. 215v-216r.

188 Anhang - Katalog/Jahreslisten, Nr. 786 mit der entspr. Anm.

189 Ebd., Nr. 1014. 
Häufig wurden diese joyaux, images und tableaux in den Rechnungen nur einfach nach dem Bild des gezeigten Heiligen oder der dargestellten Szene beschrieben: un saint Antoine garni de pierreries ${ }^{190}$, une sainte Catherine ${ }^{191}$, un saint Michel garni de pierreries ${ }^{192}$, un saint Jean-Baptiste d'or dur tablette de vermeill ${ }^{193}$, un saint Louis ${ }^{194}$ oder un saint Jean l'Evangéliste d'argent doré195 beziehungsweise un joyau d'or sur tablette d'argent à l'histoire du baptisement Nostre-Seigneur196. Häufig sind diese Gegenstände aber auch relativ präzise erfaßt worden wie das oben vorgestellte »Goldene Rößl«197 und es wird Aufschluß gegeben über Material und Edelsteinbesatz, schmückendes Beiwerk und Gesamtkomposition, aber auch über die Kreativität und Kunstfertigkeit der Goldschmiede. So ist in einem königlichen Inventar die Beschreibung eines Geschenks Ludwigs von Orléans an seinen Bruder aus dem Jahr 1398 notiert, das nach einer Rechnung des Schenkers 1.600 1. gekostet hatte: une image d'or de saint Jean l'Evangeliste lequel tient en sa main destre un reliquaire d'or ouquel a une boiste de cristal garnie de trois ballaiz, six saphirs et neuf perles et audessus dudit reliquaire une palme garnie de trois balais, quatre saphirs et neuf perles, et en la main senestre il a tient un calice ouquel a serpens esmaillez et une perle ou millieu, et a un diademe garny de huict perles et un balay au milieu, et siet sur un entablement d'argent doré esmaillé des armes de monseigneur d'Orléans ${ }^{198}$.

Der Evangelist Johannes, so der Text, hält in seiner rechten Hand ein goldenes Reliquiar mit einem Behälter aus Kristall ${ }^{199}$, der verziert ist mit drei Balasrubinen, sechs Saphiren und neun Perlen, und über dem Reliquiar befindet sich eine Palme, verziert mit drei Balasrubinen, vier Saphiren und neun Perlen, und mit der linken Hand hält er einen Kelch mit emaillierten Schlangen $^{200}$ (dem Attribut des Apostels) und einer Perle in der Mitte, und er trägt ein Diadem, das mit acht Perlen und einem Balasrubin in der Mitte geschmückt ist, und er sitzt auf einem vergoldeten Gesims aus Silber, versehen mit den emaillierten Wappen des Herzogs von Orléans.

192 Ebd., Nr. 1257.

193 Ebd., Nr. 739.

194 Ebd., Nr. 936.

195 Ebd., Nr. 1253, auf Kosten Burgunds nach Riom in die Auvergne geschickt, wo Johann von Berry seinerzeit residierte.

196 Ebd., Nr. 1035.

197 Siehe oben S. 62-64.

198 Anhang - Katalog/Jahreslisten, Nr. 899.

199 Hierzu LABORDE, Glossaire, 1872: Stw. „Cristal«, S. 233-236, sowie ELBERN, Victor H.: Art. »Kristall, -schnitt. I. Abendland«, in: LexMA, Bd. 5, 1991, Sp. 1534-1535.

200 Zur allegorischen und symbolischen Bedeutung der Schlange MCCULLOCH 1960: Stw. »snake«, S. 170f., als Element der christlichen Bildersprache SCHMIDT 1981, S. 100-108. 
Im Jahr 1400 schenkte Ludwig dem König erneut eine wertvolle Goldschmiedearbeit, die aber ohne Wertangabe nur auf der Seite des Beschenkten inventarisiert wurde: une imaige d'or de saint Denis qui tient sa teste en ses mains et est sa mittre garnie de quatre saphirs et trois ballais et de vingt six menues perles, et le diademe de trois saphirs, un balay et trois troches, chascune de trois perles, et au costez de saint Denis a deux anges esmaillees de blanc, et est l'entablement garny de huict saphirs, six balais et seize troches chascunne de deux perles, et un cristal ouquel a Dieu qui escommuche saint Denis ${ }^{201}$.

Hier ist der heilige Dionysius dargestellt, der französische Nationalheilige, der nach der Legende nach seiner Enthauptung noch bis zu dem nach ihm benannten St-Denis gewandert sein soll ${ }^{202}$. Demgemäß trägt er seinen Kopf auf seinen Händen.

Philipp der Kühne schenkte Johann von Berry im selben Jahr - nach dessen eindringlicher schriftlicher Aufforderung, in welcher er das Ausbleiben seines Neujahrsgeschenks unter Hinweis darauf, daß er dasjenige seines Neffen Ludwig von Orléans, einen saint Jacques le minor ${ }^{203}$, schon erhalten habe, monierte, und Philipp seinen ganz konkreten Wunsch nach einer ymage de saint Jacques le grant vortrug 204 - für 1.350 l. une ymage d'or de saint Jaques tenent en l'une de ses mains un livre et en l'autre un bourdon ouquel il a un balay, un saphir et deux perles, et a un dyademe ouquel a un balay, deux saphirs et huit perles; et siet ledit ymage sur un entablement d'argent doré, esmaillé aus armes de monseigneur de Berry et de Bourgoigne ${ }^{205}$, also eine Darstellung des heiligen Jakobus, der in der einen seiner Hände ein Buch hält, und in der anderen einen mit einem Balasrubin, einem Saphir und zwei Perlen geschmückten Pilgerstab (als Schutzheiliger der Pilger), und der ein Diadem trägt mit einem Balasrubin, zwei Saphiren und acht Perlen, und diese Figur befindet sich auf einem vergoldeten Gesims aus Silber, das mit den emaillierten Wappen der Herzöge von Berry und Burgund versehen ist.

Seltener wurde schlicht ung ymaige d'or ${ }^{206}$, un tableau d'or garny de pierrerie ${ }^{207}$ oder un tableau orné de pierreries ${ }^{208}$ verbucht.

201 Anhang - Katalog/Jahreslisten, Nr. 1025.

202 Siehe LOENERTZ 1961.

203 Anhang - Katalog/Jahreslisten, Nr. 1023.

204 Siehe ebd., Anm. 1204. Siehe oben S. 90 mit Anm. 84 f.

205 Ebd., Nr. 1034. Vgl zu einer ähnlichen Statue Les fastes du Gothique (Ausstellungskatalog), 1981, Nr. 179. AUTRAND, Le Jour de l'An, 1999, S. 5 spricht in diesem Zusammenhang davon, daß die sétrennes rappelaient parfois la solidarité des fleurs de lis." Vgl. AuTRAND, Jean de Berry, 2000, S. 482.

206 Anhang - Katalog/Jahreslisten, Nr. 1322.

207 Ebd., Nr. 1365.

208 Ebd., Nr. 1069. 
Thematische Ausnahmen in der Darstellung bilden eine ymage d'un Charlemagne d'or garni de pierreries assis sur entablemens d'argent doré209, die Johann von Berry 1395 von Ludwig von Orléans erhalten hatte, oder die tableaux d'or en façon d'une heures, ein Geschenk der Herzogin von Orléans an die Königin $1391^{210}$.

Schließlich fand diese Geschenkart auch im diplomatischen Verkehr Verwendung. Papst Clemens VII. verehrte Philipp der Kühne 1394, also wenige Monate vor dessen Tod im September des Jahres, un joyau d'or de l'Annonciation Nostre Dame, garni de dix balais, huit saphirs, un rubis, quatre diamants, deux grosses perles, trente deux moins grosses et neuf vingt petites, assis sur un entablement d'argent doré2 211 , der den Burgunder den beträchtlichen Preis von $2.000 \mathrm{l}$. gekostet hat. Richard II., der englische König, bekam von Philipp 1398 einen nicht minder wertvollen saint Edouard, tenant un rubis en la destre main ${ }^{212}$ zu 1.800 1. Als 1402 der Kaiser von Konstantinopel Manuel II. Palaiologos in Paris weilte, um für Unterstützung gegen die Osmanen zu bitten, erhielt er von Johann Ohnefurcht zum Neujahrstag eine tableau d'or ${ }^{213}$.

Produkte der zeitgenössischen Goldschmiedekunst waren auch Reliquiare $^{214}$, liturgische Gerätschaften und sonstige der Religionsausübung und privaten Andacht dienlichen Gegenstände215. Die Rechnungsüberlieferung

211 Ebd., Nr. 620.

212 Ebd., Nr. 991. Vgl. neuerdings STRATFORD, Gold, 2000, zum Geschenkverkehr zwischen England und Frankreich während der Regierungszeit Richards II., hier zu dem oben notierten Geschenkvorgang S. 234 mit Anm. 42.

213 Anhang - Katalog/Jahreslisten, Nr. 1155.

214 Siehe LABORDE, Glossaire, 1872: Stw. »reliquaires«, S. 477-479 und ebd.: Stw. »Reliques historiques«, S. 479.-483. Hierzu zunächst EICKELMANN 1984, S. 176ff. Reliquien behandelt allg. GAUTHIER 1983 (wenngleich zeitlich zu früh). Zur Verbindung von Reliquiar und Kult BRAUN 1940. Neueren Datums: FALK 1991/1993 zur »Entstehung und Entwicklung der metallenen Kopf-, Büsten- und Halbfigurenreliquiare im Mittelalter«. - LEGNER 1995, meint S. 272f. mit Abb. Nr. 126 auf S. 272, daß das "Goldene Rößl«, siehe oben S. 62-64, ebenfalls zu den Reliquiaren zu zählen sei, weil in einem Hohlraum des Gewölbedaches ein Stück Stoff vom Mantel Marias verborgen sei. Dagegen KAHSNITZ 1995, S. 63, 85, Anm. 21, der meint, das »Goldene Rößl« sei nicht mehr zur Aufnahme von Reliquien eingerichtet gewesen. Die »lose eingelegte, kleine Reliquie«, meint er, kann erst in späterer Zeit abgelegt worden sein. Siehe LABORDE, Glossaire, 1872: Stw. »Reliquaires«, S. 477-478.

215 Siehe neuerdings auch: Spiegel der Seligkeit (Ausstellungskatalog), 2000. 
verzeichnet neben den Reliquiaren Kreuze ${ }^{216}$ und ein Kruzifix ${ }^{217}$, Pax- beziehungsweise Kußtafeln ${ }^{218}$, einen Hostien-219 und einen Weihwasserbehälter 220.

Der Überlieferungsbestand nennt acht Gegenstände, die konkret als Reliquiar ausgewiesen sind. Alle wurden zwischen den Jahren 1402 und 1414 verschenkt, Empfänger war bis auf zwei Ausnahmen der Herzog von Berry. Wiederum war es der Burgunderherzog, dem es beschieden war, das wertvollste Exemplar zum Geschenk zu machen. Diesen äußerst einfach beschriebene Reliquienbehälter en forme de tableau d'argent doré erhielt 1404 die Königin, er kostete 8121.221 . Andere Notierungen, vor allem in den Inventaren Johanns von Berry, sind wesentlich umfangreicher. So hatte ein unbekannter Schenker dem Herzog von Berry 1404 un petit chief d'un evesque dont la teste est d'un camahieu, et la mictre et sa poictrine sont d'argent doré, garnie ladicte mictre de menue pierrerie et esmaux de petite valeur; et en la poictrine a un lieu pour mettre reliques; et a l'entour du col a escript: Gloriosus Deus in sanctis suis $^{222}$ verehrt und 1411 schenkte ihm Béatrix de Navarre, die Tochter König Karls III. von Navarra, un petit reliquiere d'or sur le roont, en façon de fons de cuve en deux pieces, esmaillé par dedens de deux ymaiges de Nostre Dame et de saint Jehan Baptiste, garni de celle part tout entour d'un filet de perles, et par dehors a plusieurs autres petites perles, et pend a un laz de soie ${ }^{223}$.

Noch aufwendiger gestaltet waren die Kreuze, neun an der Zahl, auch wenn die beiden wertvollsten Stücke wieder nur in Kurzbeschreibungen notiert sind: une croix d'or, garnie de pierreries und un croix d'or, garnie de plusieurs rubis balais et de grosses perles, Geschenke Philipps des Kühnen 1399 und 1388 an seinen Bruder Johann von Berry zu den enormen Preisen von 7.4001 .224 und 2.000 1.225. Besonders schöne Exemplare schienen die Kreuze gewesen zu sein, die Jean de Montagu, zu der Zeit Bischof von Chartres, und Isabeau de Bavière 1395 und 1403 dem König überreichten. Jean de Montagu schenkte une croix d'or de tres grant façon que soustienne quatre chevaliers, c'est assavoir saint Georges, saint Morise, saint Charles et saint Louis sur un

216 Siehe LABORDE, Glossaire, 1872: Stw. »croix«, S. 236.

217 Siehe ebd., 1872: Stw. "crucifix«, S. 237. Das Kruzifix erhielt Jean Canard von seinem Herrn 1393, siehe Anhang - Katalog/Jahreslisten, Nr. 563.

218 Siehe LABORDE, Glossaire, 1872: Stw. "paix«, S. 427f. Renate EIKELMANN wertet die Paxtafeln als eine bemerkenswerte Schöpfung der franko-flämischen Kunst, siehe EIKELMANN 1984, S. $331 \mathrm{ff}$.

219 Siehe LABORDE, Glossaire, 1872: Stw. "tabernacle«, S. 504 und das Stw. »ciboire«, S. 214.

220 Ung benoistier d'argent doré, ein Geschenk Philipps des Kühnen 1404 an einen unbekannten Empfänger, siehe Anhang - Katalog/Jahreslisten, Nr. 1321.

221 Ebd., Nr. 1301.

222 Ebd., Nr. 1296.

223 Ebd., Nr. 1499.

224 Ebd., Nr. 1099.

225 Ebd., Nr. 267. 
[...] garnie de pierreries, c'est assavoir huict ballesseaux et douze perles de compte, et est le pié de la croix assis sur une fleur de lis d'or, laquelle fleur de lys et les bras de la croix sont garnis de quarante trois grosses perles et neuf gros balaiz, et ou millieu de la fleur de lys a un gros saphir et aux pommeaus des espees de chascun desdits chevaliers a en chascun une perle. Touttes lesquelles choses sont assises sur une terrasse esmaillees de vert a fleurettes 226 .

Das Geschenk der Königin ist verzeichnet als une croix de cristal garnie d'or a un crucefix Nostre Dame, saint Jean d'or garnie de sept balaiz et un gros saphir, dessoubz le crucefix a de seize troches en chascunne trois perles, et dessoubz Nostre Dame et saint Jean a seize menus perles, et dessoubz la croix a un [...] garny de quatre troches chascune de trois perles et environ ledit [...] a vingt quatre menues perles, a ouverriere dudit [...] a un cristail garny de vingt quatre menues perles et est assise ladicte croix sur un entablement d'argent au lequel a trois angelotz d'argent dont l'un tient un pillier l'autre une lance et l'autre deux escourgiees 227.

Eine Sonderform ist das Prozessionskreuz, das Johann von Berry 1405 von Arnoul Belin, dem trésorier der Sainte-Chapelle von Bourges, erhielt: une croix d'argent doré processionaire, en laquelle est le Crucefiz et les IIII Euvangelistes de haulte taille, ouvree entour aux armes de monseigneur et de sa devise, tout de haulte taille 228 .

Auch ein reich mit Steinen besetzter Tabernakel mit den Darstellungen Unserer Lieben Frau und der heiligen Elisabeth, den Jeanne de Boulogne, die Herzogin von Berry, ihrem Gatten zum Neujahrstag 1415 geschenkt hatte, erfuhr eine genaue Beschreibung: ung petit tabernacle d'or ou il a ung ymaige de Nostre Dame grosse, dont le ventre est de nacle de perle, ceint d'une ceincture, tenant en sa main un livre et ung autre ymage de saincte Hélizabet qui embrasse ledit ymage de Nostre Dame, garniz entour de six balaiz, six perles et ung diament, fermant a deux petis huisselez de cristal; et est fait ledit tabernacle par dessus de maçonnerie, garniz de deux camahieux, quatre saphirs, quatre balaisseaux et vint troys perles, seant sur ung entablement d'or, garny de cinq balaisseaux, cinq saphirs et trente quatre petites perles ${ }^{229}$. Sein Wert von 3371.10 s.t. ist eine nachträgliche Schätzung und dürfte beim Kauf um einiges höher gewesen sein.

Die Aussage von Renate Eikelmann, daß »Paxtafeln [...] beliebte Neujahrsgeschenke [waren] [...], nur übertroffen von den massenhaft produzierten Agraffen $\aleph^{230}$, läßt sich nach einfacher zahlenmäßiger Auswertung und nach

227 Ebd., Nr. 1222.

228 Ebd., Nr. 1332.

229 Ebd., Nr. 1667.

230 EIKELMANN 1984, S. 331. 
dem oben Gesagten nicht halten. Lediglich neun Kußtäfelchen sind in den Rechnungen und Inventaren verzeichnet, die zum neuen Jahr verschenkt wurden 231. Die auch von Eikelmann als besonders schön vorgestellte Paxtafel ist mit einem Wert von 4001 . zugleich die wertvollste. Sie war 1416 ein Geschenk von Guillaume de Boisratier, dem Erzbischof von Bourges, gemeinsam mit Martin Gouge an Johann von Berry: ung portepaix d'or de demi pié de hault et de plaine paulme de large, en laquelle a par dedans une Veronique esmaillee de blanc, et entour plusieurs anges esmaillez de plusieurs couleurs, garnie entour de troys balaiz, quatre saphirs et seize perles, ouvré entour a ouvraige de Venise, ou il a de petis saphirs de Puy et grans d'esmeraude; et au dessoubz a escript: Pax vobis ${ }^{232}$.

Auch Rosenkränze, die patenostres (oder chapelets) ${ }^{233}$, sind ein verhältnismäßig selten notiertes Neujahrsgeschenk gewesen. Nicht einmal 20 Exemplare gelangten in den höfischen Geschenkverkehr, obwohl es in Paris drei Zünfte gab, die sich der Herstellung von Rosenkränzen widmeten, danach unterschieden, ob sie als Material Horn und Knochen oder Korallen ${ }^{234}$ und Perlmutt oder Bernstein 235 verarbeiteten.

Rosenkränze, die mit Edelsteinen versehen waren, wurden wiederum von den Goldschmieden hergestellt. Der Kanzler Burgunds, Jean Canard, hatte 1390 von seinem Fürsten unes patrenostrez d'or esmaillié à testes, garnies de 23 grosses perles zu immerhin 220 l. erhalten ${ }^{236}$. Der goldene Rosenkranz, den Ludwig von Orléans der Kinderfrau seines Sohnes, der Dame de Maucouvent, 1398 schenkte, dessen einzelne Knöpfe, die signeaux ${ }^{237}$, weiß emailliert waren und die Form von Veilchen hatten, hat dagegen nur 191. gekostet $^{238}$. Ein etwas ausgefalleneres Stück war dasjenige, das Charlotte de Bourbon 1416 Johann von Berry zukommen ließ: une paternostres faictes de

231 Siehe Anhang - Katalog/Jahreslisten, Nr. 1432 (1408 Jean I d'Alençon an Johann von Berry), 1652 (1414 Pierre de Gynes an Johann von Berry), 1063 (1401 Isabeau de Bavière an Johann von Berry), 1215 (1403 Beraud III d'Auvergne an Johann von Berry), 1583 (1413 Johann Ohnefurcht an Karl VI.), 1603 (1413 Marie de Berry an Johann von Berry), 1642 (1414 Louis de Vendôme an Johann von Berry) und 676 (1395 Philipp der Kühne an Benedikt XIII.).

232 Ebd., Nr. 1691.

233 Dazu und zum folgenden LABORDE, Glossaire, 1872: Stw. »patenostres«, S. 432.

234 Einzig das Johann von Berry von seinem Juwelenbewahrer 1415 verehrte Stück bestand zum Teil aus diesem Material: unes très belles paternostres de corail vermeil, esquelles a treize seignaulz d'or, siehe Anhang - Katalog/Jahreslisten, Nr. 1686.

235 Dazu LABORDE, Glossaire, 1872: Stw. »Ambre«, S. 127-129, und REINEKING von BocK, Gisela: Art. »Bernstein. C. Bernstein im mittelalterlichen Kunsthandwerk«, in: LexMA, Bd. 1, 1980, Sp. 2011-2012.

236 Anhang - Katalog/Jahreslisten, Nr. 372.

237 Siehe LABORDE, Glossaire, 1872: Stw. »signaulx«, S. 499.

238 Anhang-Katalog/Jahreslisten, Nr. 902. 
musc, enfillees en ung laz fait de filet d'or et de soye bleue, garnies de troys boutons de perles ${ }^{239}$.

All die übrigen Geschenkarten sind anderen Bereichen zuzuordnen und nur noch in wenigen Fällen ausschließlich Produkte der zeitgenössischen Goldschmiedekunst, vermitteln aber zum großen Teil einen ebensolchen Eindruck von hoher Kunstfertigkeit und phantasiebegabter Schöpfungskraft ${ }^{240}$.

Tapisserien sind wie die wertvollen Goldschmiedearbeiten genuin höfisches Repräsentationsobjekt gewesen ${ }^{241}$, stehen aber als Neujahrsgeschenke nur sechsmal in den Quellen. Den teuersten Wandteppich, als Geschenk nicht mitgezählt, hat Philipp der Kühne, der auch alle anderen Tapisserien verschenkt hat, sich selbst zum neuen Jahr 1394 gekauft: un tapis de hautelice broché d'or et d'argent de Chypre, à l'histoire des neuf preuses - ein goldund silbergewirkter Wandteppich mit der Darstellung der neun Heldinnen ${ }^{242}$ zu 2.000 1.243. Wieder war es Johann von Berry, der 1388 nicht nur den kost-

239 Anhang - Katalog/Jahreslisten, Nr. 1689.

240 Gegen HUIZINGA 1975, S. 365, der meint, daß die »französisch-burgundische Kunst des ausgehenden Mittelalters zu den Kulturen [zählt], in denen Pracht die Schönheit verdrängen will « - schließt das eine das andere aus? Ist hier tatsächlich der von Huizinga artikulierte "horror vacui«, das »Merkmal zu Ende gehender Geistesperioden«, festzustellen? Zeigt sich in der höfischen Kunst der Zeit nicht vielmehr ein ganz spezifisches Selbstverständnis, untrennbar mit dieser und nur dieser Epoche verbunden, die nicht epigonenhaft vergangenen Vorbildern nacheiferte, sondern ihre technischen und künstlerischen Gestaltungsmöglichkeiten innovativ erweitert hat (was Huizinga an anderer Stelle durchaus auch sieht)? Auch die im folgenden anhand der tapis vorgestellte Webkunst könne sich nach HUIZNGA 1975, S. 366, einem sübertriebenen Schmuckbedürfnis nicht entziehen«.

241 Siehe die Stw. "Tapis« bis »Tapis velus« bei LABORDE, Glossaire, 1872: S. 511-514. Ein neueres Werk über "Tapisserien und Politik« stammt von BRASSAT 1992, siehe hier v.a. Kap. III »Tapisserien im zwischenhöfischen Austausch«, S. 82-94 (S. 84-86 zur Schenkpraxis Philipps des Kühnen). Myriam CHEYNS hat gearbeitet über »La tapisserie à la cour de Bourgogne«: CHEYNS 1985. Grundlegend zur Geschichte der Tapisserie GUIFFREY, MÜNTZ, PINCHART, Histoire générale de la tapisserie, 3 Bde., 1880 (dazu vertiefend: PINCHART, Histoire de la tapisserie dans les Pays-Bas, 3 Bde., 1878-1885), zum Vergleich wichtig die Bände GOBBEL, Wandteppiche. Teil I. Die Niederlande, 2 Bde., 1923, GÖBEL, Wandteppiche. Teil II. Die romanischen Länder, 2 Bde., 1928 und GÖBEL 1946 (Flandern, Brabant, Holland), zum kurzen Überblick GUIFFREY, Jules-Joseph: La tapisserie aux XIV et $X^{e} V^{e}$ siècles, in: MiCHEL, Histoire de l'Art, Bd. 3,1, 1907, S. 343-374, hier v.a. S. 356-374 mit bibl. Nachweisen S. 373f. Fabienne JOUBERT hat sich nicht nur auf die Tapisserien Philipps des Kühnen konzentriert: JOUBERT 1990, sondern auch zeitlich übergreifend zu diesem Thema einen knappen Überblick erarbeitet: JOUBERT 1993, siehe v.a. die wertvolle Bibl. S. 8-23. Jean LESTOCQUOY hat sich in einer kenntnisreichen Arbeit der Zeit von 1300-1500 gewidmet: LESTOCQUOY 1978 (hier v.a. bis S. 66). Herstellungszentren waren Paris, Arras, Lille, Tournai und Brüssel.

242 Siehe zu den neun Helden und zu den möglicherweise von Eustache Deschamps eingeführten Neun Heldinnen HuIZINGA 1975, S. 92f., 487, Anm. 24 mit Hinweisen auf die entspr. Gedichte Deschamps' (zu Deschamps siehe oben S. 98-100). Aktuell nun SEDLACEK 1997 und ANROOIJ 1997 sowie FRANKE 1998, S. 27-29.

243 Anhang - Katalog/Jahreslisten, Nr. 641. 
barsten aller verschenkten Wandteppiche in Empfang nehmen konnte, sondern gleich noch einen weiteren zu einem Gesamtwert von 1.700 1., beides Arbeiten aus Arras, einem burgundischen Zentrum der Webkunst. Der größere, 32 Ellen lang und sechs Ellen hoch, also mindestens etwa 17,5 mal drei Meter, stellte Szenen aus dem Rosenroman dar244, der andere l'istoire de bergiers et bergieres $^{245}$. Die anderen von Philipp Beschenkten waren 1392 Valentina Visconti mit einem Teppich a l'istoire comment le Roy Alexandre conquist Babilonne ${ }^{246}, 1394$ Richard II. ${ }^{247}$ und 1401 sein Kanzler Jean Canard ${ }^{248}$.

Unterschiedlichster Herkunft, Beschaffenheit und Qualität waren die Stoffe ${ }^{249}$, die ganz verschiedenen Zwecken dienen konnten. Es wundert nicht, $\mathrm{da} ß$ der Burgunderherzog als Schenker auch hier im Zentrum steht. 1388 erhielt der König von ihm prächtige 9 draps d'or des trois devises de sa majesté, savoir 3 aux cerfs volants, 3 aux plumes et 3 aux annellés $\mathrm{zu}$ 1.125 1.250. Margarete von Flandern, seine Frau, bekam im selben Jahr sept draps d'or à oiziaulx et yy grijois 251 zu 9101 . und im Jahr davor waren es 4 pieces de drap d'or blans; 3 pieces de drap d'or fin en graine à nues; 2 pieces de drap d'or fin à menuz ouvraiges zu 1.0801 .252 . Auch die Königin erhielt 1387 und 1388 von Philipp Stoffe, zum einen 4 pieces de draps ouvrez d'or de Chippre sur ung champ de soye blanc zu 480 l., zum anderen 4 autres draps d'or, 2 pieces de veluyalx d'or zu 8201.253 . Verschenkt wurde Samt (pieces de veluelz ${ }^{254}$ oder pieces de velveau noir ${ }^{255}$ ), silber- und goldgewirktes Tuch

244 Anhang - Katalog/Jahreslisten, Nr. 266. - Zum Rosenroman siehe oben S. 97, S. 105, 128 mit den entspr. Anm.

245 Anhang - Katalog/Jahreslisten, Nr. 265. Zum Genre der Pastorale im zeitlichen Rahmen HUIZINGA 1975, S. $183 \mathrm{ff}$.

$246 \mathrm{Zu} 650$ 1., siehe Anhang - Katalog/Jahreslisten, Nr. 533.

$247 \mathrm{Zu} 900$ 1., siehe ebd., Nr. 644: trois tapis de hautelice ouvres d'or de Chypre.

248 Ebd., Nr. 1101: un tapis de hautelice ou sont figurés les XII pers. unbestimmten Wertes.

249 Zu den Stoffen LAURENT 1935 und POERCK 1951. Grundsätzlich wichtig in diesem Zusammenhang: Recueil des documents relatifs à l'histoire de l'industrie drapière en Flandre, hg. von SAGHER, SAGHER, WERVEKE, WYFFELS, 3 Bde., 1951-1966. Interessante und wichtige Erkenntnisse über das symbolbefrachtete Zusammenspiel der Zeit hinsichtlich der (selten zufälligen) Kombination von Farbe und Stoff bietet mit vielen Beispielen MÉRINDOL, Couleur, 1987. Mit der Kulturgeschichte der Farbe befaßt sich GAGE 1994 (siehe hier v.a. S. 79-92 zu »Farbensprache und Farbensymbolik«), mit der Bedeutung mittelalterlicher Farbgebung PASTOUREAU 1986, mit liturgischer Farbsymbolik SUNTRUP 1992 (vgl. MEIER, SUNTRUP, Lexikon der mittelalterlichen Zahlenbedeutungen, 1987). Besonders eindrucksvoll HUIZINGA 1975, S. 396-400, interessant Umberto Ecos Gedanken zur »Freude an Farbe und Licht«: ECO 1991, S. 67-72. Neueren Datums auf Savoyen bezogen PAGE 1993 (»Tissus et Couleurs à la Cour de Savoie 1427-1447«, mit Quellened. S. 143-213).

250 Anhang - Katalog/Jahreslisten, Nr. 270.

251 Ebd., Nr. 278.

252 Ebd., Nr. 234.

253 Ebd., Nr. 213 und 260.

254 Bspw. ebd., Nr. 218.

255 Bspw. ebd., Nr. 1707. 
(draps d'argent fin ${ }^{256}$ beziehungsweise draps d'or fin ${ }^{257}$ ), normales Seidentuch (tissus de soye ${ }^{258}$ ) und Seide aus Bagdad (pieces de atabis ${ }^{259}$ oder pieces de baudequins d'oultre mer ${ }^{260}$ ) oder Satin (pieces de satin noir ${ }^{261}$ ). Karl I. von Bourbon erhielt 1414 von Johann von Berry gar eine ganze Wandbekleidung, grün und mit Stickereien versehen: une chambre de seze vert contenant XII pieces, dont les trois sont ouvrees de broderie $\mathrm{zu} 100$ 1.262. Am ersten Neujahrstag, den Johann Ohnefurcht als Herzog beging, schenkte ihm der König eine couverture aux armes de Jean sans Peur ${ }^{263}$.

Insgesamt wurden über $6.000 \mathrm{l}$. für Stoffe ausgegeben - etwas mehr als ein $1 \%$ des Gesamtvolumens - und dies ist der einzige größere Posten, von dem alle Einzelwerte bekannt sind. Nicht enthalten sind in dieser Aufstellung die Stoffe, die ausdrücklich für die Herstellung von Bekleidung gedacht waren. Wahrscheinlich für ihre Amtstrachten bekamen Arnaud de Corbie, Kanzler Frankreichs, und Philippe de Moulins, Bischof von Noyon und enger Berater der Krone, von der Königin 1402 und 1403 jeweils zwölf und eine halbe Elle d'escarlate rosee de Bruxelles ${ }^{264}$. Für das Jahr 1400 ist dies im Fall des Philippe de Moulins ausdrücklich vermerkt: pour avoir une robe ${ }^{265}$. Aber nicht nur die höchsten Amtsträger, sondern auch die Inhaber und Inhaberinnen niederer Chargen wurden mit Stoffen für ihre Kleidung bedacht. Femmette, Kammerzofe der Königin, bekam zum Neujahrstag 1401 zweimal jeweils vier Ellen pour faire une houppelande, einmal de vert gay und einmal de vert brun herbeux ${ }^{266}$, beide Male aus Montiervilliers, einem Tuche produzierenden Frauenkloster in der Normandie 267.

Es bleibt die Frage, ob bei den geschilderten Vorgängen Neujahrsgeschenk und (notwendige) Versorgung oder gar Besoldung eine Verbindung eingegangen sind, die nicht problemlos aufgelöst werden kann. Diese Frage stellt sich auch bei der Verteilung bereits gefertigter Kleidung zum neuen Jahr ${ }^{268}$.

256 Bspw. Anhang - Katalog/Jahreslisten, Nr. 220.

257 Bspw. ebd., Nr. 225.

258 Bspw. ebd., Nr. 804,

259 Bspw. ebd., Nr. 210.

260 Bspw. ebd., Nr. 264.

261 Bspw. ebd., Nr. 916.

262 Ebd., Nr. 1627.

263 Ebd., Nr. 1349.

264 Siehe ebd., Nr. 1143 und 1147, 1220 und 1226.

265 Ebd., Nr. 1021.

266 Ebd., Nr. 1061 f.

267 Siehe auch SCHMIDT, Hans-Joachim: Art. "Montivilliers«, in: LexMA, Bd. 6, 1993, Sp. 809.

268 Siehe JASSEMIN 1933, S. 79 zur regelmäßigen Einkleidung der Bediensteten am ersten Januar (manteau d'hiver, vgl. bspw. ACO B 1598, fol. 124, ed. Comptes généraux de l'État Bourguignon, Bd. 2,1, 1966, S. 471, Nr. 3957: pour leur robes de l'annee commencant au 
Erwähnte Femmette hatte zum Neujahrstag 1398 keine Stoffe, sondern die houppelande selbst bekommen ${ }^{269}$. Die robes, die Karl, der spätere König, 1420 an seine Gefolgsleute Henri de Savoisy und Jean Coeur verschenkt hatte, sind wohl eher als Ergebnis fürstlicher Fürsorgepflicht zu sehen 270 .

Anders mag es sich mit den houppelandes ${ }^{271}$ und verhalten haben, die sich die Fürsten gegenseitig zum neuen Jahr überreichten. $60 \mathrm{l}$. schien der Standardpreis gewesen zu sein für das einfach gestaltete Hofkleid. Empfänger waren 1387 die Herzöge von Berry und Bourbon, 1397 dieselben und der Herzog von Orléans sowie sein Sohn, die Philipp der Kühne beschenkt hat ${ }^{272}$. Auffällig daran ist, daß sich Johann Ohnefurcht zu dieser Zeit nach der verlorenen Schlacht von Nikopolis in osmanischer Gefangenschaft befand und erst am 28. Februar 1398 wieder in Dijon eintraf. Möglicherweise hat sein Vater ihm die seinem Stand angemessene Kleidung zukommen lassen, aber in Anbetracht der Situation und konfrontiert mit den hohen Lösegeldforderungen des osmanischen Sultans auf weitere wertvolle Geschenke verzichtet ${ }^{273} .1398$ ist dann das Neujahrsgeschenk Philipps für Johann Ohnefurcht, ein collier im

premier jour de janvier an die maûtres und clercs des comptes von Dijon Johanns Ohnefurcht 1419) und zu Ostern (robe de Pâques).

269 Anhang - Katalog/Jahreslisten, Nr. 870.

270 Ebd., Nr. 1777 und 1785.

271 Siehe zu den houppelandes auch oben S. 49, Anm. 65 und S. 43, Anm. 30, u.a. behandelt bei Robert Delort unter der Abschnittsüberschrift "La règne de houppelande (vers 1360vers 1425)«: DELORT, Le commerce des forrures, Bd. 1, 1978, S. 380-401, und bei THIEL 1980 (hier S. 261-240 zur burgundischen Mode, S. 224f. zu den houppelandes). Weihnachten 1392 verschenkte der Herzog von Orléans neun houppelandes und bedachte dabei auch den Bruder der Königin, Ludwig den Bärtigen. STRAUB 1965, S. 8 wertet dies als "Zeichen besonderer Verbundenheit zwischen Schenker und Beschenktem." Literatur in Auswahl zur höfischen Mode der Zeit: EVANS 1952 (Kleidung im mittelalterlichen Frankreich, siehe hier v.a. Kap. IV »Charles VI and Charles VII 1380-1461 «, S. 38-58. Evans stilisiert Burgund mit Beginn der Vermählung Philipps des Kühnen mit Margarete von Flandern zur modebestimmenden Kraft), BAYLÉ, BEAULIEU 1956 (zur burgundischen Kleidung von 1364-1477, grundlegend mit detailliertesten Beschreibungen in Wort und Bild, hier zunächst zu den Stoffen, Pelzen und Lederwaren S. 23ff., zu den Hoflieferanten S. 35ff., dann zur Beschreibung der männlichen Kleidung S. 41 ff., der weiblichen S. 70ff. Eigene Kap. bilden die hinsichtlich ihrer Kleidung zu unterscheidenden [Alters-, Berufs- und sonstige] Gruppen sowie Rüstungen), BEAULIEU 1989 (behandelt die Kleidung des französischen Spätmittelalters als Spiegel der Mentalität; erweiterte Fassung von BEAULIEU 1979), DINGES 1992 (zur sozialen Funktion der Kleidung in der höfischen Gesellschaft der frühen Neuzeit, die Aspekte Distinktion und Identität hervorhebend), und insbes. PIPONNIER 1970 (costume et vie sociale am Hof der französischen Anjou vom 14. zum 15. Jh.). Zum Überblick der Abschn. von Harry Kühnel über »Kleidung und Gesellschaft im Gesellschaft im Mittelalter" im "Bildwörterbuch der Kleidung und Rüstung«: KüHNEL 1992. Aktuell PIPONNIER, MANE 1997. Siehe neuerdings auch SCHNITZER 1999, bezogen allerdings auf die deutschen Höfe der Frühen Neuzeit, hier S. 8ff. zum Kleidergebrauch bei Hof, S. 30f. zur Ausstattung durch den Herrn.

272 Anhang - Katalog/Jahreslisten, Nr. 217, 224, 820, 823, 828 und 830.

273 Siehe insbes. ATIYA 1938, S. 459-462. 
Wert von $1.000 \mathrm{fr}$., nach Venedig geschickt worden, wo Johann sich nach der Rückkehr aus seiner Gefangenschaft auf dem Weg nach Burgund aufhielt 274 . Wie die verzierten houppelandes ausgesehen haben mögen, kann vier Belegen entnommen werden, die diese Bekleidung als Geschenk der Jahre 1400, 1403 und 1413 verzeichnen. 1404 schenkte Philipp der Kühne seiner Enkelin Margarete und ihrem Verlobten, dem Dauphin Karl, jeweils eine houppelande de drap d'or fin, figuré à roses de cramoisy et à branches de vert ${ }^{275}$. Er selbst erhielt in diesem Jahr von Herzog Johann von Berry une longue houppelande toute d'or, zwar sanz autres soies ne couleur, dafür aber gefüttert mit Zobel ${ }^{276}$. Ludwig von Guyenne schließlich, Dauphin 1413 und im Brennpunkt der widerstrebenden armagnakischen und burgundischen Interessen, bekam von Johann Ohnefurcht zum Auftakt dieses turbulenten Jahres eine goldgewirkte houppelande, auf welcher die Übergabe der Lilien an Chlodwig durch Gott dargestellt war ${ }^{277}$. In diesem Zusammenhang zu erwähnen sind auch die livrées 278 .

Zur Kleidung gehören Accessoires und das waren im Bereich des höfischen Geschenkverkehrs Schärpen ${ }^{279}$, Gürtel und Kopfbedeckungen (die beliebten épingles erscheinen nicht als Neujahrsgeschenke) ${ }^{280}$.

Die kostbarste Schärpe war ein kunstvoll verziertes Geschenk der Königin an Karl VI., versehen mit seiner Wortdevise Jamais, den Ginsterzweigen und Maiblättern, und hatte den beträchtlichen Wert von 1.6001 l: une escharpe d'or faicte a grains fueilles de may pres apres l'une desdictes feuilles ouvree de haulte taille de branche de genestre et de cosses et l'autre feulle perce du mot du roy qui dit Jamais 281 . Eine weitere wertvolle Schärpe erhielt Margarete von Bayern von ihrem Mann Johann Ohnefurcht 1408, goldgewirkt, mit Schellen und Margeriten geschmückt, und versehen mit einer edelsteinbesetzten Spange $\mathrm{zu} 800$ 1.: une escharpe d'orlaie en fil d'or, les sonnettes en façon de

274 Siehe Anhang - Katalog/Jahreslisten, Nr. 930.

275 Ebd., Nr. 1039 und 1043.

276 Ebd., Nr. 1286. Zobel war der teuerste aller Pelze. - Den Pelzen und dem Pelzhandel hat sich in seiner großen thèse Robert DELORT gewidmet: DELORT, Le commerce des fourrures, 2 Bde., 1978, hier zu Pelzen als Gegenstände des zwischenhöfischen Austausches Bd. 2, 1978, S. 570-572 (»Les Cadeaux«), 632-634 (»Alimentation du stock: achats et cadeaux (), zu deren Funktion als hierarchieabbildendes Element Bd. 1, 1978, S. 531-537 (»Hiérarchie sociale des fourrures «). Siehe hier auch Bd. 1, 1978, S. 437-442 zu Marderfellen als Modeerscheinung der Zeit von 1380-1420.

277 Anhang - Katalog/Jahreslisten, Nr. 1585.

278 Siehe LABORDE, Glossaire, 1872: Stw. »livrée«, S. 367. Vgl. auch bei PAGE 1993, S. 191-198 die Ed. von Rechnungen für Livreen am Hof von Savoyen, die zum neuen Jahr 1447 verschenkt worden waren. Siehe auch DELORT 1993, der sich der höfischen Livrée des 14. Jh.s widmet.

279 Siehe LABORDE, Glossaire, 1872: Stw. »escharpe«, S. $266 f$.

280 Siehe zu den Accessoires BAYLÉ, BEAULIEU 1956, S. $90 \mathrm{ff}$.

281

Anhang - Katalog/Jahreslisten, Nr. 1144. 
marguerites, et au-dessus de ladite escharpe un fermail d'or, garni d'un ruby, une grosse perle, un gros dyamant en façon de fleur, une esmeraude au milieu et trois petits dyamants 282 .

Andere Schärpen waren mit Korallen oder Bernstein verziert ${ }^{283}$, konnten als Halterung für Taschen dienen oder fanden als Gürtel Verwendung. Sieben Gürtel ${ }^{284}$ stehen in den Rechnungen, deren Werte sich zwischen 600 1. - une ceinture d'or esmaillié de rouge cler, a ymages, et garnis de pierreries, ein Geschenk Philipps des Kühnen an den König 1385285 - und 6 1. - immerhin auch aus Silber, ein Geschenk der Königin 1391 an ihre folle 286 - bewegten $^{287}$. Zu den Gürteln gehörten Schnallen, die boucles de ceinture. Zwei dieser Schnallen, aus Gold und verziert mit einem Balasrubin und drei großen Perlen, bekamen 1392 Isabella von Frankreich und ihre Schwester Johanna von ihrer Mutter, der Königin 288 .

Schließlich sind Kopfbedeckungen zu nennen 289 . Margarete von Bayern wurde von Philipp dem Kühnen 1396 mit einem ihrer künftigen Rolle als Herzogin von Burgund gemäßen wertvollen chappel d'or garny de 4 balays, 4 saphirs et 32 perles 290 bedacht, der mit $600 \mathrm{l}$. in den burgundischen Rechnungsbüchern steht. Ein geringer Betrag verglichen mit dem Preis von 2.500 l., den Philipp für den chapeau bezahlen mußte, den er seiner Frau, der amtierenden Herzogin, im Jahr zuvor geschenkt hatte ${ }^{291}$, oder verglichen mit dem Preis von 1.300 l. für den chapel d'or, den die Herzogin von ihm 1393 erhielt292. Ein kleines Krönchen aus Silber zu 241 . bekam auch Isabeaus Zwergin, die folle Jehanne, zum Neujahrstag 1391293. Und Ludwig der Bärtige erhielt 1409 von Johann Ohnefurcht eine cappeline 294.

$\mathrm{Zu}$ dem Bereich der Gaben, die nicht überwiegend und fast ausschließlich repräsentativen Charakter hatten, sondern auch eine ausgeprägte Nutzfunktion

282 Anhang - Katalog/Jahreslisten, Nr. 1438.

283 Siehe ebd., Nr. 1670 und 1673, Geschenke Karls von Orléans 1415 an Guy de La Roche-Guyon und Margarete (II.) von Burgund.

284 Siehe LABORDE, Glossaire, 1872: Stw. »ceinture«, S. 195-197.

285 Anhang - Katalog/Jahreslisten, Nr. 111.

286 Ebd., Nr. 407. Siehe auch unten S. 178 mit Anm. 293 zu dem silbernen Krönchen, das Jehanne im selben Jahr erhielt.

287 Siehe zu den anderen Gürteln nach abnehmendem Wert sortiert Anhang Katalog/Jahreslisten, Nr. 111 (1385), 114 (1385), 229 (1387), 436 (1391), 133 (1385) und 1709 (1407).

288 Ebd., Nr. 485 und 1489.

289 Siehe LABORDE, Glossaire, 1872: Stw. »chappel«, S. 205-207.

290 Anhang - Katalog/Jahreslisten, Nr. 741.

291 Ebd., Nr. 686.

292 Ebd., Nr. 579.

293 Ebd., Nr. 408. Siehe auch oben S. 178 mit Anm. 286.

294 Ebd., Nr. 1461. 
aufwiesen, können Sättel ${ }^{295}$, Jagdtaschen ${ }^{296}$ und Jagdhörner, Börsen und kleine Taschen ${ }^{297}$, Tintenfäßchen ${ }^{298}$, Etuis ${ }^{299}$ und diverse Behältnisse ${ }^{300,}$ Kerzenhalter $^{301}$ und Spiegel ${ }^{302}$, aber auch Spielbretter ${ }^{303}$ und spielzeugähnliche Gegenstände gezählt werden.

So schenkte 1386 Karl VI. seiner Gattin une selle de palefroi ${ }^{304}$; es handelt sich hier im übrigen um das einzige in den Archivalien notierte Reitzubehör ${ }^{305}$.

Sechs Unbekannte erhielten 1411 von Karl von Orléans boursetes de fil d'argent blanc zu je $21.5 \mathrm{s.}{ }^{306}$ und 1416 empfing Johann von Berry von dem Dauphin Karl une gibeciere de fil d'or, garnie entour d'un balaisseau et six perles, et dessus le couvercle ung balaisseau et six perles ${ }^{307}$.

Bei dem cornet d'or garny de III saphirs VII gros ballays et $L X$ perles pendans a une petite escharpe d'or ${ }^{308}$, das Ludwig von Guyenne 1402 von seinem Onkel, dem Herzog von Orléans bekam, kann es sich in Anbetracht Ludwigs Alters von fünf Jahren um ein Spielzeug oder ein spielzeugähnliches Luxusgegeschenk repräsentativen Charakters gehandelt haben ${ }^{309}$ (es wird hier sicher weder ein Trinkhorn noch ein Tintenfäßchen ${ }^{310}$ gemeint sein). Der hohe Wert von 300 l. ließe sich als Indikator der neuen Rolle Ludwigs als Dauphin interpretieren. Margarete (II.) von Burgund, die erst am 8. Dezember 1393 zur Welt gekommen war, erhielt am Neujahrstag 1394 von ihrem Großvater Philipp dem Kühnen eine mit Perlen verzierte Kinderklapper ${ }^{311}$. Bei den beiden cornettes d'or ${ }^{312}$, die Philipp seiner Tochter Bonne und seiner Schwiegertochter Jeanne de Saint-Pol 1398 schenkte, jeweils zu dem beträchtlichen Wert von 600 l., läßt sich allerdings ausschließen, daß es sich um Spielzeug

295 Siehe LABORDE, Glossaire, 1872: Stw. »selle«, S. $495 \mathrm{f}$.

296 Siehe ebd.: Stw. "gibecière«, S. $329 f$.

297 Siehe ebd.: Stw. »bourse«, S. $170 f$.

298 Siehe ebd.: Stw. »escrin«, S. $270 f$.

299 Siehe ebd.: Stw. mestuit«, S. $308 \mathrm{f}$.

300 Siehe ebd.: Stw. mcoffre«, S. $218 f$.

301 Siehe ebd.: Stw. mchandeliers«, S. 202-204.

302 Siehe ebd.: Stw. "miroir«, S. 389-392.

303 Siehe ebd.: Stw. vtablier«, S. 509f.

304 Anhang - Katalog/Jahreslisten, Nr. 636.

305 Oder handelte es sich bei der longe d'or garnie de pierrerie, die Guy de La Trémoille 1397 von seiner Frau Marie de Sully erhalten hatte, um eine Reitgerte o.a.? Siehe Anhang Katalog/Jahreslisten, Nr. 803.

306 Ebd., Nr. 1533.

307 Ebd., Nr. 1693.

308 Ebd., Nr. 1167.

309 Vgl. oben S. 164 mit Anm. 167.

310 Siehe LABORDE, Glossaire, 1872: Stw. »corne«, S. 227, Stw. »cornet«, S. 228.

311 Anhang - Katalog/Jahreslisten, Nr. 636. Siehe LABORDE, Glossaire, 1872: Stw. "whochette«, S. 341.

312 Anhang - Katalog/Jahreslisten, Nr. 922, 928. 
gehandelt hat. (Jagd-)hörner werden es auch nicht gewesen sein, aber die karge Beschreibung gibt keinen Aufschluß. Möglich wäre, daß die beiden Frauen kostbare Haubenzipfel erhalten haben. Bei dem cornet d'or $\grave{a}$ pierres précieuses, den Philipp 1382 an Ludwig von Male geschickt hat, und dem cor d'or, einem Geschenk Karls VI. an Philippe d'Artois 1391, könnte es sich aber tatsächlich um Jagdhörner gehandelt haben.

Kostbare Tintenfäßchen waren Geschenke für Isabeau de Bavière 1386 von ihrem Schwager Ludwig - un petit escrin d'or garni de plusieurs perles et pour un gros diament mis en un annel attaché a l'anse dud. escrine $\mathrm{zu}$ 3801.313 - und für den Herzog von Berry von seinen Sekretären - ung grant ancrier d'argent blanc, ouvré par dessus et alentour, le pié aux armes de monseigneur, seant sur plusieurs ours zu 77 1.314. Die Sekretäre hatten ihrem Herrn 1410 auch ein in der Mitte zusammenklappbares vergoldetes silbernes Spielbrett mit Perlmuttverzierungen geschenkt 315 .

Etwas häufiger vertreten sind die kleinen coffrets, die ausschließlich Johann von Berry zum neuen Jahr in Empfang nahm. Drei von diesen der Größe nach möglicherweise zur Aufbewahrung von Schmuck dienenden Behältnisse waren mit Leder ummantelt ${ }^{316}$, aus Kristall ${ }^{317}$ und Zypressenholz ${ }^{318}$. Ein vierter war de musc ${ }^{319}$, hatte also entweder die Aufgabe der Aufbewahrung von Moschus oder war, wie dies auch des öfteren mit anderen Gegenständen, wie den Rosenkränzen, geschah, mit diesem Riechstoff versehen ${ }^{320}$. Ein ähnliches Behältnis war die cassette faicte en façon de maille d'or fermant a une boucle, et au bout du mordant un ruby ${ }^{321}$, die Ludwig II. von Bourbon an den König 1393 verschenkt hatte, ein gänzlich anderes Aufbewahrungsmittel hingegen die zwölf ledernen estuys für kostbare Humpen, Pokale und Trinkschalen, die Philipp der Kühne 1388 entgegennehmen konnte ${ }^{322 .}$

Endlich sind in den Quellen auch zwei Spiegel und sieben Kerzenhalter notiert. Die beiden mirouers erhielten Jeanne de Saint-Pol von Philipp dem Kühnen und Johann von Berry von Guillaume de Lodes, einem seiner

313 Anhang - Katalog/Jahreslisten, Nr. 164.

314 Ebd., Nr. 1660, wenn ancrier als escrin gelesen wird.

315 Ebd., Nr. 1468.

316 Ebd., Nr. 1071, ein Geschenk des Königs 1401: un coffre couvert de cuir, un gros balay caboichon en un culet d'or.

317 Ebd., Nr. 1374: un petit coffret de cristal garni d'or et de plusieurs perles, à petis boutons roons, esmaillez de vert et de rouge cler grenetez, Geschenk eines Unbekannten 1406.

318 Ebd., Nr. 1497, ein Geschenk Arnoul Belins: un petit coffret de cipprès marqueté, ferré d'argent, aux armes de monseigneur le Duc.

319 Ebd., Nr. 1373: un petit coffret de musc, garni d'or et de XXVII perles moiennes, Geschenk eines Unbekannten.

320 Siehe LABORDE, Glossaire, 1872: Stw. mmuglias«, S. 401 und Stw. »musc«, S. 401.

321 Anhang - Katalog/Jahreslisten, Nr. 551.

322 Ebd., Nr. 284. 
Knappen und Kammerherrn, in den Jahren 1400 und 1402 zu 330115 s. und 315 1.323. Von seinen trésoriers Joceran Frepier, Pierre de Montbertaud, Jean Despoulettes und Jean Chousat bekam Philipp der Kühne 1402 vier große vergoldete silberne Kerzenhalter ${ }^{324}$, Johann von Berry 1403 von Louis de Vendôme zwei kleine goldene mit seinem Wappen ${ }^{325}$ und derselbe von Ludwig II. von Bourbon 1408 un chandellier d'argent doré, fait en maniere d'une terrace esmailliee de vert, pour mectre oisellez de Chippre, ouquel a par dessus un arbre esmaillié de vert et un chiennet d'argent blanc 326 .

$\mathrm{Zu}$ den unterschiedlichen Pretiosen, die noch als Neujahrsgeschenke Erwähnung finden müssen, gehören neben 101 goldenen Pfauen ${ }^{327}$, die Karl VI. 1422 verschenkte ${ }^{328}$, 600 blau emaillierten goldenen Windhunden zu insgesamt 2.800 1., die der König 1419 verteilte ${ }^{329}$, einem goldenen und reich mit Edelsteinen verziertem Bären, der innen hohl war pour mectre dedens oisellez de Chipre ardans pour parfumer ${ }^{330}$ und den Berry 1410 von seiner Tochter Marie bekam, sowie einem goldenen Affen mit einer großen Perle ${ }^{331}$, den Isabeau de Bavière 1391 einer unbekannten Person überreicht hat, auch sieben pommes, sämtlich Geschenke an den Herzog von Berry. Pommes waren Objekte zum Transport von Heiligenbildnissen oder, zum Beispiel an einer Kette hängend, mitnehmbare Parfumbehälter ${ }^{332}$. Robinet d'Estampes, Berrys Juwelenverwahrer, schenkte seinem Herrn 1412 une belle pomme d'ambre et de musc qui se oeuvre par la moictié en deux pieces fermant a charnières, et pendant a une petite chaienne; en laquelle a par dedens une ymaige de Nostre Seigneur et une de Nostre Dame, de paincture ${ }^{333}$, und von Pierre de l'Esclat, einem der ersten königlichen Räte und zum betreffenden Zeitpunkt noch maittre des requêtes de l'hôtel, bekam Berry 1415 une pomme d'or en laquelle il a du musc, qui s'euvre a quatre quartiers, et ou millieu a une ymaige de Nostre Dame fermant a viz, que tient ung saint Michiel, et par dessus chascun quartier a ung ymaige garny entour de perles ${ }^{334}$.

323 Anhang - Katalog/Jahreslisten, Nr. 1033, 1340.

324 Ebd., Nr. 1152.

325 Ebd., Nr. 1234.

326 Ebd., Nr. 1445.

327 Zur allegorischen und symbolischen Bedeutung des Pfaus MCCULLOCH 1960: Stw. »peacock«, S. 153f., als Element der christlichen Bildersprache SCHMIDT 1981, S. 94-96.

328 Anhang - Katalog/Jahreslisten, Nr. 1818.

329 Ebd., Nr. 1749.

330 Ebd., Nr. 1492.

331 Ebd., Nr. 414.

332 Vgl. die Abb. einer pomme-reliquaire in: Les fastes du Gothique (Ausstellungskatalog), 1981, Nr. 209.

333 Anhang - Katalog/Jahreslisten, Nr. 1558.

334 Ebd., Nr. 1684. 
Einzigartig war der Vogelkäfig 335 , den der Herzog von Berry 1411 als Neujahrsgeschenk verehrt bekam: une cagete quarrée d'argent doré a mectre oisellez de Chipre ${ }^{336}$. Dies bietet Gelegenheit, die zu den Neujahrstagen verschenkten Tiere Revue passieren zu lassen ${ }^{337}$. Berry besaß eine Leidenschaft für Hunde ${ }^{338}$, die sich nicht nur in der Gestaltung vieler Gegenstände niederschlug, die er selbst präsentierte oder erhielt, wie die salliere de jaspre, garnie d'or, seant sur deux ours d'or et deux chiennez esmaillez de blanc ${ }^{339}$ zeigt, 1408 ein Geschenk von Ascelin Royne, seinem ehemaligen Beichtvater, sondern auch in den Gaben lebendiger Hunde ausdrückte. So schickte ihm 1400 Anne d'Auvergne einen weißen Windhund ${ }^{340}$. Bis auf zwei weiße Habichte, die der König 1400 von Philipp dem Kühnen zusammen mit einem Paar gamslederner Handschuhe bekam, die gefüttert waren mit dem Fell von Hermelinen und besetzt mit Perlen ${ }^{341}$, waren es neben vier Affen und vier Mauleseln, die König Martin von Aragon gemeinsam mit zwei Schlachtpferden und zwei Mauren (oder Mohren ${ }^{342}$ ) 1402 nach Burgund gesandt hatte ${ }^{343}$, ausschließlich Pferde ${ }^{344}$, die als Neujahrsgeschenke übertragen wurden. Allein fünf Pferde, darunter ein Packpferd und ein Zelter, stammten 1389 und 1390 von Guy und Guillaume de La Trémoille und waren für Philipp den Kühnen, Margarete von Flandern und Johann Ohnefurcht bestimmt ${ }^{345}$. Guillaume war

335 Siehe LABORDE, Glossaire, 1872: Stw. »cage«, S. 182.

336 Anhang - Katalog/Jahreslisten, Nr. 1540.

337 In diesem Zusammenhang müssen auch die Menagerien zumindest erwähnt werden, siehe zu deren Entstehung und Entwicklung neben STRICKER 1879 den interessanten Art. im Zedler (Stw. "Menagerie«, in: ZEDLER, Großes vollständiges Universal-Lexikon aller Wissenschaften und Künste, Bd. 20, 1739, Sp. 603). Vgl. den für eine Geschichte der Tiere plädierenden Robert DELORT 1984, hier zu den Hunden S. 353-372, und KLNGENDER 1971, des weiteren, hinsichtlich der Symbolgehalte von Tierdarstellungen, über Bestiarien MCCULLOCH 1960 und HASSIG 1995 (bezogen auf England 1100-1500).

338 Siehe auch oben S. 54, Anm. 81. Über Hunde an den Höfen als Medien sozialer Beziehungen TEUSCHER 1998 mit weiterführenden Nachweisen, hier v.a. S. 359-364 zu verschenkten Hunden.

339 Anhang - Katalog/Jahreslisten, Nr. 1425.

340 Ebd., Nr. 1018.

341 Ebd., Nr. 1037. 1406 schenkte Johann Ohnefurcht Karl VI. deux veruelles, pour ung faucon, siehe ebd., Nr. 1364.

342 Vgl. PARAVICINI 1994, S. 90.

343 Anhang - Katalog/Jahreslisten, Nr. 1175.

344 Zur Bedeutung des Pferdes MCCULLOCH 1960: Stw. »horse«, S. $127 \mathrm{f}$.

345 1389: Anhang - Katalog/Jahreslisten, Nr. 289-291, 1390: Nr. 328 mit den entspr. Anm. Siehe CHERRIER 1995 zu den Pferden Philipps des Kühnen, hier insbes. S. 118-123: „Le cheval, cadeau princier«, 134f.: "Chambellans et proches de Philippe le Hardi: fournisseurs de chevaux de luxe«, 136 mit Anm. 1 zu den Pferdekäufen der de La Trémoille, Von Ernest Picard stammt die Arbeit über den Marstall Philipps des Kühnen: PICARD 1905/1906). Vgl. in allg. Hinsicht auch CONTAMINE, Glanes d'hipponymie médiévale, 1993, und SCHNERB 1993 über das Pferd in den burgundischen Armeen des 14. Jh.s. 
$1389 / 1390$ in Preußen ${ }^{346}$ und es ist zu erkennen, daß große Entfernungen und persönliche Abwesenheit dem höfischen Geschenkverkehr offenbar keinen Abbruch taten, in diesem Fall wahrscheinlich sogar ein Zeichen für eine besonders innige Beziehung zwischen Schenker und Beschenktem sind. Das Schlachtpferd und der Zelter, die Heinrich III. von Spanien Philipp dem Kühnen 1396 sandte und die beiden Schlachtrösser, die Ludwig von Orléans zwei Jahre später von Karl III. von Navarra erhielt, können wie die oben bereits erwähnten Pferde Martins von Aragon als diplomatische Geschenke gewertet werden ${ }^{347}$. Bleibt zu erwähnen, daß Ludwig von Orléans 1404 sogar von Johann Ohnefurcht ein Pferd erhielt ${ }^{348}$, und 1406 beschenkte Ludwig einen Angehörigen der Familie Raguier ${ }^{349}$. Falken waren erstaunlicherweise nicht unter den Neujahrsgeschenken ${ }^{350}$.

Wurden Schlachtpferde verschenkt, so doch keine Waffen, und Rüstungsteile finden sich nur in den Darstellungen der größeren und kleineren Goldschmiedeplastiken, wie auf dem goldenen Ring, ouquel a un heaume et I escu de mesmes, fait d'un saphir, aux armes de monseigneur, un ours d'esmeraude et un cigne de cassidoine blanc soustenant ledit heaume, den Berry 1408 von Johann I. von Bourbon erhielt ${ }^{351}$. Einzige Waffe war ein großes Schwert 352 toute couverte et garnye d'or de l'ouvrage de Venize, en laquelle a ou pommeau d'icelle espee XII ballais et XII perles et en la bouterolle d'icelle un gros ballay et un saffir ${ }^{353}$, das aber hatte Ludwig von Orléans zwar $1401 \mathrm{zu}$ einem Preis von 2.2501 . erworben, um es an eine unbekannte Person als Neujahrsgeschenk zu überreichen, es dann aber doch selbst behalten.

Bücher als Geschenke zum neuen Jahr und Gedichte als Glückwünsche wurden oben behandelt ${ }^{354}$, die einzigen Exotika, ein »Einhornhorn « und der »Verlobungsring Josephs«, die Berry einst erhielt, ebenfalls ${ }^{355}$.

346 Nach Paravicini; Preußenreisen, Bd. 1, 1989, S. 94-101, Tab. 7, hier S. 99, Nr. 164, und Tab. 21, S. 173. Zu den de La Trémoille in Preußen ebd., S. 170-172.

347 Anhang - Katalog/Jahreslisten, Nr. 700, 876. - Vgl. ReITEMEIER 1999, S. 446f.

348 Anhang - Katalog/Jahreslisten, Nr. 1289.

349 Ebd., Nr. 1369.

350 Falken als Gegenstände des höfischen Geschenkverkehrs behandelt HECKMANN 1999, siehe aber schon PARAVICINI 1994, S. 90 mit weiteren Nachweisen und künftig PARAVICINI im Rahmen eines größeren Überblicks über »Tiere aus dem Norden«, in: Der erfahrene Norden. Reisen, Bilder, Stereotypen. Ringvorlesung im Sommersemester 2000 des Graduiertenkollegs Imaginatio borealis zu Kiel.

351 Anhang - Katalog/Jahreslisten, Nr. 1433.

352 Vgl. PaRAVICINI 1994, S. 90.

353 Siehe Anhang - Katalog/Jahreslisten, Nr. 1086.

354 Siehe oben S. 96-100 mit weiteren Nachweisen zu den Gedichten in den Anm., und den einführenden Abschn. III. 3. zu den Handschriften. Einen anschaulichen Überblick mit zahlreichen Abb., in: Les fastes du Gothique (Ausstellungskatalog), 1981, S. 276-362.

355 Siehe auch oben S. 61, Anm. 129 und oben S. 61, Anm. 130. - Zur Verwendung "exotischer« Materialien in der Goldschmiedekunst siehe u.a. bspw. BERGER 1950 über fossile Haifischzähne als Material mittelalterlicher Goldschmiedearbeiten«, die als »Natternzun- 
Es konnte gezeigt werden, daß die meisten Gegenstände, auch einfache Objekte, überaus kostbar sein konnten. Der Gedanke liegt nahe, daß es Fälle gegeben haben muß, wo Geld selbst verschenkt wurde, und tatsächlich sind diese Schenkakte nicht selten gewesen und betrafen alle Ebenen der höfischen Hierarchie. Fast 50.000 1. erreichten auf diese Weise ihre Empfänger, knapp $10 \%$ des Gesamtvolumens. 1410 erhielt Johann Ohnefurcht vom König 5.000 écus - das einzige Mal, daß der König Geld verschenkt hat, abgesehen von den Transfers zur Finanzierung verschiedener Geschenke Philipps des Kühnen 356 -, der König selbst bekam von Philipp dem Kühnen 14044.000 écus und Guy de La Trémoille 1386 von seinem Herrn $2.000 \mathrm{fr}$. ${ }^{357}$. Das waren die Spitzengeschenke. Johann von Berry erscheint wie der König nur ein einziges Mal, 1411, als Schenker mit einer unbestimmten Gabe monnaie an die Brüder Limburg 358 , ein Gegengeschenk für das nachgemachte Buch aus einem Stück Holz, das diese ihm verehrt hatten ${ }^{359}$. Die höchsten Ausgaben beziehen sich auf Karl, den späteren König, der allein im Jahr 1420 knapp über $16 \%$ aller Geldgeschenke an seine Gefolgschaft verteilte 360 , und auf Philipp den Kühnen mit 33.486 1. und einem Anteil von mehr als $70 \%$ an den Geldgeschenken. Johann Ohnefurcht belegt mit 1.140 l. und einem Satz von etwa 2,5\% den dritten Rang. Er beschenkte 1407 seinen Kanzler Jean de Saulx ${ }^{361}$ und seinen Berater Renier Pot ${ }^{362}$ mit je 500 Goldflorenen, 1413 Jean Marchand ${ }^{363}$, seinen Beichtvater, mit 40 fr., und 1419 Regnault Thumery ${ }^{364}$, Münzmeister des Königs, mit 100 fr. Neben Guy de La Trémoille mit 4.000 fr. war es Margarete von Flandern, die von ihres Mannes Großzügigkeit profitierte. Sie erhielt über die Jahre 24.000 l., darunter den bis 1404 stets zum ersten Januar ausgegebene Betrag von $1.000 \mathrm{fr}$.

Besonders bei den Geldgeschenken stellt sich wieder drängend die Frage, wo die Gabe endet und die Bezahlung beginnt. Aber diese Zuwendungen sind als étrennes überliefert, nicht als Gage, und müssen als étrennes behandelt werden, auch wenn gerade das Geldgeschenk notwendiger Verdienst sein konnte. Im Fall der Margarete von Flandern kommt ein weiteres Problem

gen « die Funktion eines Prüfmaterials hatten, welches Giftgehalte in Lebensmitteln anzeigen konnte, siehe LABORDE, Glossaire, 1872: Stw. "Espreuve«, S. 303 und ebd.: Stw. "Languier«, S. 354f. sowie ebd.: Stw. »Serpent«, S. 497, vgl. SELIGMANN 1999, S. 57, 138.

356 Zuwendung Karls VI. an Philipp den Kühnen in Höhe von $10.000 \mathrm{fr}$. Anhang - Katalog/Jahreslisten, Nr. 1157. - Zur Finanzierung einer Goldschmiedeplastik siehe oben S. 166 mit Anm. 188.

357 Anhang - Katalog/Jahreslisten, Nr. 1489, 1313 und 175.

358 Ebd., Nr. 1507.

359 Siehe auch oben S. 47, Anm. 59.

360 Anhang - Katalog/Jahreslisten, Nr. 1761-1784 und 1787-1809.

361 Ebd., Nr. 1394.

362 Ebd., Nr. 1404

363 Ebd., Nr. 1578.

364 Ebd., Nr. 1743. 
hinzu: Eine über die Jahre gleichbleibende regelmäßige Zuwendung, die als Geschenk deklariert ist, scheint eher den Charakter einer Apanage zu haben, zumal dann, wenn die eigentlichen höfischen Gaben trotzdem und zusätzlich präsentiert wurden. Das hohe Maß an Stetigkeit kann aber auch als Ausweis einer ganz besonders stabilen Beziehung gewertet werden und methodisch gesehen wäre es nicht haltbar, dieses Element auszuklammern. Nicht verschenkt worden waren zum neuen Jahr, dies sei abschließend noch hinzugefügt, Pflanzen, Titel, Rechte oder Ländereien.

\section{b) Geschickt und behalten}

Wie mehrfach ausgeführt, existiert fast keine Überlieferung, die darüber unterrichten würde, wie und in welchem Rahmen die Geschenke am jour de l'an zu ihren Empfängern kamen. Bekannt ist durch einige Botenentlohnungen, daß Schenker und Beschenkte mit Sicherheit nicht persönlich zusammengetroffen sein konnten an dem jeweiligen Tag ${ }^{365}$. Anhand der im Anhang gegebenen Aufenthaltsorte einiger Personen läßt sich zwar ermitteln, wo sich diese jeweils am ersten Januar eines Jahres befunden haben, aber bis auf wenige Fälle können nur Vermutungen darüber angestellt werden, ob diese am selben Ort dann auch tatsächlich gemeinsam gefeiert haben. Die Archivalien nennen zudem eine ganze Reihe der oben angeführten Gegenstände, die zwar zweckentsprechend erworben worden waren, aber keine Empfänger hatten und aus welchen Gründen auch immer im Eigentum der jeweiligen Schenker verblieben sind. Ein Grundinterpretationsgedanke ist die Vorstellung, daß eine Beziehung, die nicht durch persönliche Anwesenheit bestimmt war, aber trotzdem durch die geschickte Gabe Bestätigung erfuhr, um Grade stabiler gewesen sein könnte, als eine Beziehung, der wegen fordernder Anwesenheit nur schwer auszuweichen war. Eine weitere Überlegung zielt darauf, daß noch in Unkenntnis potentieller Schenker erworbene Gegenstände Indiz dafür sein könnten, daß die systemtheoretisch so $\mathrm{zu}$ bezeichnende "Erwartungserwartbarkeitsqualität« des Neujahrstages recht hoch gewesen sein muß - als Indiz für die institutionalisierte Verhaltenssicherheit und Systemstabilität der Einrichtung des Geschenkverkehrs zum neuen Jahr, an deren Erhalt sich die Akteure aktiv beteiligt haben. Es wurde offenbar auch fest mit Boten gerechnet, die Geschenke überbringen. Valentina Visconti investierte 1398118 francs 25 solz pour six gobelets d'argent doré pesant onze marcs sept onces donnés a ceux qui ont apporté a la duchesse les etrennes du roy, de la

365 Das Botenwesen der Zeit Karls des Kühnen behandelt unter dem Gesichtspunkt der Kommunikation (dazu auch oben S. 140, Anm. 19) SEGGERN 1998 und SEGGERN, Harm von: Herrschermedien im Spätmittelalter. Studien zur Informationsübermittlung im burgundischen Staat unter Karl dem Kühnen, Diss. Univ. Kiel 1999. 
reine ${ }^{366}$, ihr Mann 197 francs 7 s. 6 deniers tournois pour huit hanaps et gobelets d'argent doré pour donner a ceux qui luy a apporté les etrennes du roy, de la reine, de beau cousin le roy de Navarre qui lui a donna deux coursiers, de beaux oncles de Berry, de Bourgogne et de Bourbon, de la duchesse son epouse et de beau cousin de Fere ${ }^{367}$.

Die Überlieferung notiert für die Neujahrstage nicht ganz 50 Botengänge, so daß auf diese Weise nur etwas mehr als ein halbes Prozent aller Geschenke versandt wurden. In quantitativer Hinsicht kann dieser Bereich des höfischen Geschenkverkehrs deshalb dem Gesamtbild nur eine weitere Facette hinzufügen, ist aber kein entscheidendes Charakteristikum. Unbekannt geblieben ist bei dem durch Boten vermittelten Geschenkverkehr nur ein Schenker, von dem die Königin 1391 ein ungenanntes Geschenk nicht verzeichneten Wertes erhielt ${ }^{368}$. Archivalisch nicht erfaßt sind 19 Geschenke und 27 Wertzuweisungen, wobei der Gesamtwert der durch Boten überbrachten Gaben aber bei $6.650 \mathrm{l}$. liegt, pro Botengang also im Durchschnitt etwa ein Wert von $130 \mathrm{l}$. transportiert wurde. Die kostbarsten Gaben stammten wiederum von Philipp dem Kühnen. Johann von Berry war 1390 Empfänger des teuersten verschickten Gegenstandes, einem grant tablel d'or, pesant 7 marcs, garny de 10 balaiz, 12 saphirs, 66 grosses perles, et estoit de l'istoire de sainte Katherine et de saint Jehan Baptiste, et pendoit a une chainecte d'or faicte en guise d'oiziaux, et avoit au dessus de ladicte chainecte I fremail d'or garni de 3 balaiz, 3 grosses perles, et ou milieu une bien grosse perle ${ }^{369} \mathrm{zu} 1.500 \mathrm{fr}$. In diesem Jahr war der Burgunder am ersten Januar in Dendermonde in Flandern $^{370}$, der Aufenthaltsort Berrys ist nicht bekannt. 1397 sandte Philipp, der sich mit Berry und seinem Sohn zu einem gemeinsamen Bankett in Conflans bei Paris befand ${ }^{371}$, seiner Enkelin Maria (II.) von Burgund un fermail, garni d'un balay, d'un safir et $V$ perles ${ }^{372}$ zu 900 fr. Im Jahre 1398 schließlich erhielt der englische König Richard II., der sich möglicherweise in Lichfield aufhielt, während der Burgunderherzog in Arras weilte ${ }^{373}$, die bereits oben erwähnte kostbare Goldschmiedeplastik mit der Darstellung des heiligen

366 Siehe BNF ms.fr. 10431, 402 f., Nr. 2294.

367 Siehe ebd., Nr. 2299. Bei dem beau cousin de Fere handelt es sich möglicherweise um Jean de Foix.

$368 \mathrm{Zu}$ erschließen aus der Belohnung für Boten: a plusieurs autres qui lui furent present [...] de par autres seigneurs, siehe Anhang - Katalog/Jahreslisten, Nr. 445.

369 Ebd., Nr. 374.

370 Siehe Anhang - Neujahrstage und Aufenthaltsorte 1381-1422, 1. Januar 1390.

371 Siehe ebd., 1. Januar 1397.

372 Anhang-Katalog/Jahreslisten, Nr. 991.

373 Siehe Anhang - Neujahrstage und Aufenthaltsorte 1381-1422, 1. Januar 1398. 
Eduard ${ }^{374}$, die durch den burgundischen Gesandten Jean de Villeroy 375 überbracht worden ist.

Philipp der Kühne versandte insgesamt elfmal Geschenke zum neuen Jahr, Karl VI. veranlaßte dies sechsmal, Johann Ohnefurcht, Johann von Berry und Ludwig von Orléans nur jeweils dreimal. Die Königin und Ludwig II. von Bourbon hatten noch je zweimal Boten geschickt, während dies Anne d'Auvergne, Bernhard VII. von Armagnac, Dino Rapondi, Guy de La Trémoille, Heinrich III. von Spanien, Karl III. von Navarra, Ludwig von Male Graf von Flandern, Margarete von Flandern, Marie de Sully, Martin von Aragon, Richard II. und Valentina Visconti nur noch je einmal taten. Ohne erneut alle Empfänger aufzuzählen, sei zumindest erwähnt, daß Philipp in dieser Rolle siebzehnmal erscheint, Margarete von Flandern, Katharina (I.) von Burgund, Johann von Berry und Isabeau de Bavière jeweils zweimal. Es wundert ein wenig, daß die Königin die Neujahrsgaben 1391 - plusieurs gobelets et ayguieres dorez hachiez et poinçonnez ${ }^{376}$ - für ihre Hofdamen, zu denen Alips de Beauchamp, Catherine de Fastavarin, Catherine de Villiers, Isabelle La Bouteillière, Jeanne de Montueil, Jeanne de La Tour, Marguerite de Germonville und Marie de Duisy gehörten ${ }^{377}$, bringen ließ, schien sie sich doch, so läßt sich vermuten, auch wenn dies explizit nicht belegbar ist, in Paris an der Seite des Königs befunden zu haben ${ }^{378}$. Die verschenkten Gegenstände weisen keine besonderen aus dem Rahmen fallenden Auffälligkeiten auf. Allerdings erscheinen in dieser Rubrik überproportional viele Tiere ${ }^{379}$.

Was ist über die Boten bekannt? Das Geschenk Guy de La Trémoilles ist nicht bekannt, das dieser Philipp dem Kühnen 1388 sandte ${ }^{380}$, aber es wurde überreicht durch seinen Knappen Jean Regnaut ${ }^{381}$. Der König bediente sich 1389 seiner Kammerdiener Arnoul Boucher und Charles Poupart, der eine

$375 \mathrm{Vgl}$. VAUGHAN 1962, S. 108, falls der bei ihm genannte Schenkvorgang identisch ist mit dem vorliegenden.

376 Anhang - Katalog/Jahreslisten, Nr. 404.

377 Auflösung der [...] plusieurs dames et damoiselles de son hostel [...] nach GRANDEAU 1975, S. 163.

378 Siehe Anhang - Neujahrstage und Aufenthaltsorte 1381-1422, 1. Januar 1391.

379 So der Windhund, den Anne d'Auvergne Johann von Berry schickte, siehe Anhang Katalog/Jahreslisten, Nr. 1018, so das Pferd an einen der Raguiers von Johann Ohnefurcht, siehe ebd., Nr. 1369, so die vier Maulesel, vier Schlachtpferde und zwei Affen Martins von Aragon an Philipp den Kühnen, siehe ebd., Nr. 1175, so der courcier und die aguenee, die Heinrich III. von Spanien Philipp dem Kühnen 1396 sandte, siehe ebd., Nr. 700, so die zwei Pferde Karls III. von Navarra an Ludwig von Orléans 1398, siehe ebd., Nr. 876. Vermutlich waren auch die Pferde Trémoilles für den Burgunderherzog ein Botengeschenk, weilte Trémoille doch am Neujahrstag 1390 in Preußen, siehe auch oben S. 182 mit Anm. 345.

380 Siehe Anhang - Katalog/Jahreslisten, Nr. 240.

381 ACO B 1471 , fol. 24v, vgl. Inventaires mobiliers, hg. von PROST, PrOST, Bd. 2, 19081913, S. 376, Nr. 2501. 
später Schatzmeister, der andere Argentier, um les étrennes qu'il offrit a ses deux freres, les ducs de Berry et de Bourgogne zu bringen ${ }^{382}$. Die beiden Boten fertigten für ihre Auslagen eine Quittung 383 , bekamen aber auch von Philipp dem Kühnen 150 fr. ${ }^{384}$. Berry schickte 1396 Jehan Destampes ${ }^{385}$ nach Burgund, der für seinen Dienst 100 escuz, valent $112 f$ l. 10 s.t. bekam ${ }^{386} .1391$ war es ein premier vallet de chambre, der das für Philipp den Kühnen bestimmte Präsent ${ }^{387}$ beförderte und dafür von dem Burgunder 1001 . erhielt ${ }^{388}$. Ludwig von Orléans hatte 1393 seinen Barbier Salmon nach Burgund geschickt, der dort mit einem service a boire de vermeil hachié par bendes entlohnt wurde ${ }^{389}$. Philipp der Kühne hatte 1398 für eine ganze Reihe von Boten, die étrennes für ihn brachten, Silbergeschirr zu einem Gesamtwert von 344 fr. 7 s. 6 d. t. gekauft ${ }^{390}$.

Philipp selbst bediente sich 1385 für die Sendung von Diamanten ${ }^{391}$ an seine Frau seines sommeliers Willequin de Culem, der nun für den Transport von Geschenken des Herzogs selbst mit $20 \mathrm{fr}$. wesentlich weniger Lohn erhielt ${ }^{392}$ als die Boten anderer Höfe, die nach Burgund kamen. Johan Rodrigues, Gesandter des spanischen Königs Heinrichs III., konnte $200 \mathrm{fl}$. in Empfang nehmen ${ }^{393}$, als er die Pferde seines Herrn abgeliefert hatte.

Auch Guillaume Giraut, varlet des chiens de madame de Bourbon, der den Windhund Anne d'Auvergnes an Johann von Berry überbracht hatte - übrigens erst am 11. Januar 1400 - bekam nur 61.15 s.t. als Belohnung für seinen Dienst $^{394}$. Was der petit Hermite de la Sayère 1411 von Karl von Orléans für den Transport eines Geschenkes von dessem Schwiegervater Bernhard VII.

382 Siehe Anhang - Katalog/Jahreslisten, Nr. 297, vgl. Inventaires mobiliers, hg. von PROST, PROST, Bd. 2, 1908-1913, S. 474, Nr. 3116.

383 BNF, Coll. Clairambault, vol. LXXXVII, Nr. 190, siehe Inventaires mobiliers, hg. von Prost, Prost, Bd. 2, 1908-1913, S. 473, Anm. 5: „La quittance des deux varlez ne contient malheureusement aucun détail sur les étrennes offertes par le roi.«

384 ACO B 1469, fol. 44v.

385 Siehe Anhang - Katalog/Jahreslisten, Nr. 702.

386 ACO B 1508, fol. 108v.

387 Anhang - Katalog/Jahreslisten, Nr. 427.

388 ACO B 1487, fol. 89r.

389 ACO B 1495, fol. 55v, vgl. DAviD 1947, S. 57. Siehe Anhang - Katalog/Jahreslisten, Nr. 554.

390 BNF, Coll. de Bourgogne, vol. LIII, fol. 192.

391 Siehe Anhang - Katalog/Jahreslisten, Nr. 1116.

392 ACO B 1463, fol. 13lv. Siehe Inventaires mobiliers, hg. von Prost, PROST, Bd. 2, 1908-1913, S. 182, Nr. 1195. Vgl. COMMEAUX 1979, S. 244.

393 ACO B 1508, fol. 109r.

394 Siehe GUIFFREY 1899, S. 77 nach AN KK 254, fol. 46r, vgl. ebd., S. 68, siehe auch GUIFFREY, Inventaires, Bd. 1, 1894, S. CXXVf. 
von Armagnac ${ }^{395}$, nostre très chier et très amé cousin le conte d'Armignac, erhielt, ist hingegen nicht bekannt.

$\mathrm{Daß}$ in Erwartung von Neujahrsgeschenken Belohnungen für eintreffende Boten bereitgehalten worden sind, wurde gezeigt. Von vielen der Gegenstände, die nach Wert und Qualität allerdings eher für diejenigen bestimmt gewesen sein dürften, die nicht zu den Mittelpunkten des Geschenkverkehrs zu zählen sind, ist nicht nur nicht bekannt, ob sie überhaupt verschenkt worden sind, sondern auch nicht, was dann aus aus ihnen wurde. Von einigen ist bekannt, daß sie in die Schatzkammern eingelagert worden sind, nachdem sie keine Verwendung gefunden hatten. Dies sind allerdings Geschenke gewesen, die aufgrund ihrer Beschaffenheit tatsächlich für diejenigen bestimmt gewesen dürften ${ }^{396}$, die von zentraler Bedeutung für den höfischen Geschenkverkehr waren. Bis auf die beiden Posten im Schatz Karls VI.397 handelt es sich ausnahmslos um Gegenstände, die, von Johann von Berry erworben, nach 1404 in dessen Schatz verblieben und in seinen Inventaren verzeichnet sind. Zu nennen sind zunächst drei Humpen, von denen einer - un hannap d'or, tout plain, couvert, qui a sur le fretelet un ours d'or enlevé, lequel hannap poise IIII marcs III onces $V$ esterlins d'or; et a esté fait de l'or d'un grant collier d'or plat, fait à la devise de mondit seigneur 398 - mit angenommenen $600 \mathrm{fr}$. der kostbarste dieser Gegenstände war ${ }^{399}$. Alsdann sind zwei bassins ${ }^{400}$, eine aiguière in Fischform ${ }^{401}$, eine kleine ymaige d'or de saint Baptiste ${ }^{402}$, eine

395 Siehe Roman 1896, S. 247, Nr. 790 und S. 247f., Nr. 791. Siehe Anhang - Kata$\log /$ Jahreslisten, Nr. 1500.

396 Die im Katalog angegebenen Werte sind nachträgliche Schätzwerte. Auch hier dürften die ursprünglichen Preise wesentlich höher gewesen sein. Siehe Anhang - Katalog/Jahreslisten, Nr. 1287, 1347, 1348, 1362, 1380, 1381, 1382, 1457, 1458, 1506, 1568, 1569, 1570, 1636, 1637 und 1668.

397 Une XII de hanaps d'or a façon de cour de lampe a un petite souaige par dessoubz et a en chascun un esmail rond de france et un tigre ou milieu, nach BNF ms.fr. 21445 , fol. $21 \mathrm{r}$ achatez par le Roy le jour de l'an IIII ${ }^{\mathrm{X}}$, und noch im Inventar 1395 enthalten, mithin nicht nachweisbar verschenkt, siehe Anhang - Katalog/Jahreslisten, Nr. 664, und eine äußerst kostbare ymage de saint Louis, acheptez par le Roy aux estrainnes und zunächst im Schatz verwahrt, siehe BNF ms.fr. 21445, fol. 29v-30r und BNF ms.fr. 21446, fol. 107r, später an Ludwig den Bärtigen verpfändet (vgl. VALLET DE VIRIVILLE 1857, siehe v.a. aber STRAUB 1965, S. 217, Nr. 13 und S. 218 f. mit Anm. 90), der die Figur am 5. Oktober 1407 in Valenciennes verkaufen ließ, siehe STRAUB 1965, S. 240f., bzw. S. 241, Nr. 1.

398 Anhang - Katalog/Jahreslisten, Nr. 1570.

$399 \mathrm{Zu}$ den beiden anderen ebd., Nr. 1668 (1415) und 1636 (1414).

400 Ebd., Nr. 1637 (1414).

401 Ebd., Nr. 1380 (1407), zum Fisch als Element der christlichen Bildersprache SCHMIDT 1981, S. 55-63.

402 Ebd., Nr. 1348 (1405). 
fiole ${ }^{403}$, eine pincte aus Beryll ${ }^{404}$, eine verge ${ }^{405}$, sechs anneaul ${ }^{406}$ und ein goldenes $\mathrm{Kreuz}^{407}$ überliefert.

Von vergleichsweise minderer Qualität waren die vielen Geschenke für diejenigen, ou il luy plut ledit jour, en bonnes étrennes. 1382 hatte Philipp der Kühne zu diesem Zweck 50 verges d'or erworben, einen annel, zwei chennes d'or und zwei gobelets ${ }^{408}, 1383$ für jene ou il luy plut, aber auch a son grét09, une douzaine de verges d'or, plainnes, esmaillees de blanc, une patenostre d'or, 22 Spangen, drei Ringe und fünf Diamanten 410,1385 a qui il luy plairoit ${ }^{111}$ une sainture d'argent $t^{412}$ und 1397 mon dit seigneur a donné au dit jour de l'an a plusieurs personnes, tant chevaliers, escuyers, comme autres, la ou il luy a pleut13 28 Diamanten und sechs Ringe ${ }^{414}$. Valentina Visconti schließlich wartete 1398 auf Schenker mit acht gobelets couverts d'argent dorét ${ }^{415}$ pour donner aux etrennes 416 .

\section{c) Bedingt und benötigt}

Aller Beobachtung nach ist es in der Regel nicht der Fall gewesen, daß die Gaben des höfischen Geschenkverkehrs hinsichtlich ihrer Beschaffenheit einen evidenten Zusammenhang mit der Ereignisgeschichte aufwiesen. Der große Abstand von jeweils zwölf Monaten zwischen zwei Neujahrstagen mag die Reaktionsfähigkeit dieses Gabentausches in diesem Sinn zusätzlich behindert haben. Die Aktionsfähigkeit des anlaßgebundenen Gabentausches ist, schon theoretisch auf seine Funktion als Indikator bestehender Beziehungen begrenzt, schlechterdings nicht belegbar, denn das Mittel von "Schenkpolitik" wäre das Nichtschenken. Die personengebundene Ausrichtung der Schenkvorgänge läßt dann auch eher an individuelle Einflußfaktoren denken als an politische oder ereignisgeschichtliche Bedingtheiten, wobei erstere natürlich durchaus auch Vermittler zeithistorischer Kontexte sind, dann aber eben

403 Anhang - Katalog/Jahreslisten, Nr. 1287 (1404): une petite fiole d'agathe garnie de trois fillez d'argent dorez.

404 Ebd., Nr. 1347 (1405).

405 Ebd., Nr. 1458 (1409).

406 Ebd., Nr. 1362 (1406), 1381 (1407), 1382 (1407), 1457 (1409), 1506 (1411), 1568

(1413).

407 Ebd., Nr. 1569 (1413).

408 Ebd., Nr. 31-36.

409 Nach BNF, Coll. de Bourgogne, vol. XXI, fol. 12v.

410 Anhang - Katalog/Jahreslisten, Nr. 61-77.

411 Nach ACO B 1463, fol. 100v.

412 Anhang - Katalog/Jahreslisten, Nr. 133.

413 BNF, Coll. de Bourgogne, vol. LIII, fol. 167.

414 Anhang - Katalog/Jahreslisten, Nr. 840-852.

415 Ebd., Nr. 870.

416 BNF ms.fr. 10431, S. 474f., Nr. 2719. 
vermittelnd und nicht unmittelbar, die sich systemtheoretisch betrachtet folglich auch nur in reduzierter Weise im Schenksystem wiederfinden. Entsprechend besteht selbstverständlich ein Zusammenhang zwischen zeitgenössischer Kunstproduktion, ökonomischen Potenzen, politischem Selbstverständnis, kulturellem Zeitgeist und höfischem Geschenkverkehr, doch keine Identität. Die Gabe ist - höfisch gefiltert - modifiziertes Abbild und Ergebnis, das archivalisch faßbare Geschenk nicht anders als in diesem Sinn zu verstehen. Die Gaben wollen zeigen und gezeigt werden. Damit ist vor dem Hintergrund des Zieles der Anhäufung von Ehrzuweisungen das Streben nach Beziehungsmacht markiert - zunächst auf Seiten des Schenkers, der streut (Philipp der Kühne ${ }^{417}$ ), dann auf Seiten des Beschenkten, der bündelt (Johann von Berry). Der Burgunder und der Herzog von Berry mögen in dieser Hinsicht ein ideales Paar gebildet haben. Die unten angestrebte Beobachtung der Beziehungsnetze könnte darüber weiteren Aufschluß geben. Zuvor sollen jedoch noch die Geschenke behandelt werden, die einen möglicherweise engen Zusammenhang der Umwelt mit dem Schenksystem aufwiesen. Gaben, die den politschen Willen des Schenkers offenbaren, und Gaben, die für die Empfänger möglicherweise existentiell notwendig waren.

1403, an seinem vorletzten Neujahrstag, hatte Philipp der Kühne sich noch einmal bemüht, schwindenden Einflüssen, in dem Fall auf die Bretagne, entgegenzutreten. Er beging die Feier des jour de l'an in Corbeil nach der Rückkehr von seiner letzten großen Reise aus der Bretagne avec monseigneur de Bretaigne et ses freres 418 - nebenbei bemerkt war das wohl einer der seltenen Fälle, wo der Gabentausch und die Feier zeitlich auseinandertraten ${ }^{419}$. Johann V. von Bretagne stand noch bis zum 23. Dezember 1403 unter der Vormundschaft des Burgunders und dieser versuchte nun, den bald volljährigen Herzog durch die Gründung eines neuen Ordens an das Haus Burgund zu binden ${ }^{420}$. Dieser Orden $»$ vom goldenen Baum « ${ }^{421}$ hatte als Abzeichen Kollanen für die Männer und Spangen fait de l'arbre d'or et ung aigle et und lion esmaillés de blanc, versehen mit der Wortdevise en loyauté, für die

417 Die Ausführungen Patrick M. de WINTERs, der sich konkret mit der Patronanz Philipps des Kühnen beschäftigt, enttäuschen hinsichtlich der Neujahrsgeschenke. "Gifts«, so der Titel eines Absch., werden in WINTER, The Patronage of Philippe le Hardi, Bd. 1, 1976, lediglich auf den S. 197-203 behandelt.

418 PETIT 1888, S. 332 nach ACO B 1527, siehe Anhang - Neujahrstage und Aufenthaltsorte 1381-1422, 1. Januar 1403.

419 Der Hof selbst hielt sich zum Zeitpunkt der Vergabe der Neujahrsgeschenke in der Bretagne auf, vgl. POCQUET DU HAUT-JUSSÉ 1933, hier insbes. S. 197. Die Feier des nouvel an fand dann auf dem Rückweg in Corbeil statt, siehe ebd.

420 Siehe oben S. 95 mit den entspr. Anm.

421 CALMETTE 1996, S. 73 spricht vom Orden »Arbre d'Or«, der als eine Art Vorwegnahme des Ordens vom Goldenen Vlies zu sehen sei. Siehe neuerdings den Aufsatz von ChatTAWaY, Carol M.: The Heroes of Philip the Bold, im Druck. 
Frauen, die zum neuen Jahr 1403 an einen umfangreichen Personenkreis verschenkt wurden. Die teuerste Kollane zu $600 \mathrm{fr}$. erhielt der Bretonenherzog selbst ${ }^{422}$. Diesem Orden sollten zahlreiche prominente Aristokraten der Zeit angehören wie Amadeus VIII. von Savoyen und Maria (I.) von Burgund, Anton von Burgund und Jeanne de Saint-Pol, Armel de Châteaugiron, der Herr von Gavre, Georges de La Trémoille, Philipp von Burgund und Isabelle de Coucy, Jean le Voyer, Johann Ohnefurcht und Margarete von Bayern, Katharina (I.) von Burgund und Leopold IV. von Österreich, Ludwig der Bärtige, Renier Pot, Wilhelm von Bayern und Margarete (I.) von Burgund ${ }^{423}$. Die finanzielle Belastung schien Philipp jedoch zu hoch, denn er hat sogar sein eigenes Abzeichen zurückgegeben ${ }^{424}$, obwohl er von dem König für seine Reise mit 50.000 1. unterstützt worden war ${ }^{425}$ - und nahm damit unbewußt die politische Lösung der Bretagne von Burgund vorweg.

Die Höhe der königlichen Unterstützung, beileibe kein singulärer Vorgang ${ }^{426}$, könnte darauf hinweisen, daß die nach ihren jeweiligen Werten bemessenen Geschenke, auch wenn sie im Einzelfall als überaus kostbar gelten können und durchaus auch eine Funktion als Kapitalanlage hatten, auf der Ebene des gehobenen höfischen Geschenkverkehrs nicht die Aufgabe haben konnten, Beziehungen umweglos regelrecht zu kaufen oder zu finanzieren oder über die Wertzuweisungen in rein materiellem Sinn zu instrumentalisierten. Im Verhältnis waren die teilweise enormen Preise von einzelnen Geschenken dann möglicherweise doch zu gering, als daß den Gaben eine direkte Wirkung zugewiesen werden könnte, die über ihre theoretische

422 Anhang - Katalog/Jahreslisten, Nr. 1254.

423 Vgl. POCQUET DU HAUT-JUSSÉ 1933, S. 197: »A l'occasion du $1^{\text {er }}$ janvier 1403, Jean V reçut, comme les comtes de Nevers et de Rethel, sun fermail d'or de l'ordre de Monseigneur fait de l'arbre d'or et un aigle et un lion esmaillé de blanc, garni d'un gros rubis balais, d'un gros saphir et de trois grosses perles،. Quelques Breton reçurent aussi l'ordre ducal, notamment Armel de Châteaugiron, le sire du Grave, Jean le Voyer et le vicomte de la Bellière. L'écuyer tranchant de Jean V, son échanson, l'écuyer de la duchesse, et Jean le Voyer, comme chambellan de Jean V, reçurent encore differents dons. "Vgl. DAVID 1947, S. $151 \mathrm{f}$. Siehe Anhang - Katalog/Jahreslisten, Nr. 1242-1244, 1246-1248, 1251f., 1254-1256, 1258-1260, 1262f., 1267, 1269-1274, 1276f. - An dieser Stelle mag der Hinweis eriaubt sein auf den Vortrag "Deutscher Adel und westeuropäische Kultur im späteren Mittelalter. Eine Spurensuche am Beispiel der Wittelsbacher« (v.a. mit Blick auf Ludwig den Bärtigen) von Werner PARAVICINI während der Arbeitstagung des Konstanzer Arbeitskreises für mittelalterliche Geschichte auf der Insel Reichenau vom 5.-8. Oktober 1999 zum Thema "Deutschland und der Westen Europas im Mittelalter. II. Hoch- und Spätmittelalter (hg. von Joachim EHLERS, in Vorbereitung zum Druck, siehe vorerst das Protokoll Nr. 376 des Konstanzer Arbeitskreises für mittelalterliche Geschichte, S. 40f.).

424 Siehe CALMETTE 1996, S. 73.

425 Siehe POCQUET DU HAUT-JUSSÉ 1933, S. 198.

426 Siehe auch die knappen Zahlenangaben und Hinweise oben S. 85, Anm. 69 sowie die Übersicht in Kap. C. I. 
Funktion als Mittel der Anhäufung von Anerkennungszuweisungen und ihre praktische Bedeutung als Beziehungsbegleiter und -indikator hinausreichten.

1406 verschenkte Philipps Nachfolger Johann Ohnefurcht trois cent quinze rabots d'or garnis de diamants 427 , gemeinsam mit seiner Wortdevise Ic houd ${ }^{428}$ das gegen seinen Rivalen, den Herzog von Orléans, der den Knotenstock führte ${ }^{429}$, gerichtete Symbol. Entsprechend fanden auch goldene Hobelspäne mit den Hobeln durch Herzog Johann Verwendung als Geschenk an seine Gefolgsleute. 1411 benutzte Johann, vielleicht auch als Reaktion auf die 1410 gegründete antiburgundische Liga von Gien, dieses Zeichen erneut als Geschenk zum neuen Jahr, diesmal waren es $552^{430}$ goldene und silberne Hobel ${ }^{431}$. 1410 hatte der Burgunder an stous ses chevaliers et les nobles de son hostel «432 eine Vielzahl niveaux de maçon verteilt ${ }^{433}$, darunter auch an Graf Jean de Foix, der allein neun Exemplare erhielt ${ }^{434}$, sowie einen aragone-

427 An divers seigneurs, siehe auch PETIT 1888, S. 585, womit wohl alle am Hof anwesenden chevaliers gemeint sind. Zu diesem Vorgang auch SLANICKA 2000, S. $171 \mathrm{f}$.

428 Zu diesem Motto SLANICKa 2000, S. 177, Anm. 40. - Die wichtigsten Arbeiten zu den Devisen um 1400 sind BEAUNE 1981 - Rez. VAIVRE, Jean-Bernard de, in: Bulletin Monumental 141 (1983) S. 92-95 - und BRUNA 1999, neuerdings auch SLANICKA 2000 (siehe auch unten S. 194, Anm. 440). Siehe exemplarisch zur Devise Richards II. ILG 1994. Ein nach Devisen sortiertes Verzeichnis bieten CHASSANT, TAUSIN, Dictionnaire des devises historiques et héraldiques, 1878. DIELITZ 1884 weist zwar eine alphabetische Sortierung auf und besitzt einen Personenindex, ist aber ansonsten lückenhaft, mit fehlerhaften Zuordnungen und zum Teil falschen Übersetzungen.

429 Vgl. bspw. HuIzINGA 1975, S. 335 und 508, Anm. 18 (an HuizInGA orientiert CALMETTE 1996, S. 92 mit Anm. la auf S. 357). Vgl. VAUGHAN 1966, S. 234 zur Devise Johanns: "This was a carpenter's plane, which he had chosen to smooth away symbolically the duke of Orleans' club, and he used it in excessive profusion on every possible occasion." Dieser Schenkakt findet sogar an entlegeneren Stellen Beachtung, vgl. etwa BEAUNE, ARBAUMONT 1864, S. XXXV, hier allerdings ein wenig schief als Beleg für das unvergleichliche Niveau fürstlicher Prachtentfaltung des burgundischen Hofes. Siehe Anhang Katalog/Jahreslisten, Nr. 1367.

430 PARAVICINI 1982, S. 132, Anm. 6: »Hz. Johann verteilte zum 1. Januar 1411 Neujahrsgeschenke (estrennes) an 26 chambellans, 226 gentilshommes und 300 serviteurs seiner Hofhaltung.« Vgl. HENWOOD 1982, S. 157, vgl. LABORDE, Notice des émaux, bijoux et objets divers, Bd. 1, 1852, Nr. 122-124. Die Personen sind größtenteils bekannt und könnten deshalb einzeln aufgeführt werden, aber es fehlt hier an Belegen.

431 Siehe Anhang - Katalog/Jahreslisten, Nr. 1508. Vgl. VaughaN 1966, S. 234: »In 1411 he presented 200 gold planes to the gentlemen of his household and 300 silver ones to the servants.《

432 Vgl. PlanChER, MERLE, Histoire générale et particulière de Bourgogne, Bd. 3, 1748, S. 304.

433 Anhang - Katalog/Jahreslisten, Nr. 1484-1486, siehe La Chronique d'Enguerran de Monstrelet, ed. DOUËT D'ARCQ, Bd. 2, 1858, Buch I, Kap. 59, S. 57f. Hierzu auch oben S. 92ff. mit Anm. 92-103.

434 Anhang - Katalog/Jahreslisten, Nr. 1479. Jean de Foix sollte möglicherweise als profranzösischer Fürst auf die burgundische Linie gebracht werden. Sechs Jahre später war der Graf zunächst auf Seiten der Armagnacs und verwaltete mit Bernhard von Armagnac die 
sischen ${ }^{435}$ und einen spanischen Gesandten ${ }^{436}, \mathrm{zu}$ dem beträchtlichen Wert von 14.000 Goldflorenen 437 . Was es allerdings mit den VIIf IIII ${ }^{Y X}$ VI ruches d'argent blanc en chascune ruche, une mouche d'or souldix sowie den weiteren CIII ruches d'argent doré; en chascune ruche, une mouche d'or souldix und $X X$ ruches $d^{\prime}$ 'or ${ }^{438}$ auf sich hatte, konnte nicht eruiert werden ${ }^{439}$. Vermutlich handelte es sich um einen ebenso symbolträchtigen Gegenstand wie es der Hobel im »Krieg der Zeichen $₫ 440$ war. Ebenso konnte die Bedeutung der $V I^{X X}$ I panais, die Johanns Sohn Philipp, der spätere Herzog von Burgund, 1411 in den Geschenkverkehr zum neuen Jahr einbrachte, nicht erschlossen werden ${ }^{441}$. Grundsätzlich gilt mit den Worten Colette Beaunes: "[...] les devises médiévales sont plus difficiles à saisir, mais elles signifient un pouvoir et ne sont pas un jeu intellectuel. Partis politiques et gouvernements se reconnaissent à leurs couleurs et devises qui sont des programmes, reflets des préoccupations du moment $\star^{442} .1410$ war nur wenig später als zwei Jahre nach dem 1407 erfolgten Mord an Ludwig von Orléans auf Betreiben Johanns Ohnefurcht am Vorabend der Liga von Gien, die am 15. April 1410

Dauphiné, wechselte einmal auf die burgundische Seite, kehrte aber wieder zur Partei des Dauphins zurück und war schließlich 1436 gouverneur des Languedoc.

435 »[...] un autre [niveau de maçon, J.H.] à celui [der ambassadeur, J.H.] d'Aragon [...]«, siehe PlanCHER, MERLE, Histoire générale et particulière de Bourgogne, Bd. 3, 1748, S. 304. Anhang - Katalog/Jahreslisten, Nr. 1486.

436 „Il donna un de ces niveaux à l'Ambassadeur d'Espagne, qui résidoit auprès de lui«, siehe PLANCHER, MERLE, Histoire générale et particulière de Bourgogne, Bd. 3, 1748, S. 304. Siehe Anhang - Katalog/Jahreslisten, Nr. 1485.

437 Nach La Chronique d'Enguerran de Monstrelet, ed. DOUËT D'ARCQ, Bd. 2, 1858, Buch I, Kap. 59, S. 58. Bestätigend HENwOOD 1982, S. 157 nach BNF, Coll. de Bourgogne, vol. LIV, fol. 266-267v, wonach Johann Ohnefurcht dem Pariser Goldschmied Jean Mainfroy 17.443 écus 10 s. 4 d.p. bezahlt hat für joyaux et vaisselle. PLANCHER, MERLE, Histoire générale et particulière de Bourgogne, Bd. 3, 1748, S. 304 nach der Rechnungslegung des Jean de Noident, ACO B 1558, sprechen gar von 50.000 livres. Vgl. STRATFORD 1995, S. 46.

438 Siehe Anhang - Katalog/Jahreslisten, Nr. 1511-1513.

439 Die Zitate sind entnommen LABORDE, Les Ducs de Bourgogne, Bd. 1, 1849, S. 43, Nr. 163 und möglicherweise in der originalen Schreibweise wiedergegeben, ruches aber übertragen als rabots zu lesen, mouche als manche (vgl. LABORDE, Glossaire, 1872: Stw. "rabot«, S. 476, der unter (C) notiert: »Pour vicliij rabos d'or sauldis que l'on a mis et assis sur les manches«) ist nicht überzeugend.

440 So der Titel der Dissertation von Simona SLANICKA, Basel, im Druck. Siehe vorerst SLANICKA 2000. Zu den Devisen oben S. 193, Anm. 428.

441 Siehe Anhang - Katalog/Jahreslisten, Nr. 1541. Möglicherweise muß panais als pavois gelesen werden. Im selben Jahr hatte Ludwig von Guyenne zum Neujahrstag 187 esprenier [Sperber] d'or esmaillez de blanc et plantez assis sur deux branches a tout la racine dessous verteilt, BNF ms.fr. 32511, fol. 5v, siehe auch Commission du Vieux Paris, Bulletin 1999, Nr. 8, S. 13ff., hier S. 18 mit Anm. 7, freundlicher Hinweis von Werner Paravicini, Paris.

442 BEAUNE 1985, S. 464f., siehe auch BEAUNE 1981. Im 15. Jh. ist mit dem Begriff devise das figürliche Zeichen benannt worden, nicht das (begleitende) Motto, das als mot bezeichnet wurde. 
gegründet wurde und den Gegensatz zwischen Armagnacs und Bourguignons manifest werden ließ, der Punkt erreicht, an dem die Parteien auch unter $\mathrm{Zu}$ hilfenahme des Geschenkverkehrs zum neuen Jahr ihre Anhänger um sich scharten. Zwar ließ der Friede von Bicêtre vom 2. November 1410 den Kontrahenten noch eine kurze Atempause, aber schon im April 1411 begannen die feindseligen Handlungen, was in der Folge sicherlich auch zu Einflüssen auf den Geschenkverkehr geführt haben könnte.

Einem ganz anderen Einfluß mögen Geschenke unterlegen gewesen sein wie die ymage de saint Michel, sur un entablement tout d'or, garni de $\mathrm{IX}$ balais, VI safirs et LXXII perles ${ }^{443}$, eine kostbare Goldschmiedeplastik, die Philipp der Kühne Karl VI. 1397 geschenkt hat ${ }^{444}$. Die symbolische Bedeutung dieses Geschenks liegt darin begründet, daß der heilige Michael ebenso Nationalheiliger wie Schutzpatron des Rittertums und der Mont Saint-Michel Wallfahrtsziel nicht zuletzt des Königs selbst zum Zweck seiner Gesundung war ${ }^{445}$ - die im Januar 1395 geborene Königstochter Michelle trägt seinen Namen.

Bedingtheiten können auch Notwendigkeiten gewesen sein. Notwendig waren aus Sicht der Beschenkten vermutlich auch die finanziellen Zuwendungen zum neuen Jahr, wenn es sich beispielsweise um Musiker ${ }^{446}$ oder Herolde handelte. Am Neujahrstag 1386 erhielten deux petiz heraulx von Johann von Berry jeweils einen kleinen fermaillez a facon d'oreilles ${ }^{447} .1387$ belohnte Philipp der Kühne seine eigenen Musiker ${ }^{448}$ und solche des

443 BNF, Coll. de Bourgogne, vol. LIII, fol. 167, vgl. PETIT 1888, S. 555ff. - Vgl. auch DAviD 1947, S. 61 und v.a. KovaCs 1975, S. 28ff. zur sstatuette de saint Michel à Ingolstadt et l'apparition des émaux sur or en ronde-bosse«, hier insbes. S. 29 und 32, Anm. 13.

444 Anhang - Katalog/Jahreslisten, Nr. 824. 1394 hatte Karls Tochter Maria, die Nonne in Poissy war, ihrem Vater une statuette de vermeil de saint Michel geschenkt, siehe Anhang Katalog/Jahreslisten, Nr. 614.

445 Vgl. etwa AUTRAND 1986, S. 325f. Siehe auch SCHMIDT 1981, S. 149-157, hier v.a. S. 157.

446 Siehe auch oben S. 56, Anm. 91.

447 Siehe Anhang - Katalog/Jahreslisten, Nr. 155.

448 MARCHAL-VERDOODT 1971 kennt in ihrer Auswertung der comptes Philipps des Kühnen von 1383 bis 1389 neben den von mir erwähnten ménestrels des Herzogs noch Louis Ambier, Nicolas de Condom (trompette des Herzogs), Guillemot, Willemot de Hucorne, Jacot und Louiset. MARIX 1974, pass. behandelt u.a. auch die Musiker Philipps des Kühnen. S. 17 nennt sie Nicolas d'Alfous, Jehan Dynant, Loyset Mulier, Jossequin de Jardins, Villemote de Honcoigne, Senville, Claux le Taborin und Nicolas la trompete nach ACO B 1462, fol. 100 (siehe MARIX 1974, S. 17, Anm. 2). Ebd., S. 13 wird noch der Organist Jean Oudanck erwähnt, S. 88f. (nach: Inventaires mobiliers, hg. von PROST, PROST, Bd. 2, 19081913, S. 191, Nr. 1237) der harpeur und valet de chambre Baudenet de Reims (1385), siehe ebd., S. 88, Anm. 1. Siehe neuerdings ClOUZOT 1999. 
Königs 449 mit 100 fr. ${ }^{450}, 1389$ erhielten Herolde ${ }^{451}$ und Musiker von ihm $60 \mathrm{fr} .{ }^{452}$. Für 1386 können einige Namen der burgundischen Musiker den Rechnungen entnommen werden: Jean de Dinant, Jossequin de Jardins, Louiset Moullié, Nicolas d'Alfous, Nicolas Claux und Nicolas La Trompette bekamen von Philipp jeweils 12 fr. 10 s. ${ }^{453} .1398$ war es Ludwig von Orléans, der Hennequin le Poitevin, seinen Roy des menestriers ${ }^{454}$, Jean de Pontoise, einen Musiker des Königs, und andere menestriers du roy et de nos seigneurs des fleurs de liz $^{455}$ mit insgesamt 20 écus entlohnte ${ }^{456}$. Bei der Feier, die 1398 offensichtlich in Paris stattgefunden hatte, fehlte nach der unten gegebenen Aufstellung nur Philipp der Kühne, der sich in Arras aufhielt ${ }^{457}$. Anwesend waren damit neben Ludwig zumindest der König und die Königin und der Herzog von Berry mit ihrem jeweiligen Gefolge. 1407 schließlich scheint eine ähnliche Neujahrsfeier in Lüttich am Hof Johanns von Bayern musikalisch begleitet worden zu sein. Johann von Frankreich und seine Frau Jakobäa von Bayern belohnten die Musiker ihres Gastgebers ${ }^{458}$ mit sechs couronnes ${ }^{459}$.

Bedingte und benötigte Geschenke sind mithin ebenso wie geschickte und behaltene Gaben nur ein Moment des Geschenkverkehrs, nicht generell bestimmend für den Gabentausch. Allein an den Geschenken ausgerichtete Studien geben aber nach Zahl, Wert und Beschaffenheit keinen Aufschluß über eine entscheidend andere Ausrichtung des höfischen Geschenkverkehrs als diejenige an bestehenden Beziehungen und die Orientierung der Schenkvorgänge an den Personen. Ob Beobachtungen dieser sich im vorlie-

449 Zu den Musikern Karls VI. vgl. PIRRO 1930, pass. und MARIX 1974, pass. MARCHALVERDOODT 1971 nennt die königlichen ménestrels Contoux, Crenisse, Hence, Jaquinot und Triboul.

450 Anhang - Katalog/Jahreslisten, Nr. 236.

451 MARCHAL-VERDOODT 1971 weist in ihrer Indizierung der comptes Philipps des Kühnen von 1383 bis 1389 keinen Burgund zuzuordnenden Herold nach.

452 Anhang - Katalog/Jahreslisten, Nr. 301.

453 Ebd., Nr. 177-179, 182-184.

4541377 noch in Diensten Ludwigs von Anjou, vgl. PIRRO 1930, S. 3.

455 Siehe Graves 1913, S. 154, Nr. CIV nach BNF n.a.fr. 3639, Nr. 313 (vgl. Graves 1913, S. 278, Nr. CIV).

456 Siehe Anhang - Katalog/Jahreslisten, Nr. 892, Nr. 895, 903.

457 Siehe Anhang - Neujahrstage und Aufenthaltsorte 1381-1422, 1. Januar 1398.

458 Musiker des Johann von Bayern. GRANDEAU 1968, 674 nach ADN B 12377 (GRANDEAU 1968, S. 674, Anm. 2, ohne fol.-Angabe): "[...] qu'il [Jean duc de Touraine, Johann von Frankreich, J.H.] pensionnât des ménestrels ne prouve en aucune manière qu'il fût sensible à la musique.«

459 GRANDEAU 1968, S. 674 nach ADN B 12377 (GRANDEAU 1968, S. 674, Anm. 2, ohne fol.-Angabe): "As menestrels monseigneur de Liege a esteit donné de courtesie pour avoir veuilleit devant monseigneur et madame de Thouraine le jour de l'an et le jour des rois, VI coronnes dou roy - die Musiker wurden bezahlt, nicht beschenkt, aber am "jour de l'an «, weshalb diese Angabe Aufnahme in die Untersuchung fand. Siehe Anhang - Kata$\log /$ Jahreslisten, Nr. 1384. 
genden Geschenkverkehr spiegelnden Beziehungen und die Verdichtung von Schenkakten im zeitlichen Verlauf und in der Gesamtschau, von denen bereits einige qualitative und quantitative Aspekte herausgearbeitet werden konnten hier sei nur die Bedeutung Philipps des Kühnen als Schenker und die Bedeutung Johanns von Berry als Beschenkter herausgestrichen -, weitere Erkenntnisse liefern, möglicherweise dies der statistische Ort ist, der sensiblere Reaktionen auf Umweltbedingungen offenbart und in eindeutigeren Orientierungen die offensichtlich personengebundene Wertehierarchie der Geschenke bestätigt, soll in den folgenden Abschnitten geprüft werden.

\section{Schenker und Beschenkte}

a) Rang und Gewicht

Die oben gezeigte Tabelle 2 nennt die nach Zahl der Teilnahme an mindestens zehn Schenkvorgängen wichtigsten Schenker und Beschenkten. Diese Tabelle zeigt mithin nur einen Ausschnitt derer, die am höfischen Geschenkverkehr direkt in diesen Funktionen beteiligt waren, bezieht in die Zahl der Schenkvorgänge aber auch all die unbekannten Personen ein, die beschenkt wurden, deren Zahl sich also als Schenkvorgänge auf Seiten der namentlich bekannten Schenker niederschlug, und die schenkten, deren Zahl sich also in diesem Sinn auf Seiten der namentlich Beschenkten wiederfindet. Insgesamt können auf Grundlage der verarbeiteten Überlieferung 373 schenkende und beschenkte Personen namhaft gemacht werden (ohne den »Bischof der Narren«), darunter 79 Frauen, etwa $21 \%$, und 294 Männer, etwa $79 \%$. Im folgenden sollen ausschließlich diese namentlich bekannten Schenker und Beschenkten, zunächst nach Schenkvorgängen, also nach Bindungshäufigkeiten, betrachtet werden.

Insgesamt traten - siehe Tabelle 4-143 namentlich bekannte Personen als Schenker in Erscheinung, darunter 22 Frauen, die 1.791 Schenkvorgänge vornahmen, von denen die Frauen wiederum 287 tätigten. $\mathrm{Zu}$ den Frauen gehörten (die Anzahl der von ihnen bestimmten Schenkvorgänge steht in Klammern) Valentina Visconti (127), Isabeau de Bavière (91), Margarete von Flandern (13), Margarete von Bayern (11), Marie de Berry (6), Christine de Pisan (5), Jeanne de Boulogne (5), Marie de Sully (5), Bonne de Berry (3), Charlotte de Bourbon (3), Anna von Bourbon (2), Béatrix de Navarre (2), Bonne d'Artois (2), Isabella von Frankreich (2), Katharina von Alençon (2), Margarete (II.) von Burgund (2), Anne d'Auvergne (1), Antoinette de Beaufort (1), Jakobäa von Bayern (1), Jeanne de Peschin (1), Michelle von Frankreich (1) und Yolande von Aragon (1). Auf den personellen Gesamtbestand der Schenker bezogen, machte die »Frauenquote « knapp über $15 \%$ aus, innerhalb der Spitzengruppe aber etwa 28,5\%. Der Frauenanteil an den Schenkvorgängen 
lag jedoch bei nur $16 \%$. Die Gesamtrangfolge nach Bindungsqualität ist in Tabelle 4 nachgewiesen, dabei wurden den in der Spalte der Schenkvorgänge stehenden Angaben kursiv gesetzt personenbezogene Jahresdurchschnittszahlen beigegeben, die bei den ersten 13 Rängen berücksichtigen, daß nicht jeder Schenker den Gesamtzeitraum erlebte (bei Ludwig von Guyenne und Karl [VII.] gerechnet ab Thronanwartschaft, bei Karl von Orléans gezählt ab 1409 nach dem Tod Valentinas bis zu seiner Gefangennahme in der Schlacht von Azincourt 1415).

\begin{tabular}{|c|c|c|}
\hline Rang & Schenker & Zahl der Schenkvorgänge \\
\hline 1 & Philipp der Kühne & 30,95 \\
\hline 2 & Johann Ohnefurcht & 10,13 \\
\hline 3 & Ludwig von Orléans & 5,00 \\
\hline 4 & Valentina Visconti & 6,68 \\
\hline 5 & Karl VI. & 2,21 \\
\hline 6 & Isabeau de Bavière & 2,52 \\
\hline 7 & Karl (VII.) & 10,00 \\
\hline 8 & Johann von Berry & 1,25 \\
\hline 9 & Karl von Orléans & 3,71 \\
\hline 10 & Margarete von Flandern & 0,52 \\
\hline 11 & Philipp der Gute & 4,00 \\
\hline 12 & Ludwig von Guyenne - Margarete von Bayern & $11 \quad$ L.: $0,78 / \mathrm{M} .: 0,29$ \\
\hline 13 & Guy de La Trémoille & 0,52 \\
\hline 14 & $\begin{array}{l}\text { Ludwig II. von Bourbon - Ludwig von Male - } \\
\text { Martin Gouge }\end{array}$ & 8 \\
\hline 15 & Robinet d'Etampes & 7 \\
\hline 16 & $\begin{array}{l}\text { Charles d'Artois - Guillaume de Lodes - Marie } \\
\text { de Berry - Pierre de Gynes - Richard II. - Simon } \\
\text { Aligret }\end{array}$ & 6 \\
\hline 17 & $\begin{array}{l}\text { Arnoul Belin - Christine de Pisan - Erard Mori- } \\
\text { set - Guillaume de Boisratier - Jeanne de } \\
\text { Boulogne - Johann I. von Bourbon - Louis de } \\
\text { Vendôme - Ludwig II. von Anjou - Marie de } \\
\text { Sully - Michel le Beuf }\end{array}$ & 5 \\
\hline 18 & Bernhard VII. von Armagnac - Jean de La Barre & 4 \\
\hline 19 & $\begin{array}{l}\text { Beraud III d'Auvergne - Bonne de Berry - } \\
\text { Charlotte de Bourbon - Guichard Dauphin - } \\
\text { Guillaume de La Trémoille - Jean de Cande - } \\
\text { Johann von Frankreich- Ludwig der Bärtige - } \\
\text { Macé Heron - Philipp von Burgund - Waleran } \\
\text { von Luxemburg }\end{array}$ & 3 \\
\hline 20 & $\begin{array}{l}\text { Anna von Bourbon - Baude de Guy - Béatrix de } \\
\text { Navarre - Bonne d'Artois - Charles d'Albret - } \\
\text { Gérard du Puy - Guillaume Lorin - Isabella von } \\
\text { Frankreich - Jean I d'Alençon - Jean IV } \\
\text { d'Armagnac - Jean Canard - Jean de Montaigu - } \\
\text { Katharina von Alençon - Margarete (II.) von } \\
\text { Burgund - Oudart de La Barre - Renier de } \\
\text { Bouligny - Renier Pot - Thibaut Portier }\end{array}$ & 2 \\
\hline
\end{tabular}




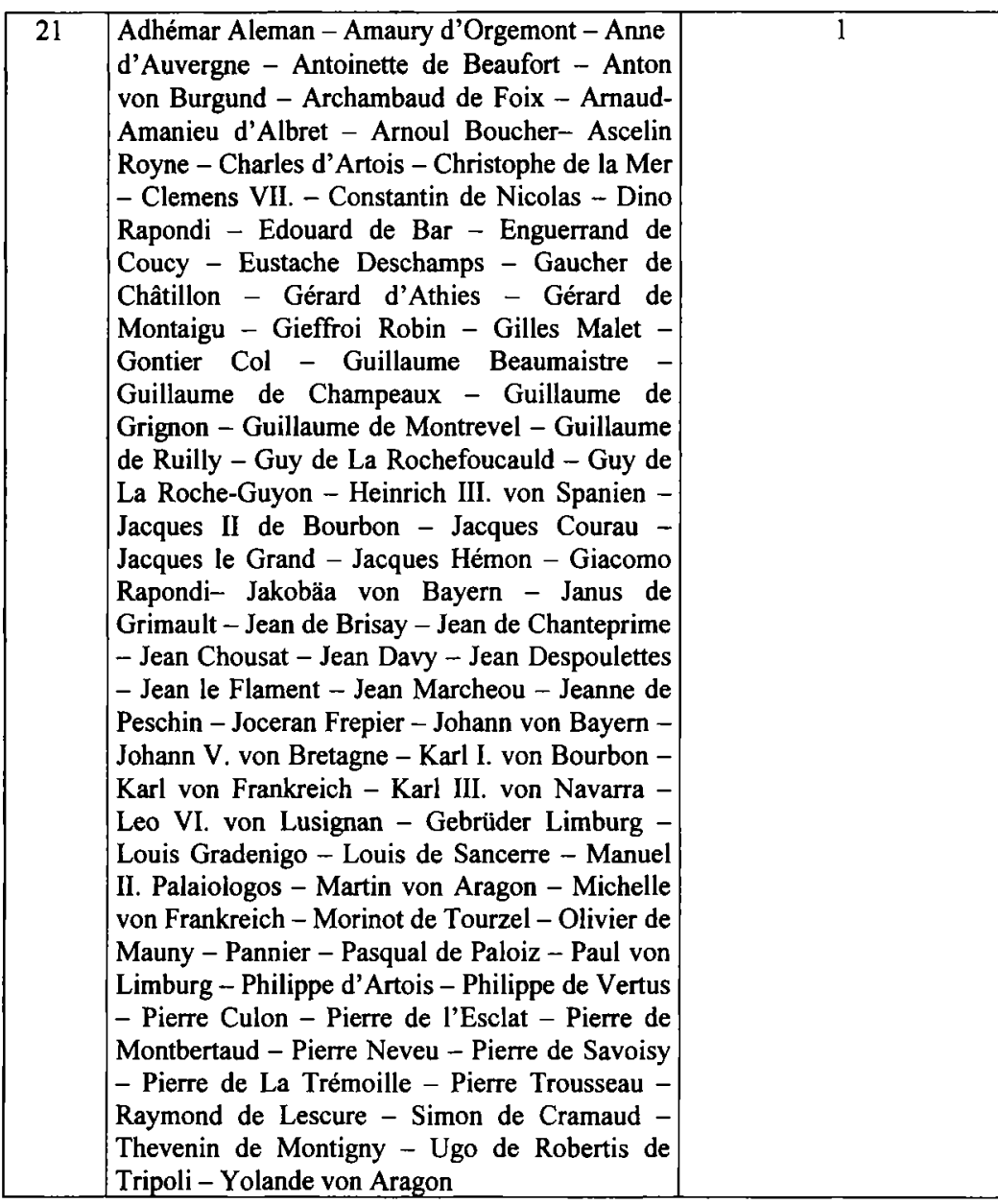

Tab. 4: Teilnehmer des höfischen Geschenkverkehrs nach Schenkvorgängen - Schenker

An der Spitze derer, denen ein ausgeprägtes Streben nach höfisch-reziprok bestimmten Anerkennungszuweisungen und Beziehungsmacht unterstellt werden kann, stehen, mit großem Abstand voneinander, Burgund und Orléans, gefolgt vom Königshaus, dem Herzog von Berry, Karl von Orléans und wieder Burgund. Ludwig von Guyenne gehörte dem Königshaus an, Margarete von Bayern wie auch Guy de La Trémoille Burgund. Erst ab dem 14. Rang wird der Personenbestand disparat. Eine Modifikation der Reihenfolge innerhalb der Führungsgruppe erfolgt, wenn die letzten Ziffern betrachtet werden. Deutlich wird, daß Philipp der Kühne, obwohl er 1404 starb, seine führende und damit den höfischen Geschenkverkehr bestimmende Position mit Abstand auch gegenüber denjenigen behaupten konnte, die wie der König den gesamten Zeitraum die Möglichkeit gehabt hätten, dem Geschenkverkehr ihren 
Stempel zumindest in quantitativer Hinsicht aufzudrücken. Daß der König aufgrund seiner Krankheit nicht als vollwertiger Teilnehmer angesehen werden kann, scheint nicht von Bedeutung gewesen zu sein, denn andere Personen, die nur phasenweise in den Geschenkverkehr eintraten, belegen dennoch hohe Ränge. Dies ist besonders bei Philipp dem Guten und Karl (VII.) der Fall. Der Burgunder wurde erst ab 1420 gewertet, belegte aber trotzdem die sechste Position, Karl erreicht den dritten Rang, obwohl er erst ab 1418 nach dem Tod seines Bruders Johann 1417 wertend einbezogen wurde. Auch Karl von Orléans ist in dieser Hinsicht eine Ausnahmeerscheinung. Er geriet 1415 in englische Gefangenschaft und steht dennoch an siebter Stelle. Ludwig von Male, dessen Durchschnittszahl nicht notiert ist, würde, obwohl er 1384 verstarb, auf den neunten Rang vorrücken. Der Idealfall bleibt Philipp der Kühne, der, dies konnte mehrfach gezeigt werden, aktiv, d.h. als Schenker, am Schengeschehen beteiligt war und mit einer hohen Bindungsziffer bei beträchtlichem finanziellen Einsatz den höfischen Geschenkverkehr nicht nur punktuell prägte.

Auf der Seite der Beschenkten zeigt sich ein ähnliches Bild (Tabelle 5). Erneut beigegeben wurden in der folgenden Tabelle kursiv gesetzt personenbezogene Jahresdurchschnittszahlen, die bei den ersten 10 Rängen berücksichtigen, daß nicht jeder Beschenkte den Gesamtzeitraum erlebte. 298 namentlich bekannte Einzelpersonen konnten erfaßt werden ${ }^{460}$, darunter 67 Frauen, die bei insgesamt 1.391 Schenkvorgängen 386 auf sich ziehen konnten. Eine »Frauenquote« also von gut $22,5 \%$ bei einem Anteil von etwas mehr als $27 \%$ an allen Schenkvorgängen. Das bedeutet, daß bei den Beschenkten der Frauenanteil insgesamt und ihr Anteil an den Schenkvorgängen im Vergleich zu ihren Anteilen in der Gruppe der Schenker um jeweils circa 7\% höher war. In der aus 24 Personen bestehenden Spitzengruppe mit zehn und mehr Schenkvorgängen waren zehn Frauen ${ }^{461}$, so daß sich in diesem Bereich ein Frauenanteil von knapp $42 \%$ ergibt, der wiederum um etwa 14\% höher ist als derjenige der Frauen in der Spitzengruppe der Schenker. Daraus kann gefolgert, aber nicht verallgemeinert werden, daß mehr Frauen Ziel von Schenkakten waren, als daß Frauen selbst aktiv in das Schenkgeschehen eingegriffen

460 Wegen jeweils nicht eindeutiger Identifikation sind der »Bischof der Narren«, die Musiker Karls VI. und Philipps des Kühnen, verschiedene Herolde, der Comte de Ventadour, die Dame de Lacques (Marie de Poix?, siehe Inventaires mobiliers, hg. von PROST, Prost, Bd. 1, 1902-1904, S. 567, Anm. 3), die Dame de Maucouvent, Madame de Marcoussis und Mademoiselle de Luxembourg, M. Raguier, M. de Labitfroste, der Seigneur de Châtillon, der Sire d'Andegnies, der Sire de La Roche, die Frau des Jean Culdoe, der Sire du Gavre und der Sire de Monceaux sowie ein nicht bestimmbarer La Trémoille aus-geklammert worden.

461 Margarete von Flandern (55) - Isabeau de Bavière (51) - Margarete von Bayern (32) Valentina Visconti (21) - Marie de Sully (16) - Margarete (II.) von Burgund (14) - Bona von Burgund (11) - Isabella von Frankreich (11) - Maria (I.) von Burgund (11) - Katharina (I.) von Burgund (10). 
hätten. Dies ließe sich wiederum in Einklang bringen mit einigen Quellenbefunden, die besagen, daß die Fürsten die Kosten für die Geschenkaufwendungen ihrer Frauen mittrugen. Sogar das Neujahrsgeschenk, das Ludwig von Orléans von seiner Frau Valentina 1401 erhielt - un hanap d'or seizelle a arbres a un fretelet garny zu $274 \mathrm{fr} .{ }^{462}$-, ist offenbar von ihm selbst finanziert worden ${ }^{463}$. Ob dies auch eine Art Mitbestimmungsanspruch evozierte, muß dahingestellt bleiben; die weiter unten gegebenen Tabellen zu einigen Beziehungsqualitäten enthalten dann entsprechend auch keine den Fürsten zuzuordnenden zeitgleichen Schenkaktivitäten ihrer Frauen oder anderer Angehöriger ihrer Familien oder ihrer Hofhaltungen.

\begin{tabular}{|c|c|c|}
\hline Rang & Beschenkte & Zahl der Schenkvorgänge \\
\hline 1 & Johann von Berry & $248 \quad 6,88$ \\
\hline 2 & Karl VI. & 1,69 \\
\hline 3 & Philipp der Kühne & 2,87 \\
\hline 4 & Ludwig von Orléans & 2,33 \\
\hline 5 & Margarete von Flandern & 2,20 \\
\hline 6 & Isabeau de Bavière & 1,37 \\
\hline 7 & Johann Ohnefurcht & 2,80 \\
\hline 8 & Margarete von Bayern & 0,86 \\
\hline 9 & Valentina Visconti & 1,10 \\
\hline 10 & Ludwig II. von Bourbon & 0,63 \\
\hline 11 & Anton von Burgund - Guy de La Trémoille & 18 \\
\hline 12 & Jean Canard & 17 \\
\hline 13 & Marie de Sully & 16 \\
\hline 14 & Margarete (II.) von Burgund - Philippe de Bar & 14 \\
\hline 15 & $\begin{array}{l}\text { Guillaume de La Trémoille - Karl von Frank- } \\
\text { reich - Pierre de Navarre }\end{array}$ & 12 \\
\hline 16 & $\begin{array}{l}\text { Bonne de Burgund - Isabella von Frankreich - } \\
\text { Maria (I.) on Burgund } \\
\end{array}$ & 11 \\
\hline 17 & Katharina (I.) von Burgund & 10 \\
\hline 18 & Charles d'Albret - Jeanne de Saint-Pol & 9 \\
\hline 19 & $\begin{array}{l}\text { Philippe d'Artois - Catherine de Fastavarin - } \\
\text { Ludwig der Bärtige - Philipp der Gute }\end{array}$ & 8 \\
\hline 20 & $\begin{array}{l}\text { Ludwig von Guyenne - Marie de Duisy - } \\
\text { Michelle von Frankreich - Philipp von Burgund } \\
\text { - Pierre de La Trémoille - Renier Pot }\end{array}$ & 7 \\
\hline 21 & $\begin{array}{l}\text { Arnaud-Amanieu d'Albret - Jean de Montaigu - } \\
\text { Jean de Saulx - Jean de Vienne - Maria (II.) von } \\
\text { Burgund }\end{array}$ & 6 \\
\hline 22 & $\begin{array}{l}\text { Catherine de Villiers - Femmette - Guy de La } \\
\text { Rochefoucauld - Jeanne de Montueil - Jeanne de } \\
\text { La Tour - Johanna von Frankreich - Ludwig II. } \\
\text { von Anjou - Ludwig von Male - Marguerite de } \\
\text { Germonville - Maria von Frankreich }\end{array}$ & 5 \\
\hline
\end{tabular}

462 BNF n.a.fr. 20028, Nr. 5 , siehe GRAVES 1913, S. 177f., Nr. CXVII.

463 BNF n.a.fr. 20028, Nr. 5, hier S. 178: duquel hanap nostre dite compaigne nous a estrenné. 


\begin{tabular}{|c|c|c|}
\hline 23 & $\begin{array}{l}\text { Alips de Beauchamp - Charles de Savoisy - } \\
\text { Gilles Malet - Guillaume Martel - Isabelle La } \\
\text { Bouteillière - Jean de Hangest - Jean de Trie - } \\
\text { Jeanne de Chepoy - Johann V. von Bretagne - } \\
\text { Leo VI. von Lusignan - Margarete (I.) von } \\
\text { Burgund - Philippe de Vertus }\end{array}$ & 4 \\
\hline 24 & $\begin{array}{l}\text { Arnaud de Corbie - Arthur de Richemont - } \\
\text { Blanche - Charles d'Ivry - Enguerrand de Coucy } \\
\text { - Georges de La Trémoille - Guillaume le } \\
\text { Bouteiller - Henri de Montbéliard - Jeanne } \\
\text { d'Harcourt - Jeanne de Soisy - Jeanne de } \\
\text { Vendôme - Jehanne - Karl I. von Bourbon - } \\
\text { Karl von Orléans - Katharina von Frankreich - } \\
\text { Louis de Sancerre - Marie de Berry - Oudard de } \\
\text { Chazeron - Philippe de Moulins - Pierre (II) } \\
\text { d'Orgemont - Regnaut d'Angennes - Robert } \\
\text { d'Aunoy - Surien des Quesnes - Wilhelm von } \\
\text { Bayern }\end{array}$ & 3 \\
\hline 25 & $\begin{array}{l}\text { Agnes von Burgund - Alain de Beaumont - } \\
\text { Amadeus VIII. von Savoyen - Anna von } \\
\text { Burgund - Bendikt XIII. - Charles d'Artois - } \\
\text { Charles de Châtillon - Clemens VII. - Dino } \\
\text { Rapondi - Gilles de Bretagne - Guichard } \\
\text { Dauphin - Guillaume de Bours - Guillaume de } \\
\text { Senlis - Guillemette de Flacourt - Guy de La } \\
\text { Roche-Guyon - Jacques de Peschin - Jean } \\
\text { d'Angoulême - Jean de Chevenon - Jean Coeur } \\
\text { - Jean de Graville - Jean de Luxembourg - Jean } \\
\text { Marchand - Jean le Meingre - Jean de Montagu } \\
\text { - Jean de Vergy - Jeanne de Dreux - Jeanne de } \\
\text { Peschin - Jehannette - Johann I. von Bourbon - } \\
\text { Johann von Frankreich - Katharina von Alençon } \\
\text { - Katharina (II.) von Burgund - Louis de Poissy } \\
\text { - Manuel II. Palaiologos - Marguerite de Landes } \\
\text { - Marguerite de Préaux - Pierre des Essarts - } \\
\text { Regnault Doriac - Richard II. - Waleran von } \\
\text { Luxemburg }\end{array}$ & 2 \\
\hline 26 & $\begin{array}{l}\text { Adam Chatelain - Adam de Champgiraut - } \\
\text { Alexandre Le Boursier - Anceau de Salins - } \\
\text { Ansaldo Spinola - Antoine de Craon - Antoine } \\
\text { Forestz - Archambaud de Foix - Armel de } \\
\text { Châteaugiron - Ascelin Royne - Bernard d'Asuel } \\
\text { - Bernhard VII. von Armagnac - Bernhard VIII. } \\
\text { von Armagnac - Berthelot Helyot - Bertrand de } \\
\text { Rochefort - Boniface - Bonne d'Armagnac - } \\
\text { Bonne de Bar - Charles de Chambly - Charles } \\
\text { Garnier - Charles de Hangest - Charles Labbé - } \\
\text { Charles de Luxembourg - Charles Poupart - } \\
\text { Charles de La Rivière - Charles de Rohan - } \\
\text { Charles de Soyecourt - Chatart de Rochedragoux } \\
\text { - Colard de Villequier - Denis de Chesne - Elion }\end{array}$ & 1 \\
\hline
\end{tabular}


de Neilhac - Estienne - Gilbert Motier de La Fayette - Gilles de Vrolende - Girard de Rigny Guillaume d'Aumay - Guillaume d'Avaugour Guillaume du Bez - Guillaume Boniface Guillaume de Champdivers - Guillaume Cousinot - Guillaume II de Craon - Guillaume de Lucé - Guillaume IV de Melun - Guillaume Paynel - Guy de Pontaillier - Hannequin Hennequin le Poitevin - Henri du Mesnil - Henri de Savoisy - Hermant - Hemauton d'Andines Hervé de Mauny - Hue d'Amboise - Hugues de Chalon - Isabeau de Barres - Isabella von Burgund - Isabelle de Coucy - Jacot Blanchet Jacques II de Bourbon - Giacomo Rapondi Jacques de la Rivière - Jacques de Trie - Jacques de Villiers - Jakobäa von Bayern - Jean d'Arpajon - Jean de Bétizac - Jean de Bonnay Jean Boschet - Jean I de Bourbon - Jean Cadart - Jean de Croy - Jean Davy - Jean de Dinant Jean de Dunois - Jean Fale - Jean Flamel - Jean de Foix - Jean de Fontaines - Jean de Gaules Jean Gouffier - Jean d'Harcourt - Jean de Holland - Jean de Juch - Jean Louvet - Jean Martel - Jean Nau - Jean de Pontoise - Jean de Poquières - Jean Pouquet - Jean de Puligny Jean de Rochechouart - Jean du Rupt - Jean de Tancarville - Jean de Toulongeon - Jean de La Trémoille - Jean de Velery - Jean le Voyer Jeanne - Jeanne de Boulogne - Jeanne de Bourbon - Jeanne de Châtillon - Jeanne de Houdetot - Jeanne de Luxembourg - Jeanne d'Orléans - Jeanne de Salçay - Jeanne Flotte Jeanne la Brune - Jehanncon - Johan Rodrigues - Johann IV. von Bretagne - Johann VI. von Bretagne - Johann von Brabant - Johann von Frankreich - Jossequin de Jardins - Karl (VII.) Karl III. von Navarra - Leopold IV. von Österreich - Gebrüder Limburg - Louis de Vendôme Louiset Moullié - Ludwig - Mabillette - Marguerite d'Orléans - Marguerite de Neufmoulin Marguerite du Solier - Marguerite Spissau Marie de Blaringhehem - Marie la Mayence Marie de Quiemieu - Morelet de Carville Morinot de Tourzel - Nicholas Feynat - Nicolas Claux - Nicolas d'Alfous - Nicolas La Trompette - Nicole d'Estrée - Oudart de L'Epinace Pasqual de Paloiz - Perrin Guire - Peter von Genf - Philibert de Maleret - Philippe de Bourgogne - Philippe de Florigny - Philippe de Jaucourt - Philippe Musier - Philippe de Savoisy - Pierre de Chantelle - Pierre de Craon - Pierre de Fontenay - Pierre Gorremont - Pierre de Montbertaud - Pierre de Villaines - Prégent de 


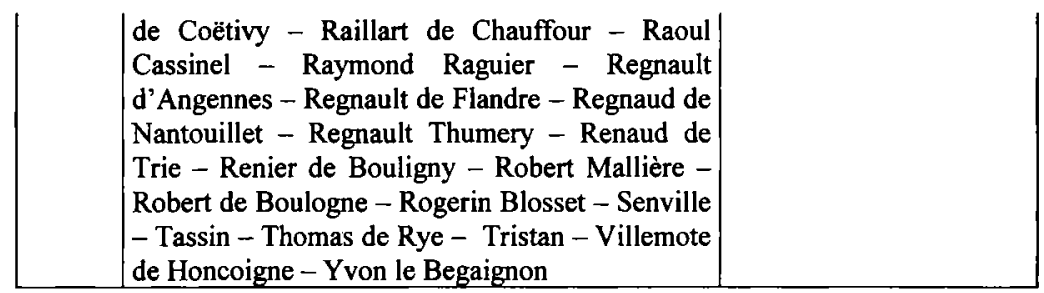

Tab. 5: Teilnehmer des höfischen Geschenkverkehrs nach Schenkvorgängen - Beschenkte

In der Spitzengruppe finden sich in veränderter Reihenfolge einige der schon aus der Tabelle der Schenker bekannten Namen wieder. An die erste Stelle gerückt ist der Herzog von Berry, dem dieser Rang auch unter Berücksichtigung der Tatsache, daß er 1416 starb, zugewiesen werden muß. Philipp der Kühne folgt ihm hinsichtlich dieses Umstandes an zweiter Stelle und auf dem dritten Rang steht in diesem Sinn dann auch schon Johann Ohnefurcht. Auch Ludwig von Orléans, Margarete von Flandern, Karl VI., Isabeau de Bavière, Valentina Visconti und Ludwig II. von Bourbon wie auch Guy de La Trémoille sind erneut vertreten. Marie de Sully, fünffache Schenkerin, erscheint nun als sechzehnfach Beschenkte, Margarete (II.) von Burgund, zweifache Schenkerin, wurde selbst vierzehnmal beschenkt. Als Rollenwechsel kann das Einrücken von Anton von Burgund, Jean Canard und Karl von Frankreich, das Ausscheiden von Karl von Orléans gedeutet werden, der nur noch dreimal beschenkt wurde. Philippe de Bar und Pierre de Navarre sind ausschließlich auf Seiten der Beschenkten notiert, dort aber an vorderer Stelle, Karl (VII.) als prominenter Schenker scheint als Ziel des Schenkens hingegen nur wenig archivalisch faßbares Interesse gefunden zu haben.

Philippe de Bar und Pierre de Navarre sind nicht die einzigen, die nur auf einer Seite des Geschenkverkehrs verzeichnet sind. Tabelle 6 reiht die Personen, die sowohl als Schenker als auch als Beschenkte auftraten, nach der Summe der Schenkvorgänge, an denen sie teilnahmen. Hintergrundüberlegung ist das Konstrukt der Reziprozität, das, wie dargestellt wurde, grundsätzlich ja nicht auf den direkten Zusammenhang von Gabe und Gegengabe angewiesen ist, als höfische Reziprozität noch nicht einmal auf den unten gesondert zu betrachtenden zeitgleich-direkten Zusammenhang einer konkreten SchenkerBeschenkter-Paarung. Hier wäre die Reihe jener, die, nach ungewerteten Schenkvorgängen sortiert, sowohl aktiv als auch passiv am Schenkgeschehen teilgenommen hatten.

Die erste Spalte nennt die quantitativ bestimmte Ranggruppe, die zweite die Namen. In der dritten Spalte ist jeweils die Summe der Schenkvorgänge notiert, an der die jeweilige Person teilgenommen hat, der zum Vergleich die Zahl der Schenkvorgänge beigegeben ist, in denen der betreffende Teilnehmer nur als Beschenkter auftrat. 


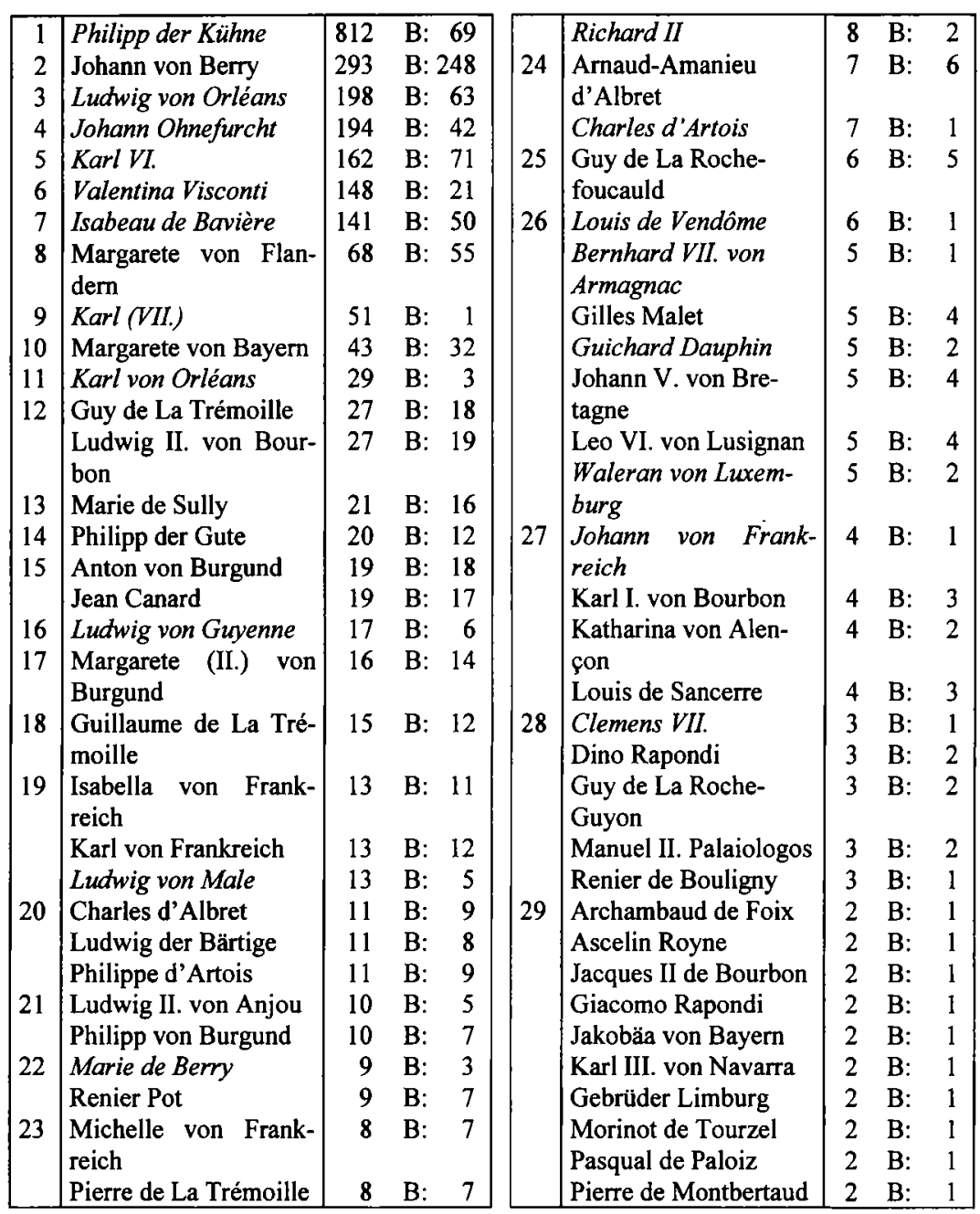

Tab. 6: Teilnehmer des höfischen Geschenkverkehrs nach Schenkvorgängen Schenker und Beschenkte (B) in einer Person

Die Tabelle zeigt, daß der Bestand dieser Gruppe mit 62 Personen deutlich kleiner ist als sowohl derjenige der Schenker als auch der Beschenkten, weil die Personen, die nur auf je einer Seite vertreten waren, und das waren in der Regel diejenigen, die nur einmaliges Ziel von Schenkakten waren, keine Berücksichtigung mehr fanden. Allerdings vereint diese Gruppe 2.561 Schenkvorgänge auf sich. Vertreten waren zehn Frauen, etwas mehr als $16 \%$, also vergleichsweise eine weder über- noch unterrepräsentierte Gruppe. Die vier Frauen in der Spitzengruppe der ersten zehn Ränge beanspruchten damit aber in dieser Gruppe einen Anteil von 40\%. Die weiblichen Mitglieder des Geschenkverkehrs nahmen an insgesamt 465 Schenkvorgängen teil und liegen 
damit mit gut $18 \%$ nur knapp über dem Prozentsatz der weiblich bestimmten Schenkvorgänge in der Gruppe der Schenker, aber deutlich unter demjenigen in der Gruppe der Beschenkten. In der Spitzengruppe konzentrieren sich allein 400 dieser Schenkvorgänge und machen damit einen Satz von knapp 19\% bei 2.110 Schenkvorgängen in den ersten zehn Rängen aus.

Die den höfischen Geschenkverkehr dominierenden Personen sind nach den Ergebnissen dieser Tabelle die schon aus den beiden vorhergehenden Tabellen bekannten Schenkerinnen und Schenker. Mit weitem Abstand an der Spitze steht Philipp der Kühne, gefolgt von Johann von Berry, dem sich ebenfalls erst mit Abstand Ludwig von Orléans und Johann Ohnefurcht anschließen. Der König, Valentina Visconti und die Königin belegen in etwa gleichauf die Ränge fünf, sechs und sieben.

Damit scheint der archivalisch faßbare höfische Geschenkverkehr im Frankreich König Karls VI. um 1400 mit einem nicht unerheblichen weiblichen Anteil männlich dominiertes Geschehen gewesen zu sein, das hauptsächlich durch die hierarchischen Spitzen des Reiches bestimmt war und sich auf die Häuser Burgund und Orléans, König und Königin und Johann von Berry konzentrierte. Die den Spitzenpositionen folgenden Ränge 11 bis 19 weisen zudem eine eindeutige burgundische Dominanz auf, und es sind burgundische Hofleute, keine Fürsten, wie Guy und Guillaume de La Trémoille und der burgundische Kanzler Jean Canard, die noch vor den Kindern Frankreichs wie Isabella und Karl rangieren, Guy de La Trémoille gar noch vor Ludwig II. von Bourbon, Philipp dem Guten, Anton von Burgund und Ludwig von Guyenne.

Die Tabellen deuten auch die jeweils kursiv gekennzeichnete Richtung der Schenkvorgänge an. Philipp der Kühne war in erster Linie Schenker, Johann von Berry Empfänger, Schenker auch Ludwig von Orléans, Johann Ohnefurcht, Karl VI., Valentina Visconti, Isabeau de Bavière, Karl (VII.) und Karl von Orléans, Empfänger hingegen Margarete von Flandern, Margarete von Bayern, Guy de La Trémoille, Ludwig II. von Bourbon oder Marie de Sully. Als Schenker zu charakterisieren sind ferner Ludwig von Guyenne, Ludwig von Male, Marie de Berry, Charles d'Artois, Louis de Vendôme, Bernhard VII. von Armagnac, Guichard Dauphin, Waleran von Luxemburg und Johann von Frankreich wie auch die beiden Mitglieder auswärtiger Höfe Richard II. und Clemens VII. Hier beginnt das Konstrukt der Reziprozität tragfähig zu werden, denn die durch Schenken charakterisierten Mitglieder der Führungsgruppe bilden einen einigermaßen homogenen Kreis, dem sich nahezu nahtlos der Großteil der anderen Personen hinzurechnen läßt. Dies scheint die Gruppe der "Standesgenossen « zu sein, die der reziprok bestimmten Ehrzuweisungen fähig ist und für die das höfische Reziprozitätsprinzip vor allem gilt. Die restlichen Mitglieder des solcherart reduzierten Geschenkverkehrs sind damit nicht »ehrlos«, sie haben die systemtheoretisch bedeutsame Rolle 
von Nichtmitgliedern, nicht bezogen auf das Gesamtsystem, aber bezogen auf die Schenkakte, denen sie zwar die Gaben zu verdanken haben, die ihnen aber nur die Rolle lassen, als Katalyt für die Prestigezuweisungen der Standesgenossen zu dienen: Ehre als Lohn von denen, denen die Großzügigkeit des eigentlichen Schenkaktes nicht galt ${ }^{464}$. Die $» D r i t t e n \ll$ theoretisch zuzuweisende wichtige Funktion als Mittel zur Desintegration von Konflikten ${ }^{465}$ läßt bei den zahlreichen Personen, die im Rahmen des höfischen Geschenkverkehrs als jeweils Dritte zu bezeichnen wären, an den Bürgerkriegskonflikt zwischen Armagnac und Bourguignons denken. Diese politische Rolle kann hier aber größtenteils ausgeschlossen werden, denn, wie gezeigt, spielte sich der Hauptteil des Geschenkverkehrs vor dem offenen Ausbruch der Konflikte ab. Andererseits wäre es natürlich denkbar, daß das Schenken als Mittel der Konfliktregulierung schon im Vorfeld eingesetzt worden ist, aber versagt hat. Dazu wiederum ist die Bedeutung des Schenkens, vor allem diejenige zum neuen Jahr, wie ausgeführt, allerdings zu gering und widerspräche ihrer Funktion als Indikator.

Bestätigend sollen noch einmal die kostbarsten Geschenke genannt werden. 1404 bekam Johann von Berry von Karl VI. den bel et gros balay longuet als Neujahrsgeschenk für die Jahre 1402, 1403 und $1404 \mathrm{zu} 18.000$ 1.466. 1403 nutzte Philipp der Kühne den Neujahrstag, um für sich selbst ein Tafelschiff zu $12.0001 . \mathrm{zu}$ erwerben ${ }^{467}$. Johann von Berry erhielt wiederum von Philipp dem Kühnen 1399 ein goldenes Kreuz, das 7.400 l. gekostet hatte ${ }^{468}, 1389$ un grant tableau de la Trinité, garny de plusieurs gros balais, gros saphirs et plusieurs grosses perles zu 6.0001 .469 und 1388 eine teure Spange zu 5.5001 .470 . Der König beschenkte Johann Ohnefurcht 1410 mit 5.000 écus $^{471}$ und 1401 Johann von Berry mit einem edelsteingeschmückten coffre zu 4.000 1.472. Von Philipp dem Kühnen bekam der König 14044.000 écus ${ }^{473}$, an neunter Stelle schließlich rangiert das Geschenk des Königs an Philipp zum Neujahrstag 1397474 und an zehnter Stelle wiederum ein "Selbstgeschenk" Philipps im Wert von 3.2001 .475 . Die Werte der nächsten 25 Ränge sind Tabelle $7 \mathrm{zu}$ entnehmen.

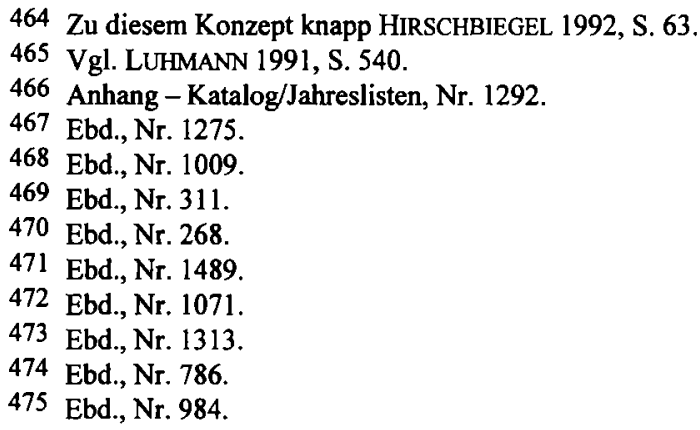




\begin{tabular}{|c|c|c|c|c|c|}
\hline Rang & Jahr & Katalognr. & Schenker & Beschenkte & Wert (1.) \\
\hline 11 & 1400 & 1046 & Philipp der Kühne & Margarete von Flandern & 3.038 \\
\hline \multirow[t]{2}{*}{12} & 1401 & 1104 & Philipp der Kühne & Karl VI. & 3.000 \\
\hline & 1402 & 1189 & Philipp der Kühne & Karl VI. & 3.000 \\
\hline \multirow[t]{2}{*}{13} & 1399 & 1011 & Philipp der Kühne & Karl VI. & 2.700 \\
\hline & 1399 & 1014 & Philipp der Kühne & Margarete von Flandern & 2.700 \\
\hline 14 & 1398 & 941 & Philipp der Kühne & Margarete von Flandern & 2.600 \\
\hline \multirow[t]{4}{*}{15} & 1395 & 686 & Philipp der Kühne & Margarete von Flandern & 2.500 \\
\hline & 1396 & 744 & Philipp der Kühne & Margarete von Flandern & 2.500 \\
\hline & 1403 & 1257 & Philipp der Kühne & Karl VI. & 2.500 \\
\hline & 1404 & 1312 & Philipp der Kühne & Karl VI. & 2.500 \\
\hline 16 & 1401 & 1107 & Philipp der Kühne & Margarete von Flandern & 2.362 \\
\hline \multirow[t]{2}{*}{17} & 1402 & 1166 & Ludwig von Orléans & Karl VI. & 2.300 \\
\hline & 1402 & 1200 & Philipp der Kühne & Margarete von Flandern & 2.300 \\
\hline \multirow[t]{3}{*}{18} & 1397 & 793 & Ludwig von Orléans & Karl VI. & 2.250 \\
\hline & 1400 & 1038 & Philipp der Kühne & Karl VI. & 2.250 \\
\hline & 1401 & 1086 & Ludwig von Orléans & Ludwig von Orléans & 2.250 \\
\hline 19 & 1403 & 1265 & Philipp der Kühne & Margarete von Flandern & 2.200 \\
\hline \multirow[t]{5}{*}{20} & 1386 & 175 & Philipp der Kühne & Guy de La Trémoille & 2.000 \\
\hline & 1388 & 267 & Philipp der Kühne & Johann von Berry & 2.000 \\
\hline & 1394 & 620 & Philipp der Kühne & Clemens VII. & 2.000 \\
\hline & 1394 & 641 & Philipp der Kühne & Philipp der Kühne & 2.000 \\
\hline & 1404 & 1319 & Philipp der Kühne & Margarete von Flandern & 2.000 \\
\hline 21 & 1397 & 835 & Philipp der Kühne & Margarete von Flandern & 1.995 \\
\hline \multirow[t]{2}{*}{22} & 1398 & 991 & Philipp der Kühne & Richard II. & 1.800 \\
\hline & 1404 & 1281 & Anton von Burgund & Philipp der Kühne & 1.800 \\
\hline \multirow[t]{3}{*}{23} & 1394 & 634 & Philipp der Kühne & Margarete von Flandern & 1.700 \\
\hline & 1396 & 733 & Philipp der Kühne & Karl VI. & 1.700 \\
\hline & 1398 & 931 & Philipp der Kühne & Karl VI. & 1.700 \\
\hline 24 & 1397 & 824 & Philipp der Kühne & Karl VI. & 1.650 \\
\hline \multirow[t]{5}{*}{25} & 1395 & 682 & Philipp der Kühne & Karl VI. & 1.600 \\
\hline & 1396 & 730 & Philipp der Kühne & Johann von Berry & 1.600 \\
\hline & 1398 & 899 & Ludwig von Orléans & Karl VI. & 1.600 \\
\hline & 1398 & 997 & Valentina Visconti & Karl VI. & 1.600 \\
\hline & 1402 & 1144 & Isabeau de Bavière & Karl VI. & 1.600 \\
\hline
\end{tabular}

Tab. 7: Teilnehmer des höfischen Geschenkverkehrs nach Geschenkhöchstwerten

Es bleibt die Frage, ob das Streben nach Anerkennungszuweisungen und Bindungsmacht in den oberen Rängen außer tatsächlich eingegangenen Beziehungen und den oben und in Tabelle 7 beispielhaft wiedergegebenen Einzelinvestitionen auch finanziellen Einsätzen des Gesamtzeitraums entsprochen hat.

Tabelle 8 zeigt die höchsten 20 Gesamtinvestitionen und es ist zu sehen, daß in den Spitzenpositionen Bindung und wertmäßiger Einsatz einander etwa entsprechen. Neu hinzugekommen sind Guillaume de Lodes, Kammerherr des Herzogs von Berry, Jeanne de Boulogne, dessen Frau, schließlich Erard Moriset, Michel le Beuf, Oudart de La Barre und Pierre de Gynes, seine Sekretäre, sowie die schon mehrfach erwähnten Guillaume de Boisratier und Martin Gouge, allerdings in beiden Fällen als jeweils gemeinschaftlich Schenkende. 
Diese Schenkakte waren ausschließlich auf Johann von Berry gerichtet und legen daher Zeugnis ab von intensiven Nahverhältnissen innerhalb des Geschenkverkehrs, haben aber keine den gemachten Aussagen für den gesamten Geschenkverkehr zuwiderlaufenden Bedeutungsgehalte. Der Parteigänger des Hauses Orléans, Louis de Vendôme, königlicher Kammerherr und 1413 maître de l'hôtel des Königs, trat ebenfalls nur als Schenker dieses Herzogs in Erscheinung. Sein letzter Schenkakt datiert von 1415, im Herbst desselben

\begin{tabular}{|l|r|}
\hline Schenker & $\begin{array}{r}\text { Ausgaben in } \\
\text { d./100.000 }\end{array}$ \\
\hline Philipp der Kühne & 778,53239 \\
Karl VI. & 129,42056 \\
Ludwig von Orléans & 96,76095 \\
Johann Ohnefurcht & 29,07565 \\
Valentina Visconti & 22,96665 \\
Karl (VII.) & 20,01600 \\
Johann von Berry & 11,02574 \\
Margarete von Bayern & 4,36368 \\
Anton von Burgund & 4,32000 \\
Isabeau de Bavière & 3,85116 \\
Margarete von Flandern & 3,84630 \\
Karl von Orléans & 3,46610 \\
Ludwig II. von Anjou & 2,20800 \\
Ludwig von Guyenne & 1,86540 \\
Guillaume de Lodes & 1,45200 \\
Jeanne de Boulogne & 1,14600 \\
Philipp der Gute & 1,02240 \\
Erard Moriset, Michel le Beuf, Oudart & 1,00080 \\
de La Barre und Pierre de Gynes & \\
Guillaume de Boisratier, Martin Gouge & 0,96000 \\
Louis de Vendôme & 0,64800 \\
\hline
\end{tabular}

Tab. 8: Teilnehmer des höfischen Geschenkverkehrs nach Ausgaben

Jahres geriet er in Folge der Schlacht von Azincourt in englische Gefangenschaft und kam erst 1427 wieder frei. Auffällig sind die hohen Investitionen Valentina Viscontis, die mit Abstand noch vor denjenigen der Königin und der etwa gleichauf liegenden Burgunderherzogin rangieren.

Tabelle 9 veranschaulicht die Seite der Beschenkten nach dem Wert aller jeweils empfangenen Geschenke. Ausgewählt wurden wieder die höchsten 20 Positionen. Diese Tabelle zeigt einige Auffälligkeiten, aber in der Gesamttendenz sind auch an dieser Stelle keine den oben erworbenen Einsichten gegenläufigen Ergebnisse zu verzeichnen. Es verwundert nicht, den Herzog von Berry auf der ersten Position zu finden, auch daß Philipp der Kühne als Beschenkter nicht den ersten Rang einnimmt, aber daß der Burgunder nach dem Wert der Geschenke, die er empfangen hat, doch mit deutlichem Abstand auf den vierten Platz verwiesen wurde, noch nach seiner Frau und dem König. Frauen sind in dieser Reihe relativ häufig vertreten, was die These der eher 


\begin{tabular}{|l|c|}
\hline Beschenkte & $\begin{array}{c}\text { Einnahmen in } \\
\text { d./100.000 }\end{array}$ \\
\hline Johann von Berry & 190,77196 \\
Margarete von Flandern & 119,85445 \\
Karl VI. & 119,70315 \\
Philipp der Kühne & 62,84640 \\
Ludwig von Orléans & 51,51200 \\
Isabeau de Bavière & 35,01344 \\
Johann Ohnefurcht & 29,23440 \\
Guy de La Trémoille & 19,68960 \\
Margarete von Bayern & 17,41635 \\
Valentina Visconti & 16,74567 \\
Ludwig II. von Bourbon & 9,74863 \\
Jean Canard & 9,34297 \\
Guillaume de La Trémoille & 8,80800 \\
Richard II. & 6,48000 \\
Margarete (II.) von Burgund & 6,04979 \\
\hline Marie de Sully & 5,94540 \\
Karl von Frankreich & 5,90778 \\
Anton von Burgund & 5,14591 \\
Maria (I.) von Burgund & 5,09850 \\
Maria (II.) von Burgund & 4,80219 \\
\hline
\end{tabular}

Tab. 9: Teilnehmer des höfischen Geschenkverkehrs nach Einnahmen

passiv als aktiv am Geschenkverkehr teilnehmenden Frauen bestätigen würde. Ansonsten erscheint die wertbestimmte Seite der Beschenkten wieder eindeutig burgundisch dominiert. Diese vorgebliche Dominanz burgundischer Beschenkter könnte aber ganz unterschiedliche Ursachen haben und im Endeffekt ein schlichter Zirkelschluß sein, wenn es sich herausstellte, daß beispielsweise vorwiegend Burgunder Burgunder beschenkt hätten - was auch tatsächlich in weiten Bereichen des höfischen Geschenkverkehrs zum neuen Jahr der Fall war.

\section{b) Nähe und Distanz}

Ein möglicher methodischer Zugang, Personengruppen über ihre Bindungsverhältnisse zu beschreiben, ist die sozialwissenschaftliche Netzwerkanalyse, deren Kategorien der Historiker Wolfgang Reinhard auf ihre Anwendbarkeit hin überprüft und am Beispiel der römischen Oligarchie um 1600 vorgeführt hat ${ }^{476}$. Im folgenden sollen die Grundbegriffe der Netzwerkananlyse nach

476 REINHARD 1979 - Rez. WUNDER, Bernd, in: Jahrbuch für Historische Forschung 9 (1982) S. 102f. -, siehe hier zu den Grundbegriffen S. 24-32, zur Methode S. 19-41. Vgl. FOUQUET, Speyerer Domkapitel, Teil 1, 1987, S. 203-205 mit weiteren Nachweisen, der, ausgehend von der Feststellung, da $\beta$ »es gerade in der Mediävistik längst bekannt [ist], daß Personenbeziehungen nicht willkürlich ablaufen, sondern regelhaft in vorgegebenen oder erzeugten Beziehungsnetzen stattfinden« (S. 204), die geschichtswissenschaftliche Anwend- 
Reinhard kurz vorgestellt und eine weitere Annäherung an den höfischen Geschenkverkehr versucht werden. Diese Grundbegriffe lassen sich in die drei Kriteriengruppen »Beziehungen«, »Struktur« und »Umwelteinflüsse« einteilen.

Die Kriterien der Gruppe »Beziehungen« sind Beziehungsherkunft, Distanz, sektorale Beziehungszugehörigkeiten, Multiplexität, Transaktionsinhalte und -richtungen und ihre Symmetrien oder Asymmetrien, dann deren Häufigkeit und Dauer ${ }^{477}$. Diese Kriterien sind bereits besprochen worden oder konnten aufgrund der Überlieferung keine abschließende Klärung erfahren. Der Einfluß der Umwelt ist nach Reinhard gekennzeichnet durch biographische Daten, den Wohnort, das Klima, durch Kulturfaktoren in ideeller, ideologischer und institutioneller Hinsicht, durch Erziehung, soziale Mobilität und Hierarchien ${ }^{478}$. Es ist schlechterdings nicht möglich, diese Daten bei jeder einzelnen Person des höfischen Geschenkverkehr vollständig zu erheben. Mit Blick auf die historischen Rahmenbedingungen sei allerdings postuliert, daß die höfische Gesellschaft der Zeit im allgemeinen denselben Gegebenheiten unterworfen war. Die Häufigkeit der Schenkakte wurde mehrfach behandelt, Auftakt und Dauer des höfischen Geschenkverkehrs ist im Überblick bereits oben auch graphisch veranschaulicht worden mit den entsprechenden Kommentaren ${ }^{479}$. Was fehlt, sind Beobachtungen an den konkreten Paarungen, die unter dem Kriterium Distanz erfaßt werden können. Die Frage nach der Symmetrie der Schenkakte hat ihre theoretisch-hypothetische Antwort im Konstrukt der höfischen Reziprozität gefunden. Der Sonderfall der zeitgleich-direkten Reziprozität wird unten behandet, die Vielzahl asymmetrischer Schenkbeziehungen ebenfalls unten im Zusammenhang mit Tabelle 10.

barkeit der von REINHARD vorgeführten Kategorien diskutiert und positiv bewertet. - Das sozialwissenschaftlich nutzbare Instrumentarium der Netzwerkanalyse ist wesentlich umfangreicher, als die oben verwendeten Kategorien vermuten ließen. Vgl. etwa: Social Networks, hg. von LEINHARDT, 1977, und BURT 1980, v.a. aber: Methoden der Netzwerkanalyse, hg. von PAPPI, 1987, zur Kurzinformation KAPPELHOFF, Peter: Art. „Netzwerk«, in: Wörterbuch der Soziologie, hg. von ENDRUWEIT, TROMMSDORF, Bd. 2, 1989, S. 465-467, schließlich WASSERMANN, FAUST 1994. Einen nachvoliziehbaren Zugang zur Netzwerkmethode auch für den sozialwissenschaftlichen Laien liefert SCHENK 1984, siehe hier zur Reziprozität S. 129f. Mein Anliegen ist allerdings weniger die virtuose Handhabung dieser Methode, als die nachvollziehbar methodische Verortung der Kategorien und analytischen Versatzstücke v.a. auf der deskriptiven Ebene. Eine Anwendungsmöglichkeit demonstriert SPITZER 1987, der die französische Generation von 1820 untersucht hat. Eine Einführung in die Netzwerkanalyse und die damit verbundenen ethnologischen Perspektiven geben mehrere Autoren in dem Sammelband: Netzwerkanalyse, hg. von SCHWEIZER, 1988, siehe hier v.a. die Hinweise zur Datenverarbeitung S. $201 \mathrm{ff}$.

477 Siehe REINHARD 1979, S. 25-27.

478 Siehe ebd., S. 29-32.

479 Vgl. oben Abschn. I. »Übersicht«. 
Tatsächlich hat sich herausgestellt, daß der höfische Gabentausch durch wenige schenkende Personen meist fürstlichen Ranges geprägt wurde, die an viele größtenteils nicht fürstliche Personen schenkten, und männlich dominiert war. Einzelne Asymmetrien zeigten sich besonders deutlich bei Philipp dem Kühnen als Schenker und Johann von Berry als Beschenktem. Damit konnte auch die Richtung der Transaktionen festgestellt werden, die allerdings je nach Gabe differenziert zu betrachten waren, was wiederum mit den verschiedenen Beziehungsherkünften und höfischen Segmenten zu begründen ist. Um noch einmal auf das höfische Reziprozitätsprinizip der Ehre Bezug zu nehmen, so findet sich in den Personen, die die Spitzenpositionen nach Zahl und Wert verschenkter oder empfangener Gaben besetzten, die Gruppe der "Standesgenossen «. Ob diese nun unterschiedlichen Parteien oder Häusern angehörten, so sind sie doch fast alle königlichen Geblüts gewesen. Die offensichtlich unterschiedlich motivierten Gaben des gesamten Geschenkverkehrs haben aber, wie oben bereits zu vermuten war, noch etwas anderes gezeigt: Die Gabe am Hof ist nicht gleichzusetzen mit der höfischen Gabe. Die höfische Gabe als kostbares Einzelstück zirkulierte fast ausschließlich in den Spitzenpositionen, obwohl sie durchaus als Leitmotiv des höfischen Gabentausches gelten kann. Daneben gab es offensichtlich zwei andere Arten von Geschenken, die einmal als integratives Moment des Gesamtzusammenhangs zu werten, dann fürstlicher Fürsorgepflicht zu verdanken sind und den Bereich des Hofhaltes bedienten. Eine in diesem Sinn uneindeutige Position nahmen die zum Neujahrstag sehr selten vergebenen diplomatischen Geschenke als einerseits dem Austausch unter Ebenbürtigen verpflichtete Kommunikationsmedien, andererseits den Integrationsbemühungen im Streben nach stabilen Beziehungen unterstellte Gaben ein. Multiplexität bedeutet im Rahmen der Netzwerkanalyse, $\mathrm{da}$ ß eine Person zu einer anderen mehrere unterschiedliche Beziehungen unterhält. Nach Reinhard sei dies allem für die Stabilität von Oligarchien von besonderer Bedeutung 480 .

Distanz schließlich fragt zunächst danach, ob Kontakte innerhalb eines Netzwerks direkt oder indirekt bestimmt sind. Der höfische Geschenkverkehr läßt durch das Medium der Gabe aber keinen anderen als den direkten Kontakt der Partner zu, denn ein Geschenk, das erst dem einen, dann einem anderen gegeben worden wäre, hätte zwangsläufig den Zusammenhang mit dem ursprünglichen Schenker verloren und die Grundeinheit hätte aus dem neuen Schenker und seinem Beschenktem bestanden, aber nicht zusätzlich aus einem "Vorschenker«, der dem zuletzt Beschenkten als Dazugehörender bewußt gewesen wäre. Außer dem einen Fall, in dem der Herzog von Berry einen Edelstein, der ihm vom König geschenkt worden war, eine Zeit später in ein Kreuz einsetzen ließ und auf diesem Weg zurückschenkte, ist kein solcher Vorgang 
bekannt. Schatzentnahmen können hier nicht erklärend herangezogen werden, denn jede Gabe folgt im Akt des Schenkens der ihr eigenen vorgezeichneten Beziehungslinie, egal, wem sie früher gehört hat. Distanz und damit Nähe muß deshalb auf eine andere Weise untersucht werden und erfährt dadurch auch einen anderen Bedeutungsgehalt. Da die archivalischen Informationen Bindungsziffern und Wertzuweisungen vorgeben, bietet es sich an, die jeweils ermittelten Einzelwerte in eine Rangordnung zu bringen und die beziehungsspezifischen Bindungswerte mit den beziehungsspezifischen Wertzuweisungen zu vergleichen. Da dies die namentlich faßbaren Beziehungsnetze des höfischen Geschenkverkehrs sind, sollen diese Tabellen trotz ihres Umfangs vollständig wiedergegeben werden.

Zunächst soll mit der nachstehenden Tabelle die Rangfolge von Schenkbeziehungen anhand von Bindungsziffern gezeigt werden (Tabelle 10). Nicht berücksichtigt ist in dieser Reihung die Trennung von personal identisch besetzten Schenkvorgängen, die sich aber durch ihre Gerichtetheit unterscheiden. Dies wurde dadurch kompensiert, daß die dritte und vierte Spalte unter Nennung der ermittelten Schenkvorgänge die mit Pfeilen gekennzeichneten Richtungen bezogen auf die jeweils vorstehenden Namen angeben. Die Rangfolge der Schenkbeziehungen, es können 550 nicht identische Paarungen angegeben werden, richtet sich nach der Summe der jeweils ermittelten Schenkakte, die in der jeweils letzten Spalte notiert ist, durch die 24 Ränge bestimmt werden können. Innerhalb der einzelnen Ränge sind die Personen alphabetisch sortiert. Fett gesetzt sind die wenigen »Selbstbeschenkungen«.

\begin{tabular}{|r|l|l|r|r|c|}
\hline Rang & Namen & $\rightarrow$ & $\leftarrow$ & $\Sigma$ \\
\hline 1 & Margarete von Flandern & Philipp der Kühne & 5 & 51 & 56 \\
\hline 2 & Karl VI. & Philipp der Kühne & 7 & 30 & 37 \\
\hline 3 & Johann von Berry & Philipp der Kühne & 8 & 30 & 31 \\
\hline 4 & Ludwig von Orléans & Philipp der Kühne & 7 & 21 & 28 \\
\hline 5 & Philipp der Kühne & Johann Ohnefurcht & 21 & 0 & 21 \\
\hline 6 & Guy de La Trémoille & Philipp der Kühne & 3 & 17 & 20 \\
\hline 7 & Jean Canard & Philipp der Kühne & 2 & 17 & 19 \\
\hline $\mathbf{8}$ & Isabeau de Bavière & Philipp der Kühne & 2 & 16 & 18 \\
\hline 9 & Johann Ohnefurcht & Ludwig von Orléans & 10 & 7 & 17 \\
\hline 10 & Ludwig II. von Bourbon & Philipp der Kühne & 2 & 13 & 15 \\
\hline 11 & Anton von Burgund & Philipp der Kühne & 1 & 13 & 14 \\
& Guillaume de La Trémoille & Philipp der Kühne & 3 & 11 & 14 \\
& Johann Ohnefurcht & Margarete von Bayern & 10 & 4 & 14 \\
& Ludwig von Orléans & Valentina Visconti & 7 & 7 & 14 \\
\hline 12 & Isabeau de Bavière & Karl VI. & 7 & 6 & 13 \\
& Isabeau de Bavière & Ludwig von Orléans & 4 & 9 & 13 \\
\hline 13 & Johann von Berry & Karl VI. & 4 & 8 & 12 \\
& Marie de Sully & Philipp der Kühne & 1 & 11 & 12 \\
\hline 14 & Philipp der Kühne & Bonne de Burgund & 11 & 0 & 11 \\
& Philipp der Kühne & Maria I. von Burgund & 11 & 0 & 11 \\
& Philipp der Kühne & Philippe de Bar & 11 & 0 & 11
\end{tabular}




\begin{tabular}{|c|c|c|c|c|c|}
\hline 15 & $\begin{array}{l}\text { Isabeau de Bavière } \\
\text { Karl VI. } \\
\text { Karl VI. } \\
\end{array}$ & \begin{tabular}{|l|} 
Valentina Visconti \\
Ludwig von Orléans \\
Valentina Visconti \\
\end{tabular} & $\begin{array}{l}5 \\
5 \\
4 \\
\end{array}$ & $\begin{array}{l}5 \\
5 \\
6 \\
\end{array}$ & $\begin{array}{l}10 \\
10 \\
10\end{array}$ \\
\hline 16 & $\begin{array}{l}\text { Johann von Berry } \\
\text { Philipp der Kühne } \\
\text { Philipp der Kühne } \\
\text { Philipp der Kühne } \\
\end{array}$ & $\begin{array}{l}\text { Ludwig von Orléans } \\
\text { Katharina I. von Burgund } \\
\text { Margarete II. von Burgund } \\
\text { Pierre de Navarre }\end{array}$ & $\begin{array}{l}\overline{4} \\
9 \\
9 \\
9\end{array}$ & $\begin{array}{l}5 \\
0 \\
0 \\
0\end{array}$ & $\begin{array}{l}9 \\
9 \\
9 \\
9\end{array}$ \\
\hline 17 & $\begin{array}{l}\text { Charles d'Artois } \\
\text { Johann Ohnefurcht } \\
\text { Philipp der Kühne }\end{array}$ & $\begin{array}{l}\text { Johann von Berry } \\
\text { Karl VI. } \\
\text { Pierre de La Trémoille } \\
\end{array}$ & $\begin{array}{l}7 \\
6 \\
7 \\
\end{array}$ & $\begin{array}{l}1 \\
2 \\
1 \\
\end{array}$ & $\begin{array}{l}8 \\
8 \\
8\end{array}$ \\
\hline 18 & $\begin{array}{l}\text { Johann Ohnefurcht } \\
\text { Martin Gouge } \\
\text { Philipp der Kühne } \\
\text { Philipp der Kühne } \\
\text { Philipp der Kühne } \\
\text { Philipp der Kühne } \\
\text { Robinet d'Etampes } \\
\text { Simon Aligret } \\
\end{array}$ & $\begin{array}{l}\text { Johann von Berry } \\
\text { Johann von Berry } \\
\text { Jeanne de Saint-Pol } \\
\text { Philippe d'Artois } \\
\text { Renier Pot } \\
\text { Valentina Visconti } \\
\text { Johann von Berry } \\
\text { Johann von Berry } \\
\end{array}$ & $\begin{array}{l}7 \\
7 \\
7 \\
6 \\
5 \\
5 \\
7 \\
7\end{array}$ & $\begin{array}{l}0 \\
0 \\
0 \\
1 \\
2 \\
2 \\
0 \\
0\end{array}$ & $\begin{array}{l}7 \\
7 \\
7 \\
7 \\
7 \\
7 \\
7 \\
7\end{array}$ \\
\hline 19 & $\begin{array}{l}\text { Guillaume de Lodes } \\
\text { Guy de La Rochefoucauld } \\
\text { Jeanne de Boulogne } \\
\text { Johann Ohnefurcht } \\
\text { Johann von Berry } \\
\text { Philipp der Kühne } \\
\text { Philipp der Kühne } \\
\text { Philipp der Kühne } \\
\text { Philipp der Kühne } \\
\end{array}$ & $\begin{array}{l}\text { Johann von Berry } \\
\text { Philipp der Kühne } \\
\text { Johann von Berry } \\
\text { Jean de Saulx } \\
\text { Louis de Vendôme } \\
\text { Charles d'Albret } \\
\text { Karl von Frankreich } \\
\text { Philipp der Kühne } \\
\text { Philipp von Burgund } \\
\end{array}$ & $\begin{array}{l}6 \\
1 \\
5 \\
6 \\
1 \\
6 \\
6 \\
6 \\
6\end{array}$ & $\begin{array}{l}0 \\
5 \\
1 \\
0 \\
5 \\
0 \\
0 \\
6 \\
0\end{array}$ & $\begin{array}{l}6 \\
6 \\
6 \\
6 \\
6 \\
6 \\
6 \\
6 \\
6 \\
6 \\
6\end{array}$ \\
\hline 20 & $\begin{array}{l}\text { Arnoul Belin } \\
\text { Erard Moriset, Jean de Cande, } \\
\text { Pierre de Gynes, Michel le } \\
\text { Beuf } \\
\text { Isabeau de Bavière } \\
\text { Isabeau de Bavière } \\
\text { Isabeau de Bavière } \\
\text { Johann I. von Bourbon } \\
\text { Ludwig II. von Anjou } \\
\text { Margarete von Flandern } \\
\text { Marie de Berry } \\
\text { Philipp der Kühne } \\
\text { Philipp der Kühne } \\
\text { Philipp der Kühne }\end{array}$ & $\begin{array}{l}\text { Johann von Berry } \\
\text { Johann von Berry } \\
\text { Catherine de Fastavarin } \\
\text { Jeanne d'Harcourt } \\
\text { Johann Ohnefurcht } \\
\text { Johann von Berry } \\
\text { Johann von Berry } \\
\text { Marie de Sully } \\
\text { Johann von Berry } \\
\text { Arnaud-Amanieu d'Albret } \\
\text { Jean de Vienne } \\
\text { Philipp der Gute }\end{array}$ & $\begin{array}{l}5 \\
5 \\
1 \\
5 \\
5 \\
3 \\
5 \\
5 \\
5 \\
5\end{array}$ & $\begin{array}{l}0 \\
0 \\
4 \\
0 \\
0 \\
2 \\
0 \\
0 \\
0 \\
0\end{array}$ & $\begin{array}{l}5 \\
5 \\
5 \\
5 \\
5 \\
5 \\
5 \\
5 \\
5 \\
5\end{array}$ \\
\hline 21 & $\begin{array}{l}\text { Bernhard VII. von Armagnac } \\
\text { Bonne de Berry } \\
\text { Guillaume de Boisratier } \\
\text { Isabeau de Bavière } \\
\text { Isabeau de Bavière } \\
\text { Isabeau de Bavière } \\
\text { Jean de La Barre } \\
\text { Johann von Berry } \\
\text { Ludwig II. von Bourbon } \\
\text { Philipp der Kühne } \\
\text { Philipp der Kühne } \\
\text { Philipp der Kühne }\end{array}$ & $\begin{array}{l}\text { Johann von Berry } \\
\text { Johann von Berry } \\
\text { Johann von Berry } \\
\text { Alips de Beauchamp } \\
\text { Femmette } \\
\text { Isabella von Frankreich } \\
\text { Johann von Berry } \\
\text { Ludwig der Bärtige } \\
\text { Ludwig von Orléans } \\
\text { Jean de Montaigu } \\
\text { Johann V. von Bretagne } \\
\text { Leo VI. von Lusignan }\end{array}$ & $\begin{array}{l}4 \\
4 \\
4 \\
4 \\
4 \\
2 \\
4 \\
1 \\
1 \\
4 \\
4 \\
4\end{array}$ & $\begin{array}{l}0 \\
0 \\
0 \\
0 \\
0 \\
2 \\
0 \\
3 \\
3 \\
0 \\
0 \\
0\end{array}$ & $\begin{array}{l}4 \\
4 \\
4 \\
4 \\
4 \\
4 \\
4 \\
4 \\
4 \\
4 \\
4 \\
4\end{array}$ \\
\hline
\end{tabular}




\begin{tabular}{|c|c|c|c|c|c|}
\hline & $\begin{array}{l}\text { Philipp der Kühne } \\
\text { Philipp der Kühne } \\
\text { Isabeau de Bavière }\end{array}$ & $\begin{array}{l}\text { Margarete I. von Burgund } \\
\text { Maria II. von Burgund } \\
\text { Marie de Duisy }\end{array}$ & $\begin{array}{l}4 \\
4 \\
4\end{array}$ & $\begin{array}{l}0 \\
0 \\
0\end{array}$ & $\begin{array}{l}4 \\
4 \\
4\end{array}$ \\
\hline 22 & $\begin{array}{l}\text { Beraud III d'Auvergne } \\
\text { Charlotte de Bourbon } \\
\text { Christine de Pisan } \\
\text { Guichard Dauphin } \\
\text { Guy de La Trémoille } \\
\text { Isabeau de Bavière } \\
\text { Isabeau de Bavière } \\
\text { Isabeau de Bavière } \\
\text { Isabeau de Bavière } \\
\text { Isabeau de Bavière } \\
\text { Isabeau de Bavière } \\
\text { Jeanne de Peschin } \\
\text { Johann Ohnefurcht } \\
\text { Johann Ohnefurcht } \\
\text { Johann Ohnefurcht } \\
\text { Johann von Berry } \\
\text { Ludwig II. von Bourbon } \\
\text { Ludwig von Male } \\
\text { Ludwig von Orléans } \\
\text { Macé Heron } \\
\text { Philipp der Kühne } \\
\text { Philipp der Kühne } \\
\text { Philipp der Kühne } \\
\text { Philipp der Kühne } \\
\text { Philipp der Kühne } \\
\text { Philipp der Kühne } \\
\text { Philipp von Burgund } \\
\text { Richard II. } \\
\text { Valentina Visconti } \\
\text { Valentina Visconti } \\
\text { Valentina Visconti } \\
\text { Valentina Visconti } \\
\text { Isabeau de Bavière }\end{array}$ & $\begin{array}{l}\text { Johann von Berry } \\
\text { Johann von Berry } \\
\text { Philipp der Kühne } \\
\text { Johann von Berry } \\
\text { Marie de Sully } \\
\text { Isabelle La Bouteillière } \\
\text { Jeanne de Montueil } \\
\text { Jehanne } \\
\text { Johann von Berry } \\
\text { Marguerite de Germonville } \\
\text { Philippe de Moulins } \\
\text { Johann Ohnefurcht } \\
\text { Ludwig II. von Anjou } \\
\text { Ludwig von Guyenne } \\
\text { Michelle von Frankreich } \\
\text { Margarete II. von Burgund } \\
\text { Johann von Berry } \\
\text { Philipp der Kühne } \\
\text { Guillaume Martel } \\
\text { Johann von Berry } \\
\text { Arthur de Richemont } \\
\text { Blanche } \\
\text { Henri de Montbéliard } \\
\text { Oudard de Chazeron } \\
\text { Waleran von Luxemburg } \\
\text { Wilhelm von Bayern } \\
\text { Johann von Berry } \\
\text { Karl VI. } \\
\text { Gilles Malet } \\
\text { Isabella von Frankreich } \\
\text { Karl von Frankreich } \\
\text { Surien des Quesnes } \\
\text { Catherine de Villiers }\end{array}$ & $\begin{array}{l}3 \\
3 \\
3 \\
3 \\
2 \\
3 \\
3 \\
3 \\
3 \\
3 \\
3 \\
1 \\
3 \\
2 \\
3 \\
1 \\
3 \\
1 \\
3 \\
3 \\
3 \\
3 \\
3 \\
3 \\
2 \\
3 \\
3 \\
3 \\
3 \\
3 \\
3 \\
3 \\
3\end{array}$ & $\begin{array}{l}0 \\
0 \\
0 \\
0 \\
1 \\
0 \\
0 \\
0 \\
0 \\
0 \\
0 \\
2 \\
0 \\
1 \\
0 \\
2 \\
0 \\
2 \\
0 \\
0 \\
0 \\
0 \\
0 \\
0 \\
1 \\
0 \\
0 \\
0 \\
0 \\
0 \\
0 \\
0 \\
0\end{array}$ & $\begin{array}{l}3 \\
3 \\
3 \\
3 \\
3 \\
3 \\
3 \\
3 \\
3 \\
3 \\
3 \\
3 \\
3 \\
3 \\
3 \\
3 \\
3 \\
3 \\
3 \\
3 \\
3 \\
3 \\
3 \\
3 \\
3 \\
3 \\
3 \\
3 \\
3 \\
3 \\
3 \\
3 \\
3\end{array}$ \\
\hline 23 & $\begin{array}{l}\text { Anna von Bourbon } \\
\text { Archambaut de Foix } \\
\text { Ascelin Royne } \\
\text { Baude de Guy } \\
\text { Béatrix de Navarre } \\
\text { Bonne d'Artois } \\
\text { Charles d'Albret } \\
\text { Christine de Pisan } \\
\text { Clemens VII. } \\
\text { Dino Rapondi } \\
\text { Gérard du Puy } \\
\text { Gilles Malet } \\
\text { Guillaume Lorin } \\
\text { Isabeau de Bavière } \\
\text { Isabeau de Bavière } \\
\text { Giacomo Rapondi }\end{array}$ & $\begin{array}{l}\text { Johann von Berry } \\
\text { Johann Ohnefurcht } \\
\text { Johann von Berry } \\
\text { Johann von Berry } \\
\text { Johann von Berry } \\
\text { Johann von Berry } \\
\text { Johann von Berry } \\
\text { Johann von Berry } \\
\text { Philipp der Kühne } \\
\text { Philipp der Kühne } \\
\text { Johann von Berry } \\
\text { Philipp der Kühne } \\
\text { Johann von Berry } \\
\text { Arnaud de Corbie } \\
\text { Karl von Orléans } \\
\text { Philipp der Kühne }\end{array}$ & $\begin{array}{l}2 \\
1 \\
1 \\
2 \\
2 \\
2 \\
2 \\
2 \\
1 \\
1 \\
2 \\
1 \\
2 \\
2 \\
1 \\
1\end{array}$ & $\begin{array}{l}0 \\
1 \\
1 \\
0 \\
0 \\
0 \\
0 \\
0\end{array}$ & $\begin{array}{l}2 \\
2 \\
2 \\
2 \\
2 \\
2 \\
2 \\
2 \\
2 \\
2 \\
2 \\
2 \\
2 \\
2 \\
2 \\
2 \\
2\end{array}$ \\
\hline
\end{tabular}




\begin{tabular}{|l} 
Jean I d'Alençon \\
Jean IV d'Armagnac \\
Johann Ohnefurcht \\
Johann Ohnefurcht \\
Johann Ohnefurcht \\
Johann Ohnefurcht \\
Johann Ohnefurcht \\
Johann Ohnefurcht \\
Johann Ohnefurcht \\
Johann Ohnefurcht \\
Johann Ohnefurcht \\
Johann Ohnefurcht \\
Johann Ohnefurcht \\
Johann Ohnefurcht \\
Johann Ohnefurcht \\
Johann Ohnefurcht \\
Johann V. von Bretagne \\
Johann von Berry \\
Johann von Berry \\
Karl III. von Navarra \\
Karl VI. \\
Karl VI. \\
Karl VI. \\
Karl (VII.) \\
Katharina von Alençon \\
Louis de Sancerre \\
Ludwig von Guyenne \\
Ludwig von Male \\
Ludwig von Orléans \\
Ludwig von Orléans \\
Ludwig von Orléans \\
Philipp der Kühne \\
Pudwig von Orléans \\
Ludwig von Orléans \\
Philipp der Kühne \\
Ludwig von Orléans \\
Ludwig von Orléans \\
Ludwig von Orléans \\
Ludwig von Orléans \\
Ludwig von Orléans \\
Margarete von Flandern \\
Pasqual de Paloiz \\
Philipp der Kühne \\
Philipp der Kühne \\
Philipp der Kühne \\
Philipp der Kühne \\
Philipp der Kühne \\
\end{tabular}

\begin{tabular}{|c|c|c|}
\hline Johann von Berry & 2 & 0 \\
\hline Johann von Berry & 2 & 0 \\
\hline Anton von Burgund & 2 & 0 \\
\hline Charles de Savoisy & 2 & 0 \\
\hline Jean de Chevenon & 2 & $\mathbf{0}$ \\
\hline Jean de Luxembourg & 2 & 0 \\
\hline Jean Marchand & 2 & 0 \\
\hline Ludwig der Bärtige & 2 & 0 \\
\hline Ludwig II. von Bourbon & 2 & 0 \\
\hline Manuel II. Palaiologos & 1 & 1 \\
\hline Margarete II. von Burgund & 2 & 0 \\
\hline Oudart de L'Epinace & 1 & 1 \\
\hline Philipp der Gute & 2 & 0 \\
\hline Pierre des Essarts & 2 & 0 \\
\hline Regnault Doriac & 2 & 0 \\
\hline Renier Pot & 2 & 0 \\
\hline Johann von Frankreich & 1 & 1 \\
\hline Karl I. von Bourbon & 1 & 1 \\
\hline Limburg, Gebrüder & 1 & 1 \\
\hline Ludwig von Orléans & 1 & 1 \\
\hline Jeanne d'Harcourt & 2 & 0 \\
\hline Jeanne de Dreux & 2 & 0 \\
\hline Ludwig II. von Bourbon & 1 & 1 \\
\hline Jean Coeur & 2 & 0 \\
\hline Johann von Berry & 2 & 0 \\
\hline Ludwig von Orléans & 1 & 1 \\
\hline Regnaut d'Angennes & 2 & 0 \\
\hline Margarete von Flandern & 1 & 1 \\
\hline Alain de Beaumont & 2 & 0 \\
\hline Charles d'Ivry & 2 & 0 \\
\hline dame de Maucouvent & 2 & 0 \\
\hline Jean de Hangest & 2 & 0 \\
\hline Jean de Trie & 2 & 0 \\
\hline Jeanne de Chepoy & 2 & 0 \\
\hline Maria von Frankreich & 2 & 0 \\
\hline Michelle von Frankreich & 2 & 0 \\
\hline Pierre de Navarre & 2 & 0 \\
\hline Robert d'Aunoy & 2 & 0 \\
\hline Philippe de Bar & 2 & 0 \\
\hline Philipp der Kühne & 1 & 1 \\
\hline Charles de Châtillon & 2 & 0 \\
\hline Georges de La Trémoille & 2 & 0 \\
\hline Gilles de Bretagne & 2 & 0 \\
\hline Guichard Dauphin & 2 & 0 \\
\hline Guillaume de Bours & 2 & 0 \\
\hline Isabella von Frankreich & 2 & 0 \\
\hline Jean de Hangest & 2 & 0 \\
\hline Jean de Trie & 2 & 0 \\
\hline Jean Le Meingre & 2 & 0 \\
\hline Katharina II. von Burgund & 2 & 0 \\
\hline Louis de Poissy & 2 & 0 \\
\hline Louis de Sancerre & 2 & 0 \\
\hline
\end{tabular}




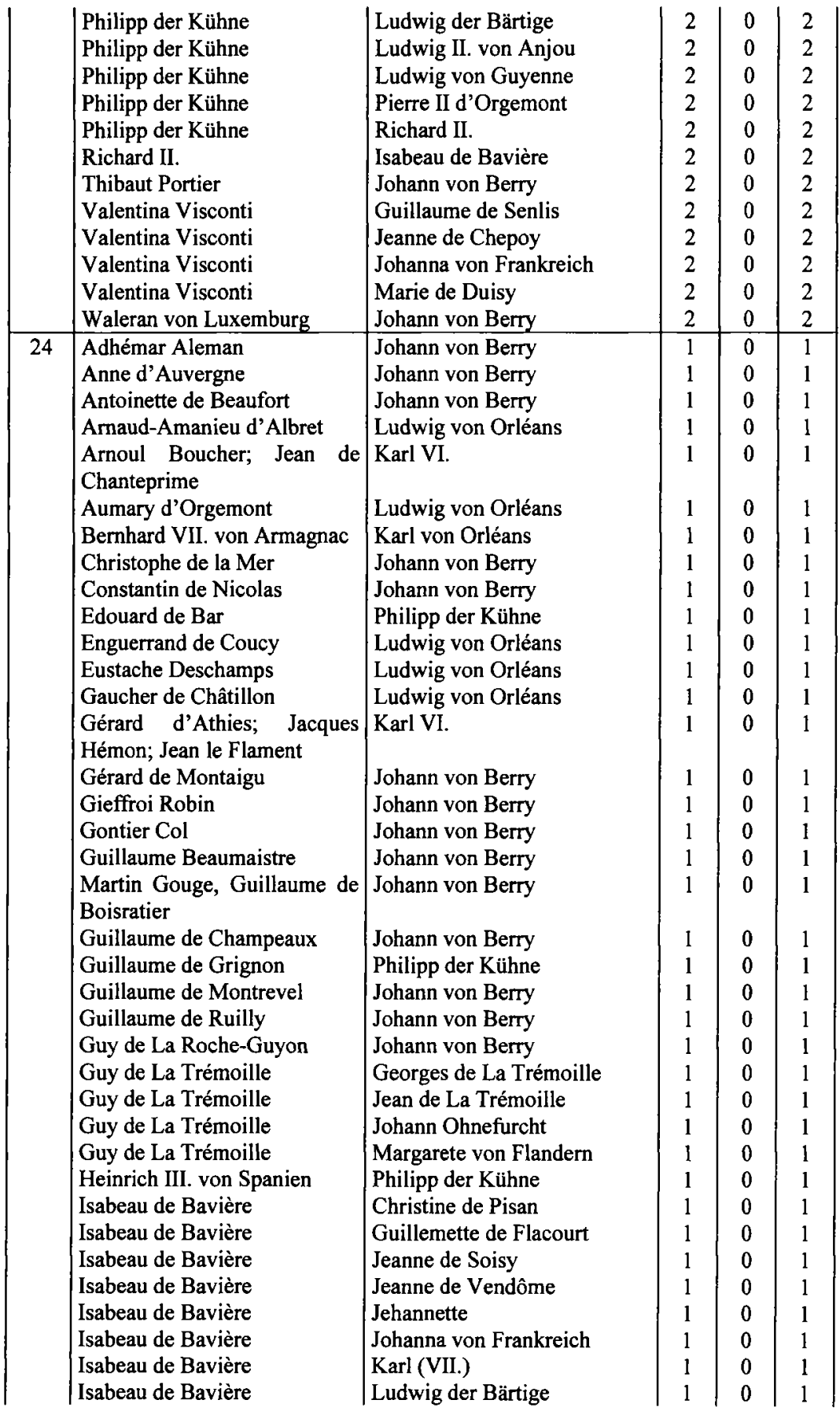




\begin{tabular}{|c|c|}
\hline $\begin{array}{l}\text { furcht } \\
\text { furcht } \\
\text { furcht } \\
\text { furcht } \\
\text { furcht }\end{array}$ & $\begin{array}{l}\text { Marguerite de Landes } \\
\text { Marguerite de Préaux } \\
\text { Raoul Cassinel } \\
\text { Johann von Berry } \\
\text { Ludwig von Orléans } \\
\text { Johann von Berry } \\
\text { Ludwig von Orléans } \\
\text { Ludwig von Orléans } \\
\text { Johann von Berry } \\
\text { Karl VI. } \\
\text { Johann von Berry } \\
\text { Philipp der Kühne } \\
\\
\\
\text { Amadeus VIII. von Savoyen } \\
\text { Ansaldo Spinola } \\
\text { Antoine de Craon } \\
\text { Antoine Forestz } \\
\text { Arnaud de Corbie } \\
\text { Bonne de Bar } \\
\text { Charles d'Artois } \\
\text { Charles de La Rivière } \\
\text { Charles de Soyecourt } \\
\text { Dino Rapondi } \\
\text { Guillaume de Champdivers } \\
\text { Jacques de la Rivière } \\
\text { Jacques de Trie } \\
\text { Jean de Croy } \\
\text { Jean de Foix } \\
\text { Jean de Graville } \\
\text { Jean de Montagu } \\
\text { Jean de Montaigu } \\
\text { Jean de Puligny } \\
\text { Jean de Toulongeon } \\
\text { Jean de Velery } \\
\text { Jean de Vergy } \\
\text { Jean de Vienne } \\
\text { Jean Fale } \\
\text { Jean Pouquet } \\
\text { Jeanne de Bourbon } \\
\text { Jeanne Flotte } \\
\text { Karl I. von Bourbon } \\
\text { Katharina von Alençon } \\
\text { Katharina von Frankreich } \\
\text { Ludwig von Male } \\
\text { Maria II. von Burgund } \\
\text { Marie de Berry } \\
\text { Nicole d'Estrée } \\
\text { Philipp von Burgund } \\
\text { Philippe de Bourgogne } \\
\text { Philippe de Vertus } \\
\text { Philippe Musnier }\end{array}$ \\
\hline
\end{tabular}




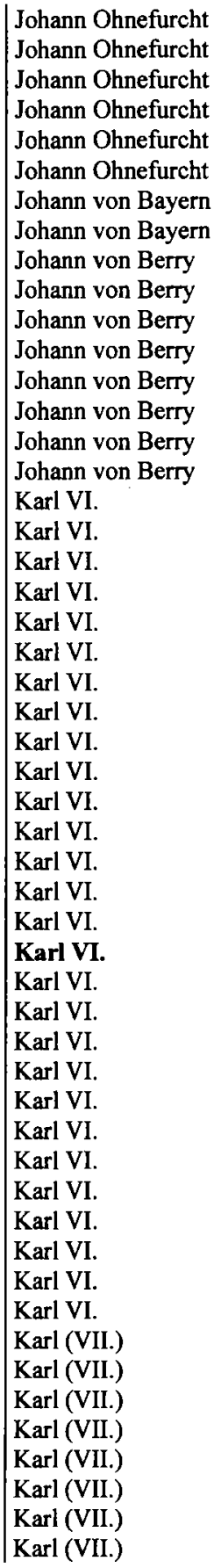

\begin{tabular}{|c|c|c|}
\hline Pierre de Fontenay & 1 & 0 \\
\hline Pierre de Montbertaud & 1 & 0 \\
\hline Pierre Gorremont & 1 & 0 \\
\hline Regnault Thumery & 1 & 0 \\
\hline Regnaut d'Angennes & 1 & 0 \\
\hline Tassin & 1 & 0 \\
\hline Jakobäa von Bayern & 1 & 0 \\
\hline Johann von Frankreich & 1 & 0 \\
\hline Estienne & 1 & 0 \\
\hline Hannequin & 1 & 0 \\
\hline Hermant & 1 & 0 \\
\hline Jean Flamel & 1 & 0 \\
\hline Jean Nau & 1 & 0 \\
\hline Jehanncon & 1 & 0 \\
\hline Nicholas Feynat & 1 & 0 \\
\hline Pierre II d'Orgemont & 1 & 0 \\
\hline Anton von Burgund & 1 & 0 \\
\hline Arnaud-Amanieu d'Albret & 1 & 0 \\
\hline Catherine de Fastavarin & 1 & 0 \\
\hline Catherine de Villiers & 1 & 0 \\
\hline Charles d'Albret & 1 & 0 \\
\hline Charles Poupart & 1 & 0 \\
\hline Enguerrand de Coucy & 1 & 0 \\
\hline Isabella von Frankreich & 1 & 0 \\
\hline Isabelle La Bouteillière & 1 & 0 \\
\hline Jacqueline Quipie & 1 & 0 \\
\hline Jeanne & 1 & 0 \\
\hline Jeanne de Châtillon & 1 & 0 \\
\hline Jeanne de La Tour & 1 & 0 \\
\hline Jeanne de Montueil & 1 & 0 \\
\hline Jeanne de Vendôme & 1 & 0 \\
\hline Karl VI. & 1 & $\mathbf{1}$ \\
\hline Katharina von Frankreich & 1 & 0 \\
\hline Ludwig der Bärtige & 1 & 0 \\
\hline Ludwig von Guyenne & 1 & 0 \\
\hline Mabillette & 1 & 0 \\
\hline Marguerite de Germonville & 1 & 0 \\
\hline Marguerite de Landes & 1 & 0 \\
\hline Marie de Berry & 1 & 0 \\
\hline Marie de Duisy & 1 & 0 \\
\hline Marie de Quiemieu & 1 & 0 \\
\hline Philippe d'Artois & 1 & 0 \\
\hline Philippe de Bar & 1 & 0 \\
\hline Pierre de Navarre & 1 & 0 \\
\hline Adam de Champgiraut & 1 & 0 \\
\hline Alexandre Le Boursier & 1 & 0 \\
\hline Bernhard VIII. von Armagnac & 1 & 0 \\
\hline Bertrand de Rochefort & 1 & 0 \\
\hline Charles d'Albret & 1 & 0 \\
\hline Charles de Luxembourg & 1 & 0 \\
\hline Charles Garnier & 1 & 0 \\
\hline Charles Labbé & 1 & 0 \\
\hline
\end{tabular}




\begin{tabular}{|l} 
Karl (VII.) \\
Karl (VII.) \\
Karl (VII.) \\
Karl (VII.) \\
Karl (VII.) \\
Karl (VII.) \\
Karl (VII.) \\
Karl (VII.) \\
Karl (VII.) \\
Karl (VII.) \\
Karl (VII.) \\
Karl (VII.) \\
Karl (VII.) \\
Karl (VII.) \\
Karl (VII.) \\
Karl (VII.) \\
Karl (VII.) \\
Karl (VII.) \\
Karl (VII.) \\
Karl (VII.) \\
Karl (VII.) \\
Karl (VII.) \\
Karl (VII.) \\
Karl (VII.) \\
Karl (VII.) \\
Karl (VII.) \\
Karl (VII.) \\
Karl (VII.) \\
Karl (VII.) \\
Karl (VII.) \\
Karl von Orléans \\
Karl von Orléans \\
Karl von Orléans \\
Karl von Orléans \\
Karl von Orléans \\
Karl von Orléans \\
Karl von Orléans \\
Karl von Orléans \\
Karl von Orléans \\
Karl von Orléans \\
Karl von Orléans \\
Karl von Orléans \\
Karl von Orléans \\
Karl von Orléans \\
Karl von Orléans \\
Karl von Orléans \\
Karl von Orléans \\
Karl von Orléans \\
Karl von Orléans \\
Karl von Orléans \\
Leo VI. von Lusignan \\
Louis Gradenigo
\end{tabular}

Chatart de Rochedragoux

Denis de Chesne

Gilbert Motier de La Fayette

Guillaume Boniface

Guillaume d'Avaugour

Guillaume de Lucé

Guillaume du Bez

Henri de Savoisy

Henri du Mesnil

Hernauton d'Andines

Isabeau de Barres

Jacques de Villiers

Jean Boschet

Jean Cadart

Jean d'Arpajon

Jean d'Harcourt

Jean de Bonnay

Jean Gouffier

Jean Louvet

Johann von Berry

Karl I. von Bourbon

Morelet de Carville

Philibert de Maleret

Pierre de Chantelle

Prégent de Coëtivy

Raymond Raguier

Renier de Bouligny

Robert Mallière

Rogerin Blosset

Yvon le Begaignon

Bonne d'Armagnac

Guillaume Cousinot

Guillaume II de Craon

Guillaume le Bouteiller

Guy de La Roche-Guyon

Hue d'Amboise

Isabeau de Bavière

Jacques de Peschin

Jean d'Angoulême

Jean Davy

Jean de Fontaines

Jean de Gaules

Jean de Juch

Jean de Rochechouart

Jeanne d'Orléans

Johann I. von Bourbon

Johann von Berry

Margarete II. von Burgund

Marguerite d'Orléans

Philippe de Vertus

Isabeau de Bavière

Johann von Berry 
Ludwig II. von Bourbon Ludwig von Guyenne Ludwig von Guyenne Ludwig von Guyenne Ludwig von Guyenne Ludwig von Guyenne Ludwig von Guyenne Ludwig von Guyenne Ludwig von Male Ludwig von Orléans Ludwig von Orléans Ludwig von Orléans Ludwig von Orléans Ludwig von Orléans Ludwig von Orléans Ludwig von Orléans Ludwig von Orléans Ludwig von Orléans Ludwig von Orléans Ludwig von Orléans Ludwig von Orléans Ludwig von Orléans Ludwig von Orléans Ludwig von Orléans Ludwig von Orléans Ludwig von Orléans Ludwig von Orléans Ludwig von Orléans Ludwig von Orléans Ludwig von Orléans Ludwig von Orléans Ludwig von Orléans Ludwig von Orléans Ludwig von Orléans Ludwig von Orléans Ludwig von Orléans Ludwig von Orléans Ludwig von Orléans Ludwig von Orléans Ludwig von Orléans Ludwig von Orléans Ludwig von Orléans Margarete von Bayern Margarete von Bayern Margarete von Bayern Margarete von Bayern Margarete von Bayern Margarete von Bayern Margarete von Flandern Margarete von Flandern Margarete von Flandern Marie de France

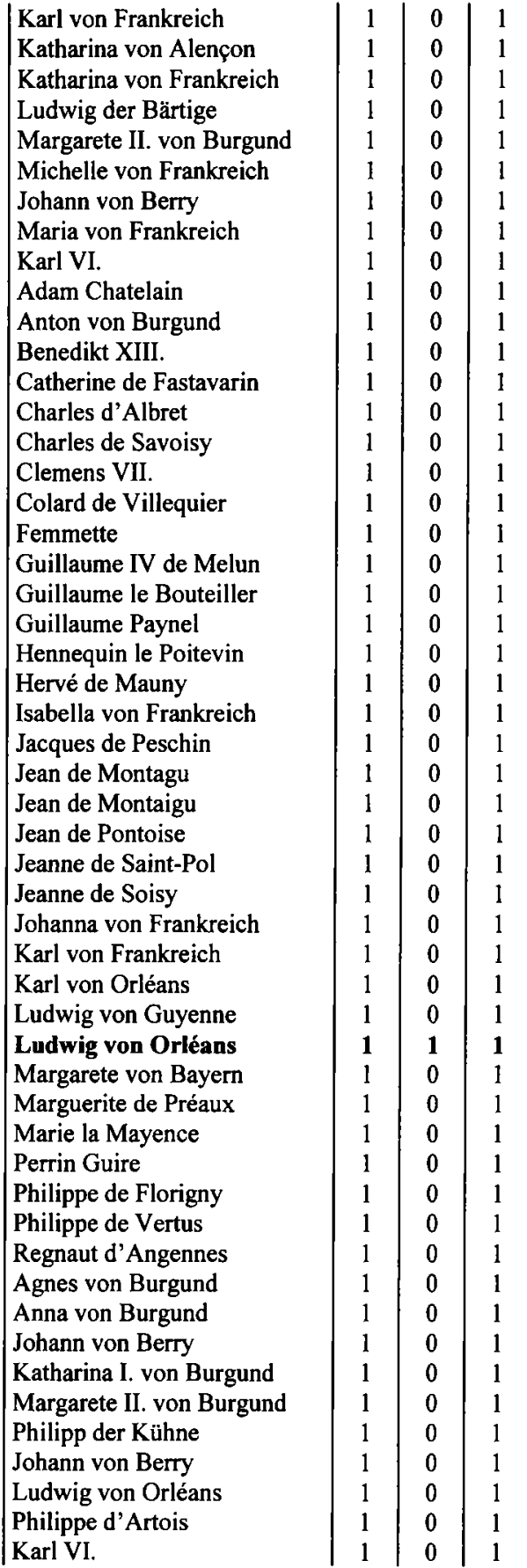




\begin{tabular}{|l} 
Martin von Aragon \\
Michelle von Frankreich \\
Olivier de Mauny \\
Pannier \\
Paul von Limburg \\
Philipp der Gute \\
Philipp der Gute \\
Philipp der Gute \\
Philipp der Gute \\
Philipp der Gute \\
Philipp der Gute \\
Philipp der Gute \\
Philipp der Gute \\
Philipp der Kühne \\
Philipp der Kühne \\
Philipp der Kühne \\
Philipp der Kühne \\
Philipp der Kühne \\
Philipp der Kühne \\
Philipp der Kühne \\
Philipp der Kühne \\
Philipp der Kühne \\
Philipp der Kühne \\
Philipp der Kühne \\
Philipp der Kühne \\
Philipp der Kühne \\
Philipp der Kühne \\
Philipp der Kühne \\
Philipp der Kühne \\
Philipp der Kühne \\
Philipp der Kühne \\
Philipp der Kühne \\
Philipp der Kühne \\
Philipp der Kühne \\
Philipp der Kühne \\
Philipp der Kühne \\
Philipp der Kühne \\
Philipp der Kühne \\
Philipp der Kühne \\
Philipp der Kühne \\
Philipp der Kühne \\
Philipp der Kühne \\
Philipp der Kühne \\
Philipp der Kühne \\
Philipp der Kühne \\
Philipp der Kühne \\
Philipp der Kühne \\
Philipp der Kühne \\
\end{tabular}

\begin{tabular}{|c|c|c|c|}
\hline Philipp der Kühne & 1 & 0 & 1 \\
\hline Johann von Berry & 1 & 0 & 1 \\
\hline Johann von Berry & 1 & 0 & 1 \\
\hline Johann von Berry & 1 & 0 & 1 \\
\hline Johann von Berry & 1 & 0 & 1 \\
\hline Agnes von Burgund & 1 & 0 & 1 \\
\hline Anna von Burgund & 1 & 0 & 1 \\
\hline Anton von Burgund & 1 & 0 & 1 \\
\hline Isabeau de Bavière & 1 & 0 & 1 \\
\hline Jean de Holland & 1 & 0 & 1 \\
\hline Johann von Berry & 1 & 0 & 1 \\
\hline Margarete von Bayern & 1 & 0 & 1 \\
\hline Maria von Frankreich & 1 & 0 & 1 \\
\hline «Bischof der Narren« & 1 & 0 & 1 \\
\hline Amadeus VIII. von Savoyen & 1 & 0 & 1 \\
\hline Anceau de Salins & 1 & 0 & 1 \\
\hline Armel de Châteaugiron & 1 & 0 & 1 \\
\hline Benedikt XIII. & 1 & 0 & 1 \\
\hline Bernard d'Asuel & 1 & 0 & 1 \\
\hline Bernhard VII. von Armagnac & 1 & 0 & 1 \\
\hline Berthelot Helyot & 1 & 0 & 1 \\
\hline Charles d'Ivry & 1 & 0 & 1 \\
\hline Charles de Chambly & 1 & 0 & 1 \\
\hline Charles de Hangest & 1 & 0 & 1 \\
\hline Charles de Rohan & 1 & 0 & 1 \\
\hline Charles de Savoisy & 1 & 0 & 1 \\
\hline Elion de Neilhac & 1 & 0 & 1 \\
\hline Enguerrand de Coucy & 1 & 0 & 1 \\
\hline Gilles de Vrolende & 1 & 0 & 1 \\
\hline Girard de Rigny & 1 & 0 & 1 \\
\hline Guillaume d'Aumas & 1 & 0 & 1 \\
\hline Guillaume Martel & 1 & 0 & 1 \\
\hline Guy de La Roche-Guyon & 1 & 0 & 1 \\
\hline Guy de Pontaillier & 1 & 0 & 1 \\
\hline Hugues de Chalon & 1 & 0 & 1 \\
\hline Isabelle de Coucy & 1 & 0 & 1 \\
\hline Jacot Blanchet & 1 & 0 & 1 \\
\hline Jacques II de Bourbon & 1 & 0 & 1 \\
\hline Jean de Bétizac & 1 & 0 & 1 \\
\hline Jean de Dinant & 1 & 0 & 1 \\
\hline Jean de Graville & 1 & 0 & 1 \\
\hline Jean de Poquières & 1 & 0 & 1 \\
\hline Jean de Tancarville & 1 & 0 & 1 \\
\hline Jean de Vergy & 1 & 0 & 1 \\
\hline Jean du Rupt & 1 & 0 & 1 \\
\hline Jean I de Bourbon & 1 & 0 & 1 \\
\hline Jean le Voyer & 1 & 0 & 1 \\
\hline Johan Rodrigues & 1 & 0 & 1 \\
\hline Johann I. von Bourbon & 1 & 0 & 1 \\
\hline Johann IV. von Bretagne & 1 & 0 & 1 \\
\hline Johann von Brabant & 1 & $\mathbf{0}$ & 1 \\
\hline Johann von Frankreich & 1 & 0 & 1 \\
\hline
\end{tabular}


Philipp der Kühne Philipp der Kühne Philipp der Kühne Philipp der Kühne Philipp der Kühne Philipp der Kühne Philipp der Kühne Philipp der Kühne Philipp der Kühne Philipp der Kühne Philipp der Kühne Philipp der Kühne Philipp der Kühne Philipp der Kühne Philipp der Kühne Philipp der Kühne Philipp der Kühne Philipp der Kühne Philipp der Kühne Philipp der Kühne Philipp der Kühne Philipp der Kühne Philipp der Kühne Philipp der Kühne Philipp der Kühne Philipp der Kühne Philippe de Vertus Pierre Culon Pierre de Gynes Pierre de l'Esclat Pierre de Savoisy Pierre Neveu Pierre Trousseau Raymond de Lescure Renier de Bouligny Richard II.

Simon de Cramaud Thevenin de Montigny Ugo de Robertis de Tripoli Valentina Visconti Valentina Visconti Valentina Visconti Valentina Visconti Valentina Visconti Valentina Visconti Valentina Visconti Valentina Visconti Valentina Visconti Valentina Visconti Valentina Visconti Valentina Visconti Valentina Visconti

\begin{tabular}{|c|c|c|}
\hline Johanna von Frankreich & 1 & 0 \\
\hline Jossequin de Jardins & 1 & 0 \\
\hline Leopold IV. von Österreich & 1 & 0 \\
\hline Louiset Moullié & 1 & 0 \\
\hline Manuel II. Palaiologos & 1 & 0 \\
\hline Marie de Berry & 1 & 0 \\
\hline Marie de Blaringhehem & 1 & 0 \\
\hline Michelle von Frankreich & 1 & 0 \\
\hline Morinot de Tourzel & 1 & 0 \\
\hline Nicolas Claux & 1 & 0 \\
\hline Nicolas d'Alfous & 1 & 0 \\
\hline Nicolas La Trompette & 1 & 0 \\
\hline Peter von Genf & 1 & 0 \\
\hline Philippe de Jaucourt & 1 & 0 \\
\hline Pierre de Craon & 1 & 0 \\
\hline Pierre de Villaines & 1 & 0 \\
\hline Raillart de Chauffour & 1 & 0 \\
\hline Regnaud de Nantouillet & 1 & 0 \\
\hline Regnault de Flandre & 1 & 0 \\
\hline Renaud de Trie & 1 & 0 \\
\hline Robert d'Aunoy & 1 & 0 \\
\hline Robinet le Tirant & 1 & 0 \\
\hline Senville & 1 & 0 \\
\hline Thomas de Rye & 1 & 0 \\
\hline Tristan & 1 & 0 \\
\hline Villemote de Honcoigne & 1 & 0 \\
\hline Johann von Berry & 1 & 0 \\
\hline Johann von Berry & 1 & 0 \\
\hline Johann von Berry & 1 & 0 \\
\hline Johann von Berry & 1 & 0 \\
\hline Johann von Berry & 1 & 0 \\
\hline Johann von Berry & 1 & 0 \\
\hline Johann von Berry & 1 & 0 \\
\hline Johann von Berry & 1 & 0 \\
\hline Johann von Berry & 1 & 0 \\
\hline Isabella von Frankreich & 1 & 0 \\
\hline Johann von Berry & 1 & 0 \\
\hline Johann von Berry & 1 & 0 \\
\hline Johann von Berry & 1 & 0 \\
\hline Boniface & 1 & 0 \\
\hline Catherine de Fastavarin & 1 & 0 \\
\hline Catherine de Villiers & 1 & 0 \\
\hline Enguerrand de Coucy & 1 & 0 \\
\hline Guillemette de Flacourt & 1 & 0 \\
\hline Jean d'Angoulême & 1 & 0 \\
\hline Jean de Dunois & 1 & 0 \\
\hline Jeanne de Houdetot & 1 & 0 \\
\hline Jeanne de La Tour & 1 & 0 \\
\hline Jeanne de Luxembourg & 1 & 0 \\
\hline Jeanne de Montueil & 1 & 0 \\
\hline Jeanne de Saint-Pol & 1 & 0 \\
\hline Jeanne de Salçay & 1 & 0 \\
\hline
\end{tabular}




\begin{tabular}{|l|l|l|l|l|} 
Valentina Visconti & Jeanne de Soisy & 1 & 0 & 1 \\
Valentina Visconti & Jeanne la Brune & 1 & 0 & 1 \\
Valentina Visconti & Jehannette & 1 & 0 & 1 \\
Valentina Visconti & Johann von Berry & 1 & 0 & 1 \\
Valentina Visconti & Ludwig von Guyenne & 1 & 0 & 1 \\
Valentina Visconti & Mademoiselle de Luxem- & 1 & 0 & 1 \\
& bourg & & & \\
Valentina Visconti & Marguerite de Germonville & 1 & 0 & 1 \\
Valentina Visconti & Marguerite de Neufmoulin & 1 & 0 & 1 \\
Valentina Visconti & Marguerite du Solier & 1 & 0 & 1 \\
Valentina Visconti & Marguerite Spissau & 1 & 0 & 1 \\
Valentina Visconti & Maria von Frankreich & 1 & 0 & 1 \\
Valentina Visconti & Philippe de Savoisy & 1 & 0 & 1 \\
Valentina Visconti & Philippe de Vertus & 1 & 0 & 1 \\
Yolande von Aragon & Karl (VII.) & 1 & 0 & 1 \\
\hline
\end{tabular}

Tab. 10: Bindungssziffern namentlich faßbarer Schenkbeziehungen

Werden die zehn höchsten Ränge betrachtet, so läßt sich feststellen, daß dort alle Schenkbeziehungen bis auf eine Ausnahme, die durch Johann Ohnefurcht bestimmt ist, von Philipp dem Kühnen dominiert worden sind, der in insgesamt 138 Schenkbeziehungen auftritt. Zum Vergleich: Johann von Berry erscheint in 96, Ludwig von Orléans in 63, Karl VI. in 44, Isabeau de Bavière in 35, und Johann Ohnefurcht in 71 Paarungen als Schenker oder Beschenkter. Der Dominanz Philipps des Kühnen haben auch Guy de La Trémoille und Jean Canard ihren Aufstieg in die Spitzengruppe zu verdanken, also als Beschenkte, nicht als Schenker. Alle Mitglieder in dieser Gruppe sind bis auf die beiden vorgenannten fürstlicher Abkunft, darunter mit Isabeau de Bavière und Margarete von Flandern zwei Frauen. Da die 10 höchsten Ränge von nur 10 nicht identischen Personen besetzt werden, beträgt hier der Frauenanteil $20 \%$. 282 Schenkvorgänge sind allein in dieser Gruppe vereint, was einem beachtlichen Anteil von etwa 16,3\% bei insgesamt 1.609 Schenkvorgängen entspricht. Wird der Blick auf die folgenden Ränge gerichtet, so zeigt sich, daß die ersten nicht fürstlichen Personen, Guillaume de La Trémoille und Marie de Sully, recht bald auf den Rängen 11 und 13 erscheinen. Auffällig sind die endlosen Reihen von in der Regel einseitig-asymmetrischen Schenkbeziehungen, die größtenteils wieder von Angehörigen der Spitzenpositionen in ihrer Funktion als Schenker bestimmt wurden. 488 dieser Beziehungen können gezählt werden, was bedeutet, daß fast $89 \%$ von den genannten 550 Schenkbeziehungen in nur einer Richtung verlaufen. Werden alle einseitig verlaufenden Schenkbeziehungen aus der Betrachtung herausgenommen, so bleiben einerseits zwar bis auf die Ränge 5, 14 und 16 die obersten 17 Ränge fast vollständig bestehen, aber der gesamte 24 . Rang bleibt unberücksichtigt. Letztlich umfaßt der in dieser Gruppe in direktem Geschenkaustausch miteinander stehende Kreis lediglich 46 (nicht ganz 12,5\%) von 373 faßbaren Personen, da- 
runter neun Frauen: Anton von Burgund, Archambaut de Foix, Ascelin Royne, Charles d'Artois, Clemens VII., Dino Rapondi, Giacomo Rapondi, Gilles Malet, Guillaume de La Trémoille, Guy de La Rochefoucauld, Guy de La Trémoille, Jean Canard, Johann Ohnefurcht, Johann V. von Bretagne, Johann von Berry, Karl I. von Bourbon, Karl III. von Navarra, Karl VI., Karl von Orléans, Gebrüder Limburg, Louis de Sancerre, Louis de Vendôme, Ludwig der Bärtige, Ludwig II. von Bourbon, Ludwig von Guyenne, Ludwig von Male, Ludwig von Orléans, Manuel II. Palaiologos, Oudart de L'Epinace, Pasqual de Paloiz, Philipp der Kühne, Philippe d'Artois, Pierre de La Trémoille, Renier Pot, Waleran von Luxemburg, Jeanne de Boulogne, Jeanne de Peschin, Isabeau de Bavière, Isabella von Frankreich, Margarete II. von Burgund, Margarete von Bayern, Margarete von Flandern, Marie de Sully und Valentina Visconti. Sind somit die Bindungshäufigkeiten anhand der Zahl der Schenkakte, für die keine Wertzuweisungen möglich waren, festgestellt und die diesbezüglich prominentesten Schenkbeziehungen und Protagonisten des höfischen Geschenkverkehrs herausgearbeitet worden, so soll Tabelle 11 die wertmäßig definierten Schenkbeziehungen zeigen. In dieser Tabelle sind die Richtungen der einzelnen Schenkvorgänge, von denen 426 festgestellt werden konnten, beibehalten worden und wurden nicht hinsichtlich der tragenden Personen zusammengefaßt.

\begin{tabular}{|c|l|l|c|}
\hline Rang & Schenker & Beschenkte & $\begin{array}{c}\text { Werte } \\
\text { d./100.000 }\end{array}$ \\
\hline 1 & Philipp der Kühne & Margarete von Flandern & 139,64160 \\
\hline 2 & Philipp der Kühne & Johann von Berry & 107,07360 \\
\hline 3 & Philipp der Kühne & Karl VI. & 87,49515 \\
\hline 4 & Karl VI. & Johann von Berry & 54,35040 \\
\hline 5 & Philipp der Kühne & Philipp der Kühne & 41,87520 \\
\hline 6 & Philipp der Kühne & Ludwig von Orléans & 37,28040 \\
\hline 7 & Karl VI. & Philipp der Kühne & 33,86880 \\
\hline 8 & Philipp der Kühne & Guy de La Trémoille & 19,33680 \\
\hline 9 & Philipp der Kühne & Isabeau de Bavière & 19,13100 \\
\hline 10 & Ludwig von Orléans & Karl VI. & 14,76000 \\
\hline 11 & Philipp der Kühne & Johann Ohnefurcht & 12,98640 \\
\hline 12 & Karl VI. & Johann Ohnefurcht & 12,12000 \\
\hline 13 & Isabeau de Bavière & Karl VI. & 11,68920 \\
\hline 14 & Ludwig von Orléans & Johann von Berry & 11,65980 \\
\hline 15 & Ludwig von Orléans & Isabeau de Bavière & 10,90484 \\
\hline 16 & Philipp der Kühne & Margarete von Bayern & 10,86390 \\
\hline 17 & Ludwig von Orléans & Valentina Visconti & 10,38567 \\
\hline 18 & Philipp der Kühne & Jean Canard & 9,34297 \\
\hline 19 & Philipp der Kühne & Guillaume de La Trémoille & $\mathbf{8 , 8 0 8 0 0}$ \\
\hline 20 & Philipp der Kühne & Ludwig II. von Bourbon & 7,48170 \\
\hline 21 & Philipp der Kühne & Richard II. & 6,48000 \\
\hline 22 & Valentina Visconti & Ludwig von Orléans & 6,31160 \\
\hline 23 & Ludwig von Orléans & Philipp der Kühne & $\mathbf{6 , 1 2 0 0 0}$ \\
\hline 24 & Johann Ohnefurcht & Margarete von Bayern & 5,99805 \\
\hline 25 & Valentina Visconti & Karl VI. & 5,56800 \\
\hline & & & \\
\hline
\end{tabular}




\begin{tabular}{|c|c|c|c|}
\hline 26 & Ludwig von Orléans & Ludwig von Orléans & 5,40000 \\
\hline 27 & Philipp der Kühne & Karl von Frankreich & 5,25600 \\
\hline 28 & Philipp der Kühne & Maria I. von Burgund & 5,09850 \\
\hline 29 & Philipp der Kühne & Margarete II. von Burgund & 4,94619 \\
\hline 30 & Philipp der Kühne & Anton von Burgund & 4,89871 \\
\hline 31 & Philipp der Kühne & Maria II. von Burgund & 4,80219 \\
\hline 32 & Philipp der Kühne & Clemens VII. & 4,80000 \\
\hline 33 & Philipp der Kühne & Bona von Burgund & 4,75291 \\
\hline 34 & Anton von Burgund & Philipp der Kühne & 4,32000 \\
\hline 35 & Philipp der Kühne & Marie de Sully & 4,10100 \\
\hline 36 & Valentina Visconti & Isabeau de Bavière & 3,89760 \\
\hline 37 & Philipp der Kühne & Pierre de Navarre & 3,75120 \\
\hline 38 & Philipp der Kühne & Valentina Visconti & 3,67200 \\
\hline 39 & Philipp der Kühne & Jeanne de Saint-Pol & 3,62281 \\
\hline 40 & Johann Ohnefurcht & Jean de Saulx & 3,48000 \\
\hline 41 & Philipp der Kühne & Johann V. von Bretagne & 3,42000 \\
\hline 42 & Philipp der Kühne & Philipp von Burgund & 3,36000 \\
\hline 43 & Philipp der Kühne & Katharina I. von Burgund & 3,28290 \\
\hline 44 & Philipp der Kühne & Philipp der Gute & 2,98200 \\
\hline 45 & Margarete von Bayem & Johann Ohnefurcht & 2,47200 \\
\hline 46 & Johann Ohnefurcht & Johann von Berry & 2,46906 \\
\hline 47 & Philipp der Kühne & Pierre de La Trémoille & 2,43933 \\
\hline 48 & Philipp der Kühne & Philippe de Bar & 2,36400 \\
\hline 49 & Karl VI. & Valentina Visconti & 2,28000 \\
\hline 50 & Ludwig II. von Anjou & \begin{tabular}{|l|} 
Johann von Berry \\
\end{tabular} & 2,20800 \\
\hline 51 & Philipp der Kühne & \begin{tabular}{|l|} 
Leo VI. von Lusignan \\
\end{tabular} & 2,10600 \\
\hline 52 & Philipp der Kühne & Arnaud-Amanieu d'Albret & 1,96800 \\
\hline 53 & Philipp der Kühne & Waleran von Luxemburg & 1,87200 \\
\hline $5 \overline{4}$ & Ludwig von Orléans & Ludwig II. von Bourbon & 1,83493 \\
\hline 55 & Margarete von Flandern & Marie de Sully & 1,77600 \\
\hline 56 & Philipp der Kühne & Wilhelm von Bayern & 1,58400 \\
\hline 57 & Philipp der Kühne & Ludwig von Male & 1,50000 \\
\hline 58 & Philipp der Kühne & Philippe d'Artois & 1,46400 \\
\hline 59 & Guillaume de Lodes & Johann von Berry & 1,45200 \\
\hline 60 & $\begin{array}{l}\text { Karl (VII.) } \\
\text { Philipp der Kühne }\end{array}$ & \begin{tabular}{|l|} 
Jean d'Harcourt \\
Ludwig von Guyenne
\end{tabular} & $\begin{array}{l}1,44000 \\
1,44000 \\
\end{array}$ \\
\hline 61 & Johann Ohnefurcht & Michelle von Frankreich & 1,39275 \\
\hline 62 & Philipp der Kühne & Guy de La Rochefoucauld & 1,35900 \\
\hline 63 & Johann Ohnefurcht & Ludwig II. von Anjou & 1,32900 \\
\hline 64 & Ludwig von Guyenne & Johann Ohnefurcht & 1,32000 \\
\hline 65 & Philipp der Kühne & Ludwig II. von Anjou & 1,26720 \\
\hline 66 & Karl (VII.) & Jean Coeur & 1,20000 \\
\hline 67 & Jeanne de Boulogne & Johann von Berry & 1,14600 \\
\hline 68 & Margarete von Flandern & Johann von Berry & 1,13430 \\
\hline 69 & Philipp der Kühne & Jean de Montaigu & 1,08600 \\
\hline 70 & $\begin{array}{l}\text { Karl VI. } \\
\text { Karl (VII.) } \\
\text { Karl von Orléans } \\
\end{array}$ & $\begin{array}{l}\text { Isabeau de Bavière } \\
\text { Adam de Champgiraut } \\
\text { Johann I. von Bourbon }\end{array}$ & $\begin{array}{l}1,08000 \\
1,08000 \\
1,08000 \\
\end{array}$ \\
\hline 71 & Johann Ohnefurcht & Jean de Montagu & 1,06725 \\
\hline
\end{tabular}




\begin{tabular}{|c|c|c|c|}
\hline 72 & $\begin{array}{l}\text { Erard Moriset, Oudart de La } \\
\text { Barre, Michel le Beuf und } \\
\text { Pierre de Gynes }\end{array}$ & Johann von Berry & 1,00080 \\
\hline 73 & \begin{tabular}{|l} 
Guillaume de Boisratier, \\
Martin Gouge \\
Isabeau de Bavière \\
Johann Ohnefurcht \\
Karl (VII.) \\
Karl (VII.) \\
Karl (VII.) \\
Karl (VII.) \\
Karl (VII.) \\
Philipp der Kühne \\
\end{tabular} & $\begin{array}{l}\text { Johann von Berry } \\
\text { Ludwig von Orléans } \\
\text { Philippe Musnier } \\
\text { Alexandre Le Boursier } \\
\text { Charles de Luxembourg } \\
\text { Guillaume de Lucé } \\
\text { Raymond Raguier } \\
\text { Renier de Bouligny } \\
\text { Pasqual de Paloiz }\end{array}$ & $\begin{array}{l}0,96000 \\
0,96000 \\
0,96000 \\
0,96000 \\
0,96000 \\
0,96000 \\
0,96000 \\
0,96000 \\
0,96000 \\
\end{array}$ \\
\hline 74 & Philipp der Kühne & Louis de Poissy & 0,91200 \\
\hline 75 & $\begin{array}{l}\text { Karl VI. } \\
\text { Philipp der Kühne }\end{array}$ & $\begin{array}{l}\text { Ludwig von Orléans } \\
\text { Jean de Vienne }\end{array}$ & $\begin{array}{l}0,84000 \\
0,84000\end{array}$ \\
\hline 76 & Ludwig von Orléans & Jean de Trie & 0,81120 \\
\hline 77 & Ludwig von Orléans & Karl III. von Navarra & 0,74498 \\
\hline 78 & \begin{tabular}{|l|} 
Isabeau de Bavière \\
Karl (VII.) \\
Karl (VII.) \\
Karl (VII.) \\
Karl (VII.) \\
Ludwig von Orléans \\
Philipp der Kühne \\
Philipp der Kühne \\
Philipp der Kühne \\
\end{tabular} & $\begin{array}{l}\text { Ludwig der Bärtige } \\
\text { Bernhard VIII. von Armagnac } \\
\text { Charles d'Albret } \\
\text { Isabeau de Barres } \\
\text { Karl I. von Bourbon } \\
\text { Ludwig von Guyenne } \\
\text { Guichard Dauphin } \\
\text { Giacomo Rapondi } \\
\text { Johann IV. von Bretagne } \\
\end{array}$ & $\begin{array}{l}0,72000 \\
0,72000 \\
0,72000 \\
0,72000 \\
0,72000 \\
0,72000 \\
0,72000 \\
0,72000 \\
0,72000 \\
\end{array}$ \\
\hline 79 & Philipp der Kühne & Charles d'Albret & 0,70320 \\
\hline 80 & $\begin{array}{l}\text { Margarete von Bayem } \\
\text { Margarete von Bayern } \\
\text { Margarete von Bayern } \\
\text { Margarete von Bayern } \\
\text { Philipp der Kühne } \\
\end{array}$ & $\begin{array}{l}\text { Agnes von Burgund } \\
\text { Anna von Burgund } \\
\text { Katharina I. von Burgund } \\
\text { Margarete II. von Burgund } \\
\text { Johann I. von Bourbon } \\
\end{array}$ & $\begin{array}{l}0,67200 \\
0,67200 \\
0,67200 \\
0,67200 \\
0,67200 \\
\end{array}$ \\
\hline 81 & \begin{tabular}{|l} 
Valentina Visconti \\
\end{tabular} & Karl von Frankreich & 0,65178 \\
\hline 82 & Louis de Vendôme & Johann von Berry & 0,64800 \\
\hline 83 & Karl von Orléans & Jean de Gaules & 0,62815 \\
\hline 84 & $\begin{array}{l}\text { Margarete von Flandern } \\
\text { Philipp der Kühne } \\
\end{array}$ & \begin{tabular}{|l|} 
Ludwig von Male \\
Oudard de Chazeron \\
\end{tabular} & $\begin{array}{l}0,60000 \\
0,60000 \\
\end{array}$ \\
\hline 85 & Ludwig von Orléans & Guillaume Martel & 0,59244 \\
\hline 86 & Johann Ohnefurcht & Jean Pouquet & 0,57937 \\
\hline 87 & Johann Ohnefurcht & Pierre des Essarts & 0,56790 \\
\hline 88 & Philipp der Kühne & Henri de Montbéliard & 0,55200 \\
\hline 89 & Margarete von Bayern & \begin{tabular}{|l|} 
Philipp der Kühne \\
\end{tabular} & 0,54240 \\
\hline 90 & $\begin{array}{l}\text { Karl VI. } \\
\text { Karl VI. } \\
\text { Philipp der Kühne }\end{array}$ & $\begin{array}{l}\text { Katharina von Frankreich } \\
\text { Marie de Berry } \\
\text { Ludwig der Bärtige }\end{array}$ & $\begin{array}{l}0,54000 \\
0,54000 \\
0,54000\end{array}$ \\
\hline 91 & Ludwig von Orléans & Isabella von Frankreich & 0,53400 \\
\hline 92 & Ludwig von Orléans & Pierre de Navarre & 0,52803 \\
\hline 93 & \begin{tabular}{|l|} 
Philipp der Kühne \\
\end{tabular} & Renier Pot & 0,52800 \\
\hline 94 & Philipp der Kühne & Jean de Hangest & 0,51840 \\
\hline 95 & Johann von Berry & Ludwig der Bärtige & 0,51188 \\
\hline
\end{tabular}




\begin{tabular}{|c|c|c|c|}
\hline 96 & $\begin{array}{l}\text { Ludwig von Orléans } \\
\text { Ludwig von Orléans }\end{array}$ & $\begin{array}{l}\text { Charles d'Ivry } \\
\text { Jean de Montagu } \\
\end{array}$ & $\begin{array}{l}0,49644 \\
0,49644 \\
\end{array}$ \\
\hline 97 & $\begin{array}{l}\text { Jean IV d'Armagnac } \\
\text { Johann Ohnefurcht } \\
\text { Johann Ohnefurcht } \\
\text { Johann Ohnefurcht } \\
\text { Johann Ohnefurcht } \\
\text { Johann Ohnefurcht } \\
\text { Johann Ohnefurcht } \\
\text { Johann Ohnefurcht } \\
\text { Johann Ohnefurcht } \\
\text { Johann Ohnefurcht } \\
\text { Karl VI. } \\
\text { Karl (VII.) } \\
\text { Karl (VII.) } \\
\text { Karl (VII.) } \\
\text { Karl (VII.) } \\
\text { Karl (VII.) } \\
\text { Karl (VII.) } \\
\text { Karl (VII.) } \\
\text { Karl (VII.) } \\
\text { Ludwig von Orléans } \\
\text { Philipp der Kühne } \\
\text { Philipp der Kühne } \\
\text { Philipp der Kühne } \\
\text { Philipp der Kühne } \\
\end{array}$ & $\begin{array}{l}\text { Johann von Berry } \\
\text { Charles de Savoisy } \\
\text { Guillaume de Champdivers } \\
\text { Jean de Puligny } \\
\text { Jean de Toulongeon } \\
\text { Jean Fale } \\
\text { Jeanne de Peschin } \\
\text { Philipp der Gute } \\
\text { Pierre Gorremont } \\
\text { Regnault Doriac } \\
\text { Arnaud-Amanieu d'Albret } \\
\text { Gilbert Motier de La Fayette } \\
\text { Guillaume d'Avaugour } \\
\text { Guillaume du Bez } \\
\text { Henri de Savoisy } \\
\text { Henri du Mesnil } \\
\text { Jean Cadart } \\
\text { Jean Louvet } \\
\text { Robert Mallière } \\
\text { Charles d'Albret } \\
\text { Gilles Malet } \\
\text { Johan Rodrigues } \\
\text { Peter von Genf } \\
\text { Tristan }\end{array}$ & $\begin{array}{l}0,48000 \\
0,48000 \\
0,48000 \\
0,48000 \\
0,48000 \\
0,48000 \\
0,48000 \\
0,48000 \\
0,48000 \\
0,48000 \\
0,48000 \\
0,48000 \\
0,48000 \\
0,48000 \\
0,48000 \\
0,48000 \\
0,48000 \\
0,48000 \\
0,48000 \\
0,48000 \\
0,48000 \\
0,48000 \\
0,48000 \\
0,48000 \\
\end{array}$ \\
\hline 98 & Ludwig von Guyenne & Regnaut d'Angennes & 0,45900 \\
\hline 99 & Johann Ohnefurcht & Ludwig der Bärtige & 0,45600 \\
\hline 100 & Isabeau de Bavière & Philippe de Moulins & 0,44388 \\
\hline 101 & Johann von Berry & Jeanne de Boulogne & 0,44212 \\
\hline 102 & \begin{tabular}{|l} 
Karl VI. \\
Philipp der Kühne \\
\end{tabular} & $\begin{array}{l}\text { Ludwig II. von Bourbon } \\
\text { Jean de Trie }\end{array}$ & $\begin{array}{l}0,43200 \\
0,43200 \\
\end{array}$ \\
\hline 103 & Philipp der Kühne & Charles de Rohan & 0,42000 \\
\hline 104 & $\begin{array}{l}\text { Isabeau de Bavière } \\
\text { Jean I d'Alençon } \\
\text { Martin Gouge }\end{array}$ & $\begin{array}{l}\text { Valentina Visconti } \\
\text { Johann von Berry } \\
\text { Johann von Berry }\end{array}$ & $\begin{array}{l}0,40800 \\
0,40800 \\
0,40800 \\
\end{array}$ \\
\hline 105 & Karl von Orléans & Bonne d'Armagnac & 0,40620 \\
\hline 106 & Jean de Montaigu & Johann von Berry & 0,40500 \\
\hline 107 & Johann von Berry & Margarete II. von Burgund & 0,39360 \\
\hline 108 & $\begin{array}{l}\text { Johann Ohnefurcht } \\
\text { Karl VI. } \\
\end{array}$ & $\begin{array}{l}\text { Ludwig von Orléans } \\
\text { Jeanne de Dreux }\end{array}$ & $\begin{array}{l}0,38400 \\
0,38400 \\
\end{array}$ \\
\hline 109 & Johann von Berry & Charles d'Artois & 0,37950 \\
\hline 110 & $\begin{array}{l}\text { Ludwig von Orléans } \\
\text { Ludwig von Orléans }\end{array}$ & $\begin{array}{l}\text { Karl von Orléans } \\
\text { Philippe de Vertus }\end{array}$ & $\begin{array}{l}0,37320 \\
0,37320 \\
\end{array}$ \\
\hline 111 & $\begin{array}{l}\text { Johann von Berry } \\
\text { Karl (VII.) } \\
\text { Philipp der Kühne } \\
\text { Philipp der Kühne } \\
\end{array}$ & $\begin{array}{l}\text { Pierre II d'Orgemont } \\
\text { Denis de Chesne } \\
\text { Enguerrand de Coucy } \\
\text { Pierre de Villaines } \\
\end{array}$ & $\begin{array}{l}0,36000 \\
0,36000 \\
0,36000 \\
0,36000 \\
\end{array}$ \\
\hline 112 & Marie de Sully & Guy de La Trémoille & 0,35280 \\
\hline 113 & Johann Ohnefurcht & Jean de Chevenon & 0,34680 \\
\hline 114 & Johann von Berry & Louis de Vendôme & 0,34652 \\
\hline
\end{tabular}




\begin{tabular}{|c|c|c|c|}
\hline 115 & \begin{tabular}{|l|} 
Margarete von Flandern \\
Philipp der Kühne
\end{tabular} & \begin{tabular}{|l|} 
Ludwig von Orléans \\
Charles de Châtillon
\end{tabular} & $\begin{array}{l}0,33600 \\
0,33600\end{array}$ \\
\hline 116 & \begin{tabular}{|l} 
Karl von Orléans \\
Philipp der Kühne
\end{tabular} & $\begin{array}{l}\text { Guy de La Roche-Guyon } \\
\text { Jean de Vergy }\end{array}$ & $\begin{array}{l}0,32400 \\
0,32400\end{array}$ \\
\hline 117 & Philipp der Kühne & Marie de Blaringhehem & 0,31619 \\
\hline 118 & Philipp der Kühne & Philippe de Jaucourt & 0,30600 \\
\hline 119 & $\begin{array}{l}\text { Isabeau de Bavière } \\
\text { Philipp der Kühne }\end{array}$ & $\begin{array}{l}\text { Isabella von Frankreich } \\
\text { Jean Le Meingre }\end{array}$ & $\begin{array}{l}0,30000 \\
0,30000\end{array}$ \\
\hline 120 & Isabeau de Bavière & Arnaud de Corbie & 0,29268 \\
\hline 121 & $\begin{array}{l}\text { Guillaume de Montrevel } \\
\text { Karl VI. } \\
\text { Karl (VII.) } \\
\text { Ludwig von Orléans } \\
\text { Philipp der Gute } \\
\text { Philipp der Kühne } \\
\text { Valentina Visconti }\end{array}$ & $\begin{array}{l}\text { Johann von Berry } \\
\text { Enguerrand de Coucy } \\
\text { Jean d'Arpajon } \\
\text { Margarete von Bayern } \\
\text { Anna von Burgund } \\
\text { Morinot de Tourzel } \\
\text { Jean d'Angoulême }\end{array}$ & $\begin{array}{l}0,28800 \\
0,28800 \\
0,28800 \\
0,28800 \\
0,28800 \\
0,28800 \\
0,28800\end{array}$ \\
\hline 122 & Bernhard VII. von Armagnac & Johann von Berry & 0,28560 \\
\hline 123 & Marie de Berry & Johann von Berry & 0,28440 \\
\hline 124 & Isabeau de Bavière & Catherine de Fastavarin & 0,27570 \\
\hline 125 & Valentina Visconti & Enguerrand de Coucy & 0,27363 \\
\hline & $\begin{array}{l}\text { Isabeau de Bavière } \\
\text { Philipp der Kühne } \\
\text { Philipp der Kühne } \\
\text { Philipp der Kühne }\end{array}$ & $\begin{array}{l}\text { Karl (VII.) } \\
\text { Arthur de Richemont } \\
\text { Gilles de Bretagne } \\
\text { Regnault de Flandre }\end{array}$ & $\begin{array}{l}0,27000 \\
0,27000 \\
0,27000 \\
0,27000\end{array}$ \\
\hline 126 & Philipp der Gute & Margarete von Bayern & 0,26640 \\
\hline 127 & Ludwig von Orléans & Jean de Hangest & 0,26400 \\
\hline 128 & Ludwig von Orléans & Alain de Beaumont & 0,24865 \\
\hline 129 & Johann Ohnefurcht & Karl VI. & 0,24480 \\
\hline 130 & $\begin{array}{l}\text { Charlotte de Bourbon } \\
\text { Johann Ohnefurcht } \\
\text { Johann Ohnefurcht } \\
\text { Johann Ohnefurcht } \\
\text { Johann Ohnefurcht } \\
\text { Johann von Berry } \\
\text { Karl VI. } \\
\text { Karl VI. } \\
\text { Karl VI. } \\
\text { Karl VI. } \\
\text { Karl (VII.) } \\
\text { Karl (VII.) } \\
\text { Karl (VII.) } \\
\text { Karl (VII.) } \\
\text { Karl (VII.) } \\
\text { Karl (VII.) } \\
\text { Ludwig von Orléans } \\
\text { Ludwig von Orléans } \\
\text { Ludwig von Orléans } \\
\text { Margarete von Bayern } \\
\text { Philipp der Gute } \\
\text { Philipp der Kühne } \\
\text { Philipp der Kühne } \\
\text { Philipp der Kühne } \\
\text { Valentina Visconti }\end{array}$ & $\begin{array}{l}\text { Johann von Berry } \\
\text { Antoine Forestz } \\
\text { Jean de Velery } \\
\text { Regnault Thumery } \\
\text { Renier Pot } \\
\text { Karl I. von Bourbon } \\
\text { Isabella von Frankreich } \\
\text { Jeanne d'Harcourt } \\
\text { Jeanne de Vendôme } \\
\text { Pierre de Navarre } \\
\text { Bertrand de Rochefort } \\
\text { Jean de Bonnay } \\
\text { Morelet de Carville } \\
\text { Pierre de Chantelle } \\
\text { Prégent de Coëtivy } \\
\text { Rogerin Blosset } \\
\text { Jacques de Peschin } \\
\text { Johann Ohnefurcht } \\
\text { Philippe de Florigny } \\
\text { Johann von Berry } \\
\text { Agnes von Burgund } \\
\text { Hugues de Chalon } \\
\text { Margarete I. von Burgund } \\
\text { Pierre II d'Orgemont } \\
\text { Ludwig von Guyenne }\end{array}$ & $\begin{array}{l}0,24000 \\
0,24000 \\
0,24000 \\
0,24000 \\
0,24000 \\
0,24000 \\
0,24000 \\
0,24000 \\
0,24000 \\
0,24000 \\
0,24000 \\
0,24000 \\
0,24000 \\
0,24000 \\
0,24000 \\
0,24000 \\
0,24000 \\
0,24000 \\
0,24000 \\
0,24000 \\
0,24000 \\
0,24000 \\
0,24000 \\
0,24000 \\
0,24000\end{array}$ \\
\hline
\end{tabular}




\begin{tabular}{|c|c|c|c|}
\hline 131 & Beraud III d'Auvergne & Johann von Berry & 0,23040 \\
\hline 132 & Karl VI. & Karl VI. & 0,21600 \\
\hline 133 & Marie de Sully & Margarete von Flandern & 0,21285 \\
\hline 134 & Philipp der Kühne & Jean de Bétizac & 0,20460 \\
\hline 135 & Ludwig von Orléans & Robert d'Aunoy & 0,19800 \\
\hline 136 & $\begin{array}{l}\text { Adhémar Aleman } \\
\text { Isabeau de Bavière } \\
\text { Janus de Grimault } \\
\text { Karl VI. } \\
\text { Morinot de Tourzel } \\
\text { Philipp der Kühne } \\
\text { Valentina Visconti } \\
\end{array}$ & $\begin{array}{l}\text { Johann von Berry } \\
\text { Jeanne de Vendôme } \\
\text { Johann von Berry } \\
\text { Philippe d'Artois } \\
\text { Johann von Berry } \\
\text { Jean I de Bourbon } \\
\text { Marie de Duisy } \\
\end{array}$ & $\begin{array}{l}0,19200 \\
0,19200 \\
0,19200 \\
0,19200 \\
0,19200 \\
0,19200 \\
0,19200 \\
\end{array}$ \\
\hline 137 & \begin{tabular}{|l|} 
Jacques Courau \\
Philipp der Kühne \\
\end{tabular} & $\begin{array}{l}\text { Johann von Berry } \\
\text { Anceau de Salins } \\
\end{array}$ & $\begin{array}{l}0,18000 \\
0,18000 \\
\end{array}$ \\
\hline 138 & Bonne de Berry & Johann von Berry & 0,17400 \\
\hline 139 & $\begin{array}{l}\text { Isabeau de Bavière } \\
\text { Isabeau de Bavière } \\
\text { Isabeau de Bavière } \\
\text { Isabeau de Bavière } \\
\text { Isabeau de Bavière } \\
\text { Isabeau de Bavière } \\
\text { Isabeau de Bavière }\end{array}$ & $\begin{array}{l}\text { Alips de Beauchamp } \\
\text { Catherine de Villiers } \\
\text { Isabelle La Bouteillière } \\
\text { Jeanne de La Tour } \\
\text { Jeanne de Montueil } \\
\text { Marguerite de Germonville } \\
\text { Marie de Duisy } \\
\end{array}$ & $\begin{array}{l}0,17310 \\
0,17310 \\
0,17310 \\
0,17310 \\
0,17310 \\
0,17310 \\
0,17310 \\
\end{array}$ \\
\hline 140 & Valentina Visconti & Jeanne de Chepoy & 0,17280 \\
\hline 141 & Christine de Pisan & Philipp der Kühne & 0,17200 \\
\hline 142 & \begin{tabular}{|l|} 
Ludwig von Orléans \\
Valentina Visconti \\
\end{tabular} & \begin{tabular}{|l|} 
Charles de Savoisy \\
Philippe de Vertus \\
\end{tabular} & $\begin{array}{l}0,16800 \\
0,16800 \\
\end{array}$ \\
\hline 143 & Ludwig von Orléans & Adam Chatelain & 0,16320 \\
\hline 144 & Philipp der Kühne & Gilles de Vrolende & 0,16200 \\
\hline 145 & Johann Ohnefurcht & Tassin & 0,15345 \\
\hline 146 & Ludwig von Orléans & Regnaut d'Angennes & 0,15000 \\
\hline 147 & $\begin{array}{l}\text { Johann Ohnefurcht } \\
\text { Johann Ohnefurcht } \\
\text { Johann Ohnefurcht } \\
\text { Johann Ohnefurcht }\end{array}$ & $\begin{array}{l}\text { Antoine de Craon } \\
\text { Jacques de Trie } \\
\text { Jean de Graville } \\
\text { Jean de Montaigu }\end{array}$ & $\begin{array}{l}0,14932 \\
0,14932 \\
0,14932 \\
0,14932 \\
\end{array}$ \\
\hline 148 & Johann Ohnefurcht & Jean Marchand & 0,14880 \\
\hline 149 & Johann Ohnefurcht & Arnaud de Corbie & 0,14580 \\
\hline 150 & $\begin{array}{l}\text { Ascelin Royne } \\
\text { Isabeau de Bavière } \\
\text { Isabeau de Bavière } \\
\text { Johann Ohnefurcht } \\
\text { Johann Ohnefurcht } \\
\text { Karl VI. } \\
\text { Karl VI. } \\
\text { Karl VI. } \\
\text { Karl (VII.) } \\
\text { Karl (VII.) } \\
\text { Karl (VII.) } \\
\text { Karl (VII.) } \\
\text { Karl (VII.) } \\
\text { Karl (VII.) } \\
\text { Karl (VII.) }\end{array}$ & $\begin{array}{l}\text { Johann von Berry } \\
\text { Jeanne d'Harcourt } \\
\text { Marguerite de Préaux } \\
\text { Jean de Vienne } \\
\text { Ludwig von Male } \\
\text { Charles d'Albret } \\
\text { Marguerite de Landes } \\
\text { Philippe de Bar } \\
\text { Chatart de Rochedragoux } \\
\text { Guillaume Boniface } \\
\text { Hernauton d'Andines } \\
\text { Jean Boschet } \\
\text { Jean Gouffier } \\
\text { Philibert de Maleret } \\
\text { Yvon le Begaignon }\end{array}$ & $\begin{array}{l}0,14400 \\
0,14400 \\
0,14400 \\
0,14400 \\
0,14400 \\
0,14400 \\
0,14400 \\
0,14400 \\
0,14400 \\
0,14400 \\
0,14400 \\
0,14400 \\
0,14400 \\
0,14400 \\
0,14400\end{array}$ \\
\hline
\end{tabular}




\begin{tabular}{|c|c|c|c|}
\hline & \begin{tabular}{|l} 
Philipp der Kühne \\
Simon de Cramaud \\
Valentina Visconti \\
\end{tabular} & $\begin{array}{l}\text { Guillaume Martel } \\
\text { Johann von Berry } \\
\text { Jean de Dunois }\end{array}$ & $\begin{array}{l}0,14400 \\
0,14400 \\
0,14400 \\
\end{array}$ \\
\hline 151 & Waleran von Luxemburg & Johann von Berry & 0,13440 \\
\hline 152 & Ludwig von Orléans & Guillaume Paynel & 0,13315 \\
\hline 153 & $\begin{array}{l}\text { Philipp der Kühne } \\
\text { Philipp der Kühne }\end{array}$ & \begin{tabular}{|l} 
Blanche \\
Guillaume de Bours
\end{tabular} & $\begin{array}{l}0,13200 \\
0,13200\end{array}$ \\
\hline 154 & Johann Ohnefurcht & Anton von Burgund & 0,12320 \\
\hline 155 & \begin{tabular}{|l} 
Johann Ohnefurcht \\
Johann Ohnefurcht \\
Karl VI. \\
Karl (VII.) \\
Karl (VII.) \\
Karl (VII.) \\
Ludwig von Orléans \\
Philipp der Kühne \\
Philipp der Kühne \\
Philipp der Kühne \\
Philipp der Kühne \\
Philipp der Kühne \\
Thibaut Portier \\
\end{tabular} & $\begin{array}{l}\text { Dino Rapondi } \\
\text { Pierre de Montbertaud } \\
\text { Jeanne de Châtillon } \\
\text { Charles Garnier } \\
\text { Charles Labbé } \\
\text { Jacques de Villiers } \\
\text { Femmette } \\
\text { Bernard d'Asuel } \\
\text { Dino Rapondi } \\
\text { Girard de Rigny } \\
\text { Guy de La Roche-Guyon } \\
\text { Katharina II. von Burgund } \\
\text { Johann von Berry } \\
\end{array}$ & $\begin{array}{l}0,12000 \\
0,12000 \\
0,12000 \\
0,12000 \\
0,12000 \\
0,12000 \\
0,12000 \\
0,12000 \\
0,12000 \\
0,12000 \\
0,12000 \\
0,12000 \\
0,12000 \\
\end{array}$ \\
\hline 156 & Ludwig von Orléans & Guillaume le Bouteiller & 0,11550 \\
\hline 157 & Isabeau de Bavière & Guillemette de Flacourt & 0,10560 \\
\hline 158 & Valentina Visconti & Isabella von Frankreich & 0,10080 \\
\hline 159 & Johann I. von Bourbon & Johann von Berry & 0,09840 \\
\hline 160 & $\begin{array}{l}\text { Johann Ohnefurcht } \\
\text { Johann Ohnefurcht } \\
\text { Karl von Orléans } \\
\text { Ludwig II. von Bourbon } \\
\text { Ludwig von Orléans } \\
\text { Philipp der Gute } \\
\text { Philipp der Kühne } \\
\text { Philipp der Kühne } \\
\text { Valentina Visconti } \\
\end{array}$ & \begin{tabular}{|l|} 
Jean de Luxembourg \\
Oudart de L'Epinace \\
Johann von Berry \\
Johann von Berry \\
Benedikt XIII. \\
Johann Ohnefurcht \\
Charles d'Ivry \\
Renaud de Trie \\
Jeanne de Luxembourg \\
\end{tabular} & $\begin{array}{l}0,09600 \\
0,09600 \\
0,09600 \\
0,09600 \\
0,09600 \\
0,09600 \\
0,09600 \\
0,09600 \\
0,09600 \\
\end{array}$ \\
\hline 161 & \begin{tabular}{|l|} 
Karl von Orléans \\
Ludwig von Guyenne \\
Ludwig von Orléans \\
Valentina Visconti \\
\end{tabular} & $\begin{array}{l}\text { Jean d'Angoulême } \\
\text { Ludwig der Bärtige } \\
\text { Jeanne de Saint-Pol } \\
\text { Johanna von Frankreich }\end{array}$ & $\begin{array}{l}0,08640 \\
0,08640 \\
0,08640 \\
0,08640 \\
\end{array}$ \\
\hline 162 & $\begin{array}{l}\text { Bonne d'Artois } \\
\text { Philipp der Kühne }\end{array}$ & $\begin{array}{l}\text { Johann von Berry } \\
\text { Charles de Chambly }\end{array}$ & $\begin{array}{l}0,08400 \\
0,08400\end{array}$ \\
\hline 163 & Philipp der Kühne & Jean du Rupt & 0,08100 \\
\hline 164 & Ludwig von Orléans & Perrin Guire & 0,07920 \\
\hline 165 & Robinet d'Etampes & Johann von Berry & 0,07740 \\
\hline 166 & Karl von Orléans & Marguerite d'Orléans & 0,07560 \\
\hline 167 & $\begin{array}{l}\text { Anna von Bourbon } \\
\text { Charles d'Albret } \\
\text { Isabeau de Bavière } \\
\text { Johann von Berry } \\
\text { Ludwig von Orléans } \\
\text { Ludwig von Orléans } \\
\text { Paul von Limburg } \\
\text { Philipp der Kühne } \\
\text { Philipp der Kühne }\end{array}$ & $\begin{array}{l}\text { Johann von Berry } \\
\text { Johann von Berry } \\
\text { Jehanne } \\
\text { Ascelin Royne } \\
\text { Colard de Villequier } \\
\text { Marguerite de Préaux } \\
\text { Johann von Berry } \\
\text { Charles de Hangest } \\
\text { Charles de Savoisy }\end{array}$ & $\begin{array}{l}0,07200 \\
0,07200 \\
0,07200 \\
0,07200 \\
0,07200 \\
0,07200 \\
0,07200 \\
0,07200 \\
0,07200\end{array}$ \\
\hline
\end{tabular}




\begin{tabular}{|c|c|c|c|}
\hline & $\begin{array}{l}\text { Philipp der Kühne } \\
\text { Pierre de Gynes }\end{array}$ & $\begin{array}{l}\text { Robert d'Aunoy } \\
\text { Johann von Berry }\end{array}$ & $\begin{array}{l}0,07200 \\
0,07200\end{array}$ \\
\hline 168 & $\begin{array}{l}\text { Isabeau de Bavière } \\
\text { Isabeau de Bavière }\end{array}$ & \begin{tabular}{|l|} 
Jean Martel \\
Raoul Cassinel \\
\end{tabular} & $\begin{array}{l}0,07080 \\
0,07080 \\
\end{array}$ \\
\hline 169 & Johann Ohnefurcht & Nicole d'Estrée & 0,06960 \\
\hline 170 & Guy de La Trémoille & Marie de Sully & 0,06840 \\
\hline 171 & Charles d'Artois & Johann von Berry & 0,06720 \\
\hline 172 & \begin{tabular}{|l|} 
Gieffroy Robin \\
Pierre Culon \\
Valentina Visconti
\end{tabular} & $\begin{array}{l}\text { Johann von Berry } \\
\text { Johann von Berry } \\
\text { Surien des Quesnes }\end{array}$ & $\begin{array}{l}0,06480 \\
0,06480 \\
0,06480\end{array}$ \\
\hline 173 & \begin{tabular}{|l|} 
Karl von Orléans \\
Karl von Orléans \\
\end{tabular} & $\begin{array}{l}\text { Hue d'Amboise } \\
\text { Jacques de Peschin }\end{array}$ & $\begin{array}{l}0,06415 \\
0,06415 \\
\end{array}$ \\
\hline 174 & $\begin{array}{l}\text { Karl VI. } \\
\text { Karl VI. } \\
\text { Karl VI. } \\
\text { Karl VI. } \\
\text { Karl VI. } \\
\text { Katharina von Alençon } \\
\text { Philipp der Kühne } \\
\text { Philipp der Kühne } \\
\text { Philipp der Kühne } \\
\text { Philipp der Kühne } \\
\end{array}$ & $\begin{array}{l}\text { Catherine de Fastavarin } \\
\text { Isabelle La Bouteillière } \\
\text { Jeanne } \\
\text { Marie de Duisy } \\
\text { Marie de Quiemieu } \\
\text { Johann von Berry } \\
\text { Elion de Neilhac } \\
\text { Jean de Graville } \\
\text { Jean de Poquières } \\
\text { Jean de Tancarville }\end{array}$ & $\begin{array}{l}0,06000 \\
0,06000 \\
0,06000 \\
0,06000 \\
0,06000 \\
0,06000 \\
0,06000 \\
0,06000 \\
0,06000 \\
0,06000 \\
\end{array}$ \\
\hline 175 & $\begin{array}{l}\text { Karl VI. } \\
\text { Raymond de Lescure } \\
\text { Valentina Visconti } \\
\text { Valentina Visconti } \\
\end{array}$ & $\begin{array}{l}\text { Jacqueline Quipie } \\
\text { Johann von Berry } \\
\text { Gilles Malet } \\
\text { Jeanne de Saint-Pol }\end{array}$ & $\begin{array}{l}0,05760 \\
0,05760 \\
0,05760 \\
0,05760 \\
\end{array}$ \\
\hline 176 & $\begin{array}{l}\text { Karl VI. } \\
\text { Karl VI. } \\
\text { Karl VI. } \\
\text { Karl VI. } \\
\text { Karl VI. } \\
\end{array}$ & $\begin{array}{l}\text { Catherine de Villiers } \\
\text { Jeanne de La Tour } \\
\text { Jeanne de Montueil } \\
\text { Mabillette } \\
\text { Marguerite de Germonville }\end{array}$ & $\begin{array}{l}0,05040 \\
0,05040 \\
0,05040 \\
0,05040 \\
0,05040\end{array}$ \\
\hline 177 & $\begin{array}{l}\text { Gérard du Puy } \\
\text { Guillaume de Boisratier } \\
\text { Jean Marcheou } \\
\text { Karl von Orléans } \\
\text { Ludwig von Orléans } \\
\text { Ludwig von Orléans } \\
\text { Philipp der Kühne } \\
\text { Philipp der Kühne } \\
\text { Philipp der Kühne } \\
\text { Philipp der Kühne } \\
\text { Philipp der Kühne } \\
\text { Valentina Visconti }\end{array}$ & $\begin{array}{l}\text { Johann von Berry } \\
\text { Johann von Berry } \\
\text { Johann von Berry } \\
\text { Philippe de Vertus } \\
\text { Hennequin le Poitevin } \\
\text { Jean de Pontoise } \\
\text { Berthelot Helyot } \\
\text { Guillaume d'Aumas } \\
\text { Raillart de Chauffour } \\
\text { Regnaud de Nantouillet } \\
\text { Robinet le Tirant } \\
\text { Boniface }\end{array}$ & $\begin{array}{l}0,04800 \\
0,04800 \\
0,04800 \\
0,04800 \\
0,04800 \\
0,04800 \\
0,04800 \\
0,04800 \\
0,04800 \\
0,04800 \\
0,04800 \\
0,04800\end{array}$ \\
\hline 178 & $\begin{array}{l}\text { Guillaume de Ruilly } \\
\text { Karl von Orléans } \\
\text { Karl von Orléans } \\
\text { Karl von Orléans } \\
\end{array}$ & $\begin{array}{l}\text { Johann von Berry } \\
\text { Guillaume II de Craon } \\
\text { Jean de Juch } \\
\text { Jean de Rochechouart }\end{array}$ & $\begin{array}{l}0,04320 \\
0,04320 \\
0,04320 \\
0,04320 \\
\end{array}$ \\
\hline 179 & Karl von Orléans & Jeanne d'Orléans & 0,04200 \\
\hline 180 & Philipp der Kühne & Jacot Blanchet & 0,04080 \\
\hline 181 & Isabeau de Bavière & Femmette & 0,03984 \\
\hline 182 & Valentina Visconti & Marguerite Spissau & 0,03840 \\
\hline 183 & Johann Ohnefurcht & Margarete II. von Burgund & 0,03800 \\
\hline
\end{tabular}




\begin{tabular}{|c|c|c|c|}
\hline 184 & Valentina Visconti & Guillaume de Senlis & 0,03600 \\
\hline 185 & Ludwig von Orléans & Marie la Mayence & 0,03480 \\
\hline 186 & Karl von Orléans & Guillaume Cousinot & 0,03240 \\
\hline 187 & $\begin{array}{l}\text { Philipp der Kühne } \\
\text { Philipp der Kühne } \\
\text { Philipp der Kühne } \\
\text { Philipp der Kühne } \\
\text { Philipp der Kühne } \\
\text { Philipp der Kühne } \\
\text { Philipp der Kühne } \\
\text { Philipp der Kühne }\end{array}$ & $\begin{array}{l}\text { Jean de Dinant } \\
\text { Jossequin de Jardins } \\
\text { Louiset Moullié } \\
\text { Nicolas Claux } \\
\text { Nicolas d'Alfous } \\
\text { Nicolas La Trompette } \\
\text { Senville } \\
\text { Villemote de Honcoigne } \\
\end{array}$ & $\begin{array}{l}0,03000 \\
0,03000 \\
0,03000 \\
0,03000 \\
0,03000 \\
0,03000 \\
0,03000 \\
0,03000 \\
\end{array}$ \\
\hline 188 & \begin{tabular}{|l|} 
Béatrix de Navarre \\
Ludwig von Orléans
\end{tabular} & $\begin{array}{l}\text { Johann von Berry } \\
\text { Catherine de Fastavarin }\end{array}$ & $\begin{array}{l}0,02880 \\
0,02880\end{array}$ \\
\hline 189 & Pierre de Savoisy & Johann von Berry & 0,02640 \\
\hline 190 & $\begin{array}{l}\text { Karl von Orléans } \\
\text { Karl von Orléans } \\
\text { Karl von Orléans }\end{array}$ & $\begin{array}{l}\text { Guillaume le Bouteiller } \\
\text { Jean Davy } \\
\text { Jean de Fontaines }\end{array}$ & $\begin{array}{l}0,02430 \\
0,02430 \\
0,02430 \\
\end{array}$ \\
\hline 191 & $\begin{array}{l}\text { Christophe de la Mer } \\
\text { Guichard Dauphin } \\
\text { Johann von Berry } \\
\text { Johann von Berry } \\
\text { Johann von Berry } \\
\text { Ludwig der Bärtige } \\
\text { Philipp der Gute } \\
\text { Simon Aligret }\end{array}$ & $\begin{array}{l}\text { Johann von Berry } \\
\text { Johann von Berry } \\
\text { Hannequin } \\
\text { Hermant } \\
\text { Jean Flamel } \\
\text { Johann von Berry } \\
\text { Anton von Burgund } \\
\text { Johann von Berry } \\
\end{array}$ & $\begin{array}{l}0,02400 \\
0,02400 \\
0,02400 \\
0,02400 \\
0,02400 \\
0,02400 \\
0,02400 \\
0,02400 \\
\end{array}$ \\
\hline 192 & $\begin{array}{l}\text { Johann von Berry } \\
\text { Johann von Berry } \\
\text { Johann von Berry } \\
\text { Olivier de Mauny }\end{array}$ & \begin{tabular}{|l} 
Jean Nau \\
Jehanncon \\
Nicholas Feynat \\
Johann von Berry
\end{tabular} & $\begin{array}{l}0,01920 \\
0,01920 \\
0,01920 \\
0,01920 \\
\end{array}$ \\
\hline 193 & \begin{tabular}{|l|} 
Johann von Berry \\
Philipp der Kühne \\
\end{tabular} & $\begin{array}{l}\text { Estienne } \\
\text { «Bischof der Narren } \ll\end{array}$ & $\begin{array}{l}0,01440 \\
0,01440 \\
\end{array}$ \\
\hline 194 & \begin{tabular}{|l|} 
Guy de La Trémoille \\
Guy de La Trémoille
\end{tabular} & \begin{tabular}{|l|} 
Georges de La Trémoille \\
Jean de La Trémoille \\
\end{tabular} & $\begin{array}{l}0,01327 \\
0,01327 \\
\end{array}$ \\
\hline 195 & Ludwig von Orléans & Jeanne de Soisy & 0,01200 \\
\hline 196 & Renier de Bouligny & Johann von Berry & 0,01080 \\
\hline 197 & Isabeau de Bavière & \begin{tabular}{|l|} 
Christine de Pisan \\
\end{tabular} & 0,00984 \\
\hline 198 & Arnoul Belin & Johann von Berry & 0,00720 \\
\hline 199 & Limburg, Gebrüder & \begin{tabular}{|l} 
Johann von Berry \\
\end{tabular} & 0,00600 \\
\hline 200 & \begin{tabular}{|l|} 
Valentina Visconti \\
Valentina Visconti \\
\end{tabular} & $\begin{array}{l}\text { Jeanne de Salçay } \\
\text { Jehannette }\end{array}$ & $\begin{array}{l}0,00480 \\
0,00480 \\
\end{array}$ \\
\hline 201 & $\begin{array}{l}\text { Ludwig von Orléans } \\
\text { Ludwig von Orléans } \\
\text { Pannier }\end{array}$ & $\begin{array}{l}\text { Maria von Frankreich } \\
\text { Michelle von Frankreich } \\
\text { Johann von Berry }\end{array}$ & $\begin{array}{l}0,00360 \\
0,00360 \\
0,00360 \\
\end{array}$ \\
\hline 202 & Valentina Visconti & Jeanne de Vendôme & 0,00240 \\
\hline
\end{tabular}

Tab. 11: Wertzuweisungen in namentlich faßbaren Schenkbeziehungen

Dies ist die Tabelle, die in den Grenzen der Überlieferung unter Berücksichtigung der Gerichtetheit der jeweiligen Schenkbeziehung meßbaren Aufschluß über (gewährte) Nähe und (bedachte) Distanz im Rahmen des Neujahrsge- 
schenkverkehrs an den französischen Höfen der Zeit zwischen 1381 und 1422 gibt - unterstellt, daß Distanz und Nähe tatsächlich in verausgabten Werten zum Ausdruck kommen. Nicht berücksichtigt in dieser Tabelle sind freilich diejenigen Schenkbeziehungen, bei denen der Wert der getauschten Geschenke unbekannt ist, folglich ist auch der in den Tabellen 10 und 11 notierte Personenkreis nicht zu 100\% identisch. Tabelle 10 nennt 371, Tabelle 11299 verschiedene Personen (jeweils ohne den »Bischof der Narren«). In Tabelle 10 sind zudem 77 Personen notiert (darunter 15 Frauen), die nicht in Tabelle 11 enthalten sind, in Tabelle 11 wiederum zwei Personen, die nicht in Tabelle 10 genannt werden. Infolgedessen ist der in den Tabellen 10 und 11 notierte Personenbestand, insgesamt identisch mit den 373 (ohne den »Bischof der Narren «) festgestellten namentlich bekannten Personen des Geschenkverkehrs zum neuen Jahr, nur zu etwa $78 \%$ deckungsgleich. Bei den weder in der einen noch in der anderen Tabelle Genannten handelt es sich jedoch um Personen, die jeweils in den unteren Bereichen der Schenkhierarchien rangieren. Folglich ist auch nicht zu erwarten, daß diese Personen in der Tabelle, in welcher sie jeweils nicht notiert sind, extrem von denjenigen Rängen abweichende Positionen einnehmen würden als die, die ihnen bereits zugewiesen werden konnten, wenn die bislang unbekannten Wertzuweisungen beziehungsweise Bindungsziffern nachgetragen werden könnten, zumal der die Spitzenpositionen einnehmende Personenkreis in beiden Tabellen annähernd identisch ist. Jean Martel und Oudart de La Barre werden ausschließlich in Tabelle 11 genannt, dort aber auf den nachgeordneten Rängen 167 beziehungsweise 72 . Außerdem teilt sich Oudart de La Barre diesen Rang mit Erard Moriset, Michel le Beuf und Pierre de Gynes und würde somit in der Hierarchie noch weiter unten auf Rang 128 angesiedelt werden müssen, wenn die dieser Position implementierte Wertzuweisung geviertelt werden würde. Diejenigen, die in Tabelle 10 notiert sind, hingegen nicht in Tabelle 11 , sind nahezu geschlossen im letzten Rang vertreten, darunter 42 aktiv, 34 ausschließlich passiv am Schenkgeschehen teilnehmende Personen.

Werden wiederum die nur einseitig verlaufenden Beziehungen aus der Betrachtung genommen, reduziert sich auch hier der Kreis derer, die miteinander aktiv in Beziehung getreten sind, auf 35 von 299 Personen, also auf etwa $11 \%$ des Personenbestandes. Diese Gruppe ist bis auf Anna von Bourbon, Bernhard VII. von Armagnac, Bonne de Berry, Charles d'Albret, Christine de Pisan, Guichard Dauphin, Jean de Montaigu, Johann I. von Bourbon, Karl (VII.), Ludwig II. von Anjou, Marie de Berry, Morinot de Tourzel, Philipp den Guten und Renier de Bouligny, die nur in Tabelle 11 vertreten sind, über Anton von Burgund, Ascelin Royne, Charles d'Artois, Guy de La Trémoille, Isabeau de Bavière, Jeanne de Boulogne, Johann Ohnefurcht, Johann von Berry, Karl VI., Karl von Orléans, Louis de Vendôme, Ludwig den Bärtigen, Ludwig II. von Bourbon, Ludwig von Guyenne, Ludwig von Orléans, Margarete von Bayern, 
Margarete von Flandern, Marie de Sully, Philipp den Kühnen, Valentina Visconti und Waleran von Luxemburg zu $30 \%$ identisch mit der Gruppe derer, die nur aufgrund der feststellbaren Schenkvorgänge ohne Wertzuweisung bekannt sind. Folgerichtig kann mit diesen nach den Tabellen 10 und 11 ermittelten Personenkreisen die Gruppe der »Ebenbürtigen« definiert werden insgesamt 70 von 373 namentlich faßbaren Personen -, die den sozialen Ort der höfischen Gabe markieren und zum größten Teil auch die einseitig verlaufenden Schenkbeziehungen bestimmt haben. Es ließe sich darüber spekulieren, daß über die Berücksichtigung von Schenkvorgängen mit Wertzuweisungen insbesondere in den Spitzenpositionen die Beziehungen unterstrichen werden konnten, die nach dem Prinzip der Reziprozität geregelt sind, denn es konnte deutlich gemacht werden, daß die Gaben tatsächlich nicht nur in einer Richtung wanderten. In diese Gruppe ist nach dem das Ergebnis von Tabelle 10 verstärkenden und bestätigenden Befund von Tabelle 11 vor allem ein Mitglied aufgestiegen, das seinen Platz auf Rang 8 dort nicht aufgrund seiner Herkunft hätte einnehmen können: Guy de La Trémoille; immerhin den 19. Rang hat sein Bruder Guillaume erreicht. Guy de La Trémoille hat seine Anwesenheit in dieser Gruppe, obwohl auch aktiver Teilhaber am Schenkgeschehen, überwiegend einseitigen Schenkbeziehungen zu verdanken, die zudem nur durch eine Person, nämlich durch Philipp den Kühnen bestimmt waren. Die herausragende Position Guy de la Trémoilles korrespondiert mit der Tatsache, daß ihm der Titel cousin ohne entsprechende verwandtschaftliche Beziehung zuerkannt worden war.

Philipp der Kühne selbst hatte auch ansonsten die in jeder Hinsicht intensivsten Nahverhältnisse unterhalten: mit seiner Frau, dann mit seinem Bruder Johann von Berry, mit Karl VI. und - mit sich selbst. Endlich hat aber auch der König den ihm gebührenden Platz eingenommen und neben ihm befinden sich die anderen Mitglieder der französischen Hocharistokratie: die Königin mit ihrem Schwager Ludwig von Orléans und dessen Frau Valentina Visconti, den Burgunder Johann Ohnefurcht und seine Frau Margarete von Bayern. Schließlich ist aber auch der burgundische Kanzler Jean Canard durch ein besonderes Nahverhältnis zu Philipp dem Kühnen ausgezeichnet. In 117 von insgesamt 426 Schenkbeziehungen ist allein Philipp der Kühne, meist aktiv, vertreten. Auch hier zum Vergleich die Zahlen für Karl VI., Ludwig von Orléans, Isabeau de Bavière, Johann von Berry und Johann Ohnefurcht: Der König erscheint in 39, die Königin in 29, des Königs Bruder Ludwig in 50, sein Kontrahent Johann Ohnefurcht in 48 und der Herzog von Berry in 74 Beziehungen. Erneut kennzeichnet dies im Zusammenhang mit den oben gegebenen Besetzungen der Ränge trotz aller Überlieferungslücken den höfischen Geschenkverkehr als überwiegend burgundisches Unternehmen. Burgund war die zentrale »Schenkinstanz« der Neujahrstage. 
Es bleiben abschließend die strukturellen Merkmale eines Beziehungsnetzes, nämlich Umfang, Dichte, Verflechtung und Zentralität ${ }^{481}$, zu beschreiben.

Umfang definiert Reinhard als eine Kategorie, die die Gesamtheit eines Netzwerkes beschreibt, deren Handhabbarkeit an verhältnismäßig eindeutig gezogene Grenzen gebunden sei. Da ein Netzwerk praktisch unendlich groß sei, würden Verflechtungsanalysen deshalb eher für auf »egos« zentrierte "sets « angefertig ${ }^{482}$. Genau dies ist der hier gewählte Weg gewesen, wenn oben unter der Kategorie Distanz eine Verengung von den Bindungsziffern über die Wertzuweisungen auf die einzelnen Beziehungsbündel erfolgte. Hier hat die archivalische Überlieferung für eine entsprechende Grenzziehung gesorgt, die den Informationsgehalt der Quellen vorgegeben limitiert hat, damit auch den Personenbestand. Die Frage der Übertragbarkeit der so gewonnenen Ergebnisse ist freilich eine andere.

Dichte ist dagegen ein von Zentralpersonen unabhängiges Verflechtungsmaß483, drückt deshalb auch nur das Verhältnis möglicher zu bestehenden Beziehungen aus und kann somit auch nur aussagen, wie weit sich ein Beziehungsnetz dem Idealzustand der Kongruenz möglicher und tatsächlicher Beziehungen angenähert hat. Ob dieser dann auch der wirklich ideale Zustand ist, muß dahingestellt bleiben.

Für den höfischen Geschenkverkehr um 1400 konnten zunächst insgesamt 1.369 unterschiedliche Beziehungen ermittelt werden, die deshalb als unterschiedlich bezeichnet werden, weil nicht nur unterschieden wurde nach Personen und Richtung, sondern auch danach, ob die einzelne Beziehung allein durch einen Schenkakt oder auch durch einen (zusätzlichen) Schenkakt mit Wertzuweisung bestimmt werden konnte. Bekam X also von $Y$ ein Geschenk, $Y$ aber auch von $X$ ein Geschenk, erhielt darüber hinaus $X$ von $Y$ zusätzlich ein Geschenk, dem ein Wert zugewiesen werden konnte und umgekehrt, dann sind dies je nach Überlieferung im Höchstfall vier verschiedene Schenkbeziehungen. Schenkende Personengruppen wie die Sekretäre des Herzogs von Berry oder die Brüder Limburg sind aufgelöst worden. Bei 426 Schenkbeziehungen konnten nach Richtung unterschiedene Paarungen nicht nur als Schenkbeziehungen festgestellt, sondern aufgrund anderer Schenkvorgänge auch mit Wertzuweisungen versehen werden, 197 Paarungen erschienen ausschließlich als beziehungsbestimmt, ohne daß Werte bekannt waren, drei Paarungen als ausschließlich wertbestimmt. Für die Berechnung der Dichte wurden personen- und richtungsgleiche Beziehungen zusammengezogen, so daß lediglich nach diesen beiden Kriterien differenziert wurde. In diesem Sinn bildeten nach Ausweis der Tabellen 10 und 11 insgesamt 373 namentlich faßbare

481 REINHARD 1979, S. 27 f.

482 Vgl. ebd., S. 27.

483 Siehe ebd., S. $27 \mathrm{f}$. 
Personen (ohne den »Bischof der Narren«) 626 nicht identische Beziehungen. Diese Beziehungen sind wie angedeutet deshalb nicht identisch, weil sie im Gabentausch grundsätzlich richtungsbestimmt sind - wenn Schenker und Beschenkter die Rollen wechselten, war die Paarung eine andere, das Geschenk mit Sicherheit nicht dasselbe - und zum größten Teil zudem auch nicht zeitgleich stattfanden. Entsprechend der Grundformel zur Dichteberechnung muß die Zahl vorhandener Beziehungen mit 100 multipliziert werden, alsdann dividiert werden durch den mit der Hälfte des Personenbestandes multiplizierten Differenzbetrag Personenbestand minus 1, also: $626 \times 100$ dividiert durch $373: 2 \times$ [373 - 1]. Es ergibt sich ein Verhältnis von $62.600 \mathrm{zu}$ 69.378, mithin ein unter normalen Umständen recht beachtliches Dichtemaß von $90,23 \%$. Allerdings handelt es sich hier um Schenkbeziehungen, deren Umkehrungen nicht identisch sind. Folglich darf der Personenbestand nicht durch 2 dividiert werden, beziehungsweise das im Nenner stehende Ergebnis der Normalformel muß mit 2 multipliziert werden. Diese Überlegung verändert das Verhältnis von tatsächlichen zu möglichen Beziehungen in $62.600 \mathrm{zu} 138.756$, was einem Dichtemaß von $45,16 \%$ entspricht. Das namentlich und archivalisch faßbare Personal des höfischen Geschenkverkehrs zum neuen Jahr hat also nicht einmal die Hälfte seiner möglichen Bindungen realisiert (möglicherweise aber, aus welchen Gründen auch immer, andere Geschenksysteme genutzt). Diese Aussage gilt allerdings nur mit der Einschränkung, daß nicht alle Personen aus den unterschiedlichsten Gründen den Gesamtzeitraum erlebten und die Überlieferung definitiv nicht vollständig ist.

Der Grad der Verflechtung in einem Netzwerk ist eine Größe, die Vergleiche zwischen verschiedenen Personen ermöglicht, in dem auf diese Weise bestimmt wird, welches spezifische Bindungsmaß die einzelnen Personen im jeweiligen Verhältnis von tatsächlich eingegangenen Beziehungen (die je doppelt gezählt werden, da zwei Richtungen berücksichtigt werden müssen) zur Zahl der Personen aufweisen ${ }^{484}$. Diese Größe muß beim höfischen Geschenkverkehr als eigenes Berechnungsmaß nicht gesondert eingeführt werden, zumal alle Einzelbeziehungen nur einfach gewertet werden dürfen, da sie stets gerichtet sind vom Schenker zum Beschenkten. Das Maß der Verflechtung ist hier also schlicht die Menge an Schenkvorgängen, an denen die jeweilige Person teilnahm, und dies ist zur Genüge vorgeführt worden.

Bleiben als letzte Kriterien Zentralität und Büschelberechnungen ${ }^{485}$. Zentralitäten werden nach der Netzwerkmethode als Verhältnis der Summe der geringsten Anzahl an Schritten von jeder Person zu jeder anderen zur Summe der geringsten Entfernungen der jeweiligen Person zu jeder anderen Person 
berechnet. Das bedeutet, daß beim Gabentausch alle existenten Mehrfachbindungen nach den ausgeprägtesten Nahverhältnissen durchsucht werden müssen, die zu summieren sind, um diese dann ins Verhältnis zu setzen zur Summe der jeweils ausgeprägtesten Nahverhältnisse, die die spezifische zu untersuchende Person unterhalten hat. Diese aufwendige Berechnungsweise steht m.E. im gegebenen Rahmen in keinem Verhältnis zum Erkenntnisgewinn. Nicht zuletzt Bindungsziffern und Wertzuweisungen haben die zentralen Figuren des Gabentausches hinreichend deutlich herausgearbeitet. Auch die sogenannten Büschel oder cluster, Bereiche besonders hoher Dichte im Netz, konnten durch einfache Beobachtung, beispielsweise auch hier wieder durch die Reihung und Addition von Bindungsziffern und Wertzuweisungen, markiert werden. Allerdings wäre es wünschenswert gewesen, das gesamte Netz des höfischen Geschenkverkehrs graphisch darzustellen. SPSS (Statistical Package for Social Sciences), die Software, mit der eine solche Graphik erstellt werden kann, verarbeitet aber, wie auch bereits einleitend angesprochen, aufgrund des implementierten Algorithmus derzeit nicht mehr als 100 Objekte. Tabelle 12 soll diesem Mangel vorerst abhelfen. Dort sind auf der Grundlage von Tabelle 11 und diese damit ergänzend 405 nicht identische und nicht gerichtete, also die Paarungen zusammenfassende, nach Werten und Personen faßbare Schenkbeziehungen notiert, die auf die in den jeweiligen Beziehungspaaren getauschten Gesamtwerte der Geschenke zurückzuführen sind. Die in den einzelnen Beziehungen notierten Paarungen sind jeweils soweit voneinander entfernt, wie es die Zahl in der letzten Spalte angibt. Diese Zahl ist der jeweils 1:x gesetzte Geschenkgesamtwert der einzelnen Schenkbeziehung, damit hohe Werte geringe Abstände, niedrige Werte entsprechend hohe Abstände der jeweiligen Partner der einzelnen Schenkbeziehung ergeben. Die Zeilen selbst sind nach den Werten der letzten Spalte hierarchisch sortiert, und somit steht an erster Stelle die intensivste Nahbeziehung des höfischen Geschenkverkehrs zum neuen Jahr. Auf der Grundlage dieser Tabelle ist es möglich, die Position jeder Person aufgrund der Distanzen zu anderen Personen, mit denen sie in Beziehung steht, eindeutig zu definieren. Unterschiedliche Erlebenszeiten der einzelnen Personen können hier vernachlässigt werden, weil selbstverständlich nur Beziehungen zwischen lebenden Personen abgebildet sind.

\begin{tabular}{|ll|c|}
\hline Schenkbeziehung & Distanz \\
\hline Philipp der Kühne & Margarete von Flandern & 0,00716117 \\
\hline Karl VI. & Philipp der Kühne & 0,00823968 \\
\hline Philipp der Kühne & Johann von Berry & 0,00933937 \\
\hline Karl VI. & Johann von Berry & 0,01839913 \\
\hline Ludwig von Orléans & Philipp der Kühne & 0,02304126 \\
\hline Philipp der Kühne & Guy de La Trémoille & 0,05171486 \\
\hline Philipp der Kühne & Isabeau de Bavière & 0,05227118 \\
\hline Ludwig von Orléans & Valentina Visconti & 0,05989003 \\
\hline
\end{tabular}




\begin{tabular}{|c|c|c|}
\hline Karl VI. & Ludwig von Orléans & 0,06410256 \\
\hline Philipp der Kühne & Johann Ohnefurcht & 0,07700363 \\
\hline Isabeau de Bavière & Karl VI. & 0,07831344 \\
\hline Johann Ohnefurcht & Karl VI. & 0,08087474 \\
\hline Isabeau de Bavière & Ludwig von Orléans & 0,08428264 \\
\hline Margarete von Bayern & Philipp der Kühne & 0,08767085 \\
\hline Philipp der Kühne & Jean Canard & 0,10703235 \\
\hline Anton von Burgund & Philipp der Kühne & 0,10847505 \\
\hline Ludwig von Orléans & Johann von Berry & 0,11111111 \\
\hline Philipp der Kühne & Guillaume de La Trémoille & 0,11353315 \\
\hline Johann Ohnefurcht & Margarete von Bayern & 0,11806306 \\
\hline Karl VI. & Valentina Visconti & 0,12742100 \\
\hline Philipp der Kühne & Ludwig II. von Bourbon & 0,13365946 \\
\hline Philipp der Kühne & Richard II. & 0,15432099 \\
\hline Philipp der Kühne & Karl von Frankreich & 0,19025875 \\
\hline Philipp der Kühne & Maria I. von Burgund & 0,19613612 \\
\hline Philipp der Kühne & Margarete II. von Burgund & 0,20217582 \\
\hline Philipp der Kühne & Maria II. von Burgund & 0,20823832 \\
\hline Philipp der Kühne & Clemens VII. & 0,20833333 \\
\hline Philipp der Kühne & Bona von Burgund & 0,21039742 \\
\hline Isabeau de Bavière & Valentina Visconti & 0,23225567 \\
\hline Philipp der Kühne & Marie de Sully & 0,24384297 \\
\hline Philipp der Kühne & Pierre de Navarre & 0,26658136 \\
\hline Philipp der Kühne & Valentina Visconti & 0,27233115 \\
\hline Philipp der Kühne & Jeanne de Saint-Pol & 0,27602883 \\
\hline Johann Ohnefurcht & Jean de Saulx & 0,28735632 \\
\hline Philipp der Kühne & Johann V. von Bretagne & 0,29239766 \\
\hline Philipp der Kühne & Philipp von Burgund & 0,29761905 \\
\hline Philipp der Kühne & Katharina I. von Burgund & 0,30460873 \\
\hline Philipp der Kühne & Philipp der Gute & 0,33534541 \\
\hline Ludwig von Orléans & Johann von Berry & 0,37596812 \\
\hline Johann Ohnefurcht & Johann von Berry & 0,40501243 \\
\hline Philipp der Kühne & Pierre de La Trémoille & 0,40994863 \\
\hline Philipp der Kühne & Philippe de Bar & 0,42301184 \\
\hline Ludwig II. von Anjou & Johann von Berry & 0,45289855 \\
\hline Philipp der Kühne & Leo VI. von Lusignan & 0,47483381 \\
\hline Margarete von Flandern & Marie de Sully & 0,50280313 \\
\hline Philipp der Kühne & Arnaud-Amanieu d'Albret & 0,50813008 \\
\hline Philipp der Kühne & Waleran von Luxemburg & 0,53418803 \\
\hline Ludwig von Orléans & Ludwig II. von Bourbon & 0,54497992 \\
\hline Jeanne de Boulogne & Johann von Berry & 0,62967534 \\
\hline Philipp der Kühne & Wilhelm von Bayern & 0,63131313 \\
\hline Philipp der Kühne & Ludwig von Male & 0,66666667 \\
\hline Philipp der Kühne & Philippe d'Artois & 0,68306011 \\
\hline Guillaume de Lodes & Johann von Berry & 0,68870523 \\
\hline Karl (VII.) & Jean d'Harcourt & 0,69444444 \\
\hline Philipp der Kühne & Ludwig von Guyenne & 0,69444444 \\
\hline Johann Ohnefurcht & Michelle von Frankreich & 0,71800395 \\
\hline Philipp der Kühne & Guy de La Rochefoucauld & 0,73583517 \\
\hline Johann Ohnefurcht & Ludwig II. von Anjou & 0,75244545 \\
\hline Ludwig von Guyenne & Johann Ohnefurcht & 0,75757576 \\
\hline
\end{tabular}




\begin{tabular}{|c|c|c|}
\hline Philipp der Kühne & Ludwig II. von Anjou & 0,78914141 \\
\hline Karl (VII.) & Jean Coeur & 0,83333333 \\
\hline Margarete von Flandern & Johann von Berry & 0,88160099 \\
\hline Philipp der Kühne & Jean de Montaigu & 0,92081031 \\
\hline Karl (VII.) & Adam de Champgiraut & 0,92592593 \\
\hline Karl von Orléans & Johann I. von Bourbon & 0,92592593 \\
\hline Johann Ohnefurcht & Jean de Montagu & 0,93698758 \\
\hline Johann von Berry & Louis de Vendôme & 1,00551020 \\
\hline Johann Ohnefurcht & Philippe Musnier & 1,04166667 \\
\hline Karl (VII.) & Alexandre Le Boursier & 1,04166667 \\
\hline Karl (VII.) & Charles de Luxembourg & 1,04166667 \\
\hline Karl (VII.) & Guillaume de Lucé & 1,04166667 \\
\hline Karl (VII.) & Raymond Raguier & 1,04166667 \\
\hline Karl (VII.) & Renier de Bouligny & 1,04166667 \\
\hline Philipp der Kühne & Pasqual de Paloiz & 1,04166667 \\
\hline Philipp der Kühne & Louis de Poissy & 1,09649123 \\
\hline Martin Gouge & Johann von Berry & 1,12612613 \\
\hline Philipp der Kühne & Jean de Vienne & 1,19047619 \\
\hline Ludwig von Orléans & Jean de Trie & 1,23274162 \\
\hline Ludwig von Orléans & Karl III. von Navarra & 1,34231791 \\
\hline Isabeau de Bavière & Ludwig der Bärtige & 1,38888889 \\
\hline Karl (VII.) & Bernhard VIII. von Armagnac & 1,38888889 \\
\hline Karl (VII.) & Charles d'Albret & 1,38888889 \\
\hline Karl (VII.) & Isabeau de Barres & 1,38888889 \\
\hline Karl (VII.) & Karl I. von Bourbon & 1,38888889 \\
\hline Ludwig von Orléans & Ludwig von Guyenne & 1,38888889 \\
\hline Philipp der Kühne & Giacomo Rapondi & 1,38888889 \\
\hline Philipp der Kühne & Guichard Dauphin & 1,38888889 \\
\hline Philipp der Kühne & Johann IV. von Bretagne & 1,38888889 \\
\hline Philipp der Kühne & Charles d'Albret & 1,42207053 \\
\hline Margarete von Bayern & Agnes von Burgund & 1,48809524 \\
\hline Margarete von Bayern & Anna von Burgund & 1,48809524 \\
\hline Margarete von Bayern & Katharina I. von Burgund & 1,48809524 \\
\hline Margarete von Bayern & Margarete II. von Burgund & 1,48809524 \\
\hline Philipp der Kühne & Johann I. von Bourbon & 1,48809524 \\
\hline Valentina Visconti & Karl von Frankreich & 1,53426003 \\
\hline Karl von Orléans & Jean de Gaules & 1,59197644 \\
\hline Johann Ohnefurcht & Ludwig von Orléans & 1,60256410 \\
\hline Margarete von Flandern & Ludwig von Male & 1,66666667 \\
\hline Philipp der Kühne & Oudard de Chazeron & 1,66666667 \\
\hline Ludwig von Orléans & Guillaume Martel & 1,68793464 \\
\hline Johann Ohnefurcht & Jean Pouquet & 1,72601274 \\
\hline Johann Ohnefurcht & Philipp der Gute & 1,73611111 \\
\hline Johann Ohnefurcht & Pierre des Essarts & 1,76087339 \\
\hline Philipp der Kühne & Henri de Montbéliard & 1,81159420 \\
\hline Karl VI. & Katharina von Frankreich & 1,85185185 \\
\hline Karl VI. & Marie de Berry & 1,85185185 \\
\hline Philipp der Kühne & Ludwig der Bärtige & 1,85185185 \\
\hline Ludwig der Bärtige & Johann von Berry & 1,86608942 \\
\hline Ludwig von Orléans & Isabella von Frankreich & 1,87265918 \\
\hline Ludwig von Orléans & Pierre de Navarre & 1,89383179 \\
\hline
\end{tabular}




\begin{tabular}{|c|c|c|}
\hline \begin{tabular}{|l} 
Guillaume de Boisratier \\
Philipp der Kühne \\
\end{tabular} & $\begin{array}{l}\text { Johann von Berry } \\
\text { Renier Pot }\end{array}$ & $\begin{array}{l}1,89393939 \\
1,89393939 \\
\end{array}$ \\
\hline Philipp der Kühne & Jean de Hangest & 1,92901235 \\
\hline Ludwig von Orléans & Charles d'Ivry & 2,01434212 \\
\hline Ludwig von Orléans & Jean de Montagu & 2,01434212 \\
\hline Jean IV d'Armagnac & Johann von Berry & 2,08333333 \\
\hline Johann Ohnefurcht & Charles de Savoisy & 2,08333333 \\
\hline Johann Ohnefurcht & Guillaume de Champdivers & 2,08333333 \\
\hline Johann Ohnefurcht & Jean de Puligny & 2,08333333 \\
\hline Johann Ohnefurcht & Jean de Toulongeon & 2,08333333 \\
\hline Johann Ohnefurcht & Jean Fale & 2,08333333 \\
\hline Johann Ohnefurcht & Jeanne de Peschin & 2,08333333 \\
\hline Johann Ohnefurcht & Pierre Gorremont & 2,08333333 \\
\hline Johann Ohnefurcht & Regnault Doriac & 2,08333333 \\
\hline Karl VI. & Arnaud-Amanieu d'Albret & 2,08333333 \\
\hline Karl (VII.) & Gilbert Motier de La Fayette & 2,08333333 \\
\hline Karl (VII.) & Guillaume d'Avaugour & 2,08333333 \\
\hline Karl (VII.) & Guillaume du Bez & 2,08333333 \\
\hline Karl (VII.) & Henri de Savoisy & 2,08333333 \\
\hline Karl (VII.) & Henri du Mesnil & 2,08333333 \\
\hline Karl (VII.) & Jean Cadart & 2,08333333 \\
\hline Karl (VII.) & Jean Louvet & 2,08333333 \\
\hline Karl (VII.) & Robert Mallière & 2,08333333 \\
\hline Ludwig von Orléans & Charles d'Albret & 2,08333333 \\
\hline Philipp der Kühne & Gilles Malet & 2,08333333 \\
\hline Philipp der Kühne & Johan Rodrigues & 2,08333333 \\
\hline Philipp der Kühne & Peter von Genf & 2,08333333 \\
\hline Philipp der Kühne & Tristan & 2,08333333 \\
\hline Ludwig von Guyenne & Regnaut d'Angennes & 2,17864924 \\
\hline Johann Ohnefurcht & Ludwig der Bärtige & 2,19298246 \\
\hline Charles d'Artois & Johann von Berry & 2,23863891 \\
\hline Isabeau de Bavière & Philippe de Moulins & 2,25286113 \\
\hline Guy de La Trémoille & Marie de Sully & 2,27066303 \\
\hline Karl VI. & Ludwig II. von Bourbon & 2,31481481 \\
\hline Philipp der Kühne & Jean de Trie & 2,31481481 \\
\hline Philipp der Kühne & Charles de Rohan & 2,38095238 \\
\hline Jean I d'Alençon & Johann von Berry & 2,45098039 \\
\hline Karl von Orléans & Bonne d'Armagnac & 2,46184146 \\
\hline Jean de Montaigu & Johann von Berry & 2,46913580 \\
\hline Johann von Berry & Margarete II. von Burgund & 2,54065041 \\
\hline Karl VI. & Jeanne de Dreux & 2,60416667 \\
\hline Ludwig von Orléans & Karl von Orléans & 2,67952840 \\
\hline Ludwig von Orléans & Philippe de Vertus & 2,67952840 \\
\hline Johann von Berry & Pierre II d'Orgemont & 2,77777778 \\
\hline Karl (VII.) & Denis de Chesne & 2,77777778 \\
\hline Philipp der Kühne & Enguerrand de Coucy & 2,77777778 \\
\hline Philipp der Kühne & Pierre de Villaines & 2,77777778 \\
\hline Johann Ohnefurcht & Jean de Chevenon & 2,88350634 \\
\hline Margarete von Flandern & Ludwig von Orléans & 2,97619048 \\
\hline Philipp der Kühne & Charles de Châtillon & 2,97619048 \\
\hline Karl von Orléans & Guy de La Roche-Guyon & 3,08641975 \\
\hline Philipp der Kühne & Jean de Vergy & 3,08641975 \\
\hline
\end{tabular}




\begin{tabular}{|c|c|c|}
\hline Philipp der Kühne & Marie de Blaringhehem & 3,16265537 \\
\hline Philipp der Kühne & Philippe de Jaucourt & 3,26797386 \\
\hline Isabeau de Bavière & Isabella von Frankreich & 3,33333333 \\
\hline Philipp der Kühne & Jean Le Meingre & 3,33333333 \\
\hline Isabeau de Bavière & Arnaud de Corbie & 3,41670083 \\
\hline Guillaume de Montrevel & Johann von Berry & 3,47222222 \\
\hline Karl VI. & Enguerrand de Coucy & 3,47222222 \\
\hline Karl (VII.) & Jean d'Arpajon & 3,47222222 \\
\hline Ludwig von Orléans & Margarete von Bayern & 3,47222222 \\
\hline Philipp der Gute & Anna von Burgund & 3,47222222 \\
\hline Philipp der Kühne & Morinot de Tourzel & 3,47222222 \\
\hline Valentina Visconti & Jean d'Angoulême & 3,47222222 \\
\hline Bernhard VII. von Armagnac & Johann von Berry & 3,50140056 \\
\hline Marie de Berry & Johann von Berry & 3,51617440 \\
\hline Isabeau de Bavière & Catherine de Fastavarin & 3,62713094 \\
\hline Valentina Visconti & Enguerrand de Coucy & 3,65457004 \\
\hline Philipp der Kühne & Arthur de Richemont & 3,70370370 \\
\hline Philipp der Kühne & Gilles de Bretagne & 3,70370370 \\
\hline Philipp der Kühne & Regnault de Flandre & 3,70370370 \\
\hline Philipp der Gute & Margarete von Bayern & 3,75375375 \\
\hline Ludwig von Orléans & Jean de Hangest & 3,78787879 \\
\hline Erard Moriset & Johann von Berry & 3,99680255 \\
\hline Michel le Beuf & Johann von Berry & 3,99680255 \\
\hline Oudart de La Barre & Johann von Berry & 3,99680255 \\
\hline Pierre de Gynes & Johann von Berry & 3,99680255 \\
\hline Ludwig von Orléans & Alain de Beaumont & 4,02171727 \\
\hline Charlotte de Bourbon & Johann von Berry & 4,16666667 \\
\hline Johann Ohnefurcht & Antoine Forestz & 4,16666667 \\
\hline Johann Ohnefurcht & Jean de Velery & 4,16666667 \\
\hline Johann Ohnefurcht & Regnault Thumery & 4,16666667 \\
\hline Johann Ohnefurcht & Renier Pot & 4,16666667 \\
\hline Johann von Berry & Karl I. von Bourbon & 4,16666667 \\
\hline Karl VI. & Isabella von Frankreich & 4,16666667 \\
\hline Karl VI. & Jeanne d'Harcourt & 4,16666667 \\
\hline Karl VI. & Jeanne de Vendôme & 4,16666667 \\
\hline Karl VI. & Pierre de Navarre & 4,16666667 \\
\hline Karl (VII.) & Bertrand de Rochefort & 4,16666667 \\
\hline Karl (VII.) & Jean de Bonnay & 4,16666667 \\
\hline Karl (VII.) & Morelet de Carville & 4,16666667 \\
\hline Karl (VII.) & Pierre de Chantelle & 4,16666667 \\
\hline Karl (VII.) & Prégent de Coëtivy & 4,16666667 \\
\hline Karl (VII.) & Rogerin Blosset & 4,16666667 \\
\hline Ludwig von Orléans & Jacques de Peschin & 4,16666667 \\
\hline Ludwig von Orléans & Philippe de Florigny & 4,16666667 \\
\hline Margarete von Bayern & Johann von Berry & 4,16666667 \\
\hline Philipp der Gute & Agnes von Burgund & 4,16666667 \\
\hline Philipp der Kühne & Hugues de Chalon & 4,16666667 \\
\hline Philipp der Kühne & Margarete I. von Burgund & 4,16666667 \\
\hline Philipp der Kühne & Pierre II d'Orgemont & 4,16666667 \\
\hline Valentina Visconti & Ludwig von Guyenne & 4,16666667 \\
\hline Beraud III d'Auvergne & Johann von Berry & 4,34027778 \\
\hline Ascelin Royme & Johann von Berry & 4,62962963 \\
\hline Philipp der Kühne & Jean de Bétizac & 4,88758553 \\
\hline
\end{tabular}




\begin{tabular}{|c|c|c|}
\hline Ludwig von Orléans & Robert d'Aunoy & 5,05050505 \\
\hline Adhémar Aleman & Johann von Berry & 5,20833333 \\
\hline Isabeau de Bavière & Jeanne de Vendôme & 5,20833333 \\
\hline Janus de Grimault & Johann von Berry & 5,20833333 \\
\hline Karl VI. & Philippe d'Artois & 5,20833333 \\
\hline Morinot de Tourzel & Johann von Berry & 5,20833333 \\
\hline Philipp der Kühne & Jean I de Bourbon & 5,20833333 \\
\hline Valentina Visconti & Marie de Duisy & 5,20833333 \\
\hline Jacques Courau & Johann von Berry & 5,55555556 \\
\hline Philipp der Kühne & Anceau de Salins & 5,55555556 \\
\hline Bonne de Berry & Johann von Berry & 5,74712644 \\
\hline Isabeau de Bavière & Alips de Beauchamp & 5,77700751 \\
\hline Isabeau de Bavière & Catherine de Villiers & 5,77700751 \\
\hline Isabeau de Bavière & Isabelle La Bouteillière & 5,77700751 \\
\hline Isabeau de Bavière & Jeanne de La Tour & 5,77700751 \\
\hline Isabeau de Bavière & Jeanne de Montueil & 5,77700751 \\
\hline Isabeau de Bavière & Marguerite de Germonville & 5,77700751 \\
\hline Isabeau de Bavière & Marie de Duisy & 5,77700751 \\
\hline Valentina Visconti & Jeanne de Chepoy & 5,78703704 \\
\hline Christine de Pisan & Philipp der Kühne & 5,81395349 \\
\hline Ludwig von Orléans & Charles de Savoisy & 5,95238095 \\
\hline Valentina Visconti & Philippe de Vertus & 5,95238095 \\
\hline Ludwig von Orléans & Adam Chatelain & 6,12745098 \\
\hline Philipp der Kühne & Gilles de Vrolende & 6,17283951 \\
\hline Johann Ohnefurcht & Tassin & 6,51678071 \\
\hline Ludwig von Orléans & Regnaut d'Angennes & 6,66666667 \\
\hline Johann Ohnefurcht & Antoine de Craon & 6,69702652 \\
\hline Johann Ohnefurcht & Jacques de Trie & 6,69702652 \\
\hline Johann Ohnefurcht & Jean de Graville & 6,69702652 \\
\hline Johann Ohnefurcht & Jean de Montaigu & 6,69702652 \\
\hline Johann Ohnefurcht & Jean Marchand & 6,72043011 \\
\hline Johann Ohnefurcht & Arnaud de Corbie & 6,85871056 \\
\hline Isabeau de Bavière & Jeanne d'Harcourt & 6,94444444 \\
\hline Isabeau de Bavière & Marguerite de Préaux & 6,94444444 \\
\hline Johann Ohnefurcht & Jean de Vienne & 6,94444444 \\
\hline Johann Ohnefurcht & Ludwig von Male & 6,94444444 \\
\hline Karl VI. & Charles d'Albret & 6,94444444 \\
\hline Karl VI. & Marguerite de Landes & 6,94444444 \\
\hline Karl VI. & Philippe de Bar & 6,94444444 \\
\hline Karl (VII.) & Chatart de Rochedragoux & 6,94444444 \\
\hline Karl (VII.) & Guillaume Boniface & 6,94444444 \\
\hline Karl (VII.) & Hernauton d'Andines & 6,94444444 \\
\hline Karl (VII.) & Jean Boschet & 6,94444444 \\
\hline Karl (VII.) & Jean Gouffier & 6,94444444 \\
\hline Karl (VII.) & Philibert de Maleret & 6,94444444 \\
\hline Karl (VII.) & Yvon le Begaignon & 6,94444444 \\
\hline Philipp der Kühne & Guillaume Martel & 6,94444444 \\
\hline Simon de Cramaud & Johann von Berry & 6,94444444 \\
\hline Valentina Visconti & Jean de Dunois & 6,94444444 \\
\hline Waleran von Luxemburg & Johann von Berry & 7,44047619 \\
\hline Ludwig von Orléans & Guillaume Paynel & 7,51032670 \\
\hline
\end{tabular}




\begin{tabular}{|c|c|c|}
\hline $\begin{array}{l}\text { Philipp der Kühne } \\
\text { Philipp der Kühne }\end{array}$ & $\begin{array}{l}\text { Blanche } \\
\text { Guillaume de Bours }\end{array}$ & $\begin{array}{l}7,57575758 \\
7,57575758 \\
\end{array}$ \\
\hline Johann Ohnefurcht & Anton von Burgund & 8,11688312 \\
\hline Johann Ohnefurcht & Dino Rapondi & 8,33333333 \\
\hline Johann Ohnefurcht & Pierre de Montbertaud & 8,33333333 \\
\hline Karl VI. & Jeanne de Châtillon & 8,33333333 \\
\hline Karl (VII.) & Charles Garnier & 8,33333333 \\
\hline Karl (VII.) & Charles Labbé & 8,33333333 \\
\hline Karl (VII.) & Jacques de Villiers & 8,33333333 \\
\hline Ludwig von Orléans & Femmette & 8,33333333 \\
\hline Philipp der Kühne & Bernard d'Asuel & 8,33333333 \\
\hline Philipp der Kühne & Dino Rapondi & 8,33333333 \\
\hline Philipp der Kühne & Girard de Rigny & 8,33333333 \\
\hline Philipp der Kühne & Guy de La Roche-Guyon & 8,33333333 \\
\hline Philipp der Kühne & Katharina II. von Burgund & 8,33333333 \\
\hline Thibaut Portier & Johann von Berry & 8,33333333 \\
\hline Ludwig von Orléans & Guillaume le Bouteiller & 8,65800866 \\
\hline Isabeau de Bavière & Guillemette de Flacourt & 9,46969697 \\
\hline Valentina Visconti & Isabella von Frankreich & 9,92063492 \\
\hline Johann I. von Bourbon & Johann von Berry & 10,16260160 \\
\hline Johann Ohnefurcht & Jean de Luxembourg & 10,4166667 \\
\hline Johann Ohnefurcht & Oudart de L'Epinace & 10,4166667 \\
\hline Karl von Orléans & Johann von Berry & 10,4166667 \\
\hline Ludwig II. von Bourbon & Johann von Berry & 10,4166667 \\
\hline Ludwig von Orléans & Benedikt XIII. & 10,4166667 \\
\hline Philipp der Kühne & Charles d'Ivry & 10,4166667 \\
\hline Philipp der Kühne & Renaud de Trie & 10,4166667 \\
\hline Valentina Visconti & Jeanne de Luxembourg & 10,4166667 \\
\hline Karl von Orléans & Jean d'Angoulême & 11,5740741 \\
\hline Ludwig von Guyenne & Ludwig der Bärtige & 11,5740741 \\
\hline Ludwig von Orléans & Jeanne de Saint-Pol & 11,5740741 \\
\hline Valentina Visconti & Johanna von Frankreich & 11,5740741 \\
\hline Bonne d'Artois & Johann von Berry & 11,9047619 \\
\hline Philipp der Kühne & Charles de Chambly & 11,9047619 \\
\hline Philipp der Kühne & Jean du Rupt & 12,3456790 \\
\hline Ludwig von Orléans & Perrin Guire & 12,6262626 \\
\hline Robinet d'Etampes & Johann von Berry & 12,9198966 \\
\hline Karl von Orléans & Marguerite d'Orléans & 13,2275132 \\
\hline Paul von Limburg & Johann von Berry & 13,6054421 \\
\hline Anna von Bourbon & Johann von Berry & 13,8888889 \\
\hline Charles d'Albret & Johann von Berry & $13, \mathbf{8 8 8 8 8 8 9}$ \\
\hline Isabeau de Bavière & Jehanne & 13,8888889 \\
\hline Ludwig von Orléans & Colard de Villequier & 13,8888889 \\
\hline Ludwig von Orléans & Marguerite de Préaux & 13,8888889 \\
\hline Philipp der Kühne & Charles de Hangest & 13,8888889 \\
\hline Philipp der Kühne & Charles de Savoisy & 13,8888889 \\
\hline Philipp der Kühne & Robert d'Aunoy & 13,8888889 \\
\hline Pierre de Gynes & Johann von Berry & 13,8888889 \\
\hline Isabeau de Bavière & Jean Martel & 14,1242938 \\
\hline Isabeau de Bavière & Raoul Cassinel & 14,1242938 \\
\hline Johann Ohnefurcht & Nicole d'Estrée & 14,3678161 \\
\hline Gieffroy Robin & Johann von Berry & 15,4320988 \\
\hline Pierre Culon & Johann von Berry & 15,4320988 \\
\hline
\end{tabular}




\begin{tabular}{|c|c|c|}
\hline Valentina Visconti & Surien des Quesnes & 15,4320988 \\
\hline Karl von Orléans & Hue d'Ámboise & 15,5884645 \\
\hline Karl von Orléans & Jacques de Peschin & 15,5884645 \\
\hline Karl VI. & Catherine de Fastavarin & 16,6666667 \\
\hline Karl VI. & Isabelle La Bouteillière & 16,6666667 \\
\hline Karl VI. & Jeanne & 16,6666667 \\
\hline Karl VI. & Marie de Duisy & 16,6666667 \\
\hline Karl VI. & Marie de Quiemieu & 16,6666667 \\
\hline Katharina von Alençon & Johann von Berry & 16,6666667 \\
\hline Philipp der Kühne & Elion de Neilhac & 16,6666667 \\
\hline Philipp der Kühne & Jean de Graville & 16,6666667 \\
\hline Philipp der Kühne & Jean de Poquières & 16,6666667 \\
\hline Philipp der Kühne & Jean de Tancarville & 16,6666667 \\
\hline Karl VI. & Jacqueline Quipie & 17,3611111 \\
\hline Raymond de Lescure & Johann von Berry & 17,3611111 \\
\hline Valentina Visconti & Gilles Malet & 17,3611111 \\
\hline Valentina Visconti & Jeanne de Saint-Pol & 17,3611111 \\
\hline Karl VI. & Catherine de Villiers & 19,8412698 \\
\hline Karl VI. & Jeanne de La Tour & 19,8412698 \\
\hline Karl VI. & Jeanne de Montueil & 19,8412698 \\
\hline Karl VI. & Mabillette & 19,8412698 \\
\hline Karl VI. & Marguerite de Germonville & 19,8412698 \\
\hline Gérard du Puy & Johann von Berry & 20,8333333 \\
\hline Jean Marcheou & Johann von Berry & 20,8333333 \\
\hline Karl von Orléans & Philippe de Vertus & 20,8333333 \\
\hline Ludwig von Orléans & Hennequin le Poitevin & 20,8333333 \\
\hline Ludwig von Orléans & Jean de Pontoise & 20,8333333 \\
\hline Philipp der Kühne & Berthelot Helyot & 20,8333333 \\
\hline Philipp der Kühne & Guillaume d'Aumas & 20,8333333 \\
\hline Philipp der Kühne & Raillart de Chauffour & 20,8333333 \\
\hline Philipp der Kühne & Regnaud de Nantouillet & 20,8333333 \\
\hline Philipp der Kühne & Robinet le Tirant & 20,8333333 \\
\hline Valentina Visconti & Boniface & 20,8333333 \\
\hline Guillaume de Ruilly & Johann von Berry & 23,1481481 \\
\hline Karl von Orléans & Guillaume II de Craon & 23,1481481 \\
\hline Karl von Orléans & Jean de Juch & 23,1481481 \\
\hline Karl von Orléans & Jean de Rochechouart & 23,1481481 \\
\hline Karl von Orléans & Jeanne d'Orléans & 23,8095238 \\
\hline Philipp der Kühne & Jacot Blanchet & 24,5098039 \\
\hline Isabeau de Bavière & Femmette & 25,1004016 \\
\hline Valentina Visconti & Marguerite Spissau & 26,0416667 \\
\hline Johann Ohnefurcht & Margarete II. von Burgund & 26,3157895 \\
\hline Valentina Visconti & Guillaume de Senlis & 27,7777778 \\
\hline Ludwig von Orléans & Marie la Mayence & 28,7356322 \\
\hline Karl von Orléans & Guillaume Cousinot & 30,8641975 \\
\hline Philipp der Kühne & Jean de Dinant & 33,3333333 \\
\hline Philipp der Kühne & Jossequin de Jardins & 33,3333333 \\
\hline Philipp der Kühne & Louiset Moullié & 33,3333333 \\
\hline Philipp der Kühne & Nicolas Claux & 33,3333333 \\
\hline Philipp der Kühne & Nicolas d'Alfous & 33,3333333 \\
\hline Philipp der Kühne & Nicolas La Trompette & 33,3333333 \\
\hline Philipp der Kühne & Senville & 33,3333333 \\
\hline Philipp der Kühne & Villemote de Honcoigne & 33,3333333 \\
\hline
\end{tabular}




\begin{tabular}{|ll|c|}
\hline Béatrix de Navarre & Johann von Berry & 34,7222222 \\
Ludwig von Orléans & Catherine de Fastavarin & 34,7222222 \\
\hline Pierre de Savoisy & Johann von Berry & 37,8787879 \\
\hline Karl von Orléans & Guillaume le Bouteiller & 41,1522634 \\
Karl von Orléans & Jean Davy & 41,1522634 \\
Karl von Orléans & Jean de Fontaines & 41,1522634 \\
\hline Christophe de la Mer & Johann von Berry & 41,6666667 \\
Guichard Dauphin & Johann von Berry & 41,6666667 \\
Johann von Berry & Hannequin & 41,6666667 \\
Johann von Berry & Hermant & 41,6666667 \\
Johann von Berry & Jean Flamel & 41,6666667 \\
Philipp der Gute & Anton von Burgund & 41,6666667 \\
Simon Aligret & Johann von Berry & 41,6666667 \\
\hline Johann von Berry & Jean Nau & 52,0833333 \\
Johann von Berry & Jehanncon & 52,0833333 \\
Johann von Berry & Nicholas Feynat & 52,0833333 \\
Olivier de Mauny & Johann von Berry & 52,0833333 \\
\hline Johann von Berry & Estienne & 69,4444444 \\
\hline Guy de La Trémoille & Georges de La Trémoille & 75,3579503 \\
Guy de La Trémoille & Jean de La Trémoille & 75,3579503 \\
\hline Ludwig von Orléans & Jeanne de Soisy & 83,3333333 \\
\hline Renier de Bouligny & Johann von Berry & 92,5925926 \\
\hline Isabeau de Bavière & Christine de Pisan & 101,6260160 \\
\hline Arnoul Belin & Johann von Berry & 138,8888890 \\
\hline Valentina Visconti & Jeanne de Salçay & 208,3333330 \\
Valentina Visconti & Jehannette & 208,3333330 \\
\hline Ludwig von Orléans & Maria von Frankreich & 277,7777780 \\
Ludwig von Orléans & Michelle von Frankreich & 277,7777780 \\
Pannier & Johann von Berry & 277,7777780 \\
\hline Valentina Visconti & Jeanne de Vendôme & 416,6666670 \\
\hline Hermann von Limburg & Johann von Berry & 500,0000000 \\
Jan von Limburg & Johann von Berry & 500,0000000 \\
\hline
\end{tabular}

Tab. 12: Schenkbeziehungen des höfischen Geschenkverkehrs nach Nähe und Distanz

Tabelle 12 zeigt, daß die auf der Grundlage von Tabelle 11 gewonnenen Ergebnisse durch den Zusammenzug gerichteter Schenkbeziehungen identischer Paarungen noch deutlicher herausgearbeitet werden konnten. Beispielsweise unterliegt Guy de La Trémoille nach dieser Tabelle nun einer noch intensiveren Nahbeziehung zu Philipp dem Kühnen. Philipp selbst figuriert in 110 Paarungen, tritt also in mehr als $25 \%$ aller Schenkbeziehungen auf. Im Vergleich dazu erscheint Johann von Berry lediglich in 73, die beiden großen Kontrahenten Ludwig von Orléans und Johann Ohnefurcht in je 44, Karl VI. in 32 und Isabeau de Bavière in gar nur 25 Schenkbeziehungen. Insgesamt nennt Tabelle 12294 Personen des höfischen Geschenkverkehrs, die miteinander auf der eingeschränkten Grundlage von den durch die Quellen belegten Geschenkwerten die aufgelisteten 405 Beziehungen eingegangen sind. 
c) Nichtschenker - Nichtbeschenkte

Bei den wenigen die archivalischen Belege kaum ergänzenden Quellen ${ }^{486}$ kann so gut wie ausschließlich auch nur auf die in den archivalischen Quellen enthaltenen Informationen Bezug genommen werden. Allerdings ist nicht durchgängig notiert, wer wem was schenkte und was der einzelne Gegenstand gekostet hat. Außer verschiedentlichen Angaben in den Archivalien über den Versand von Geschenken durch Boten ${ }^{\mathbf{4 8 7}}$ oder dem Aufschluß darüber, wer möglicherweise am jeweiligen Neujahrstag mit wem zusammen war, der durch Abgleich der Itinerare einiger weniger Personen gegeben werden $\mathrm{kann}^{488}$, muß es größtenteils auch Spekulation bleiben, wer was von wem wie bekommen hat ${ }^{489}$. Zudem war es durchaus auch möglich, wie einleitend bereits erwähnt, daß die Neujahrsfeier nicht am 1. Januar stattfand. Ebenfalls kann nur vermutet werden, wer im konkreten Einzelfall was von wem warum bekommen hat ${ }^{490}$. Es können auf Grundlage der Quellen aber vor allem keine Aussagen darüber gemacht werden, wer wann was von wem nicht bekommen hat. Denn auch wenn der Kreis der Beschenkten häufig mit Wendungen wie auxdictes dames et damoiselles de son hostel ${ }^{491}$, à certaines personnes de l'hostel du roy ${ }^{492}$, à tous les chevaliers et ecuyers qui étoient à son service ${ }^{493}$, à serviteurs de nostre hostel ${ }^{494}$ usw. bezeichnet wird und sich daraus schlieBen ließe, daß in der Regel wohl der gesamte am Neujahrstag anwesende Personenkreis mit Geschenken bedacht worden ist, ist diese Aussage nicht belegbar.

Im folgenden soll zunächst im Vergleich mit dem in der »Cour amoureuse« notierten Personenbestand, der durch die Edition von Clara Bozzolo und Hélène Loyau erschlossen worden ist ${ }^{495}$, versucht werden, den namentlich faßbaren und oben vorgestellten Personenbestand des höfischen Geschenkverkehrs zum neuen Jahr auf Vollständigkeit zu überprüfen. Die "Cour amoureuse u umfaßt 952 Positionen, darunter allerdings eine Reihe anhand ihrer Wappen nicht identifizierbarer Personen, und existierte als höfisch-lite-

486 Siehe oben im einfuhrenden Kap. die Abschn. III. 2. und 3.

487 Siehe oben den Abschn. II. 1. b) »Geschickt und behalten«. Siehe auch oben S. 55, Anm. 88.

488 Siehe Anhang - Neujahrstage und Aufenthaltsorte 1381-1422.

489 Siehe hierzu oben den einführenden Abschn. II. 3. »Le festin du mois de janvier«, hier v.a. oben S. 52 zum Personenkreis.

490 Ein Ausnahmefall ist das Geschenk Philipps des Kühnen an den Herzog Berry, das Berry schriftlich angemahnt hatte, siehe oben S. 90 mit Anm. $84 f$.

491 Siehe bspw. Anhang - Katalog/Jahreslisten, Anm. 500f.

492 Siehe bspw. ebd., Anm. 1129.

493 Siehe bspw. ebd., Anm. 1876.

494 Siehe bspw. ebd., Anm. 1960.

495 BOZzOLO, LOYAU, La cour amoureuse, 3 Bde., 1982-1992. 
rarische Gesellschaft etwa 25 Jahre, also über die gesamte zweite Hälfte des höfischen Geschenkverkehrs von 1380-1422, dem Gegenstand der vorliegenden Arbeit ${ }^{496}$. Ihr Zweck war der literarische Betrieb als höfische Kurzweil zu Themen der höfischen Minne ${ }^{497}$. Gerechtfertigt werden kann das prospektierte Vorgehen zum einen durch das oben formulierte Postulat, daß die über Mitgliedschaften festgelegten Außengrenzen von System und Subsystem durch die Identität oder Teilidentität der Personenbestände weitestgehend oder teilweise deckungsgleich seien, was damit sowohl für das höfische Subsystem des Schenkens als auch für diesen Liebeshof gleichermaßen zu gelten habe. Nicht unerhebliche Tatsache bleibt, daß die »Cour amoureuse« keine Frauen nennt, also sowohl zwischen den beiden Subsystemen der "Cour amoureuse« und dem höfischen Geschenkverkehr als auch zwischen dem System Hof und dem einzelnen Subsystem jeweils nur eine personelle Teilidentität bestehen kann, die einer Überprüfung zugänglich ist. Zum anderen war das Vorgehen bislang dadurch bestimmt, daß der höfische Geschenkverkehr von 1380 bis 1422 im ganzen betrachtet worden ist, insbesondere, was die quantitativen Übersichten anbelangt. Auch die "Cour amoureuse « unterscheidet nicht zwischen einzelnen Häusern, sondern hat die gesamte Monarchie im Blick. Um auch die weiblichen Teilnehmer des höfischen Geschenkverkehrs zumindest ansatzweise berücksichtigen zu können, soll ein weiteres höfisches Subsystem in den Blick genommen werden, das sich aus Anlaß des Todes des connétable

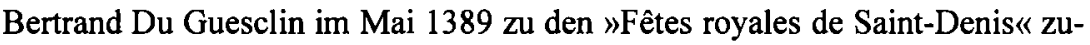
sammenfand und von Marius Barroux erschlossen wurde ${ }^{498}$. Ob in dem einen wie in dem anderen Fall diejenigen Personen, die zwar der »Cour amoureuse « angehörten oder an den "Fêtes royales de Saint-Denis« teilgenommen hatten, aber nicht als Schenker oder Beschenkte zum neuen Jahr auftraten, als vermutlich jene Nichtschenker und/oder Nichtbeschenkte benannt werden können, und ob diese nicht vielleicht doch zu dem Kreis der Schenker und Beschenkten gehört haben, nur archivalisch nicht belegt sind, muß freilich dahingestellt bleiben.

Die folgende Tabelle nennt die männlichen Teilnehmer des höfischen Geschenkverkehrs, die zugleich auch Mitglieder der »Cour amoureuse« waren, gereiht nach ihrer Stellung in der »Cour amoureuse«; innerhalb der obersten 25 Ränge zusätzlich auch diejenigen, die zwar Mitglied des Liebeshofs waren, aber nicht des höfischen Geschenkverkehrs. Da kein Maß anzugeben ist, das der einzelnen Person in der Hierarchie des höfischen Geschenkverkehrs eine eindeutige Position zuweisen würde, weil diese Person nicht zugleich nach ihren Funktionen als Schenker und Beschenkter im Zusammenhang mit den

496 Vgl. STRAUB 1961, S. If. mit Angaben zur Überlieferung in Anm. 1., und ebd., S. 4f. zur Struktur dieser Einrichtung, "ganz nach dem Vorbild der fürstlichen Höfe gegliedert«.

497 Vgl. ebd., S. 5.

498

BARROUX 1936. 
jeweiligen Bindungsziffern und Wertzuweisungen in Relation zu anderen Personen definiert werden kann, werden diesmal zum Vergleich Präsenzziffern herangezogen, die sich nach den Jahren der Teilnahme der einzelnen Personen am höfischen Geschenkverkehr bestimmen. Damit wird freilich unterschlagen, daß nicht jede Person den gesamten Zeitraum erlebte oder daß ein unverhältnismäßig wertvolles Einzelgeschenk unter Berücksichtigung der individuellen Partner einer möglicherweise singulären Schenkbeziehung eine andere Bewertung erfahren müßte als eine Vielzahl von über die Jahre verteilten Massengeschenken. Das Erkenntnisinteresse ist aber zunächst darauf gerichtet, zu erfahren, ob überhaupt namentlich bekannte Teilnehmer des höfischen Geschenkverkehrs auch Mitglieder der 》Cour amoureuse « waren; erst dann kann ermittelt werden, welche Teilnehmer des höfischen Geschenkverkehrs keine Mitglieder der "Cour amoureuse" waren und möglicherweise auch, warum, und wie hoch die jeweiligen Prozentsätze sind. In einem dritten Schritt soll der Blick auf die einzelnen Positionen in der jeweiligen Hierarchie gerichtet werden. Umgekehrt kann geprüft werden, wie hoch der Anteil derer war, die Mitglied der »Cour amoureuse« waren, aber nicht des höfischen Geschenkverkehrs: Waren dies diejenigen, die zu den Nichtschenkern und Nichtbeschenkten gehörten? Und warum?

\begin{tabular}{|l|l|c|c|}
\hline \multicolumn{1}{|c|}{ Name } & \multicolumn{1}{|c|}{ Jahre der Teilnahme } & \multicolumn{1}{|c|}{$\begin{array}{c}\text { Zahl der Jahre } \\
\text { der Teilnahme }\end{array}$} & $\begin{array}{c}\text { Rangziffer } \\
\text { in der Cour } \\
\text { amoureuse }\end{array}$ \\
\hline Karl VI. & $\begin{array}{l}1382-1406,1410,1413,1419, \\
1420,1422\end{array}$ & 29 & 1 \\
\hline Philipp der Kühne & $1381-1404$ & 24 & 2 \\
\hline $\begin{array}{l}\text { Ludwig II. von } \\
\text { Bourbon }\end{array}$ & $\begin{array}{l}1387,1389-1398,1401,1402, \\
1404,1408,1410\end{array}$ & 16 & 3 \\
\hline Ludwig der Bärtige & $1392,1403,1409,1412-1415$ & 7 & 4 \\
\hline Pierre de Navarre & $\begin{array}{l}1384,1391-1393,1396-1398, \\
1401,1402\end{array}$ & 9 & 5 \\
\hline Johann I. von Bourbon & $\begin{array}{l}1397,1403,1408,1411,1412, \\
1415\end{array}$ & 6 & 6 \\
\hline Johann Ohnefurcht & $1382,1385,1387-1390$, \\
$1392-1413,1417,1419$ & 30 & 7 \\
\hline Wilhelm von Bayern & $1388,1390,1403$ & 3 & 9 \\
\hline $\begin{array}{l}\text { Waleran III. von } \\
\text { Luxemburg }\end{array}$ & $1397,1398,1400,1410$ & 4 & 10 \\
\hline Ludwig von Orléans & $1384-1405,1407$ & 23 & 11 \\
\hline Johann von Berry & $1384-1416$ & 32 & 12 \\
\hline Edouard de Bar & 1398 & 1 & 13 \\
\hline Charles I d'Albret & $1384,1391,1393,1396-1398$, \\
\hline
\end{tabular}




\begin{tabular}{|c|c|c|c|}
\hline Ludwig von Guyenne & $\begin{array}{l}1401, \quad 1402, \quad 1404, \quad 1410 \\
1412-1415\end{array}$ & 8 & 18 \\
\hline Anton von Burgund & $\begin{array}{l}1386-1390, \quad 1393, \quad 1394, \\
1396-1398, \\
1417\end{array}$ & 15 & 19 \\
\hline Louis de Vendôme & $1403,1407,1408,1414,1415$ & 5 & 20 \\
\hline Philipp der Gute & $\begin{array}{l}1390,1397,1398,1402-1404 \\
1410,1411,1413,1415-1417 \\
1421\end{array}$ & 13 & 21 \\
\hline Philippe de Bourgogne & 1419 & 1 & 22 \\
\hline [Charles de Lorraine] & & & 23 \\
\hline \begin{tabular}{|ll} 
Pierre & de \\
Luxembourg $]$ & \\
\end{tabular} & & & 24 \\
\hline Jean de Luxembourg & 1417,1419 & 2 & 25 \\
\hline Guillaume Sanguin & $1397,1398,1407$ & 3 & 42 \\
\hline Bureau de Dampmartin & 1405 & 1 & 43 \\
\hline Gontier Col & 1405 & 1 & 59 \\
\hline Jean de Montagu & 1398,1407 & 2 & 67 \\
\hline Martin Gouge & $1404,1408,1411,1413-1416$ & 7 & 70 \\
\hline Arnaud de Corbie & 1403,1406 & 2 & 71 \\
\hline Pierre Trousseau & 1405 & 1 & 76 \\
\hline Charles de Chambly & 1391 & 1 & 97 \\
\hline Antoine de Craon & 1407 & 1 & 98 \\
\hline Regnaut d'Angennes & $1407,1412,1413,1415$ & 4 & 99 \\
\hline Guillaume de Bours & 1391,1392 & 2 & 102 \\
\hline Robert d'Aunoy & $1391,1398,1407$ & 3 & 103 \\
\hline Charles de La Rivière & 1413 & 1 & 109 \\
\hline Guillaume Martel & $1391,1398,1401,1402$ & 4 & 114 \\
\hline Charles d'Ivry & $1391,1398,1401$ & 3 & 116 \\
\hline Charles de Savoisy & $1391,1407,1410,1419$ & 4 & 120 \\
\hline $\begin{array}{l}\begin{array}{l}\text { Georges de La Tré- } \\
\text { moille }\end{array} \\
\end{array}$ & $1397,1402,1403$ & 3 & 123 \\
\hline Pierre de La Trémoille & $\begin{array}{l}1385,1393,1394,1396-1398, \\
1404\end{array}$ & 7 & 124 \\
\hline Gaucher de Châtillon & 1401 & 1 & 133 \\
\hline \begin{tabular}{|l|}
$\begin{array}{l}\text { Guillaume de Mont- } \\
\text { revel }\end{array}$ \\
\end{tabular} & 1413 & 1 & 140 \\
\hline Jacques de La Rivière & 1413 & 1 & 143 \\
\hline Pierre de Villaines & 1391 & 1 & 148 \\
\hline Colard de Villequier & 1407 & 1 & 158 \\
\hline Jean de Saulx & $1407-1409,1412,1419$ & 5 & 175 \\
\hline Jean II Le Meingre & 1393,1396 & 2 & 182 \\
\hline Jean de Croy & 1413 & 1 & 184 \\
\hline Olivier de Mauny & 1407 & 1 & 191 \\
\hline Charles de Châtillon & $1387,1391,1398$ & 3 & 195 \\
\hline Guichard Dauphin & $1384,1397,1410,1413,1414$ & 5 & 196 \\
\hline Charles de Soyecourt & 1413 & 1 & 217 \\
\hline Jean de Hangest & $1391,1397,1402,1407$ & 4 & 218 \\
\hline Pierre de Fontenay & 1419 & 1 & 237 \\
\hline Raoul Cassinel & 1395 & 1 & 240 \\
\hline $\begin{array}{l}\begin{array}{l}\text { Guillaume de Champ- } \\
\text { divers }\end{array} \\
\end{array}$ & 1419 & 1 & 258 \\
\hline
\end{tabular}




\begin{tabular}{|l|l|l|l|}
\hline Jean III de Vergy & 1397 & 1 & 271 \\
\hline Jean Pouquet & 1407 & 1 & 303 \\
\hline $\begin{array}{l}\text { Jacques de Villiers de } \\
\text { l'Isle-Adam }\end{array}$ & 1420 & 1 & 306 \\
\hline Colart d'Ongnies & 1417 & 1 & 320 \\
\hline $\begin{array}{l}\text { Jean Malet IV de Gra- } \\
\text { ville }\end{array}$ & 1388,1407 & 2 & 341 \\
\hline Jacques de Trie & 1407 & 1 & 356 \\
\hline Renier Pot & $1393,1394,1396,1398,1403$, & 8 & 367 \\
\hline Regnaud de Nantouillet & $1404,1407,1408$ & 1 & 379 \\
\hline $\begin{array}{l}\text { Guy de La Roche- } \\
\text { foucauld }\end{array}$ & $1392,1397,1398,1401,1404$ & 5 & 385 \\
\hline $\begin{array}{l}\text { Guy de La Roche- } \\
\text { Guyon }\end{array}$ & 1391,1415 & 2 & 385 \\
\hline Jean de La Trémoille & 1397 & 1 & 391 \\
\hline Michel de Laillier & 1407 & 1 & 427 \\
\hline Charles Poupart & 1392 & 1 & 428 \\
\hline Eustache Deschamps & 1398 & 1 & 437 \\
\hline Joceran Frepier & 1402 & 1 & 438 \\
\hline Dino Rapondi & 1400,1407 & 2 & 446 \\
\hline Robert de Boulogne & 1391 & 1 & 470 \\
\hline Oudart de L'Epinace & 1408 & 1 & 495 \\
\hline Jean de Toulongeon & 1419 & 1 & 535 \\
\hline Jean de Chevenon & 1407,1408 & 1 & 543 \\
\hline $\begin{array}{l}\text { Chatart de Rochedra- } \\
\text { goux }\end{array}$ & 1420 & 1 & 611 \\
\hline Guillaume du Bez & 1420 & 1 & 613 \\
\hline Renaud de Trie & 1391 & 1 & 681 \\
\hline Pierre Neveu & 1415 & 1 & 796 \\
\hline Guillaume Cousinot & 1411 & 1 & 861 \\
\hline Pierre de Montbertaud & 1402,1408 & 870 \\
\hline Renier de Bouligny & $1406,1407,1420$ & 873 \\
\hline Hémon Raguier & 1406 & 1 & 875 \\
\hline Michel le Beuf & $1404-1406,1410,1415$ & 1 & \\
\hline Jean Fale & 1414 & 1 & 1 \\
\hline
\end{tabular}

Tab. 13: Teilnehmer des höfischen Geschenkverkehrs als Mitglieder der »Cour amoureuse»

209 männliche Schenker und Beschenkte, also etwa $71 \%$ des 294 Personen umfassenden männlichen Personenbestandes des höfischen Geschenkverkehrs, werden in der "Cour amoureuse « nicht genannt. Dieser Personenkreis verkleinert sich jedoch aus verschiedenen Gründen. Mindestens 30 Personen wie die beiden Päpste Benedikt XIII. und Clemens VII. oder Heinrich III. von Spanien waren wohl schon allein aufgrund ihrer Position oder aus geographischen Gründen nicht in der "Cour amoureuse « vertreten. 24 Personen waren bereits verstorben wie Ludwig von Male oder zu Tode gekommen wie einige der Kämpfer von Nikopolis. Etwa 50 Personen, so darf vermutet werden, mögen infolge ihrer untergeordneten sozialen Stellung für eine Aufnahme in den Liebeshof gar nicht in Betracht gekommen sein, darunter beispielsweise die Mu- 
siker Philipps des Kühnen oder verschiedene Diener wie Estienne, ein Sticker des Herzogs von Berry. Jean d'Angoulême (geb. 1399), Jean de Dunois (geb. 1402) oder Philippe de Vertus (geb. 1396), die Söhne Herzog Ludwigs von Orléans, wie auch einige andere, darunter auch Karl (VII.), mögen noch zu jung gewesen sein oder noch gar nicht geboren, als der Liebeshof gegründet worden war; als sie älter waren, sind sie nicht vor Ort gewesen, weil sie sich beispielsweise nach der Schlacht von Azincourt in englischer Gefangenschaft befunden haben, oder weil sie aufgrund der politischen Frontstellungen der Zeit zu dieser Sonderform höfischer Kultur keinen Zugang hatten. Kardinal Simon de Cramaud war just zur Zeit der Gründung der "Cour amoureuse« in Ungnade gefallen. Schließlich traten am Ende des untersuchten Zeitraums mindestens 20 Personen auf, die der Gefolgschaft Karls (VII.) zuzurechnen sind, die aus ereignisgeschichtlich-politischen Gründen eher nicht als Teilnehmer der »Cour amoureuse « in Betracht kommen können, auch nicht als noch später hinzukommende ${ }^{499}$. Letztlich handelt es sich also um mindestens 130 Personen des Geschenkverkehrs zum neuen Jahr, hier nur überschlagsweise ermittelt, die nicht gleichzeitig auch Mitglieder der "Cour amoureuse" gewesen sein konnten, so daß nur noch höchstens 79 männliche Schenker und Beschenkte als mögliche Mitglieder des Liebeshofs übrig bleiben, dort aber nicht vertreten waren, was etwa $27 \%$ des männlichen Personenbestandes des Geschenkverkehrs entspricht. Gründe für das Fehlen dieser 79 Personen, darunter beispielsweise Bernhard VII. von Armagnac, können allerdings keine gegeben werden.

Etwa 164 männliche Teilnehmer des höfischen Geschenkverkehrs zum neuen Jahr hätten nach diesen Überlegungen Mitglieder der »Cour amoureuse« sein können. Nach Auskunft von Tabelle 13 waren allerdings nur 86 Personen gleichzeitig Mitglied der »Cour amoureuse« und des höfischen Geschenkverkehrs. Auffällig ist jedoch, daß die obersten 25 Positionen des Liebeshofes nahezu geschlossen auch am Geschenkverkehr zum neuen Jahr teilgenommen hatten. Es fehlen lediglich Jacques de Bourbon, Charles de Lorraine und Pierre de Luxembourg. Jacques de Bourbon war ein Sohn des Grafen von La Marche Jacques I de Bourbon und der Jeanne de Châtillon-SaintPol, verheiratet mit Marguerite de Préaux ${ }^{500}$. Da Marguerite de Préaux, eine Hofdame der Königin, 1401 und 1402 als beschenkte Teilnehmerin des Geschenkverkehrs notiert ist ${ }^{501}$, ist anzunehmen, daß das Fehlen ihres Mannes,

499 Die Aussage »eher nicht« bedeutet freilich, daß dies nur tendenziell richtig ist, denn mit Chatart de Rochedragoux (BOZZOLO, LOYAU, La cour amoureuse, Bd. 2, 1992, S. 139, Nr. 611), Guillaume du Bez (ebd., S. 141, Nr. 613), Jacques de Villiers de l'Isle-Adam (ebd., S. 15, Nr. 306) und Renier de Bouligny (ebd., Bd. 3, 1992, S. 245, Nr. 863) waren durchaus Gefolgsleute Karls (VII.) Mitglieder der »Cour amoureuse«.

500 Siehe Bozzolo, LoYAU, La cour amoureuse, Bd. 1, 1982, S. 53, Nr. 15.

501 Siehe Anhang - Katalog/Jahreslisten, Nr. 411 und 795. 
der immerhin grand-bouteiller Frankreichs war, einzig eine Folge der Überlieferung ist. Dies mag auch für Karl, Herzog von Lothringen und 1418 connétable Frankreichs, gelten, der über seine Schwester Isabelle mit Enguerrand von Coucy verschwägert war ${ }^{502}$. Enguerrand von Coucy wiederum war 1391 im Neujahrsgeschenkverkehr vertreten ${ }^{503}$, aber zur Zeit der Gründung des Liebeshofes bereits nicht mehr am Leben. Pierre de Luxembourg schließlich ${ }^{504}$ war Bruder von Jean de Luxembourg, der 1417 und 1419 am höfischen Geschenkverkehr teilgenommen hatte ${ }^{505}$. Welchen Grund sollte es geben, daß sich Pierre, Gründungsritter des Ordens vom Goldenen Vlies, grundsätzlich anders verhalten haben sollte als sein Bruder?

Werden die nach Anwesenheit bestimmten Spitzenpositionen des höfischen Geschenkverkehrs mit den Rängen der »Cour amoureuse« verglichen, können gegenüber der hierarchischen Ordnung des Liebeshofes einige leichte Verschiebungen, aber auch einige interessante Änderungen innerhalb der obersten 25 Positionen festgestellt werden, die dem zeitbestimmten Faktor der Kontinuität Rechnung tragen. Die ersten elf Plätze werden der Reihe nach von Personen eingenommen, die auch vorher schon Spitzenränge besetzt hatten: Johann von Berry, Johann Ohnefurcht, Philipp der Kühne, Ludwig von Orléans, Ludwig II. von Bourbon, Anton von Burgund, Philipp dem Guten, Pierre de Navarre, Charles I d'Albret und Ludwig von Guyenne. Nur bei Karl VI., der von Platz 1 auf Platz 3 rückte, Philipp dem Kühnen, der nach dem zweiten nun den vierten Rang besetzt, Ludwig II. von Bourbon, der vom dritten auf den sechsten Platz fiel, und Pierre de Navarre, der nach Rang 5 nun Rang 9 bekleidet, konnten leichte Positionsverschlechterungen festgestellt werden. Ludwig der Bärtige hingegen findet sich nun auf dem 13., Johann I. von Bourbon auf dem 16., Louis de Vendôme auf dem 17., Waleran von Luxemburg auf dem 22. Platz. Wilhelm von Bayern, Jacques II de Bourbon, Jean de Luxembourg, Edouard de Bar, Gilles de Bretagne, Guillaume IV de Melun und Philippe de Bourgogne, zuvor allesamt in der Gruppe der höchsten 25 Ränge der »Cour amoureuse« vertreten, sind nun erst auf den Plätzen 27 (Wilhelm von Bayern), 34 (Jacques II de Bourbon), 35 (Jean de Luxembourg), 45 (Edouard de Bar), 46 (Gilles de Bretagne), 47 (Guillaume IV de Melun) und 48 (Philippe de Bourgogne) zu finden. Interessanterweise sind aber nun nach Präsenz bestimmte Personen in die obersten Hierarchieebenen des höfischen Geschenkverkehrs aufgestiegen, die in der "Cour amoureuse « relativ niedrige Ränge bekleidet hatten: Martin Gouge, Michel le Beuf, Regnaut d'Angennes und Guillaume Martel, die der orléanistischen Sphäre zuzuordnen sind, dann der nicht eindeutig Burgund oder Orléans zuzuweisende Guy de La Roche-

502 Siehe BOzZOLO, LOYAU, La cour amoureuse, Bd. 1, 1982, S. 55, Nr. 23.

503 Siehe Anhang - Katalog/Jahreslisten, Nr. 430, 866 und 994.

504 Siehe Bozzolo, LoYAU, La cour amoureuse, Bd. 1, 1982, S. 57, Nr. 24.

505 Siehe Anhang - Katalog/Jahreslisten, Nr. 1705 und 1723. 
foucauld sowie Renier Pot, Pierre de La Trémoille, Jean de Saulx, Guichard Dauphin und Charles de Savoisy, die der burgundischen Seite zuzurechnen sind.

Martin Gouge ${ }^{506}$, Kanzler und conseiller des Herzogs von Berry, Kanzler Ludwigs von Guyenne 1415 und Kanzler Frankreichs von 1422 bis 1424 und von 1426 bis 1428 , war als Teilnehmer des höfischen Geschenkverkehrs in den Jahren 1404, 1408, 1411, und 1413 bis 1416 verbunden mit Johann von Berry 507. Michel le Beuf ${ }^{508}$, in der »Cour amoureuse « erst auf Platz 873 notiert, ist zunächst artiste am Collège de Navarre 1384 gewesen. Er war secrétaire des Herzogs von Orléans 1398 und des Herzogs von Berry 1398, 1403, 1406, 1407, 1408 und 1413 und ist bis zum Amt des Bischofs von Lodève aufgestiegen, das er von 1413 bis 1430 bekleidet hatte. Michel le Beuf hatte sich insbesondere der Großzügigkeit Karls (VII.) und des Grafen von Foix erfreuen können, stand aber wie Martin Gouge in den Jahren 1404 bis 1406, 1410 und 1415 mit dem Herzog von Berry in Beziehung509. Regnaut d'Angennes ${ }^{510}$ war in den Jahren 1380 bis 1416 in Diensten der Krone. Zunächst valet tranchant, dann capitaine des Louvre von 1392 bis 1416, war Regnaut chambellan 1405 und conseiller 1406 und 1407 des Königs und Ludwigs von Guyenne, premier chambellan Ludwigs von Guyenne 1404 und der von diesem favorisierte chambellan im Jahr 1413. Die Cabochiens hatten Regnaut d'Angennes am 22. Mai 1413 gefangengesetzt. Als Gesandter des Königs ist er 1415 in Troyes aufgetreten. Er war Protegé des Herzogs von Berry und Orléanist, zudem war Ludwig von Orléans Pate seines Sohnes. Seine Teilnahme am höfischen Geschenkverkehr in den Jahren 1407, 1412 und 1415 war bestimmt durch Ludwig von Guyenne ${ }^{511}, 1413$ hatte er aber auch von Johann Ohnefurcht einen goldenen Pokal erhalten ${ }^{512}$ : ein Versuch, Regnaut d'Angennes auf die burgundische Seite zu ziehen? Guillaume Martel $^{513}$ schließlich war der nach Froissart von Karl VI. bevorzugte chambellan und conseiller der Krone bereits Karls V. seit 1377. Als porte-oriflamme ist Guillaume Martel 1415 in der Schlacht von Azincourt gefallen. 1391, 1398,

506 BOzZolo, LOYAU, La cour amoureuse, Bd. 1, 1982, S. 93, Nr. 104. Siehe auch oben S. 53 mit Anm. 75 und S. 53, Anm. 76.

507 Siehe Anhang - Katalog/Jahreslisten, Nr. 1295, 1446, 1539, 1604, 1648, 1679, 1680 und 1691 .

508 Bozzolo, LOYAU, La cour amoureuse, Bd. 3, 1992, S. 249, Nr. 873.

509 Siehe Anhang - Katalog/Jahreslisten, Nr. 1283, 1337, 1359, 1468 und 1660.

510 BOzzOLO, LOYAU, La cour amoureuse, Bd. 1, 1982, S. 91, Nr. 99.

511 Siehe Anhang - Katalog/Jahreslisten, Nr. 1415, 1557 und 1677.

512 Siehe ebd., Nr. 1595.

513 BOZZOLO, LOYAU, La cour amoureuse, Bd. 1, 1982, S. 99, Nr. 114. 
1401 und 1402 ist Guillaume Martel in der Regel von Ludwig von Orléans beschenkt worden 514 .

Guy de La Rochefoucauld ${ }^{515}$ ist zunächst conseiller und chambellan Karls V., Karls VI. und Philipps des Kühnen gewesen, des letzteren hochdotierter pensionnaire von 1384 bis 1386, dann aber chambellan des Dauphins Ludwig von Guyenne und stand in Diensten des Herzogs von Orléans in der Guyenne. Verheiratet war Guy de La Rochefoucauld in erster Ehe mit Jeanne de SaintPol, einer Schwester Walerans von Luxemburg, in zweiter Ehe mit Marguerite de Craon, einer Tochter des Guillaume II de Craon und der Jeanne de Montbazon. Am höfischen Geschenkverkehr hatte Guy de La Rochefoucauld in den Jahren 1392, 1397, 1398, 1401 und 1404 teilgenommen und zwar als meist von Philipp dem Kühnen Beschenkter ${ }^{516}$.

Einen ähnlich außerordentlichen nach Anwesenheit bemessenen Auftritt wie Michel le Beuf und Guy de La Rochefoucauld hatte Renier Pot im höfischen Geschenkverkehr zum neuen Jahr im Vergleich zu seiner Stellung in der "Cour amoureuse«. Renier Pot ${ }^{517}$ war Mitglied des innersten Rates Philipps des Kühnen, sein échanson und chambellan, auch conseiller und chambellan des Königs, Johanns Ohnefurcht und Philipps des Guten. Daß Renier Pot Ritter des Ordens vom Goldenen Vlies bei seiner Gründung war, zeugt von einem engen Verhältnis zu seinem Herrn, dem Herzog von Burgund. Durch seine Mutter Radegonde Guénant, einer Witwe des Guy V de La Trémoille, war Renier Halbbruder von Guy, Guillaume und Pierre de La Trémoille, verheiratet war er jedoch mit Catherine Angoussoles, einer Hofdame der Herzogin von Orléans, was auch hier wieder zeigt, wie sehr die höfische $\mathrm{Ge}-$ sellschaft trotz aller Frontstellungen miteinander verwoben war. Renier Pots Teilnahme am höfischen Geschenkverkehr war in den Jahren 1393, 1394, 1396, 1398, 1403, 1404, 1407 und 1408 bestimmt durch Philipp den Kühnen ${ }^{518}$ und Johann Ohnefurcht ${ }^{519}$. Nach Ausweis von Tabelle 12 war die Schenkbeziehung, die Philipp der Kühne zu Renier Pot unterhalten hatte, eine der ausgeprägteren eines Fürsten zu einem Nichtfürsten. Noch mehr gilt dies für Pierre de La Trémoille und Jean de Saulx. Pierre de La Trémoille ${ }^{520}$, wie erwähnt einer der Halbbrüder Renier Pots, war chambellan und conseiller Philipps des Kühnen, Johanns Ohnefurcht und Karls VI. Als mehrfacher PreuBenfahrer in den Jahren 1377/1378, 1379/1380, möglicherweise auch im Sommer 1390, dann 1391/1392 und im Sommer 1394 galt Pierre de La Trémoille

514 Siehe Anhang - Katalog/Jahreslisten, Nr. 455 (Schenker: Philipp der Kühne), 891, 1076 und 1161 .

515 Bozzolo, LoYAU, La cour amoureuse, Bd. 1, 1982, S. 77, Nr. 70.

516 Siehe Anhang - Katalog/Jahreslisten, Nr. 513, 812, 869, 924, 1099 und 1300.

517 Bozzolo, LOYAU, La cour amoureuse, Bd. 2, 1992, S. 43, Nr. 367.

518 Siehe Anhang - Katalog/Jahreslisten, Nr. 601, 643, 647, 757, 993, 1276 und 1327.

519 Siehe ebd., Nr. 1404 und 1442.

520 BOZZOLO, LOYAU, La cour amoureuse, Bd. 1; 1982, S. 103, Nr. 124. 
als »der burgundische Spezialist für Preußen und den Deutschen Orden« 521. Sein Auftritt als Teilnehmer des höfischen Geschenkverkehrs in den Jahren $1385,1393,1394,1396$ bis 1398 und 1404 war ausschließlich bestimmt durch Philipp den Kühnen ${ }^{522}$. Jean de Saulx ${ }^{523}$, Kanzler Burgunds unter Johann Ohnefurcht von 1404 bis 1419 , belegt durch seine für die Jahre 1407 bis 1409 , 1412 und 1419 nachgewiesene Anwesenheit einen der diesbezüglich obersten Ränge im Geschenkverkehr zum neuen Jahr, einzig zurückzuführen auf seine Rolle als Beschenkter des Burgunderherzogs Johann Ohnefurcht ${ }^{524}$. Guichard Dauphin ${ }^{525}, 1409$ in Nachfolge des hingerichteten Jean de Montaigu grand maitre de l'hôtel Karls VI., war gouverneur der Dauphiné in der Nachfolge des Renier Pot 1414 und chambellan Johanns Ohnefurcht. Gefallen in der Schlacht von Azincourt war Guichard in den Jahren 1384, 1397, 1410, 1413 und 1414 am höfischen Geschenkverkehr als Beschenkter Philipps des Kühnen ${ }^{526}$, aber auch als Schenker Johanns von Berry527 beteiligt. Charles de Savoisy 528 schließlich war zunächst conseiller und premier chambellan Karls VI. und Ludwigs von Orléans, dann in Italien 1396 in Diensten Ludwigs II. von Anjou, Preußenreisender und grand échanson Frankreichs von 1408 bis 1413 . 1391, 1410 und 1419 erscheint Charles de Savoisy im burgundischen Kreis des höfischen Geschenkverkehrs zum neuen Jahr ${ }^{529}$. Angeklagt, einer der Mörder des Herzogs von Orléans gewesen zu sein, hatte er noch zum Neujahrstag 1407 von Ludwig von Orléans einen Diamantring geschenkt bekommen 530 .

Erst ab der nach Anwesenheit bestimmten Position 49 finden sich diejenigen Teilnehmer des höfischen Geschenkverkehrs zum neuen Jahr, die auch in der "Cour amoureuse « einen nur nachgeordneten Rang bekleidet hatten. Die letzten Plätze besetzen Pierre Neveu531, Bischof von Lavaur, Guillaume Cousinot $^{532}$, conseiller des Königs, Kanzler des Herzogs von Orléans in der Nachfolge von Jean Davy ab 1415, conseiller Karls VII., Chronist des 15. Jahrhunderts und möglicherweise auch Autor der »Geste des nobles français«, Hémon Raguier ${ }^{533}$, argentier, trésorier und receveur général vor allem in

521 PARAVICINI, Preußenreisen, Bd. 1, 1989, S. 171f.

522 Siehe Anhang - Katalog/Jahreslisten, Nr. 149, 600, 642, 646, 756, 858, 988 und 1326.

523 BOZZOLO, LOYAU, La cour amoureuse, Bd. 1, 1982, S. 125, Nr. 175.

524 Siehe Anhang - Katalog/Jahreslisten, Nr. 1339, 1394, 1435, 1460, 1548 und 1725.

525 BOZZOLO, LOYAU, La cour amoureuse, Bd. 1, 1982, S. 135, Nr. 196.

526 Siehe Anhang - Katalog/Jahreslisten, Nr. 89 und . 811.

527 Siehe ebd., Nr. 1470, 1562 und 1614.

528 Bozzolo, LoYAU, La cour amoureuse, Bd. 1, 1982, S. 101, Nr. 120.

529 Siehe Anhang - Katalog/Jahreslisten, Nr. 450, 1477 und 1720.

530 Siehe ebd., Nr. 1408.

531 BOZZOLO, LOYAU, La cour amoureuse, Bd. 3, 1992, S. 191, Nr. 715.

532 Ebd., S. 221, Nr. 796.

533 Ebd., S. 247, Nr. 870. 
Diensten der Königin, und Jean Fale ${ }^{534}$, contrôleur de la recette générale im Jahr seines Auftritts im höfischen Geschenkverkehr 1419.

Der Anteil derer, die Mitglied des Liebeshofes waren, aber nicht am höfischen Geschenkverkehr zum neuen Jahr teilgenommen hatten, beträgt fast 91\%. Den Gesamtbestand von insgesamt 952 möglichen Mitgliedern der "Cour amoureuse" zugrundegelegt und unterstellt, daß hier in etwa alle im Zentrum der höfischen Gesellschaft des ersten Viertels des 15. Jahrhunderts stehenden männlichen Vertreter notiert sind ${ }^{535}$, nahmen 866 Mitglieder des Liebeshofes nicht am höfischen Geschenkverkehr zum neuen Jahr teil. Einige dieser Personen, nämlich Jacques de Bourbon, Charles de Lorraine und Pierre de Luxembourg, sind bereits genannt worden und es konnten unter Hinweis auf die Überlieferung Vermutungen darüber angestellt werden, ob diese Personen nicht möglicherweise doch am Geschenkverkehr teilgenommen hatten, nur ihre Teilnahme nicht belegt ist ${ }^{536}$. Werden nur die ersten 50 Positionen des Liebeshofes betrachtet, so können außer den drei bereits genannten folgende Personen als potentielle Nichtschenker und/oder Nichtbeschenkte zum neuen Jahr namhaft gemacht werden: Jean de Namur ${ }^{537}$, Louis de Chalon ${ }^{538}$, Pierre de Hauteville ${ }^{539}$, Jacques de Châtillon ${ }^{540}$, Jean de Werchin ${ }^{541}$, Jean de Saint-Père ${ }^{542}$, Guillaume Cassinel ${ }^{543}$, Guillaume de Tignonville ${ }^{544}$, David de Brimeu $^{545}$, Jean de Maintenon ${ }^{546}$, Florent d'Encre ${ }^{547}$, Jean de Montenay ${ }^{548}$, Jean de Boissay ${ }^{549}$, Jacques de La Viefville ${ }^{550}$, Jean Charles ${ }^{551}$, Guillaume Foucault ${ }^{552}$, Jean d'Oinville ${ }^{553}$, Jean de Villeroy ${ }^{554}$, Henri de Boisy 555 ,

Bozzolo, LoyaU, La cour amoureuse, Bd. 3, 1992, S. 251, Nr. 875.

$\mathrm{DaB}$ dies nicht der Fall ist, belegt ein einfacher Blick in die einschlägigen Stammtafeln.

So fehlt in der »Cour amoureuse " bspw. das Haus Anjou.

536 Siehe oben S. 252.

537 BOZzOLO, LOYAU, La vour amoureuse, Bd, 1, 1982, S. 57, Nr. 26.

538 Ebd., S. 57, Nr. 27.

539 Ebd., S. 59, Nr. 28.

540 Ebd., S. 59, Nr. 29.

541 Ebd., S. 59, Nr. 30.

542 Ebd., S. 61, Nr. 31.

543 Ebd., S. 61, Nr. 32.

544 Ebd., S. 61, Nr. 33.

545 Ebd., S. 61, Nr. 34.

546 Ebd., S. 63, Nr. 35.

547 Ebd., S. 63, Nr. 36.

548 Ebd., S. 63, Nr. 37.

549 Ebd., S. 63, Nr. 38.

550 Ebd., S. 63, Nr. 39.

551 Ebd., S. 65, Nr. 40.

552 Ebd., S. 65, Nr. 41.

553 Ebd., S. 65, Nr. 44.

554 Ebd., S. 67, Nr. 45.

555 Ebd., S. 67, Nr. 46. 
Jacquet Charles 556 , Binde de Hametel ${ }^{557}$, Baude Des Bordes 558 und Guillaume Le Maigret ${ }^{559}$. Eine ganze Reihe dieser Personen stand auf die eine oder andere Weise mit Personen, die im Rahmen des Geschenkverkehrs auftraten, in Beziehung (die Jahre, in welchen die nachstehenden Personen am höfischen Geschenkverkehr zum neuen Jahr teilnahmen, stehen im folgenden in Klammern hinter den jeweiligen Namen). So war Jean de Namur, Sohn des Herzogs von Namur und der Katharina von Savoyen, über seinen Bruder Guillaume mit Jeanne d'Harcourt $(1390,1391)$ verschwägert. Louis de Chalon, Fürst von Orange, war über seine Schwester Jeanne verschwägert mit Jean de Vergy (1397). Jacques de Châtillon war verheiratet mit Jeanne de La Rivière, Schwester des Jacques de La Rivière (1413), und mit Jeanne de Flotte (1419). Jean de Saint-Père war verheiratet mit Marguerite Martel, einer Tochter des Guillaume Martel (1391, 1398, 1401, 1402). Bei Guillaume Cassinel, einem der Hofmeister der Königin, handelte es sich um den Vater von Raoul Cassinel (1395). Guillaume de Tignonville, Freund Eustache Deschamps', war Schwiegervater des Herrn von Saint-Cyr, Jean de Monceaux (1417). David de Brimeu, nicht zu verwechseln mit dem Herrn von Humbercourt, war verheiratet mit Marie de Montauban (1412). Jacques de La Viefville, ebenfalls burgundischer Gefolgsmann, war verheiratet mit Ourse Spazequerin (1412). Guillaume Foucault war verheiratet mit einer Tochter des Simon de Dampmartin (1397, 1398), also Schwager von Bureau de Dampmartin (1405). Möglicherweise gab es schließlich auch eine Beziehung zwischen Jean d'Oinville und Colard de Villequier (1407), der mit einer Jeanne d'Oinville verheiratet war. Es könnten sich noch einige weitere Verbindungslinien zwischen diesen Mitgliedern der »Cour amoureuse«, die nicht am Geschenkverkehr zum neuen Jahr teilgenommen hatten, und dem Personenkreis der Schenker und Beschenkten nennen lassen, doch bereits anhand der vorstehenden Angaben mag deutlich geworden sein, daß der Schluß, daß ein nicht unbedeutender Teil jener, die zur »Cour amoureuse " gehörten, aber nicht im Rahmen des Geschenkverkehrs zum neuen Jahr auftraten, nur von Seiten der bekannten Überlieferung aus gesehen als Schenker und/oder Beschenkte nicht in Frage kommen. Bei Pierre de Hauteville, Jean de Werchin, Jean de Maintenon, Florent d'Encre, Jean de Montenay, Jean de Boissay, Jean Charles, Jean de Villeroy, Henri de Boisy, Jacquet Charles, Binde de Hametel, Baude Des Bordes und Guillaume Le Maigret lassen sich solche Verbindungslinien allerdings nicht ziehen und nur bei diesen Personen kann vermutet werden, daß es sich hier um diejenigen handeln könnte, die zum Kreis der Nichtschenker beziehungsweise Nichtbeschenkten gehörten. Belegbar ist dies freilich nicht, weshalb sich auch 
eine andere Antwort auf die Frage nach dem »Warum« als jene, die auf die Überlieferung verweist, erübrigt, in diesem Sinne des weiteren davon absehend, zusätzlich auch die restlichen Mitglieder der "Cour amoureuse« auf mögliche Teilnahme am höfischen Geschenkverkehr zu überprüfen.

$\mathrm{Zu}$ den »Fêtes royales de Saint-Denis«, die im Mai 1389, also im Jahr nach dem Regierungsantritt Karls VI. und nach der im Januar des Jahres 1389 erfolgten Heirat Ludwigs von Touraine mit Valentina Visconti, aus Anlaß des Todes von Bertrand Du Guesclin veranstaltet worden waren, ist nicht nur der französische, sondern auch ein Teil des deutschen und des englischen Adels eingeladen gewesen ${ }^{560}$. Die Feiern müssen einen bereits den Zeitgenossen aufgefallenen Gegensatz zwischen Anlaß und Ausführung geboten haben. Marius Barroux zitiert Michelet mit den Worten: "Cette bacchanale près des tombeaux [...] eut un bizarre lendemain ... Le héros de Charles VI eut le triste honneur d'amuser de ses funérailles la folle et luxurieuse cour. «561 Was hier jedoch interessiert, sind nicht die festlichen Abläufe (und ihre mögliche Bewertung), sondern deren Teilnehmer, zumal am letzten Tag der Feierlichkeiten zahlreiche wertvolle Geschenke verteilt worden waren, über die verschiedene Rechnungsüberlieferungen unterrichten ${ }^{562}$. Barroux gibt auf der Grundlage

560 Siehe BARROUX 1936, S. 5.

561 Ebd. mit Anm. 3. Auslassung in eckigen Klammern J.H., nur gepunktete Auslassung bei Barroux.

562 Siehe ebd., S. 32-36, und ebd., S. 97-113 die entspr. Teiled. der Rechnungslegung des königlichen Argentiers Arnoul Boucher nach AN KK 20. AN KK 20, fol. 166rff. gibt die Liste derer, die bei den "Fêtes de Saint-Denis« Roben und joyaux erhalten hatten. Allein die Ausgaben für die königlichen dons de joyaux beliefen sich auf 15.971 l. 7 s. 10 d.p., ebd., fol. 94r. - Die von Karl VI. am Neujahrstag 1390 getätigten Ausgaben für die von ihm vergebenen étrennes betrugen lediglich 1.417 fr. (summiert nach den im Anhang gegebenen und belegten Werten). Empfängerinnen der Gaben waren Catherine de Fastavarin (1 dyament, BNF ms.fr. 20627, Nr. 4), Catherine de Villiers (1 dyament, BNF ms.fr. 20627, Nr. 4), Isabeau de Bavière (nach KIMM 1969, S. 24 ein goldenes Schmuckstück, das Karl VI. von seiner Reise nach Toulouse geschickt hatte, das sich öffnen ließ, und in seinem Inneren das Heilige Grab zeigte mit der Mutter Gottes, die das Jesuskind auf dem Arm hält, BNF ms.fr. 20627, Nr. 4), Isabelle La Bouteillière (1 dyament, BNF ms.fr. 20627, Nr. 4), [fille de la dicte dame, wahrscheinlich Jeanne] (I petit fermillet a trois petites perles et I saphir au milieu, BNF ms.fr. 20627, Nr. 4), Jeanne de Châtillon (1 annel a un dyament, BNF ms.fr. 20627, Nr. 4), Jeanne de Dreux (1 annel a un dyament, BNF ms.fr. 20627, Nr. 4), Jeanne d'Harcourt (I annel, BNF ms.fr. 20627, Nr. 4), Jeanne de Montueil (I dyament, BNF ms.fr. 20627, Nr. 4), Jeanne de La Tour ( 1 dyament, BNF ms.fr. 20627, Nr. 4), Jeanne de Vendôme (1 annel a un dyament, BNF ms.fr. 20627, Nr. 4), Mabillette (1 dyament, BNF ms.fr. 20627, Nr. 4), Marguerite de Germonville (1 dyament, BNF ms.fr. 20627, Nr. 4), [Marguerite de Landes] (1 patenostre et I reliquaire d'or, BNF ms.fr. 20627, Nr. 4), Marie de Duisy (1 dyament, BNF ms.fr. 20627, Nr. 4), Marie de Quiemieu (1 dyament, BNF ms.fr. 20627, Nr. 4), Jacqueline Quipie (I patenostre et 1 reliquaire d'or, BNF ms.fr. 20627, Nr. 4), vier damoiselles der Valentina Visconti N.N. (4 dyaments, BNF ms.fr. 20627, Nr. 4) und 56 damoiselles des dames estans en la compaignie de nostre dicte compaigne et aus femmes de chambre, mithin die damoiselles von Marie de Quiemieu, Catharine de Fastavarin und Isa- 
zweier Dokumente 563 eine Identifikation des dort notierten Personenbestandes ${ }^{564}$ und kann bei einem Gesamtumfang von 234 Personen 194 Personen namentlich erfassen, darunter 140 Frauen; insgesamt 40 Personen sind nicht oder nur teilweise identifiziert, aber in jedem Fall nach Zuordnung und Geschlecht (da überliefert als Madame de ... oder femme de ...). Vorgehend wie bei dem oben durchgeführten Vergleich des Personenkreises des Geschenkverkehrs zum neuen Jahr mit dem Personenbestand der »Cour amoureuse« kann festgehalten werden, daß nur 12 weibliche und 34 männliche Angehörige der Festversammlung auch als Teilnehmer des Geschenkverkehrs zum neuen Jahr bekannt sind ${ }^{565} .40$ weitere Personen standen aber auf die eine oder andere Weise mit Teilnehmern des Geschenkverkehrs in zum Teil sehr naher Beziehung, so daß auch hier vermutet werden darf, daß deren Fehlen

belle La Bouteillière sowie Marguerite de Landes. Bei den femmes de chambre handelt es sich nach GRANDEAU 1975, S. 163 wahrscheinlich um Femmette, die ouvrière Jehanette und die lavandière Jehanne ( 7 aneaul $x$ a perles, 3 patenostres d'or, 6 balaiz en 6 aneaulx, 40 petiz dyamens, BNF ms.fr. 20627, Nr. 4). Mit Ludwig (von Orléans) (un gros dyament, BNF ms.fr. 20627, Nr. 5) und Philipp dem Kühnen (Wert unbekannt, ACO B 1487, fol. 40r) sind nur zwei männliche Empfänger bekannt. Isabeau de Bavière hatte ihrem Gatten an diesem ersten Neujahrstag nach ihrer im Sommer 1389 erfolgten feierlichen Krönung und Weihe in Paris einen petit fermail d'or a un cerf voulant garni de trois grois dyamans, un roby, et trois grosses perles zu dem beträchtlichen Wert von 1.534 fr. geschenkt (BNF ms.fr. 20627, Nr. 5) - siehe Anhang - Katalog/Jahreslisten, Nr. 331-357.

563 Archives de la Seine, D. $3 \mathrm{AZ}, \mathrm{Nr} .119=\mathrm{D}$. $\mathrm{H}^{\mathrm{l}} \mathrm{S}^{\mathrm{t}}$-Denis: Relation des joutes et de la messe de Du Guesclin, Barroux 1936, S. 43-49, und AN KK 30, fol. 166-170: Listes d'assistants, BARROUX 1936, S. 50-53.

564 BARROUX 1936, S. 53-94.

565 Die Jahre der Teilnahme am Geschenkverkehr zum neuen Jahr sind jeweils in Klammern notiert: Alain de Beaumont (1401, 1402), Arnaud-Amanieu VIII d'Albret (1384, 1387, $1391,1397,1398)$, Catherine de Fastavarin (1390-1392, 1396), Catherine de Villiers (13901392, 1395), Charles d'Ivry (1391, 1398, 1401), Charles de La Rivière (1413), Charles de Savoisy (1391, 1407, 1410, 1419), Charles I d'Albret (1384, 1391, 1393, 1396-1398, 1402, $1405,1411)$, Enguerrand VII de Coucy (1391), Guillaume VI Paynel (1401), Guy de La Roche-Guyon (1391, 1415), Isabeau de Barre (1420), Isabeau de Bavière (1386-1393, 1395$1398,1400-1405,1408,1410-1415,1419,1421)$, Isabelle La Bouteillière $(1390,1391)$, Jean de Poquières (1388), Jean de Trie (1392, 1397, 1398), Jean I de Bourbon (1391), Jean III de Vergy (1397), Jean Malet IV de Graville (1388, 1407), Jeanne d'Harcourt (1390, 1391), Jeanne de Châtillon (1390), Jeanne de Dreux (1390, 1391), Jeanne de Luxembourg $(1395,1402)$, Jeanne de Vendôme $(1390,1391)$, Johann I. von Bourbon $(1397,1403,1408$, 1411,1412 , 1415), Johann Ohnefurcht $(1382,1385,1387-1390,1392-1413,1417,1419)$, Johann von Berry (1384-1416), Karl VI. (1382-1406, 1410, 1413, 1419, 1420, 1422), Leo VI. von Lusignan $(1385,1392,1393)$, Ludwig II. von Anjou (1382, 1400, 1406-1408, 1410), Ludwig II. von Bourbon (1387, 1389-1398, 1401, 1402, 1404, 1408, 1410), Ludwig von Orléans (1384-1405, 1407), Mabillette (1390), Marguerite de Préaux (1401, 1402), Marie de Duisy (1390-1392, 1395), Olivier de Mauny (1407), Philipp der Kühne (13811404), Philippe de Bar (1384-1391, 1393, 1396), Pierre de Craon (1404), Pierre de Navarre (1384, 1391-1393, 1396-1398, 1401, 1402), Pierre de Villaines (1391), Regnaud de Nantouillet (1391), Regnaut d'Angennes (1407, 1412, 1413, 1415), Renaud de Trie (1391), Robert de Boulogne (1391), Waleran III. von Luxemburg (1397, 1398, 1400, 1410). 
durch die Überlieferung bedingt ist ${ }^{566}$. Bezogen auf die Teilnehmerzahl an den „Fêtes de Saint-Denis« waren folglich 86 Personen entsprechend etwa 37\% gleichzeitig Festteilnehmer als auch Schenker und/oder Beschenkte zum Neujahrstag. Dieser im Vergleich zu den am Beispiel der "Cour amoureuse « gewonnenen Daten um einiges höhere Prozentsatz könnte auf die Berücksichtigung von Frauen zurückgeführt werden, denn deren Anteil an den »Fêtes de Saint-Denis « mit knapp 60\% ist um fast 39\% höher als der Anteil von Frauen am höfischen Geschenkverkehr zum neuen Jahr insgesamt. Aus Sicht des Geschenkverkehrs sind aber wiederum auch nur die genannten 86 Per-

566 Darunter als von Barroux namentlich nicht näher bestimmte Personen die Frau von Michel du Sablon (1395) und die Tochter von Renaud de Trie (1391). Die anderen Festteilnehmer waren (jeweils mit exemplarisch genannte Bezugspersonen mit Jahresangaben ihres Auftritts im höfischen Geschenkverkehr in Klammern) Alix d'Harcourt (Mutter von Jean de Hangest, 1391, 1397, 1402, 1407), Amadeus VII. von Savoyen (Vater von Amadeus VIII. von Savoyen, 1403, 1410), Anne d'Angelliers (verheiratet mit Regnaut d'Angennes, 1407, 1412, 1413, 1415), Biète de Cassinel (Schwester des Raoul Cassinel, 1395), Charles d'Anjou (Sohn Ludwigs II. von Anjou, 1382, 1400, 1406-1408, 1410), Ferry de Chambly (verwandt mit Charles de Chambly [?], 1391), Henry de Mauny (verwandt mit Hervé, 1401, und Olivier de Mauny, 1407), Isabeau de Châtillon (Schwiegermutter des Gaucher de Châtillon, 1401), Isabeau de Lorraine (verheiratet mit Enguerrand VII de Coucy, 1391), Isabelle de Melun (Mutter von Jeanne de Dreux, 1390, 1391), Jacques I de Bourbon (verheiratet mit Marguerite de Préaux, 1401, 1402), Jean de Berry (Sohn des Herzogs von Berry, 13841416), Jean de Saimpy (Saint-Py) (möglicherweise verschwägert mit Robert d'Aunoy, der mit Mahaut de Sempy verheiratet war, 1391, 1398, 1407), Jean I de Lorraine (Schwiegervater von Enguerrand VII de Coucy, 1391), Jean II d'Estouteville (verheiratet mit Marguerite d'Harcourt, 1396-1399, 1401), Jeanne de Bellengues (verheiratet mit Renaud de Trie, 1391, und Jean Malet IV de Graville, 1398, 1407), Jeanne de Béthune (Tochter des Robert VIII vicomte von Meaux), Jeanne de Caletot (verheiratet mit Jean de Hangest, 1391, 1397, 1402, 1407), Jeanne La Gentienne (verheiratet mit Arnoul I Boucher, 1395), Jehannette de Montaigu (Tochter des Jean de Montaigu, 1395-1397, 1401, 1402, 1407, 1410), Madame de Hangest (verheiratet mit Charles de Hangest, 1391), Mademoiselle de Mauny (verwandt mit Hervé, 1401, und Olivier Mauny, 1407). Marguerite d'Auneau (Tante von Charles de La Rivière, 1413), Marguerite d'Orgemont (Tochter von Pierre II d'Orgemont, 1386, 1390, 1396), Marguerite de Dammartin (verheiratet mit Simon de Dammartin, 1397, 1398), Marguerite de Montmorency (Schwiegermutter der Marguerite d'Harcourt, 1396-1399, 1401), Marguerite de Sainte-Maure (Schwiegertochter des Pierre d'Orgemont, 1386, 1390, 1396), Marguerite de Trie (Schwester von Renaud de Trie, 1391), Marguerite de Trousseau (Tochter von Pierre Trousseau), Marie de Blois (Frau Ludwigs II. von Anjou, 1382, 1400, 1406-1408, 1410), Marie de Paillart (verheiratet mit Aumary d'Orgemont, 1400), Mathilde von Holland (Mutter der Jeanne de Saint-Pol, 1394, 13961398, 1400, 1403, 1404), Michelle de Montdouzet (Tante von Jean II d'Estouteville, der mit Marguerite d'Harcourt verheiratet war), Perrette (verheiratet mit Guy de La Roche-Guyon, 1391, 1415) oder Jeanne de La Rivière (die mit Jacques de Châtillon verheiratet war, aber als Tochter Bureau de La Rivières Schwester der Brüder Charles und Jacques de La Rivière war, beide 1413), Pierre de Villaines (Sohn des Pierre "Le Bègue « de Villaines, 1391), Richard de Ville (Kousin des Herzogs von Lothringen), Robert de Beauchien (verheiratet mit Catherine de Fastavarin, 1390-1392, 1396), Robine de Montaigu (Großtante des kgl. secrétaire Gérard de Montaigu, 1403). 
sonen, also etwa $27 \%$ bezogen auf die Gesamtpersonenzahl des Geschenkverkehrs, die auch hier um diejenigen reduziert worden ist, die 1398 schon aus biographischen Gründen nicht an den Feiern von Saint-Denis teilnehmen konnten, als Mitglieder eines anderen höfischen Teilsystems bekannt. 148 Personen sind allerdings ausschließlich als Festteilnehmer überliefert, was auch hier mit Blick auf deren Rolle als potentielle Nichtschenker oder Nichtbeschenkte nur spekulativ als mögliche Folge der Überlieferung gedeutet werden kann ${ }^{567}$. Mit Karl VI. und Isabeau de Bavière, Johann von Berry, Philipp dem Kühnen, Ludwig von Orléans, Johann Ohnefurcht, Ludwig II. von Bourbon, Jean I de Bourbon, Johann I. von Bourbon, Ludwig II. von Anjou oder Waleran III. von Luxemburg, um nur einige zu nennen, ist aber auch hier die Spitze der höfischen Gesellschaft vertreten, nicht jedoch beispielsweise Margarete von Flandern, Valentina Visconti oder Margarete von Bayern.

567 Es handelt sich neben 28 nicht namentlich bekannten weiblichen Personen um Adam d'Aveluy, Agnès de Maisières, Alain Budes, Aleaume Boistel, Alix de Montagu, Anne de Graville, Béatrix de Beaussart, Bequet de Chivres, Brunissand de Lautrec, Charles de Bar, Edouard de Grand-Pré, Enguerrand de Marcoignet, Madame de Montmort, Guillaume de Beaujeu, Guillaume de Vienne, Guillaume des Bordes, Guy XII de Laval, Henri de Bar, Isabeau Mauvinet, Isabelle de Coucy l'aînée, Jean de Cagent, Jean de Chambrilhac, Jean de la Heuse, Jean de Pressy, Jean de Rieux, Jean de Rochefort, Jean de Saumes, Jean des Portes, Jean Harpedenne, Jean Perier, Jean V de Salm, Jeanette d'Angeliers, Jeanne de Beauvillier, Jeanne de Mathefelon, Jeanne de Quesnoy, Jeanne Le Mire, Madame d'Erian, Madame de Bailleul, Madame de Billebaut, Madame de Boulainvillier, Madame de Bris, Madame de Chin, Madame de Couray, Madame de Course, Madame de Falvy, Madame de Fontenay, Madame de Godanville, Madame de Graville (Frau des Guy Malet IV de Graville), Madame de Haplaincourt, Madame de Harvilly (Hervilly), Madame de La Bruière, Madame de la Motte, Madame de Launoy (wahrscheinlich handelt es sich hier um Marie de Quiemieu, siehe Anhang - Katalog/Jahreslisten, Nr. 349), Madame de Lespinay, Madame de Mainbeville, Madame de Milly, Madame de Montenglant, Madame de Montigny, Madame de Passy, Madame de Rully, Madame de Saint-Sauflieu, Madame de Saint-Simon, Madame de Saumont, Madame de Savigny, Madame de Spifame, Madame de Vauviller, Madame du Merle, Madame le Hongre, Madame Taupin de Villers, Mademoiselle d'Aude, Mademoiselle d'Avranchy, Mademoiselle d'Enfernet, Mademoiselle de Gaucourt, Mademoiselle de Hangest, Mademoiselle de Harenchy, Mademoiselle de Jouy, Mademoiselle de Lyon, Mademoiselle de Marcoignet, Mademoiselle de Poullette, Mademoiselle de Sarquegny, Mademoiselle de Serigny, Mademoiselle Le Breton, Marguerite d'Aunoy, Marguerite de Brétigny, Marguerite de Bruyères, Marie d'Enghien, Marie de Cramaille, Marie de Ferières, Marie de Nédonchel, Micaille Gauvain, Michelle de Vitry, Monseigneur de Ferrières, Monseigneur de Montencourt, Monseigneur le Maréchal, Morice de la Belotière, Morice de Trezeguidy, Olivier de Clisson, Olivier de Launoy, Olivier Du Guesclin, Olivier Pasquier, Perceval d'Esneval, Perrette de Chivry, Perrette de Trie, Perrette de Vaudetar, Philippe de Juilly, Pimpernel de Saint-Cler, R. de Barris, Raoul de Boschet, Raoul de Montfort, Regnaud de Roye, Regnault de Fontenel, Rincars de Vous, Robert de Beaurevoir (Beaumanoir), Robert de Boissay, Robert de Montdoucet, Robert Herzog von Irland, Favorit Richards II., Robin de Cressonnières, Robinet d'Esneval, Robinet de Vaucourt, Thibaut de Chantemelle. 
Die oben formulierte Vermutung, daß die durch den Neujahrstag erfolgte Terminvorgabe für den Austausch von Geschenken um 1400 flächendeckend gegriffen haben mag, daß also unterstellt werden kann, daß sich diesem Termin in der Regel wohl kaum jemand entziehen konnte ${ }^{568}$, läßt sich vor dem Hintergrund dieser Zahlen in diesem allgemeinen Sinn nicht halten. Zutreffend ist diese Vermutung nur mit dem differenzierten Blick auf die obersten Positionen der gesellschaftlichen Hierarchie, auf die Hauptträger der höfischen Kultur. Welcher Erkenntnisfortschritt für den sozialen Zusammenhang der höfischen Gesellschaft allerdings vor dem Hintergrund der Spekulation, daß im Einzelfall eine Teilnahme am höfischen Geschenkverkehr bestanden haben könnte, nur nicht belegt ist, durch die Ermittlung von Personen erzielt werden kann, die nach dem Befund der Quellen nicht dem höfischen Geschenkverkehr angehört haben, aber nachweislich anderen höfischen Subsystemen, bleibt fraglich, vor allem dann, wenn die Zugehörigkeit zur höfischen Gesellschaft im jeweiligen Einzelfall nach Aussage der Quellen wiederum außer Frage steht.

\section{Ergänzende exemplarisch-vergleichende Betrachtungen des Schenkverhaltens}

Aus methodischen Gründen scheint es geboten, nicht nur das Schenkverhalten eines Schenkers zu verschiedenen Jahren, sondern das Schenkverhalten einiger ausgewählter Teilnehmer des höfischen Geschenkverkehrs zum neuen Jahr in mehreren vergleichsweise ähnlich gut dokumentierten Jahren zu untersuchen. Bereits Tabelle 1 aber zeigt, daß die archivalische Überlieferung eine solche vergleichende Betrachtung kaum zuläßt, da die burgundische Überlieferung nahezu konkurrenzlos ist. Da jedoch bislang im großen und ganzen stets der Gesamtzeitraum des Geschenkverkehrs beobachtet worden ist, soll an einigen beispielhaft ausgewählten Zentralpersonen der zeitliche Verlauf ihres Schenkverhaltens nach Bindungsziffern und Wertzuweisungen untersucht werden, die die archivalische Überlieferung in diesem Sinn auflöst. Ausgewählt wurden zwei jeweils durch Ludwig und Karl von Orléans, dann durch den König und zuletzt durch Philipp den Kühnen, Johann Ohnefurcht und Philipp den Guten bestimmte Zeitreihen als Schenker unter Ausschluß ihrer Frauen und Hofhaltungen, wobei die Zeitreihe des Hauses Orléans aber bereits 1415 mit dem Ausscheiden Karls von Orléans endet.

Die beiden Graphiken 6 und 7 zeigen die in den Tabellen 14 und 15 verzeichneten Bindungsziffern und Wertzuweisungen jeweils in der Zusammenschau und es soll das Augenmerk vor allem auf die Neujahrstage gerichtet werden, die bestimmten Ereignissen folgten, die, so zur Überprüfung der 
eigentlich gegenläufigen Hypothese, deutliche und direkte Folgen für die personal geprägten Schenkbeziehungen gehabt haben könnten. Dies waren der Neujahrstag 1381, der dem Regierungsantritt des noch unmündigen Königs Karl VI. folgte, und der Neujahrstag 1389 nach Übernahme der Regierungsgeschäfte, dann der erste Januar nach dem Ausbruch der Krankheit des Königs im August 1392, der Jahresanfang 1397 nach dem desaströsen Ausgang der Schlacht von Nikopolis (möglicherweise zusätzlich beeinflußt durch den im Jahr 1396 abgeschlossenen und durch die Verheiratung Isabellas von Frankreich mit Richard II. bekräftigten Waffenstillstandsvertrag zwischen England und Frankreich), sodann der 1. Januar 1408, der auf den von Johann Ohnefurcht veranlaßten Mord am Herzog von Orléans folgte, schließlich der Neujahrstag 1412, nach dem sich nach der im Jahr 1410 gebildeten Liga von Gien, die den burgundisch-orléanistischen Gegensatz manifest werden ließ und den Burgundern nun erklärtermaßen die Häuser Berry, Orléans, Alençon, Clermont, Armagnac und Bretagne gegenüberstanden, die Kontrahenten im Jahr 1411 erste blutige Auseinandersetzungen lieferten, des weiteren der Jahresanfang 1416, der eigentlich erwarten läßt, daß nach der Schlacht von Azincourt der höfische Geschenkverkehr sein vorläufiges Ende gefunden haben könnte, und zuletzt der dem Mord an Johann Ohnefurcht folgende jour de l'an 1420 , der wohl auch kaum Anlaß für einen umfangreichen Austausch von Geschenken gegeben haben könnte.

Ohne also oben abgelehnten Ereigniseinflüssen nun doch das Wort reden zu wollen, soll erneut geprüft werden, inwieweit sich außersystemische Faktoren in direkter persönlicher Konsequenz in den Schenkbeziehungen niederschlugen. Was gemeint ist, wird deutlich am Beispiel der Schlacht von Azincourt. Nicht dieses Ereignis würde sich nach der Hypothese im Geschenkverkehr spiegeln, sondern die Tatsache, daß die meisten Teilnehmer tot sind bei grundsätzlicher Offenheit des Schenksystems auch für ein gegenteiliges Ergebnis, das dann für ein engeres Zusammenrücken der verbliebenen Akteure sprechen würde.

Tabelle 14 zeigt, daß solche Zusammenhänge durchaus rekonstruiert werden können. Zwar bietet das Jahr 1381 noch keinen Anlaß, weitergehende Schlüsse zu ziehen, aber 1389 gehen die Ziffern deutlich nach unten im Vergleich zum Vorjahr, als ob sich die Teilnehmer erst wieder auf die neue Situation einstellen müßten. Karls Werte steigen in den beiden Folgejahren auch auffällig an und könnten für die Aufwertung seiner Position sprechen. 1393 ist es nur die burgundische Bindungsgröße, die noch steigt, die Ziffern Karls und diejenigen des Hauses Orléans stagnieren. Die Werte des Jahres 1397 schließlich sperren sich einer sofortigen Auflösung. Burgund vergrößerte sein Beziehungsnetz möglicherweise im Zusammenhang mit den Verhandlungen um Lösegeld und Freilassung Johanns Ohnefurcht. Die Bindungsziffer allein scheint hier aber noch zu wenig Aussagekraft zu besitzen. Deutlich sind die 
Ziffern hingegen für 1408 nach dem Mord an Ludwig von Orléans. Daß der Austausch von Geschenken weiterging und nichts passierte, wie Françoise Autrand in ihrer Biographie Karls VI. bemerkt: »Noël passa. Et les fêtes de jour de l'an. On échange des étrennes comme si rien n'était arrivé «569, ist

\begin{tabular}{|c|c|c|c|r|r|r|r|}
\hline Jahr & Karl VI. & Orléans & Burgund & Jahr & Karl VI. & Orléans & Burgund \\
\hline 1381 & $\mathbf{0}$ & $\mathbf{0}$ & $\mathbf{1 6}$ & 1402 & 2 & 270 & 355 \\
1382 & 0 & 0 & 63 & 1403 & 1 & 4 & 227 \\
1383 & 6 & 0 & 46 & 1404 & 1 & 2 & 280 \\
1384 & 4 & 0 & 22 & 1405 & 0 & 1 & 1 \\
1385 & 0 & 0 & 135 & 1406 & 1 & 0 & 332 \\
1386 & 1 & 1 & 31 & 1407 & 0 & 11 & 21 \\
1387 & 1 & 0 & 33 & 1408 & $\mathbf{0}$ & $\mathbf{0}$ & 9 \\
1388 & 27 & 1 & 38 & 1409 & 0 & 0 & 3 \\
1389 & 3 & $\mathbf{0}$ & $\mathbf{2 7}$ & 1410 & 1 & 0 & 13 \\
1390 & 81 & 3 & 34 & 1411 & 0 & 64 & 1616 \\
1391 & 16 & 0 & 27 & 1412 & 3 & 0 & 2 \\
1392 & 4 & 1 & 24 & 1413 & 1 & 0 & 26 \\
1393 & 1 & 2 & 47 & 1414 & 0 & 0 & 0 \\
1394 & 1 & 1 & 74 & 1415 & 0 & 4 & 0 \\
1395 & 2 & 7 & 72 & 1416 & 0 & - & 0 \\
1396 & 1 & 11 & 42 & 1417 & 0 & - & 20 \\
1397 & 1 & 14 & $\mathbf{7 4}$ & 1418 & 0 & - & 0 \\
1398 & 28 & 32 & 75 & 1419 & 632 & - & 28 \\
1399 & 0 & 2 & 9 & 1420 & 8 & - & 0 \\
1400 & 0 & 4 & 96 & 1421 & 0 & - & 6 \\
1401 & 3 & 44 & 120 & 1422 & 101 & - & 0 \\
\hline
\end{tabular}

Tab. 14: Bindungsziffern im Zeitverlauf: Karl VI./Orléans/Burgund

archivalisch nur am Beispiel des Gabentausches zwischen Isabeau und Johann Ohnefurcht greifbar ${ }^{570}$. Denn nun, 1408, gruppierten sich die Prinzen um Berry: »Il sont huit à se manifester le premier janvier 1408«571, schreibt Autrand 13 Jahre später nach eingehender Analyse der Inventare Berrys, in denen sich die antiburgundische Koalition widerspiegelt ${ }^{572}$. Auch der Geschenkverkehr im Januar 1412 weist einen rekonstruierbaren Zusammenhang mit den Vorgängen des zurückliegenden Jahres auf. Mögen sich 1411 noch die Akteure bemüht haben, ihre Anhänger zu sammeln, wie dies im Fall des burgundischen

569 AUTRAND 1986, S. 357.

570 Siehe Anhang - Katalog/Jahreslisten, Nr. 1430. Vgl. FAMIGLIETTI 1986, S. 66, der die Interpretation dieses Schenkvorganges bei LEHOUX, Jean de France, Bd. 3, 1968, S. 112 dahingehend kritisiert, daß es sich hier nicht um den Ausdruck einer charakterlichen Disposition Isabeaus gehandelt habe, sondern schlicht um die konsequente Einstellung auf die von Berry und Anjou vorgegebene neue Linie der Versöhnung. Vgl. auch GiBBONS 2000, S. 392. 571 AUTRAND, Le Jour de l'An, 1999, S. 6.

572 Siehe Anhang - Katalog/Jahreslisten, Nr. 1426 (Béatrix de Navarre, verheiratet mit Jacques II de Bourbon, Graf de La Marche), 1427 (Beraud III d'Auvergne), 1428 (Charles d'Artois), 1432 (Jean d'Alençon), (Johann I. von Bourbon), 1443 (Louis de Vendôme), 1444 (Ludwig II. von Anjou), 1445 (Ludwig II. von Bourbon). 
Herzogs an anderer Stelle bereits skizziert wurde ${ }^{573}$, so scheinen 1412 die Fronten klar zu stehen. Die Schlacht von Azincourt schließlich könnte tatsächlich schlicht durch den Tod vieler und die Gefangennahme einiger den Geschenkverkehr zum neuen Jahr nahezu endgültig zum Erliegen gebracht haben. 1420 endlich weist auf einen 1408 vergleichbaren Effekt hin.

Tabelle 15 und Graphik 6 konfrontieren die Bindungsziffern und ihre Interpretationen mit den eingesetzten Werten.

Das Jahr 1381 ist wegen fehlender Vergleiche zu Vorjahren wiederum keine interpretierbare Größe und für 1389 lassen sich keine über die Bewertung der Bindungsziffern hinausreichenden Aussagen treffen. Der Neujahrstag 1397 zeigt hingegen beträchtliche Investitionszuwächse bei Karl VI. und Orléans, bei Burgund eine auf 1396 bezogene über 30\%ige Aktivitätszunahme. Die Beobachtung der Wertzuweisungen der Schenkvorgänge der Jahre 1408 und 1412 liegen parallel den Ergebnissen der Betrachtung der Bindungsziffern, ebenso bietet das Jahr 1416 keine Erkenntnisvermehrung durch Beobachtung der Wertekonstellationen. 1420 scheint sich Burgund zunächst in einer abwartenden Positionen befunden zu haben, Karl VI. brachte hingegen bei einer erheblich niedrigeren Bindungsziffer als im Vorjahr unverhältnismäßig hohe Werte in den Geschenkverkehr ein. 1420 ist aber im übrigen auch das

\begin{tabular}{|c|c|c|c|c|c|c|c|}
\hline Jahr & Karl VI. & Orléans & Burgund & Jahr & Karl VI. & Orléans & Burgund \\
\hline 1381 & 0 & $\mathbf{0}$ & $\mathbf{8 , 4 3 4 5 7}$ & 1402 & 24,00000 & 15,39780 & 23,76037 \\
\hline 1382 & 0 & 0 & 5,74785 & 1403 & 0 & 6,24000 & 51,96000 \\
\hline 1383 & 1,94400 & 0 & 7,73760 & 1404 & 43,20000 & 0 & 40,43040 \\
\hline 1384 & 0 & 0 & 10,43040 & 1405 & 0 & 0 & 0 \\
\hline 1385 & 0 & 0 & 19,60620 & 1406 & 0,01440 & & 1,12280 \\
\hline 1386 & 0,00768 & 0,91200 & 19,06080 & 1407 & 0 & 1,14000 & 6,64490 \\
\hline 1387 & 0 & 0 & 20,25600 & 1408 & 0 & 0 & 5,66640 \\
\hline 1388 & 0,03192 & 0,96000 & 44,32560 & 1409 & 0 & 0 & 0,36000 \\
\hline 1389 & $\mathbf{0}$ & 0 & 33,53595 & 1410 & 12,00000 & 0 & 0 \\
\hline 1390 & 3,76080 & 0,02880 & 137,22060 & 1411 & 0 & 3,11025 & 1,77174 \\
\hline 1391 & 7,89120 & 0 & 10,25040 & 1412 & 0,03200 & 0 & 0,72000 \\
\hline 1392 & 0 & 0 & 13,91460 & 1413 & 0 & 0 & 0,73200 \\
\hline 1393 & 0 & 0 & 34,76520 & 1414 & 0 & 0 & 0 \\
\hline 1394 & 0 & 0 & 33,70200 & 1415 & 0 & 0,42000 & 0 \\
\hline 1395 & 0 & 3,52203 & 21,46320 & 1416 & 0) & - & 0 \\
\hline 1396 & 0 & 8,33400 & 33,40998 & 1417 & 0 & - & 2,73675 \\
\hline 1397 & 8,64000 & 14,84414 & 43,01187 & 1418 & 0 & - & 0 \\
\hline 1398 & 0 & 29,45223 & 67,14720 & 1419 & 10,56000 & - & 5,04000 \\
\hline 1399 & 0 & 0 & 39,84000 & 1420 & 12,20000 & -1 & $\mathbf{0}$ \\
\hline 1400 & 0 & 0 & 35,95860 & 1421 & 0 & - & 0,79440 \\
\hline 1401 & 9,60000 & 16,23830 & 25,15500 & 1422 & 0 & - & 0 \\
\hline
\end{tabular}

Tab. 15: Bindungswerte im Zeitverlauf: Karl VI./Orléans/Burgund (d./100.000) 
Bindungswerte im Zeitverlauf - Karl VI./Orléans/Burgund

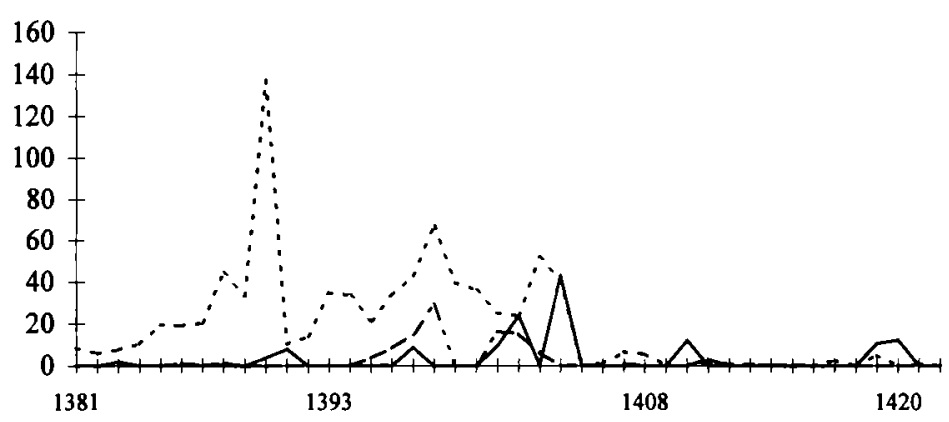

Graphik 6: Zeitreihe VI

Jahr des Auftritts Karls (VII.) gewesen, der an seine Gefolgschaft Neujahrsgeschenke im überlieferten Gesamtwert von 8.3441 . verteilt hat ${ }^{574}$,was einem sehr hohen Bindungswert von 20,0256 entspricht. Was sich zeigt, ist, daß eine Beobachtung des Schenkverhaltens verschiedener Schenker zwar Aufschluß geben kann über die sich im Zeitverlauf ändernden Bindungsziffern und werte, Einzelaussagen aber kaum zu treffen sind, wenn sie nicht begleitet werden von personenbezogenen Beobachtungen, die die je individuell verschiedenen Schenkvorgänge selbst in den Blick nehmen. Die Jahre 1396 und 1397 bieten dazu exemplarisch Anlaß.

Diese Jahre waren zunächst gekennzeichnet von der mit der Verheiratung Isabellas von Frankreich mit Richard II. von England verbundenen Hoffnung auf Haltbarkeit des am 11. März 1396 zwischen dem französischen und dem englischen König auf 28 Jahre angelegten Waffenstillstandsvertrages. Zudem waren es Jahre, in denen sich der anbahnende burgundisch-orléanistische Konflikt mit der Unterstellung Genuas unter die französische Krone und der daraus vorerst resultierenden Aufgabe des orléanistischen Planes, ein adriatisches Königreich zu errichten, scheinbar beruhigt hatte. Schließlich handelte es sich auch um eine Zeit, die gekennzeichnet war von dem Bemühen um Beilegung des Schismas, beginnend mit der Reise der Herzöge nach Avignon im Frühling 1395 im Anschluß an die erste Pariser Nationalsynode, endend mit der Aufkündigung der Obödienz gegenüber Benedikt XIII. durch Frankreich am 27. Juli 1398. Das Jahr 1396 hatte Philipp dem Kühnen aber auch einen seiner größten Mißerfolge beschert: die verlorene Schlacht von Nikopolis ge- 
gen die Osmanen am 28. September $1396^{575}$. Wenige hatten diese Schlacht überlebt und sein Sohn Johann Ohnefurcht hat nur gegen Zahlung eines hohen Lösegeldes aus der Gefangenschaft freigekauft werden können. Es handelt sich also um Jahre, über die der Kenntnisstand relativ gut ist. Es stellt sich die Frage, an wen Philipp was in welchem Wert verschenkte und wer ihn bedachte.

Diejenigen, die Philipp beschenkt hatten, waren seine Frau Margarete ${ }^{576}$, König Karl und Königin Isabeau, Herzog Ludwig von Orléans und Valentina Visconti, Johann von Berry577, König Heinrich III. von Spanien und Gilles Malet, garde de la librairie des Louvre und maître de l'hôtel des Königs sowie maître de l'hôtel der Valentina Visconti, die selbst bereits seit April 1393 nach dem »Bal des Ardents《 vom königlichen Hof verbannt gewesen war ${ }^{578}$. Bis auf Valentina hat es sich ausnahmslos um auch von Philipp Beschenkte gehandelt. Für 1396 sind sogar sechs gegenseitige Schenkbeziehungen feststellbar und der Mittelwert der Geschenke Philipps an die acht Personen, die ihm 1396 etwas geschenkt hatten, beträgt 828,44 1.t. Ein Wert mithin, der fast doppelt so hoch ist wie der mittlere Gesamtgeschenkwert und beträchtlich über dem Mittelwert der Geschenke an die Personen liegt, von denen Philipp 1396 nichts erhalten hatte. Gegenseitigkeit des Schenkens führt also vordergründig zu einem deutlich höheren Geschenkwert.

Was Philipp konkret erhalten hatte, ist nur von Gilles Malet, Heinrich III. von Spanien und Karl VI. bekannt. So hatte Gilles Malet dem Herzog 1396 unes belles croniques de France ${ }^{579}$ geschenkt und von ihm selbst vaisselle d'argent im Wert von 200 fl. 580 erhalten. Heinrich III. hat Philipp im selben Jahr, vermittelt durch seinen ambassadeur Johan Rodrigues, zwei Pferde überbringen lassen; möglicherweise zeugt dieses Geschenk von den allgemeinen Bündnisverhandlungen der Zeit angesichts der osmanischen Bedrohung und von den Vorbereitungen des Nikopoliszuges vom Herbst 1396. Rodrigues hatte als Geschenk und zugleich als Lohn für seinen Botendienst $200 \mathrm{fl}$. von Philipp erhalten ${ }^{581}$. Karl VI. schließlich hatte Philipp 1396 un saint

575 Siehe Nicopolis, hg. von PAVIOT, CHAUNEY-Boulllot, 1997, grundlegend ATIYA 1934.

576 Für 1396 zu erschließen aus einer Belohnung in Höhe von $80 \mathrm{fl}$. für einen Boten der Herzogin, den Kammerdiener Guille (Gille, Guillaume?), ACO B 1508, fol. 108v.

577 Für 1396 zu erschließen aus den Belohnungen für Boten, ACO B 1508, fol. 108v: 30 escuz valent $33 \mathrm{fl}$. 15 s.t. für einen Boten Isabeaus, $40 \mathrm{fl}$. für einen Boten Ludwigs von Orléans, den Barbier Salmon, $30 \mathrm{fl}$. für einen Boten der Valentina Visconti und 100 escuz valent 112 fl. 10 s.t für den Boten Jehan Destamps des Herzogs Berry.

$578 \mathrm{Vgl}$. AUTRAND 1986, S. $289 \mathrm{ff}$.

579 ACO B 1508, fol. 109r nennt das Gegengeschenk für Gilles Malet, so daß diese Notiz. auch das Geschenk Malets selbst verzeichnet. Siehe Anhang - Katalog/Jahreslisten, Nr. 699.

580 Siehe Anhang - Katalog/Jahreslisten, Nr. 719.

581 Siehe ebd., Nr. 700. 
Denis d'or 582 geschenkt. Der Bote, der dieses Geschenk überbracht hatte, hat von Philipp 50 fl. erhalten ${ }^{583} .1397$ hat Philipp von Karl 2.000 l. zum Kauf einer Goldschmiedeplastik bekommen ${ }^{584}$. Von Philipp wiederum hatte Karl 1396 un colier d'or a un fermail pendant garni de 3 balays a bon chouces et de 3 grosses perles $585 \mathrm{im}$ Wert von $1.700 \mathrm{fl}$. und 1397 une ymage de saint Michel, sur un entablement tout d'or, garni de $L X$ balais, VI safirs et LXXII perles 586 im Wert von $1.650 \mathrm{fr}$. erhalten.

Margarete, Philipps Frau, hat von ihrem Mann wie jedes Jahr zum 1. Januar so auch 1396 und 1397 jeweils 1.000 fr. ${ }^{587}$ bekommen, zusätzlich 1396 wie König Karl un colier d'or garny de 10 balais, un saphir, 44 perles et un grant balay ${ }^{588}$, aber um $800 \mathrm{fl}$. wertvoller als dasjenige, das Karl erhalten hatte, und 1397 XII tasses et un couvercle d'or ${ }^{589} \mathrm{im}$ Wert von 1.995 fr.: hohe Werte, die als Reflex auf besondere soziale Nähe interpretiert werden könnten. In diesem Sinn waren die Geschenke an die Königin auch entsprechend niedrigeren Wertes. Isabeau ist von Philipp 1396 mit einem 480 fl. teuren hanap d'or garny d'un grant saphir, 3 balaiz et 3 grosses perles 590 beschenkt worden und 1397 mit einem saint Antoine d'or, garni de pierreries ${ }^{591}$, der 660 fr. gekostet hatte. Ludwig von Orléans hingegen hat 1396 und 1397 jeweils gleich zwei Geschenke erhalten: 1396 eine ymaige de saint Jehan d'or garny de deux grant balaiz, 2 saphirs et 4 grosses perles assis sur un entablement d'argent doré592 im Wert von 360 fr. und un saint Jean-Baptiste d'or sur tablette de vermeil ${ }^{593}$, der mit $1.400 \mathrm{fl}$. zu Buche schlug, 1397 une ymage de la Magdeleine d'or, son diademe, et la bonté qu'elle tient ${ }^{594}$, garnies de pierres et de perles ${ }^{595}$ zu einem Wert von $1.350 \mathrm{fr}$., gleichzeitig une livrée de robe de drap cramoisi wie übrigens auch Johann von Berry, Johann Ohnefurcht und Ludwig II. von Bourbon ${ }^{596}$, jeweils gebucht mit 60 fr., wobei auch Johann von Berry und Ludwig II. von Bourbon 1397 zusätzlich ein weiteres Geschenk

Siehe ebd., Nr. 703.

583 ACO B 1508, fol. 108v.

584 Siehe Anhang - Katalog/Jahreslisten, Nr. 786. Siehe auch oben S. 166.

585 Siehe Anhang - Katalog/Jahreslisten, Nr. 733.

586 Siehe ebd., Nr. 824.

587 Hierzu Inventaires mobiliers, hg. von PROST, PROST, Bd. 2, 1908-1913, S. 69, Anm. 4:

„C'était le chiffre habituel des étrennes du duc à la duchesse [...]«.

588 Siehe Anhang - Katalog/Jahreslisten, Nr. 744.

589 Siehe ebd., Nr. 835.

590 Siehe ebd., Nr. 721.

591 Siehe ebd., Nr. 813.

592 Siehe ebd., Nr. 738.

593 Siehe ebd., Nr. 739.

594 Siehe ebd., Nr. 831. Erklärung nach DAVID 1947, S. 61: »un coffret aux aromates, variante de l'iconographie consacrée du vase à parfums.«

595 BNF, Coll. de Bourgogne, vol. LIII, fol. 167, vgl. PETIT 1888, S. $555 f f$.

596 ACO B 1511, fol. 92v, vgl. DAVID 1947, S. 61 . 
haben annehmen können ${ }^{597}$. Die Annahme, die einzelnen Geschenkwerte könnten die jeweilige politische Bedeutung der Beschenkten spiegeln, kann nicht ganz von der Hand gewiesen werden. Eine Ausnahme bildet die Tatsache, daß Johann Ohnefurcht, der sich in osmanischer Gefangenschaft befunden hatte, nur eine livrée geschenkt bekommen hat ${ }^{598} .1396$ hatte Johann von Philipp noch wie seine Frau Margarete von Bayern une anneau a une grant dyament ${ }^{599} \mathrm{zu} 180 \mathrm{fl}$. erhalten und ung fermail d'or garny d'un grant balay et 6 grosses perles $600 \mathrm{zu} 600 \mathrm{fl}$.

Margarete von Bayern, Tochter Herzog Albrechts von Bayern und der Margarete von Brieg, ist von Philipp 1396 mit einem wertvollen chappel d'or garny de 4 balays, 4 saphirs et 32 perles 601 bedacht worden, der mit $600 \mathrm{fl}$. in den burgundischen Rechnungsbüchern verzeichnet ist. Anton, der spätere Herzog von Brabant und Limburg, hat 1396, gerade elf Jahre alt, un colier d'or garny de 36 perles et un balay assis en un pendant erhalten, das Philipp $200 \mathrm{fl}$. gekostet hatte ${ }^{602}$. Seine Frau Jeanne de Saint-Pol, die Erbtochter Walerans von Luxemburg, hatte 1396 einen colier d'or garny de 36 perles, un saphir, un balay et 5 aultres perles assis en un pendant $603 \mathrm{zu} 280 \mathrm{fl}$. bekommen, Bona von Burgund wie ihre Schwester Maria (I.) von Burgund 1396 und 1397 die gleichen Geschenke wie Jeanne de Saint-Pol604. Jeannes Verlobter Johann I. von Bourbon wird 1396 nicht erwähnt, hat aber im Folgejahr ein fermail garni

597 Berry hatte une ymage de Nostre Dame d'or, garnie la couronne de pierreries et perles bekommen(ACO B 338 und BNF, Coll. de Bourgogne, vol. LIII, fol. 167, vgl. PETIT 1888, S. 556. Aufgeführt im Inventar des Herzogs von Berry, ed. GUIFFREY, Inventaires, Bd. 2, 1896, S. 11, Nr. 31, vgl. ebd., S. 460), das Philipp wie das Geschenk an Ludwig von Orléans $1.350 \mathrm{fr}$. gekostet hat (1396 hatte Berry eine ymaige de saint Denis d'or garny d'un grant balay et de 6 perles assis sur un entablement d'argent doré für 1.600 fl. erhalten, ACO B 1508, fol. 120r und ACO B 338, vgl. DAVID 1947, S. 61. Enthalten im Inventar des Herzogs, ed. GUIFFREY, Inventaires, Bd. 2, 1896, S. 13, Nr. 38, vgl. ebd., S. 460). Bourbon hatte lediglich einen hanap d'or erhalten(BNF, Coll. de Bourgogne, vol. LIII, fol. 167, vgl. PETIT 1888, S. $555 \mathrm{ff}$.) von 273 fr. 2 s. 6 d.t. (1396 ebenfalls nur einen hanap d'or garny d'un balay et 3 grosses perles von $300 \mathrm{fl}$., ACO B 1508, fol. 122r und BNF, Coll. de Bourgogne, vol. LIII, fol. 166, vgl. PETIT 1888, S. 553).

598 Siehe hierzu oben S. 176.

599 Siehe Anhang - Katalog/Jahreslisten, Nr. 731 und 740.

600 Siehe ebd., Nr. 732.

601 Siehe oben S. 178.1397 ist es nur ein hanap d'or zu 235 fr. 2 s. 6 d.t. gewesen, den Margarete bekommen hatte, BNF, Coll. de Bourgogne, vol. LIII, fol. 167, vgl. PETIT 1888, S. $555 \mathrm{ff}$.

602 Siehe Anhang - Katalog/Jahreslisten, Nr. 716.1397 hatte Anton dann einen hanap d'or zu 148 fr. 15 s. 1 d.t. erhalten, BNF, Coll. de Bourgogne, vol. LIII, fol. 167, vgl. PETIT 1888, S. $555 \mathrm{ff}$.

603 Siehe Anhang - Katalog/Jahreslisten, Nr. 728. 1397 hatte sie ebenfalls einen hanap d'or gleichen Wertes wie ihr Mann erhalten, BNF, Coll. de Bourgogne, vol. LIII, fol. 167, vgl. PETIT 1888, S. 555ff.

604 Siehe Anhang - Katalog/Jahreslisten, Nr. 717, 808. 
d'un bel balay, III safirs et vI perles belles ${ }^{605} \mathrm{zu} 280 \mathrm{fr}$. bekommen. Margarete (II.) von Burgund, 1396 noch nicht einmal drei Jahre alt, ist von Philipp immerhin mit einem petit gobelet d'or 606 beschenkt worden, 1397 aber dann mit einem fermail, garni d'un balay, d'un safir et $V$ perles, der 900 fr. gekostet hat: Folge der Verlobung mit dem Dauphin Karl von Frankreich? Der Dauphin, der 1396 noch mit einem fermail d'or garny d'un balay et 4 grosses perles zu $140 \mathrm{fl}$. hatte Vorlieb nehmen müssen, hat 1397, nun auch schon fast fünf Jahre alt, eine chayne d'or de coste et de fleurs de genestes à plusieurs sonettes pendants et à ycelle pendant un fermail d'un tigre, garni de III perles et d'un ruby zu $500 \mathrm{fl}$. entgegen nehmen können ${ }^{607}$. Daß Karls Schwester Isabella, künftige Königin Englands, 1396 von Philipp ein Geschenk erhalten hatte, ist bekannt, aber nicht, was und zu welchem Wert. Für 1397 fehlen die Angaben ganz. Maria (II.) ist 1396 wie Margarete (II.) mit einem petit gobelet d'or bedacht worden, 1397 immerhin mit einem $900 \mathrm{fr}$. teuren fermail, garni d'un balay, d'un safir et $V$ perles. Das Neujahrsgeschenk 1396 für Philipp von Burgund ist ein colier d'or garny de 36 perles et un balay assis en un pendant zu 200 fl. gewesen; 1397 hatte er wie seine Schwester Maria (I.) von Burgund einen fermail d'or garni d'un beau balay et VI perles zu $160 \mathrm{fr}$. erhalten. Katharina (I.) von Burgund, der Herzogin von Österreich, ist 1396 und 1397 je ein fermail d'or garny d'un balay, 3 saphirs et 4 grosses perles überreicht worden, das in dem einen Jahr $225 \mathrm{fl}$., in dem anderen $250 \mathrm{fl}$. gekostet hatte. Philipp schließlich, der spätere Burgunderherzog, hatte 1397 einen fermail garni d'un balay et VI perles zu $100 \mathrm{fr} .{ }^{608}$ bekommen.

Es fehlen Margarete (I.) von Burgund und ihren Mann, Wilhelm von Bayern, dann Amadeus VIII. von Savoyen, den Mann Marias (I.) von Burgund, und Leopold IV. von Östereich, Gatte Katharinas (I.). Wie andere Jahre zeigen, schien Philipp sehr wohl darauf geachtet zu haben, daß keines seiner Kinder und Enkelkinder von ihm vergessen wurde. Demgemäß kann es sich bei den Lücken nur um ein Problem der Überlieferung handeln und nicht um eine fehlende Schenkneigung des Burgunderherzogs gegenüber diesen Personen.

Marie de Sully, eine der Favoritinnen Philipps und Frau des Guy de La Trémoille, premier chambellan Philipps, der auf der Rückreise aus der Gefangenschaft nach Nikopolis 1397 auf Rhodos gestorben ist und mit Sicherheit auf der Liste der Beschenkten gestand hatte, hatte von Philipp 1396 un ruby assis en un annel d'or im Wert von 214 fl., 1397 einen ruby und einen anel zu 200 fr. bekommen ${ }^{609}$.

605 Siehe Anhang - Katalog/Jahreslisten, Nr. 822.

$606 \mathrm{Im}$ Wert von nur 100 fl. 18 s. 3 d.t., siehe ebd., Nr. 833.

607 Vgl. oben S. 164.

608 Siehe Anhang - Katalog/Jahreslisten, Nr. 855.

609 Siehe ebd., Nr. 748 und 838. 
Was Charles d'Albret, der künftige connétable Frankreichs, Guillaume de La Trémoille, maréchal von Burgund und Nikopoliskämpfer, der 1397 ebenfalls in Gefangenschaft gestorben ist, Jacques II de Bourbon, der Graf von La Marche und künftige Titularkönig Neapels und Jerusalems, Jean Le Meingre, der maréchal de Boucicout, der prominente Marmouset Jean de Montaigu, der 1409 auf Geheiß Johanns Ohnefurcht hingerichtet worden ist, Jean de Vienne, der amiral Frankreichs, der sein Leben gleichfalls in der Schlacht von Nikopolis gelassen hat, Louis de Sancerre, maréchal Frankreichs, Oudard de Chazeron, chambellan Philipps, Philippe d'Artois, connétable von Frankreich (auch er gestorben 1397 in osmanischer Gefangenschaft), Philippe de Bar, chambellan Philipps (gefallen in der Nikopolisschlacht), Pierre (II) d'Orgemont, Bischof von Paris, Pierre de Navarre, Sohn Karls des Bösen, des Königs von Navarra und pair Frankreichs, Pierre de La Trémoille, chambellan Philipps und Nikopoliskämpfer, und Renier Pot, einer der engsten Vertrauten Philipps, im einzelnen 1396 erhalten hatten und wie wertvoll ihre Geschenke gewesen sind, ist nicht bekannt, nur daß sie Geschenke erhalten haben. Allesamt sind sie Inhaber entscheidender militärischer, kirchlicher und politischer Positionen gewesen und damit eine eindrucksvolle Parade einflußreicher Männer des Königreiches. Lediglich von Jean Canard, dem Kanzler Burgunds, ist bekannt, daß er un hanap et une aiguiere d'or $610 \mathrm{im}$ nicht unbeträchtlichen Wert von $600 \mathrm{fl}$. erhalten hatte, im übrigen das gleiche Geschenk $1397 \mathrm{im}$ Wert von 304 fr. ${ }^{611}$. Auch Marie de Berry, Tochter des Herzogs Johann von Berry und Frau des Philippe d'Artois sind von Philipp beschenkt worden 612 . Von den genannten Personen erscheinen Charles d'Albret, Jean de Montaigu, Pierre de La Trémoille und Pierre de Navarre auch 1397 als Beschenkte613. Zusätzlich nennt die Überlieferung für das Jahr 1397 Arnaud-Amanieu d'Albret, Charles de Rohan, Guichard Dauphin, Guy de La Rochefoucauld, Jean de Hangest, Jean de Trie, Jean de Vergy, Louis de Poissy und Waleran von Luxemburg614.

610 Siehe Anhang - Katalog/Jahreslisten, Nr. 724.

611 Siehe ebd., Nr. 814.

612 Siehe ebd., Nr. 745.

613 BNF, Coll. de Bourgogne, vol. LIII, fol. 167, vgl. PETIT 1888, S. 555ff.: Charles d'Albret: un fermail garni d'un grand safir à VIII costés, II grands balais et III troches de perles, $150 \mathrm{fr}$; Jean de Montaigu: une grande coupe d'argent dorée couverte, esmailliee, $322 \mathrm{fr}$. 10 s.t, vgl. DAvid 1947, S. 61; Pierre de La Trémoille: un hanap d'or, 304 fr.; Pierre de Navarre: un fermail d'un safir, II balais quarrés et $V$ perles, $170 \mathrm{fr}$.

614 BNF, Coll. de Bourgogne, vol. LIII, fol. 167, vgl. PETIT 1888, S. $555 \mathrm{ff}$.: Arnaud-Amanieu d'Albret: un fermail d'un safir quarré au milieu, III beaux balays et vI perles, $260 \mathrm{fr}$.; Charles de Rohan: un fermail d'un safir à VIII costés, un balay quarré et V perls rondes, 175 fr.; Guichard Dauphin: un fermail de moutons, garni d'un balay et d'une perle belle, 300 fr., vgl. DAVID 1947, S. 61.; Guy de La Rochefoucauld: un fermail d'or, garni d'un gros balay et VI grosses perles, $360 \mathrm{fr}$.; Jean de Hangest: un fermail d'un balay beau et $V$ perles belles, 180 fr.; Jean de Trie: un fermail garny d'un balay, II safirs et VI perles, 120 fr.; Jean 
Für die Jahre 1396 und 1397 können bei insgesamt 105 Philipp den Kühnen betreffenden Schenkvorgängen fünfzig Personen benannt werden, denen Philipp der Kühne zum ersten Januar an mindestens einem der beiden Jahre entweder ein Geschenk gemacht oder von denen er eines erhalten hat. Drei von ihnen sind Anfang des Jahres 1397 nicht mehr am Leben gewesen, weil sie in der Schlacht von Nikopolis ihr Leben gelassen haben: Jean de Vienne, der amiral Frankreichs, Oudard de Chazeron, chambellan Philipps, und Philippe de Bar. Philipps Enkel, der spätere Herzog Philipp der Gute, war am Neujahrstag 1396 noch nicht geboren und hat daher erst 1397 mit einer Neujahrsgabe bedacht werden können. So hat Philipp also letztlich in den Jahren 1396 und 1397 Schenkentscheidungen für 46 namentlich nachweisbare Personen getroffen. Die Gesamtsumme der verschenkten Werte beträgt für 1396 12.170,82 1.t. bei 21 Personen, was einem mittleren Geschenkwert von 579,56 1.t. entspricht - unter Ausschluß von insgesamt 16 Personen, von denen die Werte der Geschenke, die sie erhalten hatten, nicht bekannt sind. 1397 wird ein Gesamtgeschenkwert von 14.483,51 l.t. erreicht bei einem mittleren Geschenkwert 425,99 1.t. bezogen auf 34 Personen615. Der mittlere Geschenkwert 1397 ist also niedriger als 1396, der Gesamtgeschenkwert aber höher und der Personenkreis größer: Überlieferungszufall oder Folge bewußter Entscheidungen? Eine Frage, die vorerst unbeantwortet bleiben muß. Tendenziell ließe sich aber aufgrund der vorhandenen Angaben die Neigung Philipps, Einzelinvestitionen zu reduzieren, ablesen. Einerseits kann also der Ausbau des Beziehungsnetzes festgestellt werden, andererseits eine sich erst auf den zweiten Blick erschließende Tendenz, Bindungen kostengünstiger zu gestalten. Darauf würde auch die Entwicklung bekannter Geschenkwerte wie derjenigen Margaretes von Flandern (1396: 3.500 fr., 1397: 2.995 fr.), Ludwigs von Orléans (1396: $1.760 \mathrm{fr} ., 1397$ : $1.410 \mathrm{fr}$.), Johanns von Berry (1396: $1.600 \mathrm{fl}$., 1397: 1.410 fr.) oder Karls VI. (1396: 1.700 fr., 1397: 1.650 fr.) verweisen. Schließlich hatten 23 Personen von Philipp sowohl 1396 als auch 1397 Neujahrsgeschenke erhalten, was einem Prozentsatz von etwa $48 \%$ des hier betrachteten Personenbestandes entspricht. Der mittlere Geschenkwert in dieser Gruppe beträgt bei den 1396 Beschenkten 353,63 1.t. In der Gruppe der 1396 Nichtbeschenkten beträgt er hingegen lediglich 189,23 l.t. Hier also mag es

de Vergy: un gros diamant à un anel esmaillé, 135 fr.; Louis de Poissy: un fermail de moutons, garni d'un balay et d'une perle belle, 300 fr., vgl. DAVID 1947, S. 61; Waleran von Luxemburg: un fermail garni d'un beau safir en maniere de croissant, d'un balay carré et $X I$ perles, $250 \mathrm{fr}$.

$615 \mathrm{Da}$ hier nur die bekannten Geschenkwerte zugrunde gelegt werden konnten, bedeutete dies, daß Philipp der Kühne in beiden Jahren mindestens zwischen ca. 3,5\% (1396) bzw. ca. 4,3\% (1397) seiner geschätzten mittleren jährlichen jährlichen Einnahmen von 340.700 l.t. bei geschätzten mittleren Ausgaben von 345.554 l.t. für Neujahrsgeschenke aufgewendet hatte, vgl. EwERT 1999, S. 205, Anhang B. 
sich um eine gegenläufige Tendenz handeln, die als Honorierung von auf Dauer gestellter Beziehungen verstanden werden könnte.

Hinsichtlich der Frage, welches die Wesensmerkmale von Schenkbeziehungen des höfischen Geschenkverkehrs zum neuen Jahr gewesen sein könnten, ist am Beispiel dieser hier vorgeführten Schenkvorgänge mit Blick auf Philipp den Kühnen eine andernorts vorgenommene statistische Modellierung des burgundischen Geschenkverkehrs zu den Neujahrstagen 1396 und 1397 durchgeführt worden ${ }^{616}$. Es ist zu erwarten, daß sich die Ergebnisse dieser Untersuchung, angewendet auf das Schenkverhalten anderer Schenker zu anderen Neujahrstagen, so oder ähnlich bestätigen, so daß hier auf eine Wiederholung der mit erheblichem Aufwand durchgeführten statistischen Analysen verzichtet wird, der Gang der Untersuchung selbst und vor allem die Ergebnisse aber kurz skizziert werden sollen.

Ausgangspunkt der Überlegungen war, daß im Zuge einer allgemeinen systemtheoretischen Betrachtung von Schenksystemen implizit suggeriert würde, daß die Gegenseitigkeit von Schenkbeziehungen eine integrierende Wirkung für das gesamte Schenksystem habe, weil gegenseitige Schenkbeziehungen im Zeitverlauf als stabiler zu gelten haben als einseitige, denn sie würden den Erwartungshaltungen der Mitglieder des Systems durch die Reduktion von Kontingenz Rechnung tragen ${ }^{617}$. Damit würde postuliert, daß die Wahrscheinlichkeit, daß zwei an einer gegenseitigen Schenkbeziehung einer bestimmten Periode beteiligten Personen diese Beziehung auch in der nächsten Periode wieder eingehen werden, signifikant höher sei als sie es für zwei Personen einer nur einseitig strukturierten Schenkbeziehung wäre. Diese Hypothese müsse aber abgelehnt werden, wenn das Schenksystem seinen Bestand wahrte, Schenkbeziehungen also immer von neuem wieder eingegangen würden, ohne daß eine genügend große Zahl gegenseitiger Schenkbeziehungen nachzuweisen wäre, was beim Geschenkverkehr zum neuen Jahr um 1400 ja tatsächlich der Fall gewesen ist. Innerhalb einer makroskopischen Betrachtung von Schenkbeziehungen müßte deshalb ein aus Gewohnheit stattfindendes Schenken von einem im engeren Sinn reziproken Schenken unterschieden werden. Beim Schenken aus Gewohnheit würde sich die schenkende Person nämlich nicht auf das Handeln des Gegenüber beziehen. Reziprozität des Schenkens würde hingegen immer dann vorliegen, wenn die schenkende Person in bewußter Bezugnahme auf ein zuvor erhaltenes Geschenk oder in Antizipation eines noch zu erhaltenden Geschenkes der Gegenseite schenkt. $\mathrm{Da}$ es sich bei Schenkbeziehungen wie denjenigen zum neuen Jahr um stets wiederkehrende zeitlich festgelegte Schenkbeziehungen handelt, zu dem von beiden Personen einer zustandekommenden Schenkbeziehung gleichzeitig

617 Siehe v.a. oben S. $124 \mathrm{ff}$. 
geschenkt wird, würde eine deutliche Konkurrenz beider Motivationen, die nicht getrennt voneinander betrachtet werden können, entstehen. Schenkbeziehungen würden demnach stabil bleiben, weil beide Personen in ihrem Handeln - dem Schenken - auf das Handeln des Gegenüber Bezug nehmen, beide Akte des Schenkens somit verknüpft seien ${ }^{618}$. Welche konkrete Motivation der Personen, deren gegenseitige Schenkbeziehung an einem Schenkanlaß wie dem Neujahrstag zu beobachten ist, im Einzelfall vorliegt, sei aus der bloßen Betrachtung einer solchen gegenseitigen Schenkbeziehung aber kaum zu erschließen. Es wäre sogar denkbar, daß beide Personen mit einem jeweils anderen Motiv schenken, nämlich die eine aus Gewohnheit, die andere in Reaktion auf bereits erhaltene oder in Antizipation erwarteter Geschenke. Gleichwohl würde dennoch immer eine gegenseitige Schenkbeziehung entstehen. Daher schien es angebracht, die Untersuchungsperspektive von den gegenseitigen, also reziproken Schenkbeziehungen, die unten gesondert betrachtet werden ${ }^{619}$, auf die Motivationen der diese Beziehungen eingehenden Personen $\mathrm{zu}$ verlagern. Untersucht werden sollte somit nicht das Ergebnis zweier individueller Schenkentscheidungen, sondern die jeweils dazu führenden Entscheidungen selbst. Dabei wurde angenommen, daß es sich bei den Schenkentscheidungen um rationale Wahlhandlungen handele, die den Nutzen des Schenkenden mehren oder mindern ${ }^{620}$. Anhand der Einzelentscheidungen, zu schenken, sollte dann festgestellt werden können, welchen Stellenwert Gewohnheit und Reziprozität für das Schenken des Einzelnen und damit für den Zusammenhalt des Schenksystems haben. Es muß betont werden, daß die Existenz reziproker Beziehungen nicht in Frage gestellt wird, auch nicht deren Bedeutung für den höfischen Geschenkverkehr. Bereits oben ist unterstrichen worden, daß es das Gabe und Gegengabe trennende Zeitintervall ist, das erst eigentlich den sozial verpflichtenden und verbindenden Charakter gegenseitigen Schenkens ausmacht, und daß es beileibe auch nicht die bloße Entsprechung von Gabe und Gegengabe ist, die, zumal am Hof, unter dem Begriff Reziprozität verstanden wird621.

Anhand eines einfachen Vergleichs der oben wiedergegebenen Mittelwerte ist zunächst als Zwischenergebnis formuliert worden, daß tatsächlich ganz offensichtlich Reziprozität und Gewohnheit für das Schenkverhalten Philipps des Kühnen als Motive relevant gewesen waren. Die Tatsache, 1396 schon ein Neujahrsgeschenk von Philipp bekommen zu haben einerseits und andererseits

618 Erfolgreiche Interaktion setzt immer ein gewisses $\mathrm{Maß}$ an Übereinstimmung der Erwartungen voraus und die so begründeten Beziehungen würden sich dann im Zeitverlauf als so stabil erweisen, daß sie sich annahmegemäß in fortlaufenden Perioden gleichsam immer wieder selbst erzeugen, vgl. KRANTON 1996, S. 830.

619 Siehe im vorliegenden Kap. Abschn. III.

620 Siehe EWERT, HiRSCHBIEGEL 2000, S. 8 mit Anm. 19.

621 Siehe oben S. 124ff., insbes. S. 125, Anm. 20. 
die Tatsache, ihm zu diesem Anlaß selbst ein Geschenk gemacht zu haben, führten bei den untersuchten Personen zu im Mittel deutlich höheren Geschenkwerten des Folgejahres. Es blieb die Frage, ob diese Schlußfolgerungen überhaupt zulässig waren. Bekam Karl VI. nicht vielleicht allein deshalb ein so wertvolles Geschenk, weil er als französischer König den höchsten Rang der durch Philipp beschenkten Personen belegte? Ließe sich die hohe Geschenksumme der Margarete von Flandern unter Umständen darauf zurückführen, daß sie als Gemahlin des burgundischen Herzogs über die größte soziale Nähe zu Philipp verfügte? Beide Motivationen, zu schenken, mußten daher gemeinsam untersucht werden, um ihren relativen Einfluß auf die Schenkentscheidung Philipps des Kühnen beurteilen zu können. Und nur wenn das zunächst gewonnene Ergebnis außerdem hinsichtlich variierender anderer Bestimmungsfaktoren wie Rang, soziale Nähe, Verwandtschaft oder Geschlecht kontrolliert werden konnte, sollte ein Urteil darüber gefällt werden können, ob und in welchem Maß die beiden zentralen Schenkmotivationen für den Entscheidungsprozeß einer Person, zu schenken oder nicht zu schenken (und wenn ja, wieviel), bedeutsam waren.

Innerhalb eines multivariaten Untersuchungsdesigns sind die folgenden, theoretisch begründbaren und daher für Philipps Entscheidungen über Geschenk und Geschenkwert möglicherweise relevanten Faktoren untersucht worden 622 .

Es wurde erstens angenommen, daß die (transaktionskostentheoretisch abgeleitete ${ }^{623}$ ) Gewohnheit, zu schenken, darin zum Ausdruck kommt, wieviel Philipp einer bestimmten Person bereits aus Anlaß des vorangegangenen Neujahrs geschenkt hat und folglich anhand des Wertes dieses zu Neujahr 1396 gemachten Geschenkes gemessen werden kann. Innerhalb der oben vorgestellten Personengruppe befinden sich allerdings einige Personen, bei denen zwar die Tatsache festgestellt werden kann, daß sie 1396 ein Neujahrsgeschenk erhalten hatten, nicht aber der Wert dieses Geschenkes. Der Einfluß der Gewohnheit ist daher zweifach gemessen worden, nämlich in der nur qualitativen Unterscheidung zwischen Personen, die 1396 etwas geschenkt bekommen hatten, und denen, die nichts geschenkt bekommen hatten, dann zusätzlich für die Personen, deren Geschenkwert des Jahres 1396 bekannt ist als Wert des dort erhaltenen Neujahrsgeschenkes.

Zweitens wurde zur Abschätzung des (spieltheoretisch begründeten ${ }^{624}$ ) Einflusses der Antizipation eines Gegengeschenkes auf das Entscheidungsverhalten Philipps festgestellt, ob eine bestimmte Person am Neujahrstag des Jahres 1396 Philipp ein Geschenk gemacht hatte oder nicht. Da aufgrund des festen Schenktermins üblicherweise eine Gleichzeitigkeit des Schenkens vor-

622 Zu den benutzten Variablenwerten siehe EWERT, HIRSCHBIEGEL 2000, S. 36, Tab. 4.

623 Siehe ebd., S. 11.

624 Siehe ebd., S. 8 mit Anm. 20 und S. 10 mit den entspr. Anm. 
liegt, diente die Tatsache des Gegengeschenkes einer Person im Jahr 1396 als Indikator für die Erwartung Philipps, erneut ein Gegengeschenk zum Schenktermin des Jahres 1397 durch ebendiese Person zu erhalten. Leider sind bei allen Gegengeschenken des Jahres 1396 keinerlei Werte bekannt gewesen, so daß in diesem Punkt auf einem qualitativen Meßniveau verharrt werden mußte.

Drittens wurden zusätzlich personenspezifische Kontrollvariablen verwendet. Diese Größen waren das Geschlecht der beschenkten Personen, ihr Rang, ihre soziale Nähe zu Philipp dem Kühnen sowie die Tatsache, mit Philipp in einem Verwandtschaftsverhältnis zu stehen. Die einzelnen Ränge, die die einzelnen Personen innehatten, sind dabei mit Koeffizienten belegt worden, die zeitpunktfixiert und personenorientiert eine Zusammenziehung von Funktion, Amt, Prominenz beziehungsweise Bedeutung und Abstammung darstellen sollten 625 .

Viertens schließlich erschien es als nicht ausreichend, allein die Tatsache des Gegengeschenkes oder das Ausmaß etwa sozialer Nähe zu betrachten, daher wurden zusätzlich Kombinationen aus dem Gewohnheits- beziehungsweise Reziprozitätseinfluß und der sozialen Nähe zu Philipp dem Kühnen beziehungsweise dem Rang einer Person untersucht.

Um die verschiedenen Einflußgrößen in ihrem Verhältnis zueinander abschätzen zu können, wurde das Entscheidungskalkül des burgundischen Herzogs zunächst als statistisches Modell formuliert, das seine Schenkentscheidung für den Neujahrstag 1397 bezüglich jeder Person in einen linearen Zusammenhang mit den aufgeführten erklärenden Faktoren brachte ${ }^{626}$. Um aber den relativen Einfluß aller aufgeführten Faktoren - Gewohnheit, Reziprozität, Geschlecht, soziale Nähe, Verwandtschaft und Rang sowie Inter-

625 Hier war ein hohes $\mathrm{Ma} ß$ an subjektiven Entscheidungen bei der Vergabe der einzelnen Koeffizienten notwendig, so daß diese Entscheidungen im Einzelfall durchaus zu diskutieren sind. Die für den Index "soziale Nähe« vergebenen personengebundenen Koeffizienten erklären sich aus den auf Phlipp den Kühnen bezogenen Beziehungsbereichen »Verwandtschaft « und "Vertrauen « und ergänzten die mit »ja-nein $=1-0$ « in die Berechnungen eingegangene Grundfeststellung über "verwandt-nicht verwandt《. Ließ sich der Verwandtschaftsgrad als Blutsverwandtschaft oder Schwägerschaft noch relativ genau bestimmen, so mußte der Vertrauensgrad nach teilweise wiederum sehr subjektiven Kriterien festgelegt werden. Die Verwandtschaftsgrade sind in der Weise definiert worden, daß bis auf Margarete von Flandern und Marie de Sully, die jeweils den Wert $-0,25$ erhielten, jeder Generationenschritt zu einer Subtraktion von 0,5 führte und angeheiratete Personen mit zusätzlich 0,25 Einheiten, subtrahiert vom Koeffizienten des Gatten oder der Gattin, belastet wurden. Der Vertrauensgrad hatte sich, da er wie der Verwandtschaftsgrad auch als Maß der Entfernung zu Philipp dem Kühnen bestimmt worden ist, zunächst aus der Zuordnung der jeweiligen Person zu einer anderen ergeben, die bereits Inhaber eines Verwandtschaftskoeffizienten war. $\mathrm{Zu}$ diesem Koeffizienten wurde in Schritten von 0,05 das jeweils betreffende Vertrauensmaß subtrahiert. So hätte bspw. der nächste Vertraute Karls VI. den Wert -1,5 - 0,05 entspr. $-1,55$ erhalten.

626 Siehe EWERT, HIRSCHBIEGEL 2000, S. 26-29. 
aktionseffekte zwischen sozialer Nähe bzw. Rang und Gewohnheit/Reziprozität - auf Schenkneigung bzw. Schenkentscheidung Philipps gemeinsam beurteilen zu können, wurde ein sogenanntes vollspezifiziertes Modell geschätzt, daß alle Faktoren enthielt ${ }^{627}$.

Dieses vollspezifizierte Modell hatte zum Ergebnis, daß die Hypothese, alle vermuteten Einflußfaktoren hätten gemeinsam eine erhebliche Wirkung auf das Entscheidungsverhalten Philipps gehabt, nicht zu widerlegen war. Das Ausmaß des Einflusses jedes einzelnen Regressors auf die Schenkneigung Philipps war im Verhältnis zu einer Referenzperson zu interpretieren, deren Variablenwerte allesamt Null sind und für die die Schenkneigung Philipps ihr gegenüber allein durch den Wert der Konstante beschrieben worden ist. Diese - für die vorliegende Personengruppe nur fiktive - Person war weiblichen Geschlechts, verfügte über die geringste soziale Nähe zu Philipp, sollte mit ihm weder blutsverwandt noch verschwägert sein, hatte den geringsten Rang und im Jahr 1396 von Phlipp weder ein Neujahrsgeschenk erhalten noch diesem selbst eines gemacht. Innerhalb des vollspezifizierten Modells waren nur drei der elf getesteten Effekte signifikant von Null verschieden. Dies waren der Einfluß des Vorjahresgeschenkwertes, der gemeinsame Einfluß sozialer Nähe und Reziprozität sowie der gemeinsame Einfluß von Rang und Gewohnheit. Vor allem Geschlecht und Verwandtschaft hatten sich hinsichtlich der Schenkneigung beziehungsweise Schenkentscheidung Philipps als nur wenig trennscharfe Kategorien erwiesen.

In einem letzten Schritt wurde auf die nicht signifikanten Faktoren zur Erklärung der Schenkentscheidung beziehungsweise -neigung Philipps verzichtet und ein reduziertes Modell betrachtet ${ }^{628}$, auf dessen Parameterschätzungen sich alle weiteren Aussagen gründeten. Dieses Modell enthielt neben dem Gewohnheitseffekt des Schenkens und den beiden Interaktionseffekten, die sich im vollständigen Modell als signifikant erwiesen hatten, alle Einzelgrößen, die in die jeweiligen Interaktionen mit eingeflossen sind wie soziale Nähe, Rang und Reziprozität. Damit ist auf diesem Weg, nebenbei bemerkt, auch die Aussagefähigkeit der oben gegebenen Tabellen 11 und vor allem 12 bestätigt worden. Die Güte dieses Modells war dem des vollständigen Modells vergleichbar und erlaubte einige überraschende Aussagen über den Einfluß von Gewohnheit und Reziprozität auf das Schenkverhalten.

So ist mit zunehmendem Wert des erhaltenen Vorjahresgeschenkes zunächst einmal die Wahrscheinlichkeit gewachsen, im Jahr 1397 überhaupt etwas von Philipp dem Kühnen geschenkt zu bekommen, es trat also ein positiver Wahrscheinlichkeitseffekt der Motivation "Gewohnheit« auf. Außerdem erhielt jemand, der zur Gruppe der 1397 tatsächlich Beschenkten gehört 
hatte, mit zunehmendem Wert des erhaltenen Vorjahresgeschenkes auch Neujahrsgeschenke größeren Wertes, es trat also auch ein positiver Größeneffekt der Motivation »Gewohnheit« auf. Dieser Mechanismus war jedoch deutlich unterproportional ausgeprägt, denn isoliert betrachtet hatte sich der Wert des erhaltenen Geschenkes nur um 0,337 1.t. je 1 l.t. des Vorjahresgeschenkes erhöht. Jeweils negativ wirkten hingegen - und dies war infolge der Untersuchung gruppenspezifischer mittlerer Geschenkwerte so nicht $\mathrm{zu}$ erwarten gewesen - die bloße Tatsache, 1396 ein Geschenk bekommen zu haben oder 1396 Philipp selbst eines gemacht zu haben. Dies bedeutete allerdings nicht, daß die integrierende Funktion des gegenseitigen Schenkens grundsätzlich widerlegt war. Reziprozität und Schenken aus Gewohnheit waren aber ganz offensichtlich - je für sich betrachtet - zu einfache Erklärungsmuster der Schenkneigung beziehungsweise Schenkentscheidung. Hier war eine differenzierte Erklärung notwendig, die mit dem signifikant positiven $\mathrm{Zu}-$ sammenspiel von sozialer Nähe und Reziprozität einerseits und der ebenso positiv wirkenden Interaktion von Rang und Gewohnheit andererseits geliefert wurde. Hatte jemand zu denen gehört, die Philipp 1396 ein Neujahrsgeschenk gemacht hatten, so hatte sich die zunehmende soziale Nähe zu Philipp nicht nur auf dessen Schenkneigung, sondern auch auf die Wahrscheinlichkeit, 1397 ein Geschenk zu bekommen sowie auf dessen Wert positiv ausgewirkt. Dies galt auch für die gemeinsame Wirkung von Rang und Gewohnheit. Hatte jemand auch 1396 ein Neujahrsgeschenk erhalten, sind sowohl die Wahrscheinlichkeit, 1397 erneut eines zu bekommen, als auch der Wert dieses Geschenkes mit zunehmendem Rang gestiegen. Zu erwarten war gewesen, daß sich die Furcht, bloßgestellt zu werden, weil genommen, aber nicht gegeben wird, als zentrales Movens gegenseitigen Schenkens auf höchster sozialer Ebene erwiesen hätte, während Gewohnheitsschenken ein Mittel der regelmäßigen Stabilisierung sozialer Bindungen vor allem zu Personen großer sozialer Nähe, aber nicht entsprechend hohen Ranges gewesen wäre. Das genaue Gegenteil war jedoch der Fall. Reziprozität als Motivation des Schenkens hatte sich bei Philipp dem Kühnen offensichtlich vor allem auf Mitglieder der näheren sozialen Umgebung - die Ehefrau oder Höflinge des eigenen Hofes erstreckt, während das Motiv der Gewohnheit sich eher im Schenken gegenüber Personen gleichen und höheren Ranges - wie beispielsweise Karl VI., Ludwig von Orléans oder Johann von Berry - manifestiert hatte.

Die Parameterschätzungen des Modells erlaubten aber auch, den Einfluß der Regressorvariablen auf die nicht direkt meßbare wirkliche Schenkneigung Philipps des Kühnen für die Schätzung dieser wirklichen Schenkneigung des Jahres 1397 heranzuziehen. Außerdem konnte für die 1397 tatsächlich beschenkten Personen aufgrund ihrer Variablenwerte eine Prognose ihres Geschenkwertes abgegeben werden. 
Im Ergebnis zeigte sich, daß Philipp gegenüber einer nicht unerheblichen Zahl dieser Personen eine Abneigung zu schenken gehabt zu haben schien. Auch ist seine Schenkneigung nur wenigen Personen gegenüber wirklich gröBer als gegenüber der bereits beschriebenen fiktiven Referenzperson. Zu diesen Personen gehörten Angehörige der engeren Familie wie Ehefrau, Sohn und Schwiegertochter sowie politisch bedeutsame Personen wie der König Karl VI. nebst Gemahlin, Ludwig von Orléans oder Johann von Berry.

Es wurde zudem deutlich, in welchem Verhältnis Schenkneigung und tatsächliche Schenkentscheidung standen. Karl VI. hatte 1397 das Höchstmaß einer Schenkentscheidung auf sich vereinigen können bei einer nur um ein geringes Maß kleineren Schenkneigung Philipps für Margarete von Flandern, für die er die zweithöchste Schenkentscheidung getroffen hatte, gefolgt von Johann von Berry und Ludwig von Orléans. Auch die Königin stach noch aus der Masse der Beschenkten heraus, während Johann Ohnefurcht und Margarete von Bayern zwar ein noch ganz ansehnliches Maß der Schenkneigung auf sich vereinigen konnten, aber tatsächlich relativ wenig geschenkt bekommen hatten. Auffällig sind auch noch die Werte von Margarete (II.) von Burgund gewesen, der Enkelin des burgundischen Herzogs, für die dieser offensichtlich eine nur geringe Schenkneigung besessen hatte, aber für sie als Frau des Dauphins mit eine der höchsten Schenkentscheidungen traf - eine höhere noch als für den mit einer weit größeren Schenkneigung versehenen Dauphin selbst. Im Gegensatz dazu stand das Verhältnis von Schenkneigung und Schenkentscheidung Philipps für Margaretes Schwester Maria (II.) von Burgund. Sie hatte dasselbe erhalten, schien aber bei ihrem Großvater ungleich beliebter gewesen zu sein. Im allgemeinen hatten die erwähnten politisch bedeutenden Personen des damaligen Frankreich tatsächlich mehr bekommen, als die entsprechend am Modell geschätzte Neigung Philipps dies angezeigt hatte. Unter ihnen war auch Jean Canard, der burgundische Kanzler, dessen im Vergleich zur Schenkneigung höherer Geschenkwert darin begründet liegen mag, daß Philipp hier die soziale Beziehung zum politisch sicherlich engsten Vertrauten hat unterstützen wollen. Ein analoges Erklärungsmuster, die eher private Sphäre betreffend, hat sich für die Schenkentscheidung gegenüber Marie de Sully angeboten, deren Geschenkwert ebenfalls oberhalb der Proportionalitätslinie lag. Angehörige hingegen haben durchweg $\mathrm{Ge}-$ schenkwerte erhalten, die im Verhältnis zur Neigung Philipps zu schenken, geringer ausgefallen sind. Die meisten Beschenkten rangierten aber deutlich konzentriert im untersten Bereich bei einem relativ ausgewogenen Verhältnis von Schenkentscheidung zu Schenkneigung. Valentina Visconti, Gilles Malet oder Heinrich III. von Spanien hingegen - von allen dreien hatte Philipp 1396 ein Neujahrsgeschenk erhalten - waren in den Minusbereich seiner Schenkneigung abgerutscht und hatten nichts erhalten. 
Schließlich wurden für die Personen, die 1397 Neujahrsgeschenke bekommen hatten, geschätzte Geschenkwerte des Modells und tatsächliche Schenkentscheidungen miteinander verglichen. Die Differenz beider Werte erlaubte eine Einschätzung darüber, welchen Stellenwert eine historischindividuelle Erklärung des erhaltenen Geschenkwertes jeder Person im Vergleich zu der aus dem postulierten Modell heraus vorgenommenen strukturellen Erklärung haben könnte. Hier hat sich die Erklärungsgüte des Modells auch für jeden Einzelfall erwiesen. Maßgeblich dafür waren allerdings nicht die absoluten Abweichungen zwischen Geschenkwert und Schätzwert, sondern deren relative Differenz. Große relative Abweichungen wiesen vor allem Philipps Sohn Johann Ohnefurcht, dessen Ehefrau und Philipps Enkelinnen Margarete (II.) und Maria (II.) von Burgund auf. Doch ausgerechnet für die prominentesten Personen der hier untersuchten Personengruppe - Karl VI., Isabeau de Bavière, Dauphin, Johann von Berry und Ludwig von Orléans sowie für die Personen mit größter persönlicher Bedeutung für Philipp den Kühnen - Ehefrau, Favoritin und Kanzler -, für die am ehesten eine individuelle, außerhalb des postulierten Modells liegende Erklärung hätte vermutet werden können, war die relative Differenz zwischen prognostiziertem und tatsächlichem Geschenkwert sehr gering. Sie betrug nie mehr als $11 \%{ }^{629}$. Für diese Personen konnten die Werte der erhaltenen Geschenke sehr präzise vorhergesagt werden und das durch historisch-individuelle Interpretation hinzufügbare Erklärungspotential war allenfalls marginal. Einzig für Johann Ohnefurcht bestand tatsächlich mit der durch seine osmanische Gefangenschaft infolge der Schlacht von Nikopolis bedingten Abwesenheit zu Neujahr 1397 eine einzigartige historische Erklärung seines vergleichsweise geringwertigen Neujahrsgeschenkes. Doch der außerordentliche Stellenwert dieser Erklärung ist erst vor dem Hintergrund des statistisch-analytischen Erklärungsmusters wirklich greifbar geworden.

629 Karl VI. (ca. - 10,9\%); Isabeau de Bavière (ca. +9,5\%); Johann von Berry (ca. $-8,3 \%$ ); Ludwig von Orléans (ca. -10,2\%); Karl von Frankreich (ca. -7,8\%); Margarete von Flandern (ca. $+7,9 \%$ ); Marie de Sully (ca. $+10,4 \%$ ); Jean Canard (ca. $-8,7 \%$ ), siehe ebd., S. 34 mit Anm. 122. 